Aus dem Fachbereich Medizin

der Johann Wolfgang Goethe-Universität

Frankfurt am Main

betreut am

DRK-Blutspendedienst Baden-Württemberg-Hessen

Institut für Transfusionsmedizin und Immunhämatologie Frankfurt am Main

Direktor: Prof. Dr. Dr. med. Erhard Seifried

\title{
ALLELISCHE SUBTYPISIERUNG UND FUNKTIONSANALYSE VON \\ INHIBITORISCHEN NK-ZELL-REZEPTOREN KIR2DL1 UND KIR3DL1 ZUR \\ OPTIMIERUNG DER SPENDERAUSWAHL BEI NK-ZELL-BASIERTER \\ IMMUNTHERAPIE
}

\author{
Dissertation \\ zur Erlangung des Doktorgrades der Medizin \\ des Fachbereichs Medizin \\ der Johann Wolfgang Goethe-Universität \\ Frankfurt am Main
}

vorgelegt von

\author{
Yasmin El-Nahry \\ aus Stuttgart.
}

Frankfurt am Main, 2020 
Dekan:

Referent:

Korreferent:

Tag der mündlichen Prüfung:
Prof. Dr. med. Stefan Zenzem

Prof. Dr. med. Christian Seidl

Prof. Dr. med. Peter Bader

26.05.2021 


\section{Inhaltsverzeichnis}

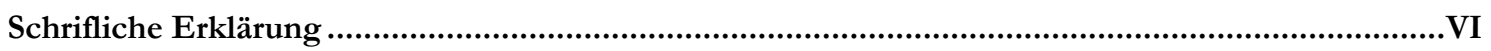

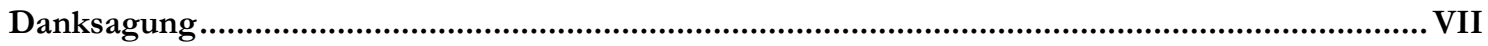

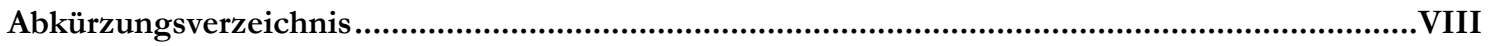

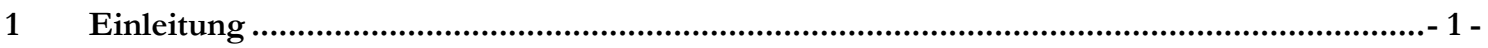

$1.1 \quad$ Natürliche Killerzellen als Mitglied der lympathischen Zellreihe ....................................................................- 1 -

1.1.1 Reifestadien von NK-Zellen ................................................................................................ - 2 -

1.1.2 Funktionelle Phänotypen ....................................................................................................... - 3 -

1.2 Zytotoxiz̨itätsmechanismen und Lizensierung von NK-Zellen .......................................................................... 4 -

1.3 Killerzell-Immunglobulin-ähnliche Rezeptoren …….....................................................................................- 5 -

1.3.1 Struktur und Funktion............................................................................................................ - 6 -

1.3.2 Genetische Diversität .............................................................................................................. - 8 -

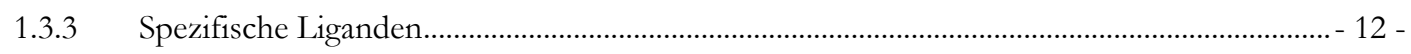

1.4 Funktionelle Erkennungsmechanismen von NK-Zellen ................................................................................... - 15 -

1.4.1 „Missing-self“-Erkennung ...................................................................................................... 16 -

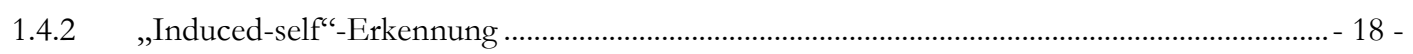

1.5 Therapeutische Konzepte im Rahmen von Leukämien und malignen Lymphomen ......................................... - 19 -

1.5.1 Hämatopoetischen Stammzelltransplantation (HSZT) ...............................................................- 21 -

1.5.2 Autologe und Allogene Stammzelltransplantation ....................................................................... 21 -

1.5.3 Graft-versus-Leukemia/ Graft-versus-Host-Effekt ...................................................................... 23 -

1.6 NK-Zellen als potenzielles Zelltherapeutikum .................................................................................. - 25 -

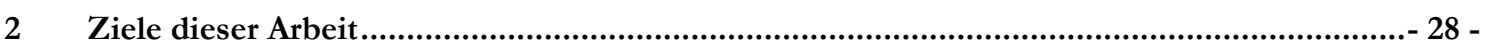

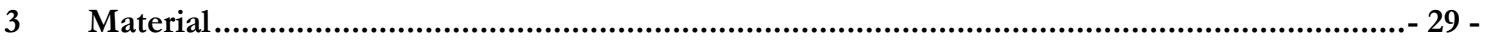

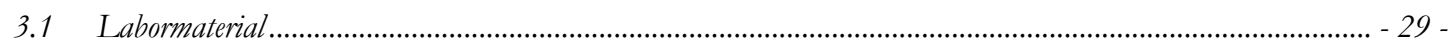

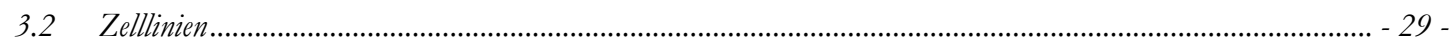

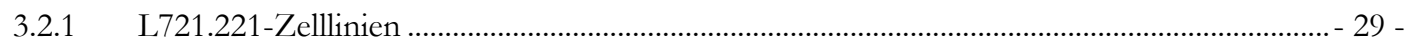

3.2.2 Primäre NK-Zellen ....................................................................................................................... 30 -

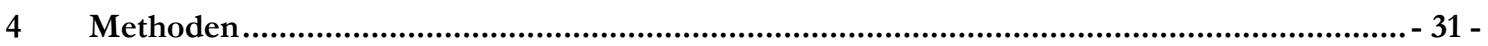

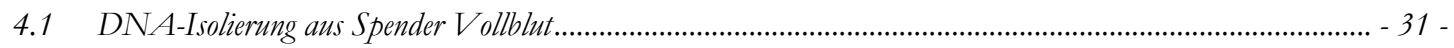

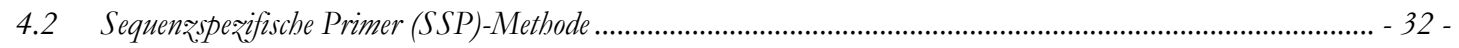

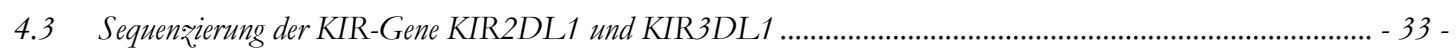

4.3.1 Erste Sequenzier-PCR: Amplikation exonischer Gensequenzabschnitte.................................- 34 - 
4.3.2 Überprüfung der Amplifikation über Gelelektrophorese .........................................................- 38 -

4.3.3 Verdünnung und Aufreinigung der amplifizierten DNA-Abschnitte.......................................- 39 -

4.3.4 Zweite Sequenzier-PCR: Generierung spezifischer Exon-Amplifikate ...................................- 40 -

4.3.5 Aufreinigung der Sequenzierungsprodukte ............................................................................. 41 -

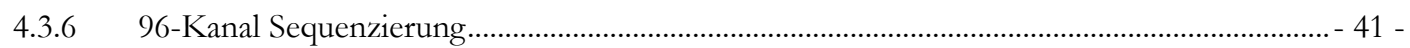

4.3.7 Auswertung der KIR-Gensequenzen........................................................................................... 42 -

4.4 Isolierung von peripheren mononukleärer Zellen aus Vollblutproben .............................................................. - 43 -

4.5 NK-Zellisolierung aus Proben mit peripheren mononukeleärer Zellen ........................................................... - 45 -

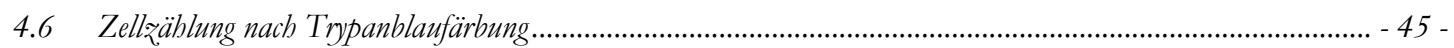

4.7 Zellkulturtechniken ............................................................................................................................... - 47 -

4.7.1 Aliquotierung und Kyrokonservierung von Zellen ................................................................... 47 -

4.7.2 Auftauen kyrokonservierter Zellen .....................................................................................................- 47 -

4.7.3 Kultivierung der L721.221-Zelllinien........................................................................................- 48 -

4.7.4 Kultivierung der primären NK-Zellen ........................................................................................- 49 -

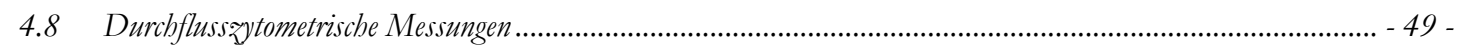

4.8.1 Oberflächenfärbung der L721.221-Zelllinien................................................................................. 51 -

4.8.2 Immunphänotypisierung der Spender NK-Zellen .....................................................................- 52 -

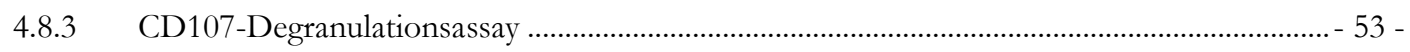

4.8.4 Auswertung der ermittelten FACS-Daten mittels FlowJo ${ }^{\circledR}$-Software......................................- 56 -

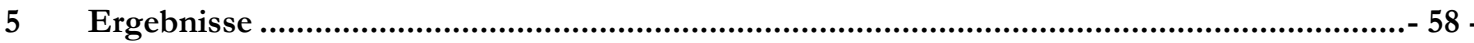

Teil 1: Ergebnisse der KIR- und HLA-Typisierung der NK-Zell-Spender................................. 58 -

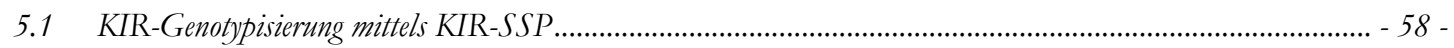

5.1.1 Haplotyp-Bestimmung ................................................................................................... 59 -

5.2 Selektive HLA-Typisierung der Spender............................................................................................... - 59 -

5.3 Ergebnisse der allelischen KIR2DL1 -Subtypisierung ................................................................................ - 61 -

5.3.1 Untersuchung auf relevante KIR2DL1-Polymorphismen ....................................................... 62 -

5.4 Ergebnisse der allelischen KIR3 DL1-Subtypisierung …................................................................................ - 65 -

5.4.1 Spendergruppierung anhand von KIR3DL1-Expressionsmustern..........................................- 68 -

Teil 2: Ergebnisse der durchflusszytometrischen Messungen ............................................ - 71 -

5.5 HLA-Oberflächenfärbung der verwendeten Zielzellinien .......................................................................... - 71 -

5.6 KIR2DL1 - und KIR3DL1-Oberflächenexpression der NK-Zell-Spender .................................................. - 71 -

5.7 Untersuchung der Total-KIR ${ }^{+} /$Single-KIR ${ }^{+}$NK-Zell-Populationen ........................................................... - 73 -

5.8 Ergebnisse des funktionellen CD107-Degranulationsassays ........................................................................ - 75 -

5.8.1 Funktionelle Untersuchung des Haplotyps-AA und -Bx ......................................................- 76 -

5.8.2 Funktionelle Untersuchung des spenderspezifischen MHC-I-Profils .......................................- 79 - 
5.8.3 NK-Zellaktivität der subtypisierten KIR2DL1-Spender.

5.8.4 NK-Zellaktivität der subtypisierten KIR3DL1-Spender.

6.1 KIRom-basierte NK-Zell-Spenderauswabl -89 -

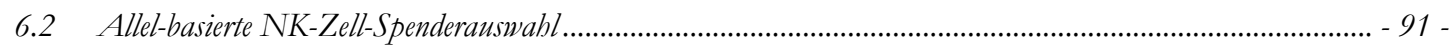

6.2.1 Alloreaktivität der subtypisierten Spender NK-Zellen ............................................................- 95 -

6.3 Einfluss der KIR-HLA-Spezifität und des MHC-I-Profils der Spender auf die NK-Zell-Alloreaktivität....... - 98 -

6.4 Zukunftsvisionen NK-Zell-basierter Therapieansätz̨e............................................................................. - 104 -

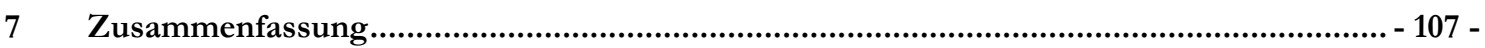

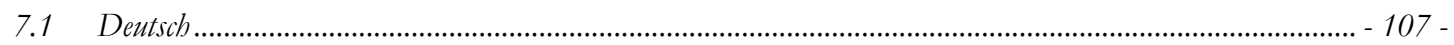

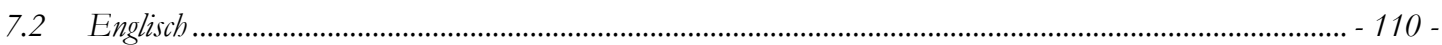

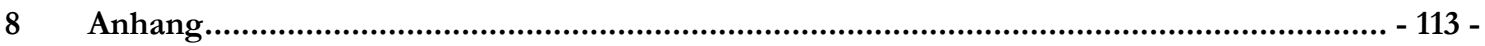

8.1 Ergänzende Abbildungen und Tabellen ........................................................................................................ - 113 -

8.2 Auswertungs- und Ergebnistabellen der Subtypisierung von KIR2DL1 und KIR3DL1 ............................. - 121 -

8.3 Labormaterial ....................................................................................................................................... - 132 -

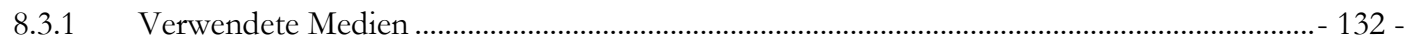

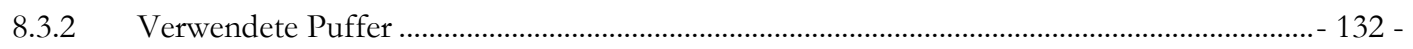

8.3.3 Verwendete Lösungen ........................................................................................................ 133 -

8.3.4 Chemische Verbrauchsprodukte …………........................................................................... 133 -

8.3.5 Verwendete Kit-Systeme _............................................................................................. 134 -

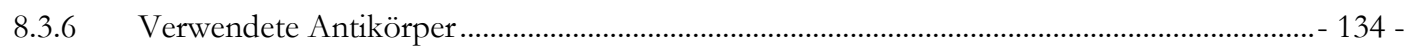

8.3.7 Technische Geräte ......................................................................................................... 135 -

8.3.8 Verbrauchsmaterialien ...................................................................................................... 135 -

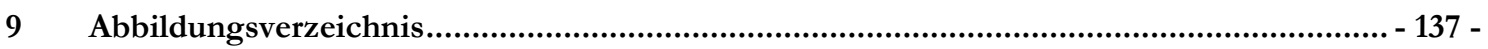

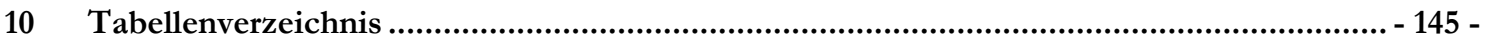

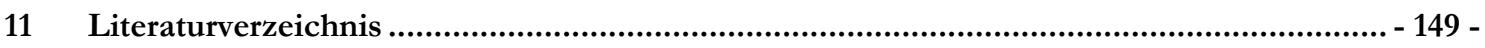

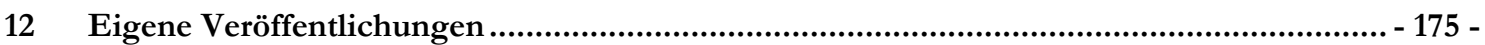

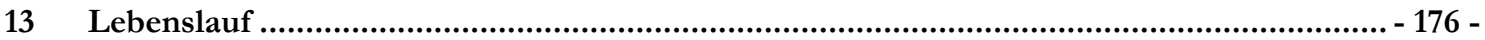




\section{Schrifliche Erklärung}

Ich erkläre ehrenwörtlich, dass ich die dem Fachbereich Medizin der Johann Wolfgang Goethe-Universität Frankfurt am Main zur Promotionsprüfung eingereichte Dissertation mit dem Titel

\section{ALLELISCHE SUBTYPISIERUNG UND FUNKTIONSANALYSE VON INHIBITORISCHEN NK-ZELL-REZEPTOREN KIR2DL1 UND KIR3DL1 ZUR OPTIMIERUNG DER SPENDERAUSWAHL BEI NK-ZELL-BASIERTER IMMUNTHERAPIE}

in dem Institut für Transfusionsmedizin und Immunhämatologie Frankfurt am Main unter Betreuung und Anleitung von Prof. Dr. Christian Seidl mit Unterstützung durch Dr. rer. nat. Petra Becker ohne sonstige Hilfe selbst durchgeführt und bei der Abfassung der Arbeit keine anderen als die in der Dissertation angeführten Hilfsmittel benutzt habe. Darüber hinaus versichere ich, nicht die Hilfe einer kommerziellen Promotionsvermittlung in Anspruch genommen zu haben.

Ich habe bisher an keiner in- oder ausländischen Universität ein Gesuch um Zulassung zur Promotion eingereicht. Die vorliegende Arbeit wurde bisher nicht als Dissertation eingereicht.

Berlin, 10.07.2020

(Ort, Datum)

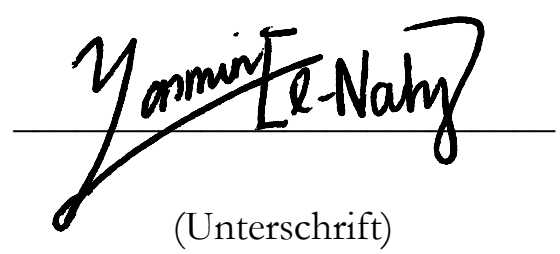




\section{Abkürzungsverzeichnis}

aKIR

ALL

AML

APT

CAR-T-Zelle

CCD

CCR7

CD

CLL

CML

CyA

dNTP

ddNTP

DAP12

DNA

DRK

EBV

EDTA

engl.

FACS

FCS

FcyRll

G-CSF

GM-CSF

GvL

$\mathrm{GvH}(\mathrm{D})$
Aktivierender Killer-Immunglobulin-ähnlicher Rezeptor

Akute lymphatische Leukämie

Akute myeloische Leukämie

Aminoglykosid-Phospho-Transferase

engl.: chimeric antigen receptor $T$ cell

engl.: charged-coupled device

C-C Chemokinrezeptor Typ 7

engl.: cluster of differentiation

Chronische lymphatische Leukämie

Chronische myeloische Leukämie

Cyclosporin A

Desoxynukleosidtriphosphat

Didesoxynukleosidtriphosphat

Synonym: KARAP Adapterprotein

engl.: desoxyribonucleic acid

Deutsches Rotes Kreuz

Ebstein-Bar-Virus

engl.: ethylene diamine tetraacetic acid

Englisch

engl.: fluorescence activated cell sorter

engl.: fetal calf serum

engl.: Fc gamma region immunoglobin receptor IIIa

engl:: granulocyte stimulating factor

Granulozyten-Monozyten-Kolonie-stimulierender Faktor

engl.: Graft-versus-Leukemia

engl.: Graft-versus-Host (Disease) 
engl.: forward scatter

HL

Hodgkin-Lymphom

HLA

Humane Leukozyten Antigene

HSZ

Hämatopoetische Stammzelle

HSZT

Hämatopoetische Stammzellen Transplantation

IPD

engl.: Immuno Polymorphism Database

$\operatorname{Ig}$

Immunoglobulin

iKIR

Inhibitorischer Killer-Immunglobulin-ähnlicher Rezeptor

IL

Interleukin

IFN

Interferon

ITAM

Immunorezeptor Tyrosin-basiertes Aktivierungsmotiv

ITIM

Immunorezeptor Tyrosin-basiertes Inhibitionsmotiv

KIR

Killerzell-Immunoglobulin-ähnlicher-Rezeptor

LRC

engl.: leukocyte receptor complex

MHC

engl.: major histocompatibility complex

MMF

Mycophenolat Mofetil

MRD

engl.: matched-related donor

MSD

engl.: matched-sibling donor

MTX

Methotrexat

MUD

engl.: matched-unrelated donor

NGS

engl.: Next-Generation Sequencing

NK-Zellen

Natürliche Killerzellen

NZR

NK-Zell-Rezeptor

NHL

PBMZ

Non-Hodgkin Lymphom

engl:: peripheral blood mononuclear cells (PBMC)

PCR

engl.: polymerase chain reaction

RNA

engl.: ribonucleic acid 
rpm

RPMI 1640

SSC

SHP

SSP

TAC

TNF

UCBT

UV-Transilluminator

WHO engl.: rounds per minute (Zentrifugationseinheit)

Roswell Park Memorial Institute (RPMI) 1640 Medium

engl.: side scatter

Src homology region 2 domain-containing phosphatase

Sequenzspezifische Primer

engl:: tetrametric antibody complex

Tumornekrosefaktor

engl.: umbilical cord blood transplantation

engl:: ultra violett transilluminator

engl.: World Health Organization 


\section{Einleitung}

\subsection{Natürliche Killerzellen als Mitglied der lympathischen Zellreihe}

Natürliche Killerzellen (NK-Zellen) bilden 5\% bis maximal 20\% aller peripher zirkulierenden Lymphozyten im menschlichen Blut. Sie stellen damit neben T- und B-Zellen die verhältnismäßig kleinste Lymphozytenpopulation dar. Allen drei Zellreihen gemeinsam ist ihre hämatopoetische Entwicklung aus einer im Knochenmark ansässigen lymphatischen Vorläuferzelle. ${ }^{1,2}$ Je nach Herkunft der Zellen können unterschiedliche Formen von Blutkrebs (Leukämie) entstehen (Abb. 1).

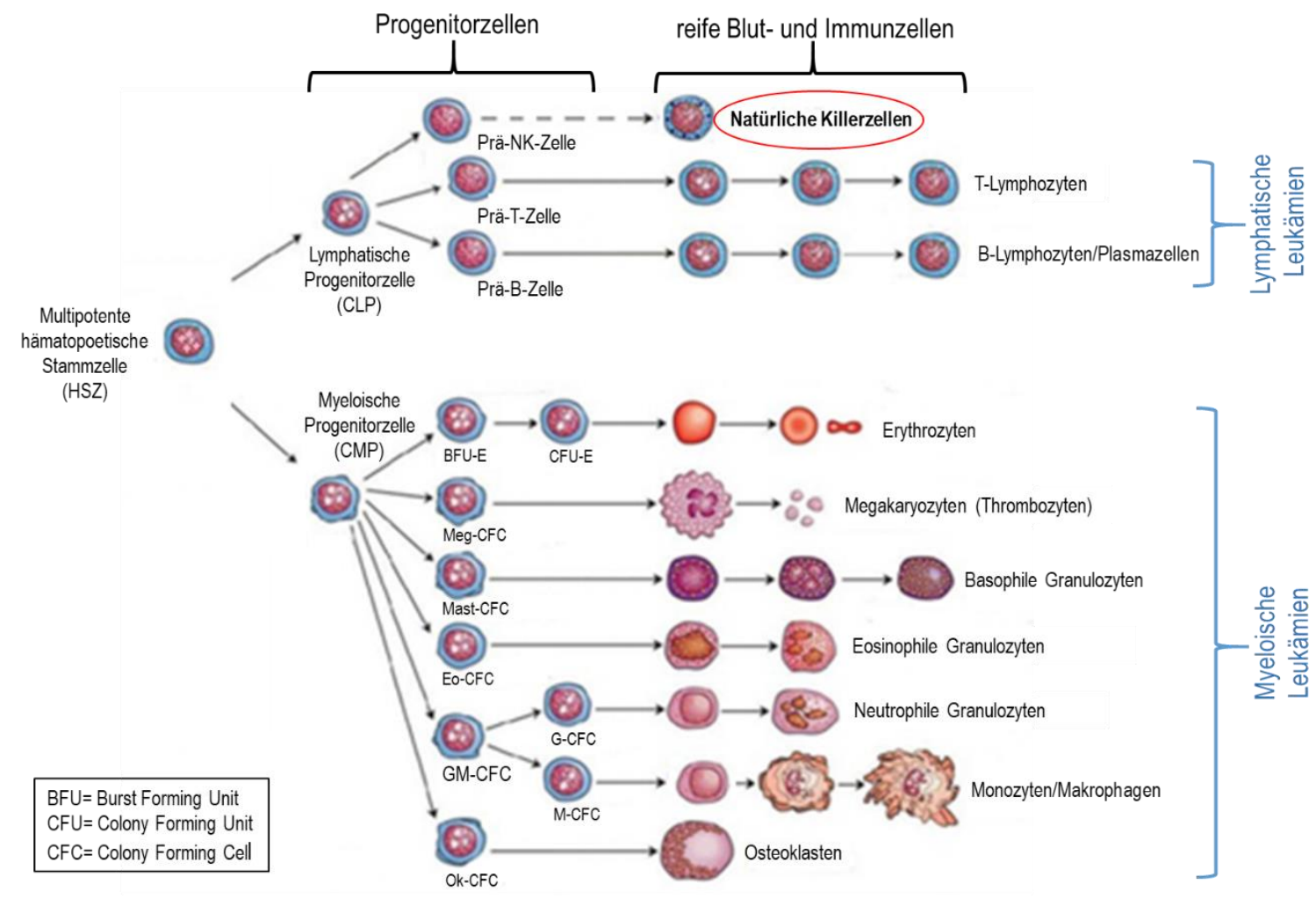

Abbildung 1 Schematischer Überblick der Blutzellbildung (Hämatopoese). Die hämatopoetische Stammzelle (HSZ) bildet hierbei den Ursprung aller Blutzellen. NK-Zellen sind Abkömmlinge der lymphatischen Zellreihe und bilden die verhältnismäßig kleinste Lymphozytenpopulation in menschlichen Blut. [Abbildung modifiziert mit Genehmigung von Donald Metcalf (2007) $\left.{ }^{3}\right]$

Anders als die T-Zelllinie, welche aus dem Knochenmark zur weiteren Differenzierung vorerst in den Thymus wandert, werden ausdifferenzierte B- und NK-Zellen aus dem Knochenmark direkt in das periphere Blut freigesetzt. Naive B-Zellen werden bis zu ihrer Antigen-abhängigen Aktivierung zusätzlich in sekundär lymphatischen Organen (Milz, 
Lymphknoten, Schleimhäute) eingespeichert. Mikroskopisch präsentieren sich T- und BZellen als nahezu identisch kugelige Zellen mit einer Größe von etwa 7,5 $\mu \mathrm{m}$. Aufgrund dieser ähnlichen Zellmorphologie können $\mathrm{T}$ - und B-Zellen ausschließlich mittels immunhistochemischer Färbung voneinander unterschieden werden. Im Gegensatz dazu handelt es sich bei NK-Zellen, analog zu ihrer englischen Bezeichnung als „large granular lymphocytes“, um deutlich größere $(>10 \mu \mathrm{m})$ Immunzellen, welche bereits unter dem Mikroskop durch ihre ausgeprägte Granulierung gut zu erkennen sind (Abb. 2). ${ }^{4}$ Humane NK-Zellen befinden sich zu einem großen Teil in soliden Organen (Lunge $>$ Milz $>$ Leber), sind aber auch peripher in Blut und Lymphknoten zu finden. ${ }^{5,6}$ Sie besitzen eine durchschnittliche Lebensdauer von etwa 14 Tagen. $^{7}$

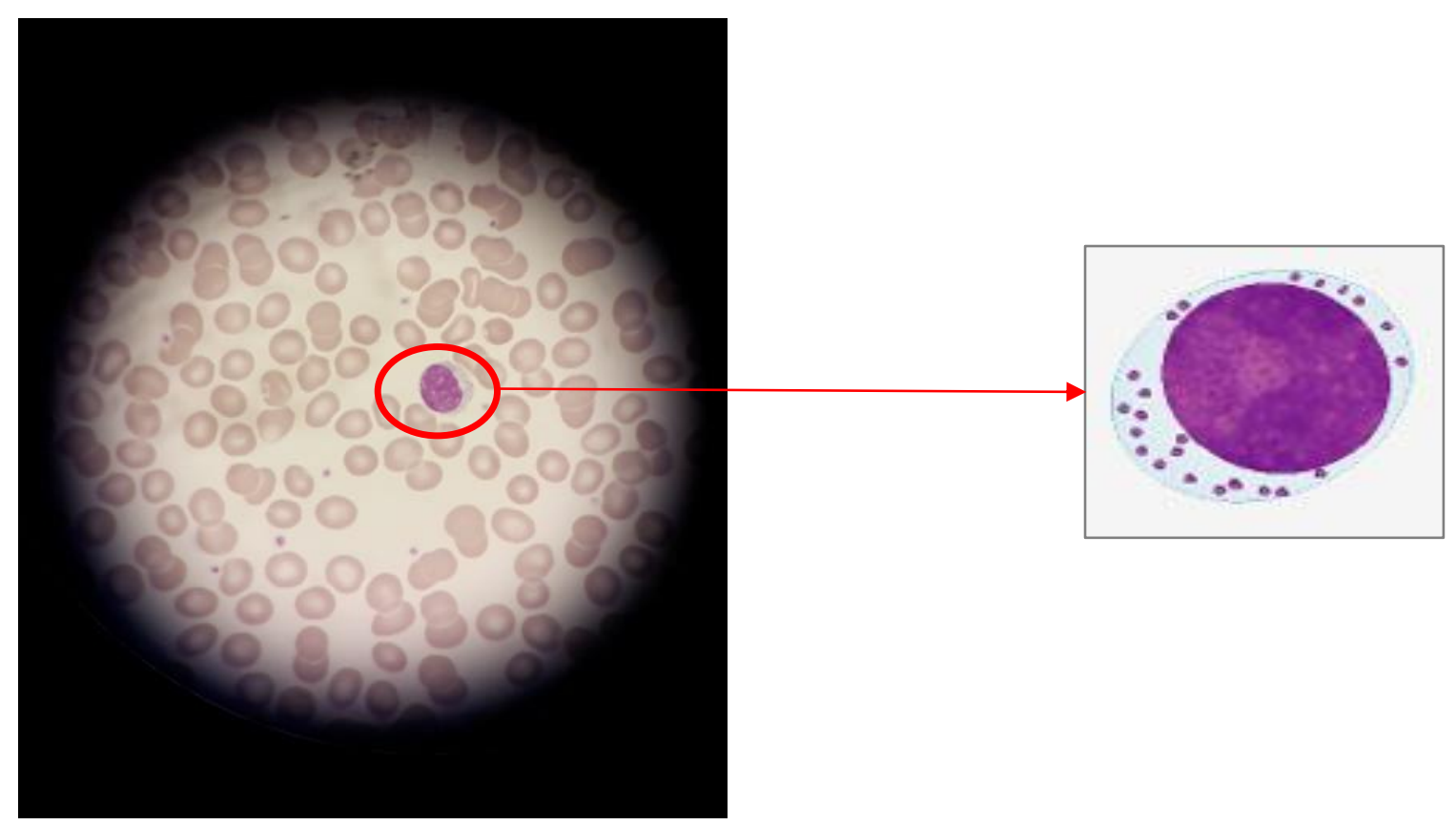

Abbildung 2 Mikroskopische Aufnahme einer lymphoiden Natürlichen Killerzelle (eigene Erhebung).

\subsubsection{Reifestadien von NK-Zellen}

Während die Bildung der NK-Zellen zweifelsohne im Knochenmark ${ }^{8,9}$ stattfindet, ist die Systematik weiterer Differenzierungsschritte und Reifungsorte nicht abschließend erforscht. Die Prä-NK-Zelle ist primär gekennzeichnet durch die Expression des Oberflächenmarkers CD34, der sich ebenfalls auf hämatopoetischen Stammzellen (HSZ) befindet. Im Zuge der Zellreifung kommt es dann zu einer zunehmenden Expression von CD117 und CD161 bei allmählichem Verlust des Stammzell-Markers CD34. ${ }^{10,11}$ Verschiedene Forschungsgruppen konnten bisher unterschiedliche Reifestadien von NK-Zellen in Thymus, Milz, Leber und den Lymphknoten ${ }^{12-16}$ isolieren, jedoch in Ermangelung weiterer spezifischer Zellmarker 
nicht genauer charakterisieren. Reife NK-Zellen wurden erstmals 1975 mikroskopisch im Blutausstrich von Mäusen durch Kiessling, Klein et. al. entdeckt. ${ }^{17}$ Phänotypisch werden humane NK-Zellen über die Expression der Oberflächenmarker CD56 und/oder CD16, bei gleichzeitigem Fehlen von CD3, definiert. ${ }^{18}$ Letzterer stellt das typische Erkennungsmerkmal für T-Zellen dar, während B-Zellen den immunhistochemischen Marker CD19 spezifisch exprimieren.

\subsubsection{Funktionelle Phänotypen}

Nach heutigem Kenntnisstand lassen sich zwei Hauptphänotypen von NK-Zellen unterscheiden: die $\mathrm{CD}_{16}{ }^{+} \mathrm{CD} 56_{\operatorname{dim}} \mathrm{NK}$-Zellen (^CD56 $6^{\text {armer }}-$ Phänotyp) und die $\mathrm{CD}^{-}$ CD56 bright $\mathrm{NK}$-Zellen (^CD56 ${ }^{\text {reicher }}$-Phänotyp). ${ }^{19,20,11}$ NK-Zell-Phänotypen scheinen mit unterschiedlicher Häufigkeitsverteilung in lymphatischen und nicht-lymphatischen Geweben vorzukommen. Laut Reeves et al. kommen $\mathrm{CD} 16^{+} \mathrm{CD} 56_{\text {dim }} \mathrm{NK}-$ Zellen vornehmlich als peripher zirkulierende Effektorzellen vor, während $\mathrm{CD}^{-} 6^{-} \mathrm{CD} 56_{\text {bright }}$ NK-Zellen mehrheitlich in lymphatischem Gewebe lokalisiert sind. ${ }^{21} \mathrm{NK}-Z$ ellen des CD56 ${ }^{\text {armen }}$ Phänotyps machen mit $>90 \%$ den Großteil der peripheren NK-Zellen aus. ${ }^{22}$ Neben morphologischen Aspekten, wie der deutlich ausgeprägteren intrazellulären Menge zytotoxischer Granula, unterscheiden sie sich vom CD56 $6^{\text {reichen }}$-Phänotyp durch eine bereits im Ruhezustand deutlich erhöhte zytotoxische Aktivität ${ }^{23}$ und eine wirksamere Konjugatbildung bei der Interaktion mit ihren Zielzellen. ${ }^{24}$ Bei dem zusätzlich exprimierten CD16a handelt es sich um ein Glykoprotein mit intrazellulärer Immunorezeptor Tyrosinbasierter Aktivierungsmotiv (ITAM) Domäne, welches sich ebenfalls auf der Oberfläche weiterer Immunzellen befindet. ${ }^{25(184), 26}$ Durch die Bindung dieses Rezeptors an die leichten Ketten des konstanten Teils, dem sogenannten Fc-Abschnitt, des Immunoglobins IgG der Zielzellen wird eine charakteristische Zytotoxizitätskaskade ausgelöst, welche zum Abbau der Zielzelle durch Aufhebung ihrer äußeren Membranintegrität (Zytolyse) führt. Außerdem ist CD16a, im Gegensatz zum nahe verwandten CD16b, an diversen PhagozytoseMechanismen beteiligt. ${ }^{27}$ Die restlichen $<10 \%$ der peripheren NK-Zellen beim Menschen

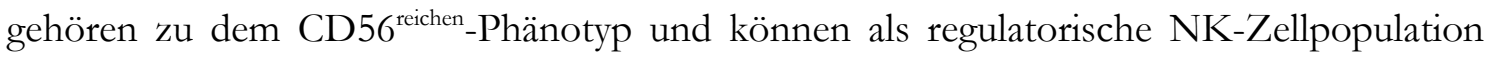

a Synonym: Fc $\gamma \mathrm{RIII}$ (engl.: Fc gamma region immunoglobin receptor IIIa) 
angesehen werden. Ihre primäre Aufgabe ist die Produktion von Zytokinen (Signalstoffe) bzw. Chemokinen (Lockstoffe). ${ }^{28}$ Adaptive NK-Zellen (aNK), welche in der Literatur auch als „Gedächnis“-NK-Zellen bezeichnet werden, bilden eine weitere interessante Subpopulation der Natürlichen Killerzellen, welche zunehmend in den Fokus wissenschaftlichen Interesses rücken. Obwohl NK-Zellen keiner primären Aktivierung bedürfen, kann ihr Aktivitätslevel durch verschiedene selbst- (endogen) oder fremd- (exogen) produzierte Zytokine verstärkt werden. Besonders relevant in diesem Kontext sind Interferon-gamma (IFN- $\gamma)$, Tumornekrosefaktor-alpha (TNF- $\alpha$ ) und der GranulozytenMonozyten-Kolonie-stimulierender Faktor (GM-CSF). Für die Migration von CD56 bright NK-Zellen in lymphatisches Gewebe scheint die Expression von CD62L (L-Selektin) und

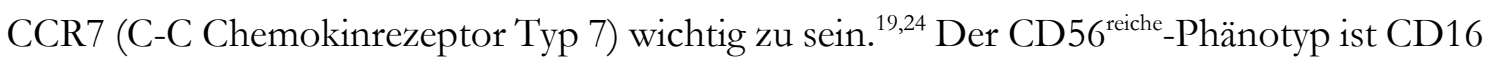
negativ und exprimiert konstitutiv den hochaffinen Interleukin-2 (IL2)-Rezeptor. ${ }^{29}$ Dies erklärt, warum es maßgeblich nach IL-2 Stimulation zu einer deutlichen Proliferation- und Zytotoxizitätssteigerung dieser NK-Subpopulation kommt. ${ }^{30-33}$ Einige exogene Interleukine, wie IL-10 und -13, sind zudem an verschiedenen Aktivierungs- und Reifungsprozessen anderer Zellarten, wie der dendritischen Zellen (DCs), an dem sogenannten „Priming“ von T-Zellen sowie monozytären Phagozytoseprozesse beteiligt. In Forschungsarbeiten konnte gezeigt werden, dass von NK-Zellen endogen produzierte Zytokine diese nach Ausschüttung befähigen in schwer erreichbares, entzündetes Gewebe vorzudringen. ${ }^{34}$ Darüber hinaus besitzen zahlreiche solcher Zytokine nachweislich einen direkten antiviralen und/oder antiproliferativen Effekt gegenüber erkrankten Zellen. ${ }^{19,35-39}$

\subsection{Zytotoxizitätsmechanismen und Lizensierung von NK-Zellen}

Bei NK-Zellen handelt es sich um nicht-phagozytierende, zytotoxische Immunzellen, welche durch Blut- und Lymphgefäße zirkulieren und nach krebstransformierten oder virusinfizierten Zellen suchen. Ihre Zytotoxizitätsmechanismen beinhalten: (1) Gerichtete Exozytose zytotoxischer Granula (Degranulation) ${ }^{40,41}$, (2) Aktivierung der Tumornekrosefaktor (TNF)-Todesrezeptor-Familie (Apoptose) ${ }^{42,43}$, (3) proinflammatorische Freisetzung von Zytokinen sowie (4) Freisetzung chemotaktischer Botenstoffe zur Anlockung phagozytierender Zellen. Die Immunantwort von NK-Zellen erfolgt typischerweise prompt und unspezifisch, d.h. unabhängig von vorheriger Antigenvermittelter Sensitivierung. ${ }^{44}$ Dieser augenscheinliche „Nachteil“ bildet einen entscheidenen Vorteil für das Immunsystem, denn auf diese Weise erkennen NK-Zellen selbst jene 
mutierten Zellen, welche den zytotoxischen T-Zellen entgehen, weil die Antigene auf der Zellmembran erkrankter Zielzellen nahezu unverändert geblieben sind. NK-Zellen nehmen aktiv an der primären Immunabwehr teil, haben jedoch darüber hinaus durch die Freisetzung von Botenstoffen auch eine passiv-vermittelnde Rolle, zwischen dem erworbenen und adaptiven Immunsystem. ${ }^{45}$ Sie exprimieren ebenfalls keine Rezeptoren zur Erkennung anderer lymphoider Zellen. ${ }^{46,47} \mathrm{NK}$-Zellen, die gelernt haben, ausschließlich auf fremde oder erkrankte Zielzellen mit Zytolyse zu reagieren, erhalten die Lizenz zu töten. Dazu durchlaufen NK-Zellen mit inhibitorischen Rezeptoren einen vorgeschalteten Reifungsprozess $^{48}$, bei dem sie beweisen müssen, dass sie ihre spezifischen Humanen Leukozyten Antigene (HLA), entsprechend der HLA-Klasse-I-Liganden HLA-Bw4, -C1 oder -C2, auf benachbarten Zellen erkennen können. ${ }^{49}$ Damit wird eine unkontrollierte Effektorantwort verhindert. Unlizenzierte NK-Zellen reagieren dagegen kaum, man spricht von Hyporesponsivität. ${ }^{50}$ Neben der Eliminierung krebsveränderter Körperzellen stellt die immunologische Überwachung gegenüber defekten oder „gestressten“ Zellen eine weitere Kernaufgabe dar. Um ihre Aufgabe als zytotoxische Immunzellen erfüllen zu können, verfügen NK-Zellen über eine Fülle verschiedenener Rezeptortypen, die im Folgenden vorgestellt werden. Damit es zur Lyse bzw. Apoptoseeinleitung einer Zielzelle kommt, bildet die NK-Zelle eine Kontaktfläche (,immunologische Synapse“) zu erkrankten Körperzellen aus. Die Entscheidung, ob eine als krankhaft erkannte Zelle abgetötet wird, ist dann von dem Überwiegen aktivierender gegenüber inhibierender Rezeptorsignale abhängig. Um NKZellaktivität auszulösen, ist hierbei in der Regel eine Vernetzung von mindestens zwei verschiedenen aktivierenden Rezeptoren erforderlich. Die einzige Ausnahme bildet CD16, bei dem das „Crosslinking“ innerhalb des Rezeptors selbst ausreicht, um eine NK-ZellDegranulation zu verursachen. ${ }^{51}$

\subsection{Killerzell-Immunglobulin-ähnliche Rezeptoren}

Bei den Killerzell-Immunoglobulin-ähnlichen-Rezeptoren ${ }^{\mathrm{b}}$ (KIRs) handelt es sich um eine wichtige Gruppe regulierender Oberflächenproteine auf lymphoiden Zellen. KIRs sind TypI-Transmembranglykoproteine ${ }^{52,53}$, welche üblicherweise als Monomere auf der

\footnotetext{
b Synonym: CD158, engl.: killer cell immunoglobulin-like receptor
} 
Zelloberfläche humaner NK-Zellen exprimiert werden. Darüber hinaus finden sich einige inhibitorische KIR-Typen (iKIRs) ebenfalls auf zytotoxischen T-Zellen exprimiert. ${ }^{54,55} \mathrm{Nach}$ heutigem Wissenstand zählt man insgesamt 15 aktivierende und inhibierende Rezeptoren zu der KIR-Rezeptorfamilie ${ }^{56}$, zusätzlich sind zwei KIR-Pseudogene, die für KIR2DP1 und 3DP1 kodieren, beschrieben. Trotz der großen Anzahl an potenziell möglichen Keimbahnkodierten KIRs exprimiert jede NK-Zelle typischerweise nur einen kleinen Anteil dieser Rezeptoren auf ihrer Oberfläche, wobei unklare Kombinationsmechanismen das Repertoire mitzubestimmen scheinen. ${ }^{57,58}$ Die meisten Liganden der KIR-Familie sind Untergruppen von HLA-Klasse-I-Molekülen ( $\rightarrow$ vgl. Abschnitt 1.3.3), wobei die aktivierenden Rezeptoren im Allgemeinen eine geringere Affinität zu den Liganden haben als ihre inhibitorischen Kontrahenten. ${ }^{59,60}$

\subsubsection{Struktur und Funktion}

Strukturell bestehen alle aktivierenden und inhibierenden KIR-Rezeptoren aus drei Regionen, einer extrazellulären Domäne, einer Transmembranregion und einer intrazellulären Domäne, die den zytoplasmatischen Schwanzteil bildet (Abb. 3).

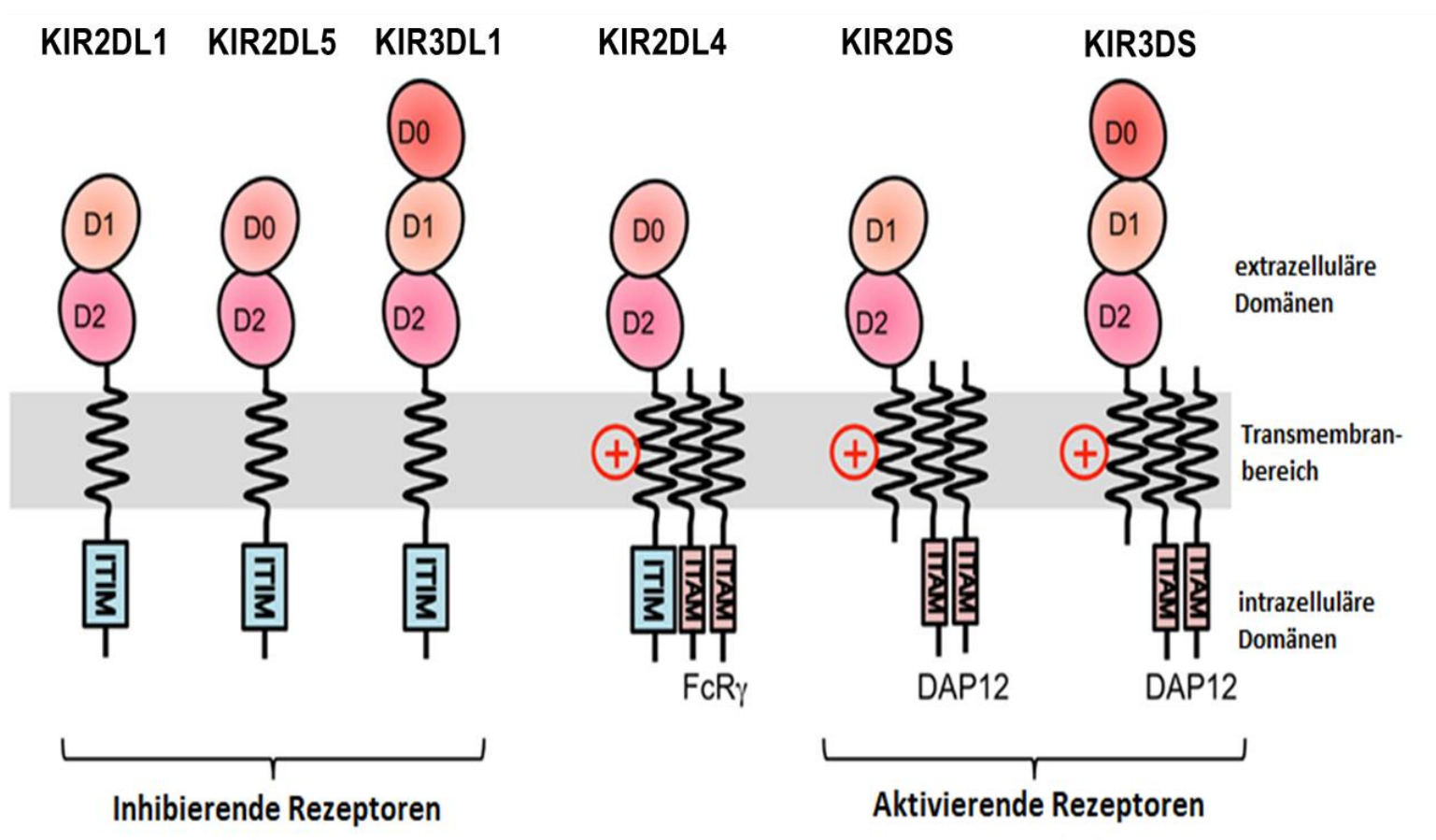

Abbildung 3 Darstellung des strukturellen Aufbaus verschiedener KIRs. Dargestellt sind KIRs mit 2 oder 3 namensgebenden extrazellulären Immunoglobin (Ig)-Domänen. Anhand der Länge ihrer intrazellulären Domäne (KIRL („Iong") oder KIR-S (,short")) und ihrer Signalmotive (ITIM oder ITAM) werden KIRs funktionell in aktivierende und inhibierende Rezeptortypen eingeteilt. [Abbildung modifiziert mit Genehmigung von Kuroki, Furukawa et al. (2012)61] 
Im Bereich der äußeren, extrazellulären Domänen unterscheiden sich KIRs in der Anzahl ihrer Ig-Domänen (D0 - D2). Je nach dem ob es sich um zwei oder drei Ig-Domänen handelt, spricht man nomenklatorisch von KIR2D oder -3D. ${ }^{62}$ Durch die Beschaffenheit der inneren, intrazellulären Domäne werden KIRs weiter funktionell eingeteilt. Solche mit langen, zytosplasmatischen Domänen („L“ von engl. long) bilden inhibierende KIR-Rezeptortypen (iKIR), während solche mit kurzen Domänen („S“ von engl. short) aktivierende KIRRezeptortypen (aKIR) darstellen. Eine Ausnahme bildet KIR2DL4, ein Rezeptortyp, der trotz langen zytoplasmatischen Domänen mehrheitlich aktivierende Funktionen, wie die Zytokin- und Chemokinsekretion, vermittelt. Im Gegensatz zu allen anderen KIRs, die auf der Oberfläche von NK-Zellen exprimiert werden, bleibt KIR2DL4 innerhalb der Zelle in Zellorganellen, die als Endosomen bezeichnet werden, und interagiert mit löslichem HLAG. Andere iKIRs, wie KIR2DL und -3DL, entfalten ihre inhibitorische Wirkung über zwei Immunorezeptor Tyrosin-basierte Inhibitionsmotive (ITIM). Die iKIRs erkennen HLAKlasse-I-Moleküle auf der Oberfläche gesunder Zellen, die ihnen signalisieren, dass die jeweiligen Zellen als körpereigen einzustufen sind, und sie dann vor den tödlichen NK-ZellAngriff schützen. Durch Phosphorylierung der Tyrosin-Reste der ITIMs kommt es zu der Rekrutierung von den Phosphatasen SHP-1 und SHP-2 ${ }^{c}$. Beide Phosphatasen inhibieren die aktivierenden Signalwege, sodass es zu einer deutlich schwächeren Phosporylierung zahlreicher intrazellulärer Signalproteine kommt. ${ }^{63,64,59}$ Die aktivierenden KIR-Rezeptoren mit kurzen zytoplasmatischen Domänen, wie KIR2DS und -3DS, assoziieren mit einem Dimer des Immunorezeptor Tyrosin-basierten Aktivierungsmotivs (ITAM), welches das Adapterprotein DAP12 (Synonym: KARAP) trägt und aktivierende Signale vermittelt. ${ }^{65,66}$ Auch andere wichtige NZRs, wie CD5, CD22 und Fc $\gamma$ RII nutzen ITIMs und ITAMs. ${ }^{67}$ 


\subsubsection{Genetische Diversität}

Das KIR-Gencluster befindet sich auf dem langen Arm des Chromosoms 19 (Genlocus: 19q13.4) innerhalb des sogenannten Leukozyten-Rezeptor-Komplexes ${ }^{d}$. Nach heutigem Kenntnisstand befinden sich innerhalb des erweiterten $>1 \mathrm{mb}$ langen LRC neben den KIRGenen mindestens weitere 40 Mitglieder der Ig-Rezeptor-Superfamilie (Abb. 4).

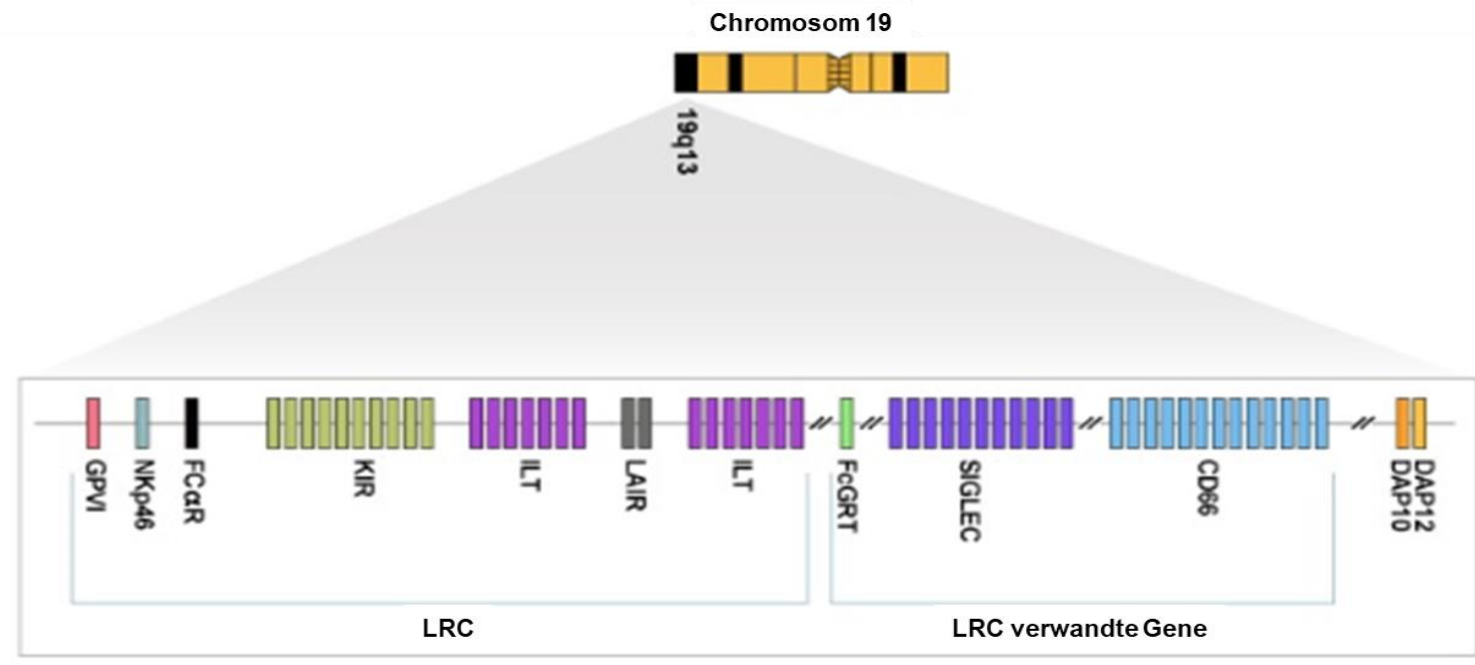

Abbildung 4 Genetische Karte des erweiterten $>1$ mb langen Leukozyten-Rezeptor-Komplexes (LCR) auf Chromosom 19q13. [Abbildung übersetzt mit Genehmigung von Trowsdale, Barten et al. (2001)68 und Blackwell Publishing Ltd.]

Der LCR hat sich als bemerkenswert komplex und polymorph herausgestellt ${ }^{56}$ und kodiert unter anderem für die insgesamt 15 KIR-Gene sowie zwei KIR-Pseudogene. ${ }^{69,70}$ Pseudogene sind Segmente der Desoxyribonukleinsäure (engl.: desoxyribonucleic acid, DNA), die zwar wie ein Gen aufgebaut sind, jedoch entweder nicht transkribiert werden (inaktive Gene) oder durch ihre mutierte Nukleotidsequenz funktionslose Proteinvorstufen bilden. ${ }^{71}$ Sie haben damit keinen phänotypischen Effekt auf den Organismus. Wissenschaftler vermuten jedoch, dass nicht alle Pseudogene funktionslos $\operatorname{sind}^{72-78}$, sondern angenommen werden kann, dass zumindest bei einigen Pseudogenen, die mRNA (engl.: messenger ribonucleic acid) als eine Art „regulatorische RNA“ Steuerungsfunktionen bei der Transkription (bzw. Translation) echter Gene übernimmt. ${ }^{79}$ Ähnliche Vermutungen bestehen in Hinblick auf die KIR-Pseudogene.

\footnotetext{
d engl.: leukocyte receptor complex, LRC
} 
Die Vererbung der KIR-Gene erfolgt, ähnlich der Humanen Leukozyten Antigene (HLA)Merkmale, zusammenhängend (,en-bloc “) in sogenannten Haplotypen. Jeder Mensch erbt von seinen biologischen Eltern KIR-Gen-Varianten, welche zusammengesetzt zu einem individuellen genetischen KIR-Repertoire führen. Entwicklungsgeschichtlich folgt die Verebung beim Menschen einem artspezifischen KIR-Haplotyp-Regime, welches individuen- und populationsabhängig erforscht wurde. ${ }^{80}$ Von den 17 KIRs kodieren neun Gene für inhibitorische Rezeptoren (KIR2DL1, KIR2DL2, KIR2DL3, KIR2DL4, KIR2DL5A, KIR2DL5B, KIR3DL1, KIR3DL2 und KIR3DL3) und sechs für aktivierende Rezeptoren (KIR2DS1, KIR2DS2, KIR2DS3, KIR2DS4, KIR2DS5 und KIR3DS1). ${ }^{81}$ Bei den verbleibenden zwei handelt es sich um Pseudogene (KIR2DP1 und KIR3DP1) mit unbekannten Funktionen. ${ }^{82}$

In verschiedenen Arbeiten ${ }^{56,81}$ wurden unterschiedliche Kriterien zur Einteilung von A- und B-Haplotypen verwendet. Die zwei Haplotypen unterscheiden sich von der Genausstattung in der zentromerischen und telomerischen Hälfte des KIR-Genlocus (Abb. 5).

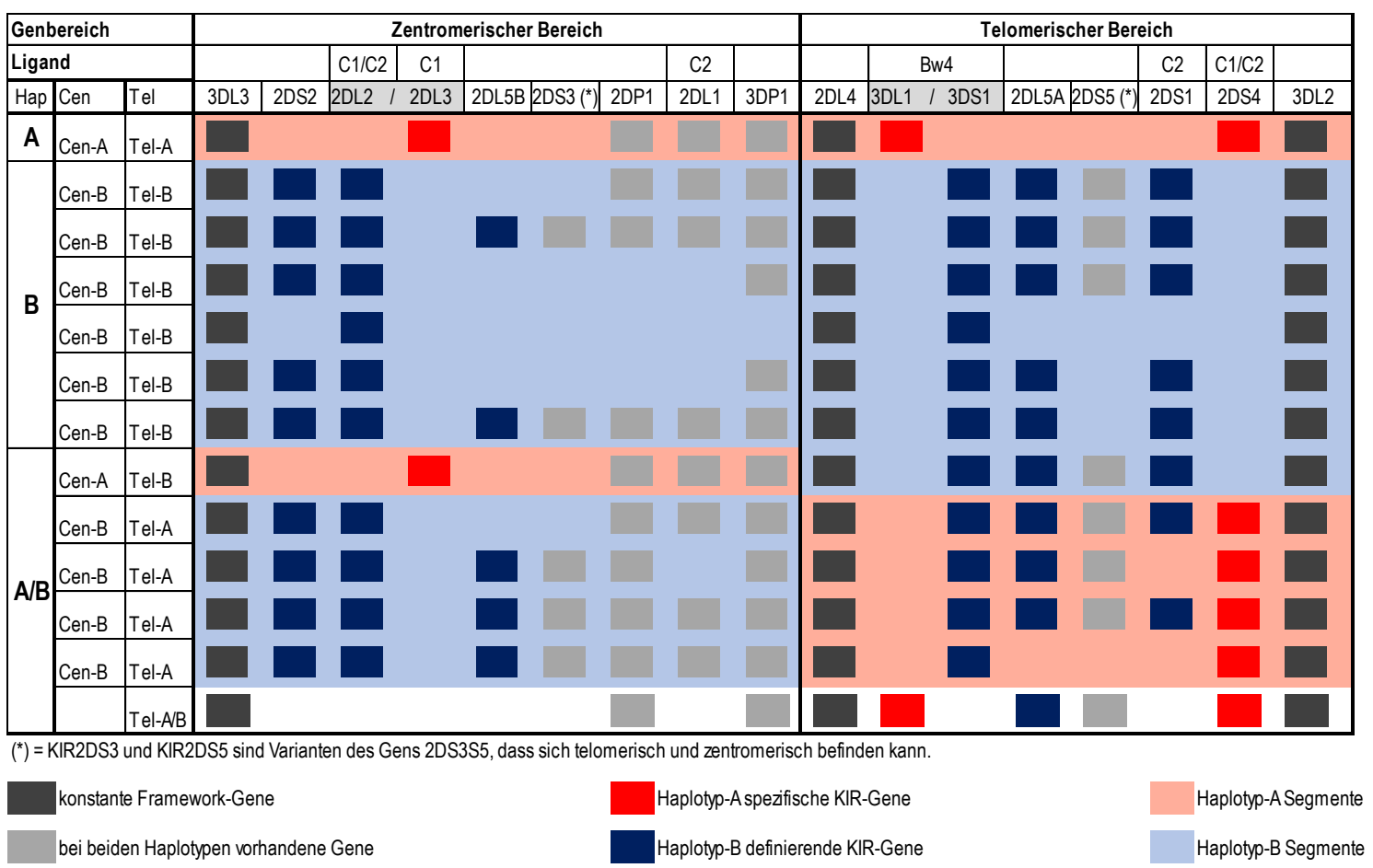

Abbildung 5 Genanordnung und -inhalt der humanen KIR-Haplotypen (,Hap“) A, B und A/B. Die Zugehörigkeiten der aktivierenden und inhibierenden KIR-Rezeptoren sind in Bezug zu ihren zentromerischen („Cen“) bzw. telomerischen (,Tel") Gensegmenten B innerhalb des KIR-Genlocus dargestellt. (rot= Haplotyp-A Segmente; blau= Haplotyp-B Segmente)

Eine gängige und in der vorliegenden Arbeit verwendete Unterscheidung richtet sich nach dem genetischen Umfang aktivierender KIR-Rezeptoren (aKIRs) innerhalb des jeweiligen Genabschnitts auf Chromosom 19. Individuen, welche den Haplotyp-B geerbt haben, tragen 
neben den konstanten Framework-Genen ${ }^{83,84}$ KIR3DL3, 2DL4 und 3DL2 typischerweise Kombinationen aktivierender KIR-Gene, wie 2DS1, 2DS2, 2DS3, 2DS5, 3DS1 sowie KIR2DL5. Umgekehrt sind Haplotyp-A Träger durch das Fehlen all dieser Gene gekennzeichnet und kodieren neben KIR2DL1, 2DL3 und 3DL1 ausschließlich für einen aktivierenden KIR, nämlich KIR2DS4 ${ }^{85}$ Der B-Haplotyp besitzt demnach sowohl in Bezug auf die Gesamtheit der KIR-Gene, als auch in Hinblick auf seine aktivierenden KIRs mehr kodierte Gene als der A-Haplotyp. In der Literatur spricht man bei Trägern des Haplotyp-A deshalb vereinfacht von einem eher inhibierenden Genotyp, bei Trägern des Haplotyp-B von einem aktivierenden Genotyp.

Die Anzahl der letztendlich in einem Genom vorhandenen KIR-Gene, das sogenannnte KIRom, variiert von Mensch zu Mensch. Die einzelnen KIRs weisen dabei untereinander eine hohe Sequenzähnlichkeit von bis zu 95\% auf. ${ }^{86}$ In jeder vererbten Genvariante existieren wiederherum geringfügige Unterschiede in den einzelnen Nukleotid-Sequenzen, also in der Abfolge der einzelnen DNA-Basen (Adenin, Guanin, Cytosin und Thymin). Diese minimalen Abweichungen (Polymorphismen) entstehen durch Mutationen und lassen alternativen Formen eines Gens entstehen, die man Allele nennt. ${ }^{87}$ Erbt ein Individuum eine mütterliche Genvariante (Allel 1) sowie ein väterliches Allel (Allel 2), spricht man von einem heterozygoten Nachkommen. Erbt ein Individuum dagegen identische Genvarianten, spricht man von einer homozygoten Vererbung. Eine aktuelle Übersicht der wissenschaftlich bestätigten KIR-Allele (insgesamt 977 Allele) findet sich in Tabelle 1 zusammengefasst.

Tabelle 1 Aktuelle Übersicht der Anzahl aller bisher bekannter Allele pro Killerzell-Immunoglobulin-ähnlichemRezeptortypen (KIR.) [Quelle: IPD Datenbank unter https://www.ebi.ac.uk/ipd/kir/alleles.html; Stand Januar 2019]

\begin{tabular}{|l|cccccccc|}
\hline \multicolumn{10}{|c|}{ Übersicht: KIR-Allele } \\
\hline Gen & 2DL1 & 2DL2 & 2DL3 & 2DL4 & 2DL5 & 2DS1 & 2DS2 & 2DS3 \\
\hline Allele & 64 & 33 & 59 & 70 & 54 & 16 & 24 & 16 \\
Nullallele & 2 & 0 & 1 & 0 & 0 & 0 & 0 & 1 \\
Proteine & 36 & 15 & 34 & 41 & 24 & 8 & 9 & 7 \\
\hline Gen & 2DS4 & 2DS5 & 3DL1 & 3DS1 & 3DL2 & 3DL3 & 2DP1 & 3DP1 \\
\hline Allele & 37 & 24 & 147 & 39 & 161 & 164 & 40 & 29 \\
Nullallele & 0 & 0 & 3 & 1 & 1 & 0 & 0 & 0 \\
Proteine & 16 & 17 & 91 & 22 & 111 & 92 & 0 & 0 \\
\hline
\end{tabular}

Neben wichtigen Begriffen wie Hetero- und Homozygotie spricht man bei dem Versuch der Bestimmung von Genvarianten von dem Auftreten von Ambiguitäten, nämlich immer dann, wenn es nicht gelingt im Rahmen der Typisierung einer DNA-Probe alle polymorphen Stellen eines Gens hochauflösend zu bestimmen. Analog zu den HLA-Merkmalen nimmt die Komplexizität bei der Bestimmung von KIR-Allelvariante durch die stetig wachsende 
Anzahl an neu entdeckten Polymorphismen weiter zu. Dies macht das Auftreten von Ambiguitäten bei der Typisierung wahrscheinlicher und stellt eine technische Herausforderung dar.

Die Nomenklatur von KIR-Allelen folgt der Systematik, die auch bei der Benennung von Allelvarianten im HLA-System angewandt wird. Sie umfasst den KIR-Gennamen an erster Stelle, gefolgt durch ein Stern-Symbol als Trennzeichen vor der weiteren numerischen Allelbezeichnung. Die ersten drei Nummernziffern werden dabei verwendet, um Allele anzuzeigen, die sich bereits in den Sequenzen ihrer kodierten Proteine unterscheiden. Die nächsten zwei Ziffern werden verwendet, um Allele zu unterscheiden, die sich lediglich durch synonyme, das heißt nicht-kodierende und damit silente Variationen innerhalb der Kodierungssequenz unterscheiden. Die letzten zwei Ziffern unterscheiden Allele, die sich weiter durch Substitutionen in einem Intron, Promotor oder einem anderen nichtkodierenden Bereich der Sequenz kontrastieren (Abb.6).

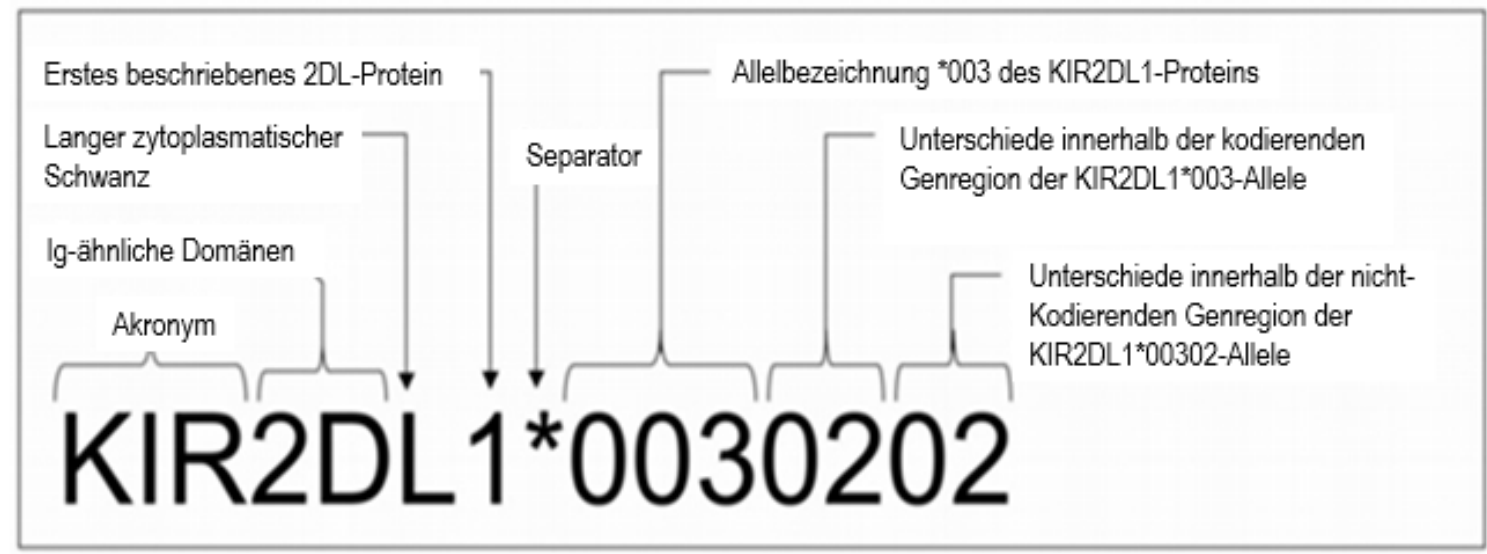

Abbildung 6 Systematik zur numerischen Nomenklatur von KIR-Allelen, am Beispiel von KIR2DL1. [Quelle: IPD Datenbank; https://www.ebi.ac.uk/ipd/kir/alleles.html] 


\subsubsection{Spezifische Liganden}

Kurz nach der Entdeckung der NK-Zell-Rezeptoren (NZR) begann die Erforschung ihrer korrespondierenden Partner. Bei der Interaktion mit KIR spielen Humane LeukozytenAntigene (HLA) als spezifische Liganden eine wesentliche Rolle. Sie wurden zuerst auf der Oberfläche von Leukozyten entdeckt und haben medizinische Signifikanz, da sie Transplantation, Transfusion, Tumorabwehr und Krankheitsdisposition beeinflussen. Sie sollen im Folgenden näher vorgestellt werden.

Alle HLA-Moleküle werden über den MHC -Komplex, einem hoch komplexen Gencluster auf dem kurzen Arm des menschlichen Chromosoms 6, kodiert. Das Gen besitzt drei Genregionen, die man von Klasse I (telomerwärts) bis Klasse III (zetromerwärts) einteilen kann. Der HLA-Klasse-I-Loci beinhaltet die sogenannten klassischen HLA-Klasse-Ia- und die nichtklassischen HLA-Klasse-Ib-Gene. Die HLA-A, -B, -C Moleküle werden über die HLA-Klasse-Ia-Gene kodiert. Die HLA-Klasse-Ib-Gene repräsentieren den Loci für die ubiquitär vorkommenden Gewebsmerkmale HLA-E, -X, -F, -G, -H und -J, über deren Funktion noch wenig bekannt ist. Sie werden differenzierungs- und gewebsabhängig exprimiert und spielen vermutlich bereits in der Embryonalentwicklung eine wichtige Rolle.

HLA-Klasse-I-Moleküle (MHC-I) befinden sich auf der Oberfläche aller kernhaltigen Körperzellen und bestehen aus einer transmembranär verankerten $\alpha$-Kette mit 3 Domänen $\left(\alpha_{1}-\alpha_{3}\right)$, der an der extrazellulären Seite ein $\beta_{2}$-Mikroglobulin angelagert ist. Sie werden nach ihrer Synthese im Endoplasmatischen Retikulum über den Golgi-Apparat an die Zelloberfläche geschleust. Die Hauptfunktion von MHC-I besteht darin, Körperzellen als eigen (engl.: self) zu markieren und dadurch von Fremdzellen (engl:: non-self / missing-self) im Immunsystem unterscheidbar zu machen. c kommen selektiv auf einigen Immunzellen, wie antikörperbildenden B-Lymphozyten, Makrophagen und spezialisierten dendritischen Zellen, vor. MHC-II besteht charakteristisch aus 4 extrazellulären Domänen, welche sich aus $\alpha_{1} / \alpha_{2}$ - und $\beta_{1} / \beta_{2}$-Ketten zusammensetzen. Im Gegensatz zu MHC-I sind bei MHC-II beide Protein-Untereinheiten in der Zellmembran verankert (Abb. 7). Zudem bildet das CoRezeptor-Protein CD4 ein weiteres wesentliches Unterscheidungsmerkmal an der

e engl.: major histocompatibility complex, $\mathrm{MHC}$ 
Außenseite der $\beta_{2}$-Kette von MHC-II. HLA-Klasse-III-Moleküle werden eher historisch mit zum HLA-System gezählt und beinhaltet neben den Tumornekrosefaktoren (TNF- $\alpha$ und $\beta$ ) auch die Komplementfaktoren $\mathrm{B}, \mathrm{C} 2, \mathrm{C} 4 \mathrm{~A}$ und $\mathrm{C} 4 \mathrm{~B}$, welche für die Blutgerinnung wichtige Funktionen übernehmen.
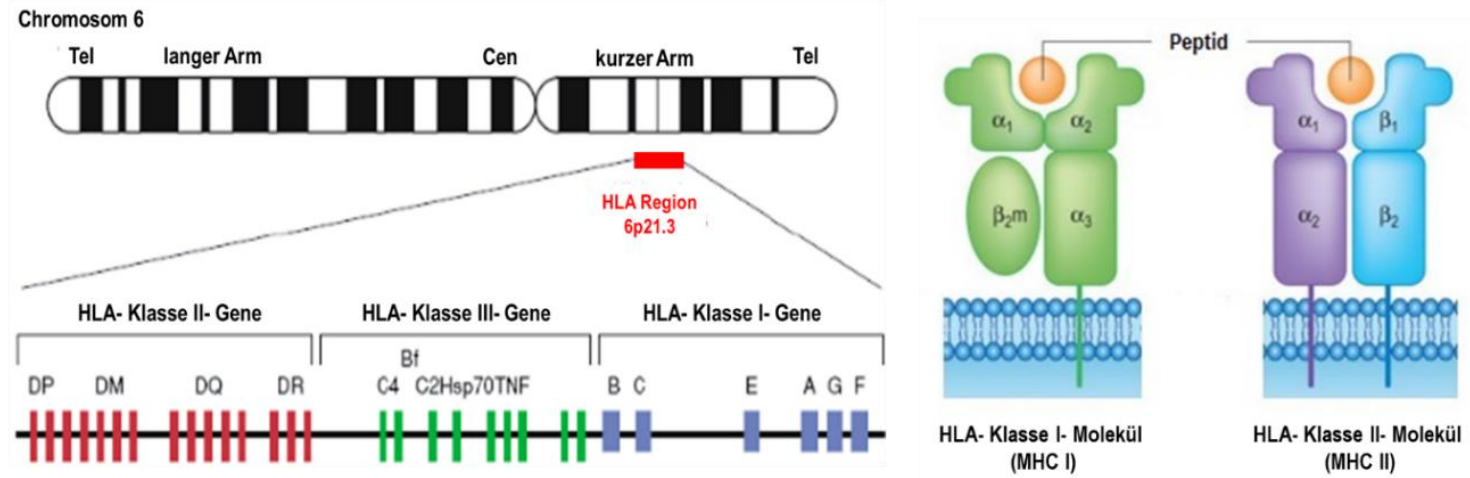

Abbildung 7 Organisiation des MHC-Genlocus auf Chromosom 6. Hier befindet sich die genetische Information aller humanen Leukozytenantigene (HLA), welche in ihrer Gesamtheit das sogenannte HLA-System bilden (links) [Abbildung im Original aus der Publikation Berlingerio, Bonchi et al. (2009)88]. Molekularer Aufbau eines HLA-KlasseI-Moleküle (MHC-I) und-Klasse-II-Moleküls (MHC-II). Das angelagerte $\beta 2$-Mikroglobulin wird dabei über Chromosom 15 kodiert (rechts) [Abbildung mit Genehmigung; modifiziert nach Moffett-King, Entrican et al. (2002)89].

Die hohe Rate an HLA-Polymorphismen führt analog zu KIR zu einer komplexen allelischen Vielfalt. Diese ist dafür verantwortlich, dass nur wenige Individuen aus einer Familie trotz nahem Verwandtschaftsgrad HLA-identisch sind. Alle exprimierten HLA-C-Allele werden abhängig von der Aminosäurenstruktur ihrer $\alpha 1$-Helix zur C1- oder C2-Gruppe ${ }^{90}$ gezählt und die meisten HLA-B-Allele können anhand ihrer Epitope Bw4 oder Bw6 in zwei Gruppen klassifiziert werden. ${ }^{91}$ Wie in Tabelle 2 dargestellt, unterscheiden sich HLA-C C1 und C2 Moleküle dabei grundsätzlich in den Aminosäuren(AS)-Positionen 77 und 89 innerhalb der MHC-I $\alpha_{1}$-Helix, Bw4-Varianten dagegen im Bereich der AS-Positionen 77 bis 81. ${ }^{92-94}$ Zusätzliche Abweichungen zu den Bw6-Epitopen ergeben sich des Weiteren in den AS-Positionen 82 und 83.95,96

Tabelle 2 Differenzialtabelle zur Unterscheidung der HLA-Epitope Bw4, Bw6, C1 und C2 anhand der Aminosäurenreste an den Positionen 77 - 83 innerhalb der $\alpha_{1}$-Helix von HLA-A, -B und -C.

\begin{tabular}{|c|c|c|c|c|c|c|}
\hline \multirow{2}{*}{ MHC-I } & \multirow{2}{*}{ Epitop } & \multicolumn{5}{|c|}{ Aminosäurenposition } \\
\hline & & 77 & 80 & 81 & 82 & 83 \\
\hline HLA- A & Bw4 & S (Serin) & I (Isoleucin) & A (Alanin) & L (Leucin) & $\mathrm{R}$ (Arginin) \\
\hline \multirow[t]{6}{*}{ HLA-B } & \multirow[t]{4}{*}{ Bw4 } & $\mathrm{N}$ (Asparagin) & I (Isoleucin) & A (Alanin) & L (Leucin) & $\mathrm{R}$ (Arginin) \\
\hline & & $\mathrm{N}$ (Asparagin) & $\mathrm{T}$ (Threonin) & A (Alanin) & L (Leucin) & $\mathrm{R}$ (Arginin) \\
\hline & & D (Asparaginsäure) & $\mathrm{T}$ (Threonin) & L (Leucin) & L (Leucin) & $\mathrm{R}$ (Arginin) \\
\hline & & S (Serin) & $\mathrm{T}$ (Threonin) & L (Leucin) & L (Leucin) & $\mathrm{R}$ (Arginin) \\
\hline & \multirow[t]{2}{*}{ Bw6 } & G (Glycin) & $\mathrm{N}$ (Asparagin) & L (Leucin) & $\mathrm{R}$ (Arginin) & G (Glycin) \\
\hline & & S (Serin) & $\mathrm{N}$ (Asparagin) & L (Leucin) & $\mathrm{R}$ (Arginin) & G (Glycin) \\
\hline \multirow[t]{2}{*}{ HLA-C } & C1 & S (Serin) & $\mathrm{N}$ (Asparagin) & & & \\
\hline & $\mathrm{C} 2$ & $\mathrm{~N}$ (Asparagin) & $\mathrm{K}$ (Lysin) & & & \\
\hline
\end{tabular}


Tabelle 24 im Anhang zeigt die die Hauptantigene der HLA-Klasse-I-Moleküle A, B und C mit ihren jeweiligen Unterantigenen sowie ihrem korrespondierendem HLA-Epitop. Die iKIRs 2DL2 und 2DL3 interagieren mit HLA-C-Allelen mit einem Asparagin an Aminosäureposition 80 (HLA-C1) an der schweren Kette $^{97-99}$ und KIR2DL1 erkennen HLAC-Allele mit einem Lysin an dieser Position (HLA-C2). ${ }^{98,100}$ Mehrere Forschungsgruppen haben gezeigt, dass die iKIRs 2DL2 und 2DL3 auch mit HLA-C2-Allelen wechselwirken, aber nicht in gleichem Maße wie mit HLA-C1 oder im Falle von iKIR2DL1 mit HLAC2. ${ }^{101,102}$ Es konnte außerdem gezeigt werden, dass NK-Zellen, die die iKIRs 2DL1, 2DL3 und 3DL1 exprimieren, weniger wahrscheinlich positiv für CD16 sind, als ihre iKIRnegativen Kontrahenten. ${ }^{103}$ Der KIR2DL3-Rezeptor kann jedoch auch bestimmte Allelvarianten von HLA-C2 binden, allerdings mit geringerer Affinität als KIR2DL1.9 KIR3DL1 erkennt HLA-A- und HLA-B-Allele mit einem Bw4-Motiv innerhalb der Aminosäurepositionen 77 bis $80 .{ }^{92-94} \mathrm{Bw} 4-$ Antigene unterscheiden sich von den übrigen Bw6 HLA-B-Varianten, die allesamt nicht mit 3DL1 interagieren, an den Aminosäurepositionen 77 bis 83 der schweren HLA-Kette $\left(\rightarrow\right.$ vgl. Tabelle 2, Abschnitt 1.3.3) ${ }^{104}$ Schließlich besitzt der aKIR 2DS1 den gleichen Liganden HLA-C2 wie der iKIR 2DL1, wobei KIR2DS1 eine geringere Bindungsaffinität zu diesem Liganden aufweist. ${ }^{105}$

Je nachdem ob derjeweilige HLA-Ligand im jeweiligen Individuum vorhanden ist, also beispielsweise im Falle KIR2DL3-tragender NK-Zellen der HLA-C1 Ligand spezifisch exprimiert wird, werden die Immunzellen in höherem Maße ausgereift. Analog zeigt sich auf der anderen Seite ein schwächerer Reifungsgrad von NK-Zellen bei Individuen, die ausschließlich HLA C2 als Ligand exprimieren. Durch ihre Interaktion mit KIR-Isotypen, die die Aktivität von Natürlichen Killerzellen inhibieren, sind bestimmte HLA-Klasse-IMoleküle bekannt dafür, gesunde Zellen vor einer Zerstörung durch NK-Zell-vermittelte Zytolyse zu schützen. Dies spielt bei der Aufrechterhaltung der Selbsttoleranz eine wesentliche Rolle. ${ }^{106}$ Die Killer-Immunoglobin-Rezeptoren KIR2DL1, KIR2DL2 und KIR3DL1 binden jeweils den KIR-Liganden C2, C1 und Bw4, was zur Inhibierung der durch NK-Zellen vermittelten Lyse führt.

In Tabelle 3 auf der nachfolgenden Seite sind die bisher bekannten HLA-Liganden der KIR sowie einige weitere NZR aufgelistet. Abbildung 8 zeigt die enge Interaktion von KIR2DL1 mit seinem HLA-C2 Liganden Cw4 mittels Kristallstrukturanalyse. ${ }^{61}$ 
Tabelle 3 NK-Zell-Rezeptoren und ihre spezifischen Liganden im Überblick. Vertreter der KIR-Rezeptorfamilie auf NKZellen können lediglich an die $\alpha-K e t t e n$ von HLA-A, -B oder -C binden. Einzelne KIRs favorisieren bei der Interaktion in der Regel ein bestimmtes HLA-Klasse-I-Molekül. [Erweiterte Tabelle in Anlehnung an Locatelli, Pende et al. $\left.(2013)^{107}\right]$

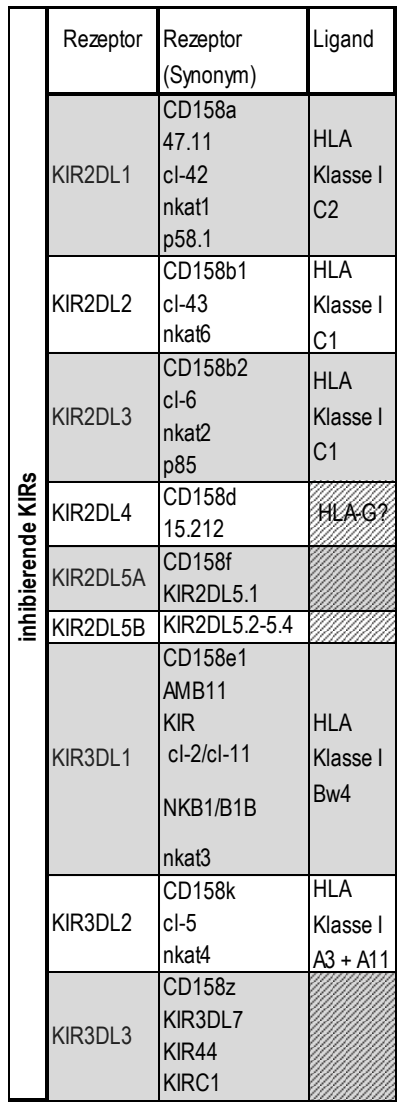

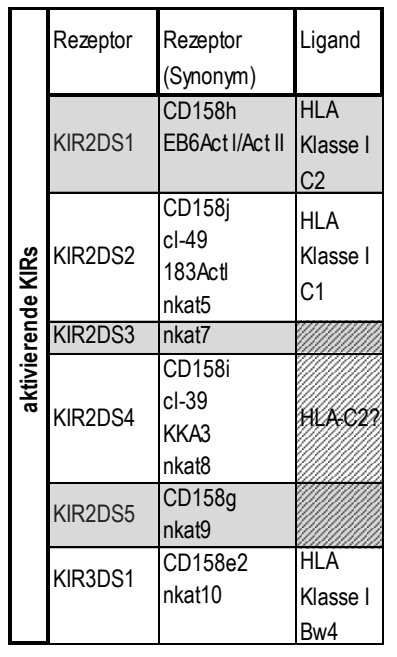

\begin{tabular}{|c|c|c|c|c|}
\hline \multirow{3}{*}{ 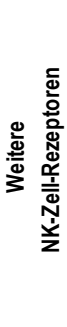 } & \multicolumn{2}{|c|}{ Rezeptor } & $\begin{array}{l}\text { Rezeptor } \\
\text { (Synonym) }\end{array}$ & Ligand \\
\hline & 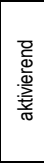 & $\begin{array}{l}\text { NKG2C } \\
\text { NKG2D } \\
\text { NKp30 } \\
\text { NKp44 } \\
\text { NKp46 }\end{array}$ & $\begin{array}{l}\text { CD159c, KLRC2, } \\
\text { CD314, KLRC1 } \\
\text { NCR3, CD337 } \\
\text { NCR2, CD336 } \\
\text { NCR1, CD335 }\end{array}$ & $\begin{array}{l}\text { HLA-E } \\
\text { MICA, MICB } \\
\text { u.a. BAT3 }\end{array}$ \\
\hline & 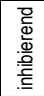 & $\begin{array}{l}\text { LILRB1 } \\
\text { NKG2A } \\
\text { NKG2B }\end{array}$ & $\begin{array}{l}\text { CD85j, ILT-2, LIR-1, MIR-7, PIR-B } \\
\text { CD94-NKG2A } \\
\text { CD94-NKG2B }\end{array}$ & $\begin{array}{l}\text { HLA-A bis -G } \\
\text { HLA-E } \\
\text { HLA-E }\end{array}$ \\
\hline
\end{tabular}

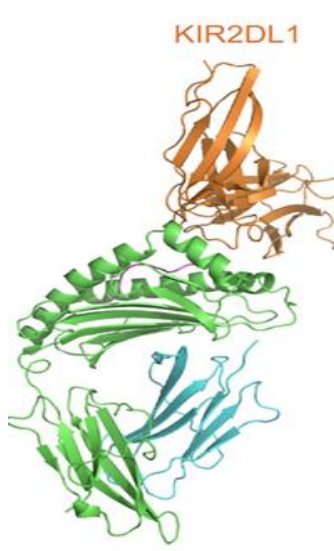

Abbildung $\quad 8$ Kristallstrukturanalyse der Interaktion von KIR2DL1 mit seinem spezifischen HLALiganden CW4 (Gruppe HLA-C2). [Abbildung im Original aus Kuroki, Furukawa et al. (2012)61]

\subsection{Funktionelle Erkennungsmechanismen von NK-Zellen}

In den letzten 20 Jahren wurden große Fortschritte bei dem detaillierten Verständnis der Erkennungsmechanismen gemacht, die es einer NK-Zelle ermöglichen, krankhaft veränderte Zellen von gesunden "Selbst"-Zellen zu unterscheiden. Verschiedene Arbeiten, die ab dem Jahr 2005 veröffentlicht wurden, zeigten, dass NK-Zellen, ähnlich der Selektionierung bei TLymphozyten im Thymus, einen Zellreifungsprozess durchlaufen, um ihre funktionelle Kompetenz zu erwerben (Lizensierung). Bestehen NK-Zellen diese immunologische Zulassungsprüfung, erhalten sie die „Lizenz zu Töten“ und können fortan als responsible NK-Effektorzellen bezeichnet werden. ${ }^{50,48,108,49,109}$ Die Selbsttoleranz gegenüber gesundem, körpereigenem Gewebe schützt den Körper vor autoimmunologischen Phänomenen.

Im Zusammenhang mit Lizensierung lassen sich vorab zwei Hypothesen diskutieren, die im Englischen als „arming“- und „disarming“-Modell bezeichnet werden. NK-Zellen werden 
lizensiert, indem sie entweder effektive Responsivität erwerben und entsprechende Zielzellen effektiv attackieren (engl.: arming, „Bewaffnung“). Sie verfallen dagegen in eine Anergie bei anhaltender Stimulation bzw. verbleiben hyporesponsiv, wenn ihnen inhibitorische Rezeptoren für körpereigene MHC-I Proteine fehlen oder diese vorhanden, aber MHCinkompatibel sind (engl.: disarming, „Entwaffnung“). Bei näherer Betrachtung schließen sich beide Modelle trotz unterschiedlichem Ausgangspunkt gegenseitig nicht aus, sondern bilden gemeinsam die komplexe funktionelle Optimierung von immunologischen Effektorzellen sinnvoll ab. Unter dem „dynamic equilibrium“-Konzept, welches ebenfalls häufig in der Literatur auftaucht, versteht man letzlich die Verrechnung aller aktivierenden Signale, ausgelöst durch Stressliganden (engl.: induced-self) oder fehlende Liganden (engl.: missing-self) auf Zielzellen mit den hemmenden Signalen durch Erkennung von HLA-Klasse-I-Proteinen auf Körperzellen (engl.: self) auf Rezeptorebene. ${ }^{110,111,59}$ Die NK-Zell-Aktivierung ist außerdem in hohem Maß von externen Stimuli, wie der IL-12 und IL-15 Ausschüttung, beeinflussbar und profitiert insbesondere von einer engen Interaktion mit dendritischen Zellen im menschlichen Körper. ${ }^{112}$

\subsection{1 „Missing-self“-Erkennung}

Die immunologische Funktionalität mit der Kernkompetenz des Erkennens zwischen körpereigen und körperfremd sowie die Fähigkeit zur kontrollierten lytischen Zytotoxizität muss also im Vorfeld „erlernt“ werden (engl.: education, „Ausbildung“). Bei der Ausbildung helfen HLA-Klasse-I-Moleküle (MHC-I Proteine), die als Oberflächenmarker auf allen kernhaltigen Körperzellen exprimiert werden. Erste Beobachtungen von Kärre et al. ließen bereits 1986 vermuten, dass Natürliche Killerzellen Zielzellen, denen die MHC-I Expression fehlt, abtöten ${ }^{113}$, während Zielzellen, die ausreichend MHC-I Moleküle präsentieren, verschont bleiben. ${ }^{114}$ Grundvoraussetzung für dieses Modell der Eigenerkennung ${ }^{115,116}$ ist, dass jede NK-Zelle mindestens einen MHC-I-detektierenden Rezeptor auf seiner Oberfläche exprimiert. ${ }^{57} \mathrm{NK}-Z$ Zllen können demnach beides Pathogene („Non-self“-Erkennung), sowie die Herabregulation eigener Proteine auf Körperzellen („Missing-self-Erkennung) erkennen (Abb. 9). 


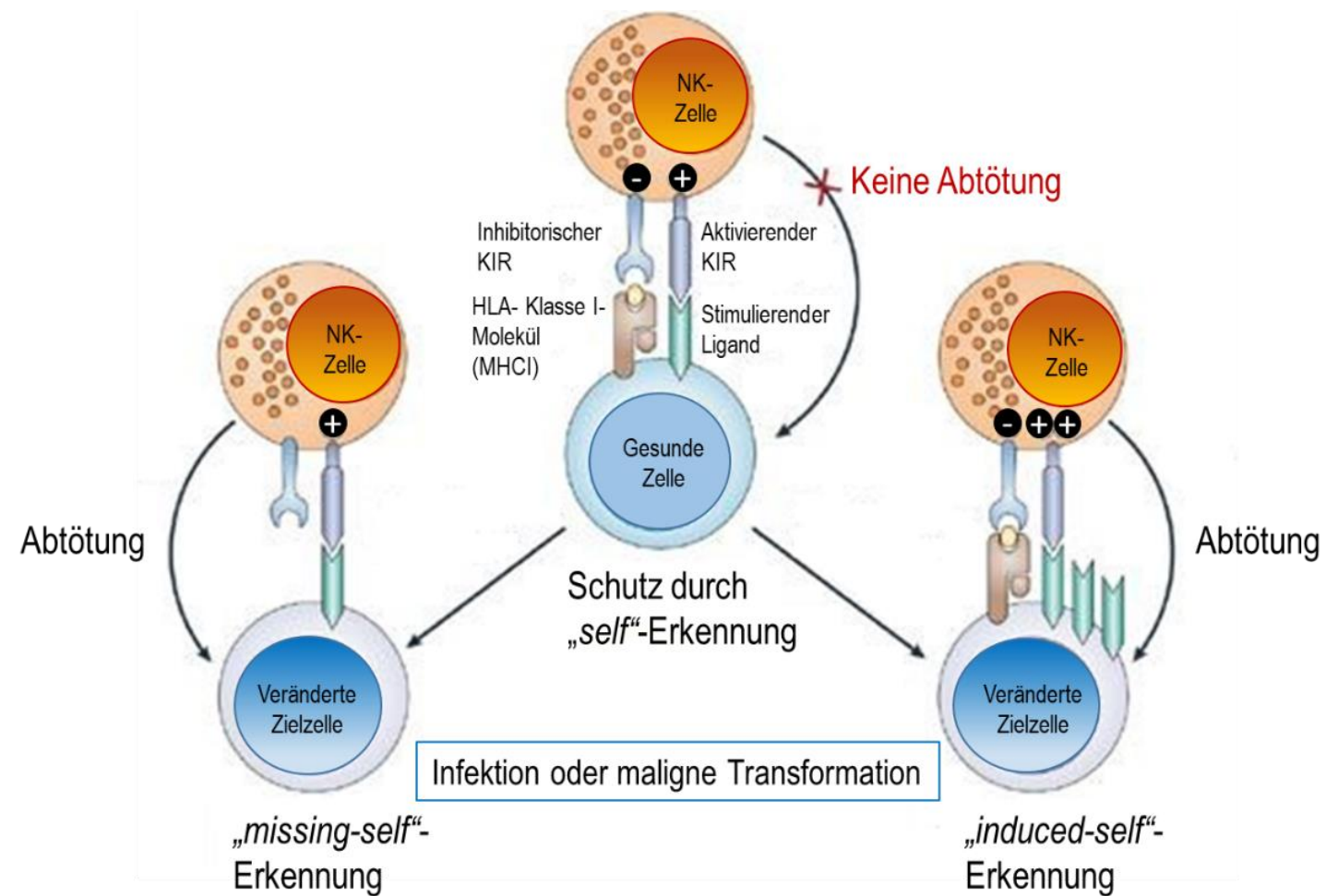

Abbildung 9 Schematische Darstellung der funktionellen Erkennungsmechanismen von NK-Zellen. Der „missing-self"und "induced-self"-Erkennungsmechanismus von reaktiven NK-Zellen dient der Abtötung von veränderten oder transformierten Zielzellen führt. Im Rahmen der Selbsttoleranz werden gesunde Zellen anhand ihrer HLA-Klasse-IMoleküle als körpereigen eingestuft und vor Zerstörung geschützt. [Abbildung modifiziert im Original aus Raulet, Vance et al. (2006) $)^{117]}$

Durch die Entdeckung der HLA-Klasse-I-Moleküle als spezifische Liganden vieler inhibitorischer NK-Rezeptoren ${ }^{118,58,119,85}$ festigte sich der Gedanke, dass ihnen eine besondere funktionelle Bedeutung im Rahmen der Selbsttoleranz zukommt. Forschungsarbeiten von 2009 zeigten alsbald, dass neben den HLA-Klasse-I-Moleküle erkennenden inhibitorischen Rezeptoren, insbesondere iKIRs, wie KIR2DL1, -2DL2/3 und -3DL1, der CD94/NKG2ARezeptor eine entscheidende Rolle in der Aufrechterhaltung der Selbsttoleranz spielt. ${ }^{120,121}$ Dabei erkennt der NKG2A-Rezeptor die nicht-klassischen HLA-Klasse-Ib-Moleküle $(\mathrm{MHC}-\mathrm{E})^{122}$, während die iKIRs an die klassischen HLA-Klasse-Ia-Moleküle binden. ${ }^{123,85}$ Andere Arbeiten zeigten, dass die Expression der inhibierenden Rezeptoren erst spät innerhalb der letzten Entwicklungsschritte ausgereifter NK-Zellen stattfindet ${ }^{124}$ und möglicherweise der Rezeptor NKG2A, der noch vor den KIRs auf der NK-Zell-Oberfläche exprimiert wird, relevant sein könnte. ${ }^{125}$ Dieser Aspekt scheint auch deshalb interessant zu sein, weil er erklären könnte, weshalb die NKG2A-Expression bei fehlender KIRExpression auf $\mathrm{CD}_{5} 6_{\text {bright }}$ NK-Zellen hoch ausfällt, während sie auf den meisten zytotoxischen $\mathrm{CD} 56_{\text {dim }}$ NK-Zellen stark herunterreguliert ist und dafür die KIR-Expression hochreguliert wird..$^{24,126,125}$ Raulet et al. sprach in diesem Zusammenhang von dem ,at-least- 
one“-Modell ${ }^{58}$, welches besagt, dass die Selbsttoleranz durch mindestens einen inhibitorischen Rezeptor gewährleistet wird. ${ }^{57,127}$ Mehrere große Populationsanalysen reifer NK-Zellen beim Menschen und in Mausmodellen zeigten jedoch, dass ein wesentlicher Teil der residierenden NK-Zellpopulationen keine MHC-I spezifischen inhibitorischen Rezeptoren exprimieren und trotzdem tolerant gegenüber sich selbst sind..$^{50,48,49,125}$ Das funktionelle Niveau solcher CD56 $\operatorname{dim}$ NKG2A negativen KIR negativen NK-Zellen liegt zwar deutlich unter dem der KIR-tragenden NK-Zellen, dennoch kann längst nicht von einer Anergie gesprochen werden. Es handelt sich vielmehr um unreife Zellen mit geringer Zytotoxizität, aber der Fähigkeit zur IFN- $\gamma$ Produktion. Auch konnten aktive KIR positive NK-Zellen ohne korrespondierende Liganden in Spendern identifiziert werden ${ }^{128}$, wenngleich sie sich ebenfalls in vergleichenden Studien hyporesponsiv verhielten. Damit sind an dem komplexen Prozess der NK-Zell-regulierten Selbsttoleranz nach heutigem Wissenstand, sowohl MHC-I abhängigen als auch MHC-I unabhängigen Mechanismen beteiligt.

\section{4 .2 „Induced-self“-Erkennung}

Ein weiterer signifikanter Erkennungsmechanismus ist die sogenannte „Induced-self“Erkennung. ${ }^{129}$ Dieser ist insbesondere dann interessant, wenn man Erkennungsmechanismen gegenüber humanen Zellen ohne MHC-I Expression hinterfragt. Davon betroffen sind beispielsweise die roten Blutkörperchen (Erythrozyten), welche als kernlose Zellen keine HLA-Moleküle auf ihrer Oberfläche exprimieren. Trotz des Fehlens von MHC-I werden Erythrozyten nicht von NK-Zellen attackiert und lysiert. ${ }^{115}$ Dafür verantwortlich ist ein NZR namens NKG2D, ein aktivierender homodimerischer Rezeptor mit einer Lektin-ähnlicher Domäne, welcher bei NK-Zellen und T-Zellen nachweisbar ist. NKG2D überträgt seine Signale durch Assoziation mit dem Adapterprotein DAP10. ${ }^{130,131}$ In Mausexperimenten konnte zusätzlich eine direkte Aktivierung durch Vernetzen von NKG2D ex vivo nachgewiesen werden. ${ }^{132}$ NKG2D wird, neben $C D 8^{+}$T-Zellen, konstitutiv auf ruhenden humanen NK-Zellen exprimiert. ${ }^{130}$ Liganden des Rezeptors werden im Allgemeinen nicht auf der Oberfläche von gesunden Zellen und Geweben exprimiert, sondern sind als „zelluläre Stressmarker“ anzusehen ${ }^{133-135}$, welche erst im Rahmen von Tumortransformation, Hitzeschock oder viraler bzw. bakterieller Infektion induziert werden. Eine Ausnahme dazu bildet Wundgewebe oder embryonales Gewebe. Auch bei Entzündungs- und Regenerationsprozessen ${ }^{136}$ blutbildender hämatopoetischer Zellen nach 
Stammzelltransplantationen kann die Expression bestimmter NKG2D-Liganden charakteristisch hochreguliert sein. ${ }^{137,138}$ Auf molekularer Ebene werden die NKG2DLiganden durch eine Vielzahl transkriptionaler und translationaler, als auch posttranslationaler Mechanismen reguliert. ${ }^{139}$ Manche Tumoren bewirken allerdings auch eine Herunterrregulierung der oberflächlichen NKG2D-Rezeptoren oder eine Anergie der Effektorzellen durch Freisetzung löslicher NKG2D-Liganden. Auf diese Weise kommt es zu einer erfolgreichen Immunevasion. ${ }^{140}$ Bislang geht man davon aus, dass die Interaktion von NKG2D mit einem spezifischen Liganden allein nicht ausreichendend ist, zellvermittelte Zytotoxizität oder Zytokinproduktion ruhender humaner NK-Zellen auszulösen. ${ }^{141,142}$ Vielmehr geht man davon aus, dass zusätzliche kostimulatorische Rezeptoren wie NKp46 (CD335) oder 2B4 (CD244) essentiell notwendig sind bzw. ein externes Interleukin-Priming mit IL-2 oder IL-15 als Stimulus ausreichend ist. ${ }^{64}$

\subsection{Therapeutische Konzepte im Rahmen von Leukämien und malignen Lymphomen}

Unter den allgemeinen Begriff Leukämie (Blutkrebs) fallen verschiedenstartige maligne Erkrankung des blutbildenden oder des lymphatischen Systems. Die Leukämie ist genauer betrachtet eine schwere Erkrankung des Knochenmarks, bei der es in Folge von Veränderung des Genmaterials (Mutationen) von weißen Blutkörperchen (Leukozyten) zu einer Vermehrung unreifer und defekter Vorläuferzellen (leukämischer Blasten) kommt. Dieser Prozess führt $\mathrm{zu}$ einer fortschreitenden Verdrängung des reifen Knochenmarksgewebes, sodass fortan weniger Raum für die lebenswichtige Bildung aller Blutzellreihen besteht. Durch den essentiellen Mangel an roten Blutkörperchen kommt es zu einer ausgeprägten Anämie, sodass der adäquate Sauerstofftransport im Blut nicht mehr gewährleistet ist. Der Mangel an Blutplättchen, klinisch als Thrombozytopenie bezeichnet, beeinträchtigt die Blutgerinnung. Die gedrosselte Bildung reifer weißer Blutkörperchen (Leukozytopenie) hindert das Immunsystem daran, den Organismus ausreichend vor eindringenden Keimen zu schützen. Die zusätzliche Ausschwemmung maligner Leukämiezellen in das periphere Blut führt zur funktionellen Zerstörung verschiedener Organsysteme sowie Lymphknoten. Nimmt der Krebs seinen primären Ursprung in direkt lymphatischen Zellen, die sich im Zuge unkontrolliert vermehren, spricht man von sogenannten malignen Lymphomen. Die verantwortliche Mutagenese kann peripher in Lmyphknoten, den Rachenmanden oder der Milz, aber auch zentral im Knochenmark 
stattfinden. Nach WHO-Klassifikation werden maligne Lymphome in das HodgkinLymphom (HL) und die Gruppe der Non-Hodgkin-Lymphome (NHL) unterteilt. NHL werden entsprechend ihres zellulären Ursprungs weiter in B-Zell- oder T-Zell-Lymphome klassifiziert.

Leukämische Erkrankungen können sowohl akut als auch chronisch entstehen. Akute Leukämieformen zeigen dabei eine rasche Progredienz und können unbehandelt bereits innerhalb weniger Wochen bis Monate zum Tod führen. Im Gegensatz dazu entwickeln sich chronische Formen über einen längeren Zeitraum und zeigen dadurch auch erst spät krankheitsassoziierte Symptome. In Deutschland erkranken pro Jahr bis zu 12.000 Menschen neu an Leukämie. ${ }^{143}$ Dies betrifft Erwachsene wie Kinder. Nachdem in der Vergangenheit zahlreiche krankheitsauslösende Faktoren kontrovers diskutiert worden sind, besteht heute Konsens in Bezug auf die schädigende Wirkung ionisierender Strahlung, wie Röntgenstrahlung, ultravioletter und radioaktiver Strahlung auf das Knochenmark. Auch Substanzen wie Benzole und Zytostatika gelten als gesicherte Risikofaktoren bei der Entstehung von Leukämien. Unbestritten besitzt die Erkrankung zudem eine ausgeprägte genetische Komponente, bei der sowohl die vererbte interindividuelle Chromosomenstabiliät als auch etwaige schützende DNA-Reparaturmechanismen eine essentielle Rolle spielen.

Für die Therapie der Leukämie stehen unterschiedliche Behandlungskonzepte zur Verfügung, welche alle darauf abzielen, die im Körper verstreuten Leukämiezellen möglichst vollständig abzutöten und damit die Krankheit selbst sowie Rückfälle (Rezidive) zu verhindern. Bei einer Chemotherapie erhält der Patient spezielle Medikamente, die Zytostatika genannt werden, weil sie in der Lage sind, das Wachstum von Leukämiezellen zu hemmen. Trotz der Effektivität dieser Behandlung greifen Zytostatika neben den zu zerstörenden leukämischen Blasten auch gesunde Körperzellen an und zerstören diese. Der Katalog an Nebenwirkungen ist deshalb lang und nicht selten kommt es bei den Patienten zu bleibender Unfruchtbarkeit, da auch die männlichen und weiblichen Keimzellen nicht unverschont bleiben. Neben der medikamentösen Chemotherapie stellt die hämatopoetische Stammzelltransplantation (HSZT) eine potenziell kurative Behandlungsform dar. Sie ist heutzutage zur Behandlung einer Vielzahl von hämatologischen Malignomen, einschließlich der vier Haupt-Leukämie-Typen der AML (akute myeloische Leukämie), der ALL (akute lymphatische Leukämie), der CLL (chronische lymphatische Leukämie) und weniger der CML (chronische myeloische Leukämie) klinisch etabliert. ${ }^{144}$ Ziel der HSZT ist es, durch die 
Transplantation von gesundem Gewebe das erkrankte Knochenmark zu ersetzen, sodass dieses seine ursprüngliche Funktion - die Blutbildung - wiederaufnehmen kann.

\subsubsection{Hämatopoetischen Stammzelltransplantation (HSZT)}

Bei der hämatopoetischen Stammzelltransplantation (HSZT) werden dem Patienten aufgereinigte Blutstammzellen eines passenden Spenders (allogen) oder des Patienten selbst (autolog) mittels Infusion verabreicht. Dafür benötigte Stammzellen können routinemäßig entweder per Beckenkammpunktion direkt aus dem Knochenmark entnommen oder aber aus dem peripheren Blut per Leukapherese herausgefiltert werden. Die periphere Gewinnung von Stammzellen stellt die bevorzugte Methode dar, erfordert jedoch eine etwa fünftägige Behandlung des Spenders mit einem speziellen Wachstumsfaktor (G-CSF, granulocyte stimulating factor) zur Mobilisation der Stammzellen in das periphere Blut. Die dritte Gewinnungsquelle von Stammzellen ist die aus kyrokonserviertem Nabelschnurblut (engl.: umbilical cord blood transplantation, UCBT). Die HSZT stellt für die Patienten ein strapaziöses, risikoreiches Verfahren dar, weshalb die Entscheidung in Hinblick auf den Allgemeinzustand, das Alter, die Leukämieform sowie die Anzahl bisheriger Rückfälle (Rezidive) bzw. das individuelle Rückfallrisikos getroffen werden sollte. Auch nach frustranen Chemotherapie-Versuchen kann eine Stammzelltransplantation für den Patienten sinnvoll sein. Um die Erfolgsaussichten der Stammzelltherapie zu erhöhen, müssen im Empfängerorganismus zuvor möglichst alle Leukämiezellen abgetötet werden. Dafür kommen hochdosierte Chemotherapien bzw. Radiotherapien vor der Transplantation zum Einsatz.

\subsubsection{Autologe und Allogene Stammzelltransplantation}

Im Falle einer onkologischen Erkrankung können Patienten entweder auf eigene Stammzellen (autologe Eigenspende) zurückgreifen oder sind auf eine Fremdspende (allogene Stammzelltransplantation) angewiesen. Bei der Behandlung akuter und chronischer Leukämien spielt die autologe HSZT eine eher untergeordnete Rolle, sodass meist nach einem passenden verwandten oder nicht verwandten Fremdspender für den erkrankten Patienten gesucht wird. Bei allen Formen der Fremdspende muss auf ausreichende Gewebsübereinstimmung geachtet werden. Hierfür müssen die HLA-Merkmale als wichtige Transplantationsproteine zwischen Spender und Empfänger übereinstimmen, da dies für die 
Prognose nach HSZT von größter Relevanz ist. Die HLA-Kompatibilität basiert auf der molekularen Typisierung der Genloci für die Allele von HLA-A, -B, -C, -DRB1 und DQB1. ${ }^{145}$ Von einer „10/10“-Kompatibilität (HLA-match) wird gesprochen, wenn alle obengenannten HLA-Merkmale vollkommen übereinstimmend sind. Analog kann bei Fehlpaarung eines einzelnen HLA-Merkmals von einer „9/10“-Teilkompatibilität gesprochen werden. Während die einfache Nicht-Übereinstimmung in den Genloci für HLA A-, B-, C- und DRB1 bereits zu gesteigerter Morbidität und Mortalität nach AlloHSZT führt ${ }^{146,147}$, zeigt ein isolierter DQB1 Mismatch prognostisch kaum einen relevanten negativen Effekt. ${ }^{148}$ Je mehr sich die HLA-Merkmale von Spender und Empfänger ähneln, desto umwahrscheinlicher ist das Auftreten von Abstoßungsreaktionen. Bei der HLAidentischen Variante handelt es sich seitens der Spender meist um direkte Familienmitglieder des Patienten ${ }^{\mathrm{f}}$ oder um HLA-identische, nicht verwandte Fremdspender ${ }^{\mathrm{g}}$. Die statistische Wahrscheinlichkeit für ein HLA-identisches Familienmitglied, z.B. Geschwister, liegt bei 25\%. Findet sich kein HLA-identischer Spender muss die Spendersuche erweitert werden. Bei der allogenen haploidenten HSZT werden in der Regel zuerst die Eltern des Patienten als potenzielle Spender herangezogen. Da jeder Mensch seine HLA-Allele jeweils zur Hälfte von dem Vater und der Mutter erbt, stimmen die Eltern jeweils zur Hälfte mit ihren Nachkommen auf HLA-Ebene überein. Sie sind damit also stets mindestens „halb“ (haplo)identisch zu ihrem Kind. Während bzw. nach erfolgreicher Spendersuche sollten spätestens vor allogener Stammzelltransplantation von Blut und Knochenmark die HLA-Testresultate von Patient und potentiellem verwandtem oder unverwandten Spender an jeweils neu gewonnenen Blutproben bestätigt werden. Eine solche „Bestätigungstypisierung“ ist essentiell, um eine Probenverwechslung zu vermeiden. Bei intermediärem Krankheitsrisiko wird ein 10/10 oder 9/10 HLA-kompatibler, nicht verwandter Spender zur Transplantation empfohlen. Trotz nicht ganz eindeutiger Datenlage sollte des Weiteren bei der Auswahl nicht verwandter Spender ein Allel-mismatch einem Antigen-mismatch vorgezogen werden. ${ }^{149}$ Die Spendersuche gestaltet sich in Realität jedoch häufig schwierig, sodass ein möglichst HLAidentischen nicht verwandter Fremdspender in nationalen bzw. internationalen Datenbanken/Registern/Dateien gesucht werden muss. Bei Nicht-Vorhandensein eines

f engl.: matched-related donor, MRD; engl.: matched-sibling donor, MSD

g engl.: matched-unrelated donor, MUD 
passenden (mindestens 9/10) Fremd- oder Familienspenders sowie bei Hochrisikoerkrankung mit hoher Rezidivrate sollte bei negativer Fremdspendersuche eine Abwägung bezüglich der Durchführung einer haploidenten, 8/10 HLA-kompatiblen bzw. einer UCBT. ${ }^{150}$

\subsubsection{Graft-versus-Leukemia/ Graft-versus-Host-Effekt}

Im Gegensatz zu autologen Verfahren besitzt das (teilweise) fremde Transplantat eines allogenen Spenders eine immunologische Aktivität im Empfängerorganismus, welche sich prognoseverbessernd auswirken kann. Anders als bei der Ganzkörperbestrahlung und/oder Chemotherapie, bei der es zur Zerstörung von Immunzellen kommt, können bei HSZT durch die im Transplantat verbliebenen immunologischen Effektorzellen maligne entartete Blutzellen zerstört werden, wodurch das Risiko eines Krankheitsrückfalls (Rezidivwahrscheinlichkeit) nachhaltig minimiert wird. Man spricht in diesem Zusammenhang von dem Transplantat-gegen-Leukämie-Effekt (engl:: Graft-versus-Leukemia, GvL). ${ }^{151}$ Der GvL-Effekt scheint insbesondere bei HLA-identischen allogenen Transplantationen das Anwachsen des Transplantats (engl.: engraftment) positiv zu beeinflussen und durch Abtötung verbliebener chemotherapieresistenter Leukämiezellen die Rezidivraten zu senken. ${ }^{152-154}$ Direkte Evidenz für das kurative Potenzial des T-Lymphozyten und NK-Zell-vermittelten GvL-Effektes lieferten verschiedene Arbeiten, die allesamt zeigten, dass es durch den zusätzlichen Einsatz von NK-Zell-Infusionen zu einer beträchtliche Senkung der Rezidivrate kam. ${ }^{155-157,153,158}$ Dieser neue Impuls inspirierte Kliniker und Forscher dahingehend weiter an milderen Konditionierungsschemata mit minimaler Hämatotoxizität $\mathrm{zu}$ arbeiten ${ }^{159}$, sodass heutzutage eine intensive Hochdosistherapie mit Myeloablation nicht mehr zwingend für ein erfolgreiches Engraftment erforderlich ist. ${ }^{150}$ Auf der Kehrseite führt der immunmodulatorische Effekt eines Fremdtransplantats nach AlloHSZT jedoch auch weiter zu gefürchteten transplantationsassoziierten Abstoßungsreaktionen ${ }^{160,161}$, welche unter den Begriff der Transplantat-gegen-WirtKrankheit (engl.: Graft-versus-Host Disease, GvHD) fallen. Die GvHD wird vor allem durch alloreaktive zytotoxische T-Zellen hervorgerufen, welche gesundes Wirtsgewebe attackieren. Sie gilt als Hauptkomplikation der HSZT und macht durchschnittllich 10-30\% aller transplantationsassoziierter Todesfälle aus. T-zellvermittelte GvH-Reaktionen werden durch Maßnahmen wie T-Zell-Depletion und medikamentöse GvH-Prophylaxe verringert. Wenn Spender und Empfänger eineiige Zwillinge sind, erübrigt sich die Prophylaxe, da eine GvHD 
ausgeschlossen ist. Die Intensität der vorgenommenen T-Zell-Depletion wird in Logstufen angegeben. Die in Deutschland am häufigsten genutzte medikamnetöse Standardprophylaxe der GvHD ist die Kombination eines Calcineurin-Inhibitors wie Cyclosporin A (CyA), Tacrolimus mit Methotrexat (MTX) oder Mycophenolat Mofetil (MMF). ${ }^{150}$ Bei zu starker Senkung der Spender Lymphozyten kommt es zu einem signifikanten Anstieg der Abstoßungsrate sowie der Zunahme leukämischer Rezidive. ${ }^{162}$ Um ein gutes Engraftment trotz einer hohen T-Zelldepletion zu gewährleisten, müssen also große Mengen peripherer Blutstammzellen transplantiert werden. ${ }^{163}$ Forscher der Universität von Perugia demonstrierten, dass das „Megadosis-Konzept“ zur Eindämmung schwerer GvHReaktionen sinnvoll ist und dabei gleichzeitig die Abstoßungsrate nicht nennenswert erhöht. ${ }^{164-166}$ Bisher können die T-Zell-Depletion und die medikamentöse GvH-Prophylaxe das Ausmaß von akuter und chronischer GvHD demnach mildern, wenngleich nicht komplett verhindern.

Wie relevant der zugesprochene GvL-Effekt von gespendeten NK-Zellen ist, zeigt sich in demographischen Untersuchungen. So weisen Personen mit niedriger NK-Zellaktivität ein erhöhtes absolutes Risiko auf Krebs zu entwickeln ${ }^{167}$, wohingegen eine hohe Anzahl intratumoraler NK-Zellen mit einer verbesserten Prognose für Patienten unterschiedlicher Tumorentität korreliert. ${ }^{168-173}$ Insbesondere bei dem Krankheitsbild des Glioblastoms, einem aggressiven Hirntumor mit schlechter Prognose, zeigte sich eine vielversprechende lytische NK-Zell-Aktivität gegen experimentell kultivierte intrakranielle Tumorzellen. ${ }^{174,175}$ Zudem gibt es deutliche Hinweise darauf, dass NK-Zellen modulatorisch bei Metastasierungsprozessen Einfluss auf das Patientenüberleben nehmen. ${ }^{176}$ Trotz weltweiter Erfolge bei der Erprobung sind NK-Zell-therapeutische Ansätze zur Behandlung solider Tumore nur limitiert einsetzbar. Die größten Erfolge ließen sich bis heute bei der Behandlung neoplastischer Bluterkrankungen (Leukämie) verzeichnen. Zusätzlich zur HLAÜbereinstimmung (HLA-match) erhöht die Spenderauswahl nach spezifischen KIR-Genen (KIR-mismatch) den Schutz vor dem Wiederauftreten der Erkrankung (engl.: relapse) und verbessert die Gesamtüberlebensrate nach der Transplantation bei akuter myeloischer Leukämie (AML). 


\subsection{NK-Zellen als potenzielles Zelltherapeutikum}

Zur Kompensation des durch die T-Zelldepletion eingebüßten Graft-versus-Leukämie (GvL)-Effekts bei Stammzelltransplantationen rücken NK-Zellen als wirksame AntitumorEffektorzellen zunehmend in den Fokus wissenschaftlichen Interesses. ${ }^{177-180}$ KIRRezeptoren, denen ihr Ligand fehlte, zeigten nach Transfusion in den Empfängerorganismus eine höhere Alloreaktivität ${ }^{181}$, resultierend in einem verstärkten GvL-Effekt (Abb. 10).

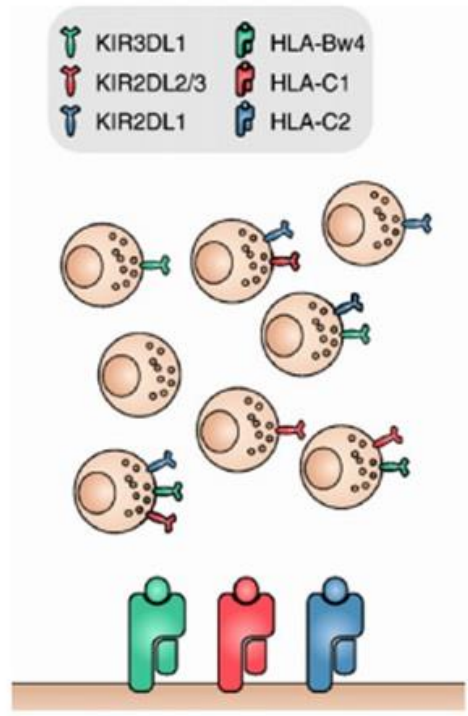

KIR- Ligand- match

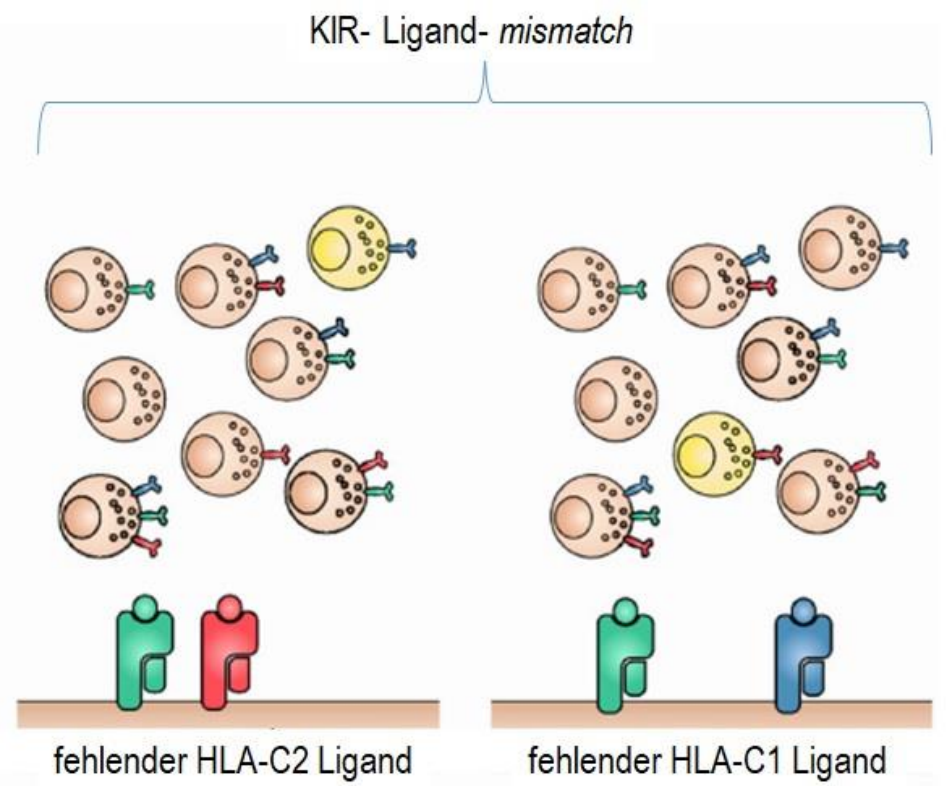

Abbildung 10 Schematische Darstellung des KIR-Ligand-mismatch Modells bei alloreaktiven NK-Zellen mit unterschiedlichem KIR-Set. In gelb dargestellt sind die aktiven NK-Zellen, die bei hämatopoetischer Stammzelltransplantation (HSZT) aufgrund fehlender inhibitorischer Liganden auf Seiten des Empfängers zur Lyse aktiviert werden und dadurch den GvL-Effekt steigern. [Abbildung übersetzt im Original aus Andersson, Malmberg et al. (2010)182]

Transplantationsstrategien, die auf KIR-Ligand-Fehlpaarungen (mismatch) basieren, um die Alloreaktivität von NK-Zellen vorherzusagen, führten nach Aussagen bekannter Studien von Ruggeri et al. zu weniger Rückfällen, weniger GvHD und einem besseren Gesamtüberleben bei Patienten mit akuter myeloischer Leukämie (AML). ${ }^{183}$ Der Nutzen von NK-Zellen als potenzielles Zelltherapeutikum konnte in zahlreichen Forschungsarbeiten der letzten Jahre weiter bestätigt werden. ${ }^{184-186}$ Caligiuri et al. konnte die Effektivität alsbald auch für Patienten mit chronisch-myeloischen Leukämie (CML), Non-Hodgkin-Lymphomen und dem Multiplen Myelom bestätigen, wohingegen bei der Behandlung von Patienten mit akuter lymphatischer Leukämie (ALL) kein direkter NK-Zell-vermittelter Effekt auf die Rückfallrate oder die Überlebenswahrscheinlichkeit nachgewiesen werden konnte. ${ }^{187}$ 
Alloreaktive Spender NK-Zellen können Patienten therapeutisch im Verlauf einer Stammzelltransplantation oder bei Verdacht auf Rezidiv auf direktem Wege per Infusion verabreicht werden. Infundiert zeigen sie sowohl eine unmittelbar auftretenden Wirkung innerhalb weniger Tage als auch einen verzögerten antileukämischen Effekt einige Wochen nach ihrer Gabe (Abb. 11). Zeitgleich wurde bei therapeutischer Anwendung von NK-Zellen in Tierexperimenten ein gleichbleibendes bzw. verringertes GvHD-Risiko beobachtet. ${ }^{188-190}$ Die Abnahme der GvHD wird darauf zurückgeführt, dass alloreaktive NK-Zellen neben leukämischen Wirtzellen auch die Elimination GvDH-induzierender, ,autoaggressiver“ $\mathrm{T}$ Zellen und Antigen-präsentierende Zellen, wie bspw. dendritische Zellen, begünstigen. ${ }^{191,184}$ Eine andere Hypothese ist, dass es durch die Interaktion mit Spender NK-Zellen zu einer verminderten Antigenpräsentation der dendritschen Zellen für Spender-T-Zellen im Empfängerorgaismus kommt und daraus der GvH-protektive Effekt resultiert. ${ }^{192}$

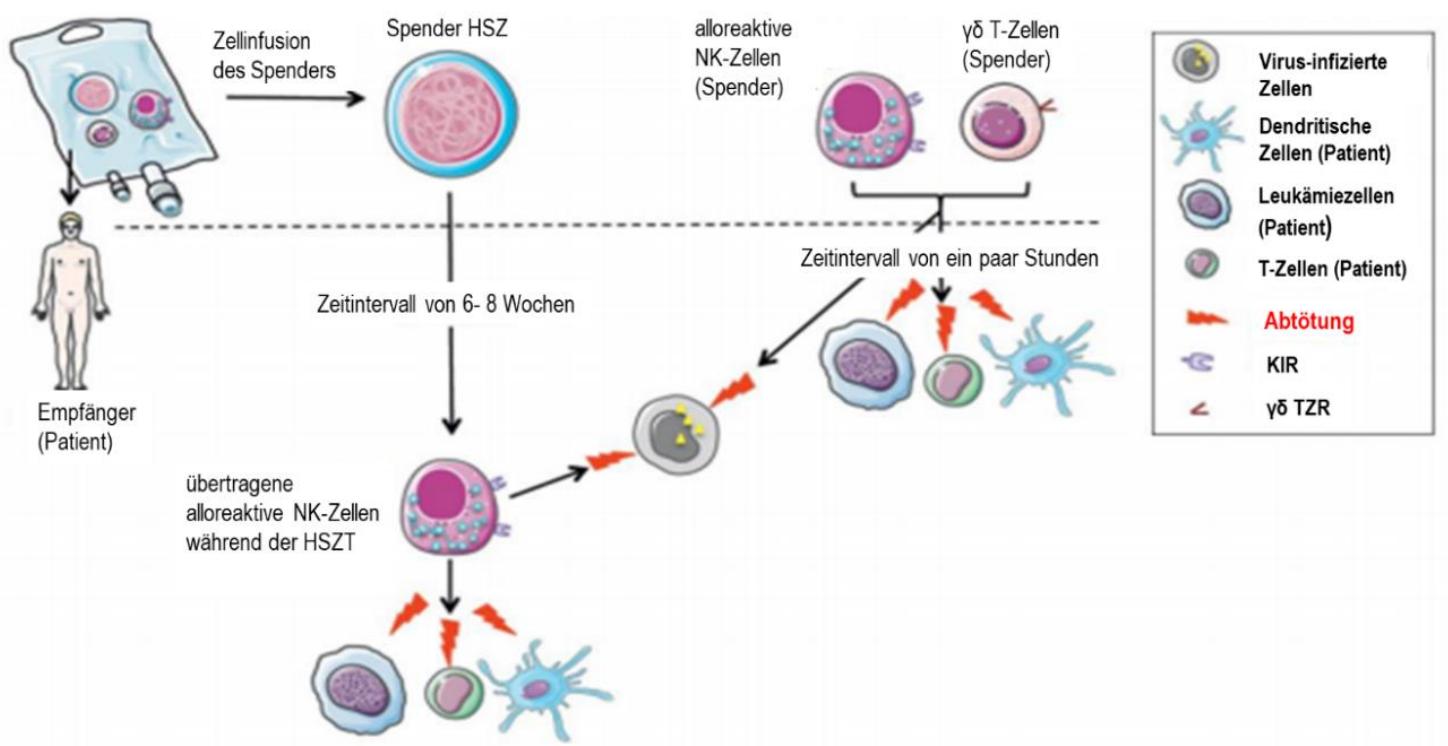

Abbildung 11 Zeitversetzt zur Transplantation der hämatopoetischen Stammzellen werden dem Patienten zusätzlich alloreaktive Spende-NK-Zellen sowie Spender-T-Zellen verabreicht, die in der Lage sind virusinfizierte Zellen ( $\downarrow$ Infektionsrate), dendritische Zellen ( $\downarrow G v H D)$, sowie verbleibende Leukämiezellen ( $\uparrow G v L-E f f e k t)$ auf Empfängerseite direkt zu eliminieren. Aus den transplantierten Spender-HSZ entstehen nach etwa 6-8 Wochen die ersten „reifen"NKZellen. [Abbildung übersetzt im Original aus Moretta et al. (2014) ${ }^{193}$ ]

Im Feld der Immuntherapie wird derzeit an der Weiterentwicklung diverser zellulärer und Antikörper-basierter Immunzellkonzepte zur Behandlung der Leukämie gearbeitet. ${ }^{194}$ Aufgrund der bisweilen heterogenen Wirkung KIR-therapeutischer Ansätze auf verschiedene Tumorentitäten wird neben NK-Zellen auch intensiv an T-Zellen geforscht. In den vergangenen Jahren hat sich die Behandlung mit CAR-T-Zellen als eine der erfolgsversprechendsten Innovationen in der Onkologie herausgestellt. ${ }^{195}$ CAR-T-Zellen (engl.: chimeric antigen receptor $T$ cells) sind genetisch veränderte T-Lymphozyten, die zusätzlich 
zu den natürlichen T-Zell-Rezeptoren andere Oberflächenmerkmale besitzen, welche spezifisch an Malignomzellpopulationen binden. Transfizierte CARs können ex vivo vermehrt, im Anschluss eingefroren und dem Patienten zum passenden Zeitpunkt reinfundiert werden. Limitationen in der breiten Anwendung stellt die zeitintensive technische Herstellung von CAR-T-Zellen dar sowie das davon ausgehende Risiko der Entwicklung einer GvHD.

Es existieren bereits Bestrebungen NK-Zellen mit CARs genetisch zu modifizieren, um ihre Fähigkeit zur Abtötung von Tumoren weiter zu schärfen. ${ }^{196}$ Neben vielen diskutierten Vorteilen gilt, dass bei der Anwendung von CAR-NK-Zellen mit einem günstigeren Nebenwirkungsprofil als bei CAR-T-Zelltherapieansätzen gerechnet werden kann. Schon lange besteht Einigkeit darin, dass NK-Zell-Präparate allgemein eine sehr gute Verträglichkeit besitzen und zusätzlich den entscheidenen Vorteil in Bezug auf den GvLEffekt gegenüber zytotoxischer T-Lymphozyten nach HSZT ausmachen. Eine Übertragung von NK-Zellen in großen Mengen ist ohne nennenswerte Nebenwirkungen möglich und die Voraktivierung von Spender NK-Zellen mit IL-12, -15 und -18 erhöht ihre Antitumoraktivität. ${ }^{197}$ In einer kürzlich erschienenen Arbeit einer amerikanischen Forschungsgruppe konnte im Tiermodell eindrücklich gezeigt werden, dass sich die NKZell-Aktivität ebenfalls durch die Anwendung von Radiotherapie im transfundierten Empfängerorganismus erhöhen lässt. ${ }^{198}$ Immer weitere Strategien zur Verbesserung der Sicherheit und Wirksamkeit der CAR-NK-Zelltherapie werden erforscht, sodass in den kommenden Jahren mit einem stetigen Zuwachs klinischer Erfolge zu rechnen ist. 


\section{Ziele dieser Arbeit}

Die passende Spenderauswahl stellt bei jeder Art der Transplantation den ersten Schritt einer langen Handlungskette dar. Die NK-Zell-Forschung stellt hierbei im Bereich der experimentellen Immunologie ein im Vergleich junges Interessengebiet für Mediziner und Wissenschaftler dar. In bestehenden Studien konnte überzeugend dargelegt werden, dass bei NK-Zell-Infusionen die ausgeprägten KIR-Merkmale des Spenders einen relevanten Einfluss auf das Gesamtüberleben bei Leukämie-erkrankten Patienten nach hämatopoetischer Stammzelltransplantation (HSZT) hat. Obwohl die Applikation von NK-Zellen in großer Menge als technisch möglich und für den Patienten als unbedenklich eingestuft wurde, wird der eindeutige klinische Nutzen von NK-Zell-Therapeutika international weiterhin kontrovers diskutiert. So bestehen sowohl seitens Grundlagenforschung zu der Genetik, Beschaffenheit und Funktionalität der NK-Zelle als auch in Hinblick auf ihren klinischen Nutzen bei der Behandlung verschiedener hämatoonkologischer Krankheitsbilder weiterhin zahlreiche offene Fragen.

Da die Stärke der Alloreaktivität gespendeter NK-Zellen für die Immuntherapie interindividuell variiert und sowohl von genotypischen als auch allelischen Vererbungsmustern abhängt, war das primäre Ziel der Arbeit die Etablierung eines optimierten KIR-Subtypisierungsverfahren. Der Schwerpunkt der Genanalyse wurde auf zwei in der durchschnittlichen Weltbevölkerung besonders häufig vorkommende und für die Regulation der NK-Zell-Reaktivität relevante inhibitorische Killerzell-Immunoglobulin-ähnliche Rezeptoren gelegt. Für die Experimente wurden die NK-Zellen von 20 gesunden, nicht verwandten Spendern HLA- und KIR-genetisch untersucht. Im zweiten Teil der Forschungsarbeit wurden die mittels Sequenzierung ermittelten Subtypisierungsergebnisse für KIR2DL1 und KIR3DL1 in Bezug auf ihre Zuordnung zu bestimmten Allel- bzw. Expressionsgruppen funktionell analysiert. Um die funktionelle Potenz der gespendeten NK-Zellen experimentell vergleichen zu können, wurden vier transgene Zielzellen mit unterschiedlichen HLA-Merkmalen als Reaktionspartner verwendet. Weiterführendes Ziel der Arbeit war es, innerhalb der 20 ausgewählten Versuchspersonen besonders potente NK-Zell-Spender zu identifizieren und anhand bestimmter Polymorphismen und/oder Expressionsmuster auf KIR-Rezeptorebene weiter zu charakterisieren. Die Forschungsarbeit verfolgt damit den wissenschaftlichen Ansatz durch die Kombination von Datensätzen der analytischen Genetik und der experimentellen Funktionsanalyse von den inhibitorischen NK-Zell-Rezeptoren KIR2DL1 und -3DL1 weitere Grundlagen zur Optimierung der Spenderauswahl bei NK-Zell-basierten Immuntherapieansätzen zu schaffen. 


\section{Material}

\subsection{Labormaterial}

Detaillierte Angaben zu den in den folgenden Experimenten verwendeten Chemikalien, Medien sowie der technischen Geräte finden sich im Anhang unter Kapitel 8 ( $\rightarrow$ Abschnitt 8.3).

\subsection{Zelllinien}

\subsubsection{L721.221-Zelllinien}

Für die Funktionsanalysen der Spender NK-Zellen wurden Zielzellen der Blymphoblastoiden L721.221-Zelllinie verwendet. Diese Zelllinie zeichnet sich dadurch aus, dass sie endogen keine HLA-Moleküle exprimiert. ${ }^{199}$ Sie kann deshalb mittels geklonter HLA-A, -B oder -C Gene transfiziert werden. ${ }^{200}$ Jede der insgesamt vier transgenen L721.221-Zelllinien wurden für den experimentellen Teil der Untersuchung so ausgewählt, dass sie jeweils nur ein bzw. in einem Falle kein HLA-Merkmal auf der Zelloberfläche exprimieren (Tabelle 4). Dies ermöglicht eine vergleichende Untersuchung der NK-ZellAlloreaktivität auf isolierte HLA-Liganden, repräsentiert durch die jeweilige Zielzelllinie. Die Zelllinie wurde dafür zuvor mittels Ebstein-Bar-Virus-Infektion immortalisiert. Alle verwendeten Zelllinien wurden dankenswerterweise von dem deutschen Forschungszentrum für Gesundheit und Umwelt sowie dem amerikanischen Fred Hutchinson Cancer Research Center bereitgestellt.

Tabelle 4 Ursprung und HLA-Oberflächenmerkmale der verwendeten L721.221-Zelllinien.

\begin{tabular}{|l|l|l|}
\hline Zelllinien & HLA-Klasse-I-Merkmale & Herkunft der Zellinie \\
\hline L721.221-ØHLA & Keine Expression & $\begin{array}{l}\text { Prof.Schendel, Deutsches } \\
\text { Forschungszentrum für Gesundheit und } \\
\text { Umwelt, München }\end{array}$ \\
\hline L721.221-Cw1 (C1) & HLA-C*01:02 & \\
\hline L721.221-Cw6 (C2) & HLA-C*06:02 & $\begin{array}{l}\text { E.Geraghty, Fred Hutchinson Cancer } \\
\text { Research Center, Seattle }\end{array}$ \\
\hline L721.221-Bw4 & HLA-B*58:01 & \\
\hline
\end{tabular}




\subsubsection{Primäre NK-Zellen}

Als primäre NK-Zell-Spender wurden 20 nicht verwandte, gesunde Personen nach KIRTypisierung anhand einer hausinternen KIR-Datenbank der Abteilung für Transplantationsimmunologie ausgewählt. Zur Isolierung der NK-Zellen wurden Vollblutproben der Studienteilnehmer benötigt, welche während des Experimentzeitraums eigenständig oder durch die Unterstützung des hausinternen Personals in der Abteilung für Zellseparation des DRK-Blutspendedienstes Frankfurt am Main gewonnen wurden. Um die Blutgerinnung der Proben während des Entnahmevorgangs und anschließenden Transportes in die Laborräume zu verhindern, wurden heparinisierte Blutentnahmeröhrchen $(3 \times 9 \mathrm{ml}$ pro Spender) verwendet. Die schriftliche Zustimmung der Spender für die Nutzung ihrer Blutproben lag vor. 


\section{Methoden}

\subsection{DNA-Isolierung aus Spender Vollblut}

Pro Spender wurden jeweils $6 \mathrm{ml}$ EDTA-Vollblut für die DNA-Isolierung für initial $10 \mathrm{~min}$ bei $1500 \mathrm{rpm}$ zentrifugiert. Der nach der Zentrifugation entstandene Buffy Coat wurde anschließend mit Hilfe einer Einmalpipette in ein Eppendorf-Reaktionsgefäß überführt und die weitere DNA-Präparation nach Protokoll eines QIAamp ${ }^{\circledR}$ DNA Mini Kits (Qiagen) durchgeführt. Zum Zellaufschluss und Proteinverdau wird auf 50 - $100 \mu$ l Buffy-Coat hierbei je $20 \mu \mathrm{l}$ Proteinase K-Lösung zugegeben und die Suspension für 10 min auf einem Heizblock bei $65^{\circ} \mathrm{C}$ inkubiert. Danach werden die Proben mit jeweils $200 \mu \mathrm{l} 96 \%$ igem Ethanol gewaschen und die entstandenen Lysate mit Hilfe einer im Kit mitgelieferten Qiagen MiniSäule erneut bei $8000 \mathrm{rpm}$ zentrifugiert. Der äußere Säuleninhalt wird verworfen, wohingegen die DNA in der Membran des inneren Röhrchens verbleibt und nach mehrfachen Waschungen mit Pufferlösung schließlich über die Zugabe von Elutionspuffer aus der Membran in das finale Reaktionsgefäß gelöst wird. Die Ermittlung der erzielten DNA-Konzentration post isolationem erfolgte durch Messung der optischen Dichte der DNA-Probe in Wasser bei einem Absorptionsmaximum von $260 \mathrm{~nm}$ über das Gerät Nanodrop $2000^{\mathrm{TM}}$ (ThermoScientific). Zur Kontrolle wurde zu jeder Messung die optische Dichte einer Wasserprobe mitgeführt und bei der Konzentrationsbestimmung berücksichtigt. Physikalisch beschreibt die Absorption die Abschwächung der Lichtintensität einer Strahlung beim Durchqueren von Materie, in diesem Fall menschlicher DNA, in Abhängigkeit von der spezifischen Konzentration der absorbierenden Substanz und der Schichtdicke, welche dabei durchwandert wird. Bei Absorption wird die Transmission einer Welle oder Strahlung durch einen Stoff demnach abgeschwächt. Durch die Anwendung des Lambert Beer'schen Gesetzes (siehe Formel 1) kann die technisch ermittelte Absorption dafür verwendet werden, die DNA-Konzentration einer Probe zu bestimmen.

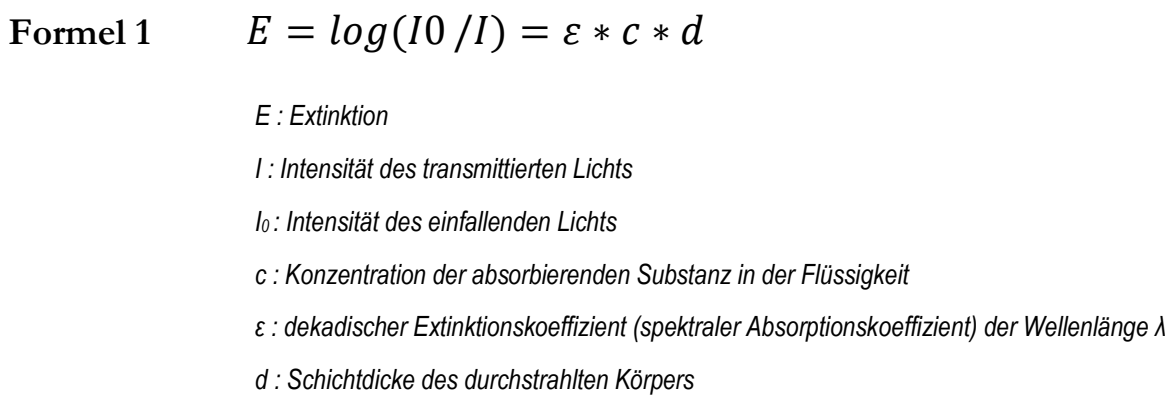


Bei der Quantifizierung entspricht eine Absorption (A) von 1 einer DNA-Konzentration von $50 \mathrm{mg}$ pro $1 \mathrm{ml}$ doppelsträngiger DNA. Zusätzlich dient der Quotient aus der Absorption bei $260 \mathrm{~nm}$ und der Absorption bei $280 \mathrm{~nm}$ zur Beurteilung der Reinheit der isolierten DNA (alternativ auch RNA). Ein A260/A280-Quotient zwischen 1,8 und 2,0 spricht für eine hohe Reinheit, während ein Wert $<1,8$ auf eine Verunreinigung der Probe hinweist. Für die optimalen Durchführung der Sequenzierungen wurde auf eine DNAAusgangswert von A260/A280 >1,8 nach der Isolierung geachtet.

\subsection{Sequenzspezifische Primer (SSP)-Methode}

Die für die vorliegende Arbeit ausgewählten 20 Studienteilnehmer wurden eigens mittels KIR-SSP genotypisiert. Für die Bestimmung des genetischen Umfangs vorhandener KIRGene (Genotypisierung) wurde das Olerup SSP ${ }^{\circledR}$ KIR Genotyping Kit gewählt. Im verwendeten Kit befinden sich vorpipettierte, getrocknete allelspezifische Primermixe und Nukleotide in einer Platte, welche durch die Hinzugabe spenderspezifischen DNA, einer Taq-Polymerase $^{\mathrm{h}}(5 \mathrm{U} / \mu \mathrm{l})$ und eines im Kit enthaltenen Puffers auf ein Endvolumen von 10 $\mu l$ gebracht wurden. Die Reaktionsgefäße wurden anschließend in den Cycler gestellt und gemäß der Herstellerangaben amplifiziert. Das Prinzip der SSP beruht auf sequenzspezifischen Primern, welche nur bestimmte KIR-Varianten eines Gens amplifizieren, wenn sie vollständig mit der Zielsequenz übereinstimmen. Nicht komplementäre Primer binden nicht und produzieren analog kein Amplifikat. Methodisch erlaubt diese Form der DNA-Analyse die Abbildung der genetischen Vielfalt von KIRRezeptoren innerhalb einzelner Spender und lässt im zweiten Schritt ebenfalls die Bestimmung ihres Haplotypen zu ( $\rightarrow$ vgl. Abschnitt 1.3.2). Die Amplifikationsprodukte wurden ohne Hinzugabe eines zusätzlichen Probenpuffers vorsichtig in die Taschen eines 1\%igen Agarose-Gels pipettiert. Die Auftrennung nach Größe dauerte 30 min bei 10-12 $\mathrm{V} / \mathrm{cm}$. Danach wurde das Gel in einer Ethidiumbromid-Lösung gefärbt und anschließend für die Fotodokumentation auf ein UV-Transilluminator (220 - $310 \mathrm{~nm})$ gelegt. In Abbildung 12 auf der nachfolgenden Seite ist ein angefärbtes Agarosegel mit entsprechender Auswertung der KIR-SSP exemplarisch dargestellt.

${ }^{\mathrm{h}}$ DNA-Polymerase aus dem Bakterium Thermus aquaticus 


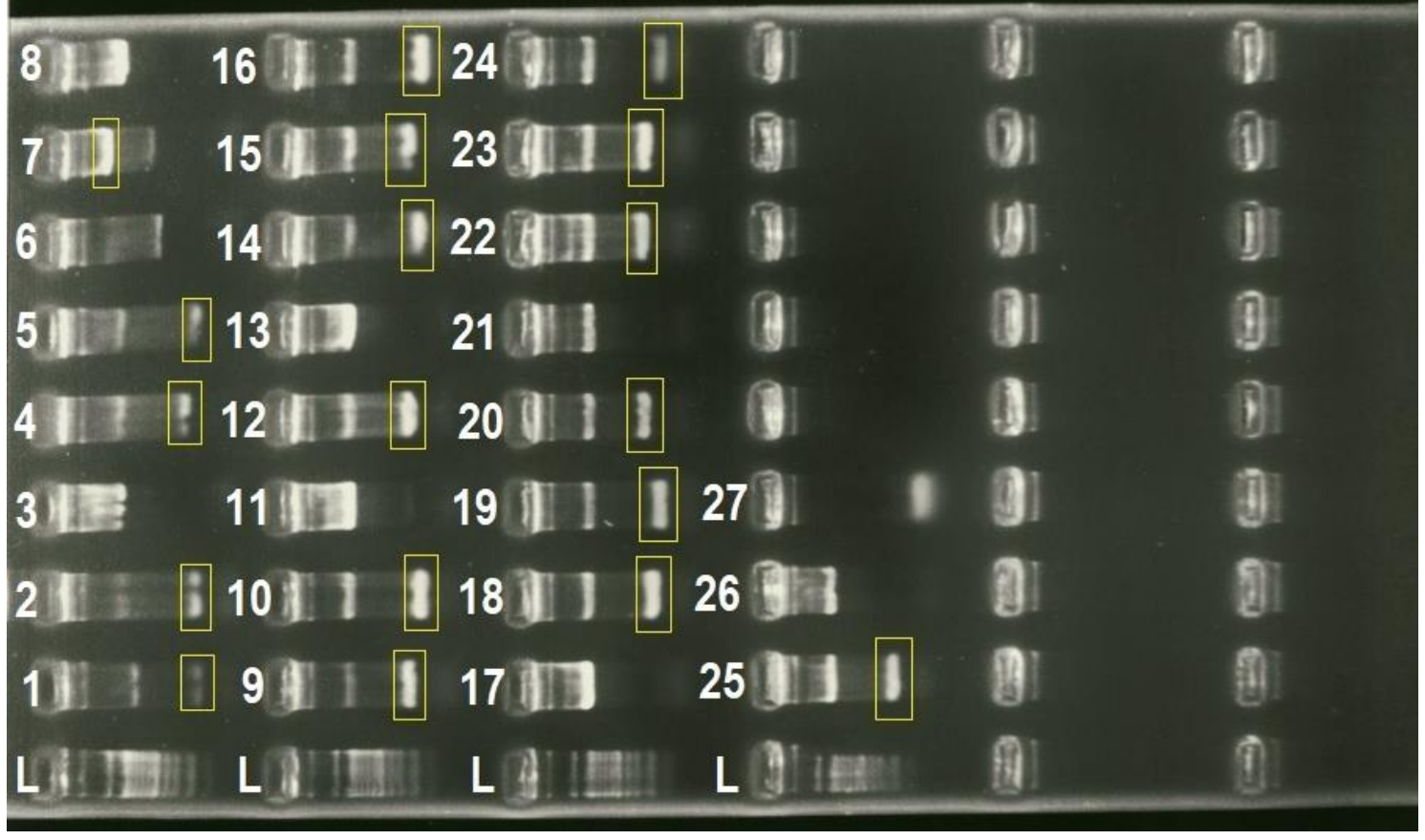

Abbildung 12 Auswertung eines Agarosegels nach Amplifikation mittels KIR Sequenz-spezifischer Primer (SSP)Methode. Für die Genotypisierung wurde eine vollständige Haplotyp-Längen-Sequenzierung via KIR-SSP durchgeführt. Das mit Ethidiumbromid angefärbte Agarosegel zeigt das KIR-SSP Ergebnis für Spender 16. Die eingefügten gelben Rechtecke demonstrieren die spezifischen Banden von KIRs und bestätigen des genetischen Vorhandenseins des jeweiligen KIR-Rezeptors bei dem untersuchten Spender.

Die anschließende Auswertung der DNA-Banden erfolgte anhand eines Arbeitsbogens (engl.: worksheet), in welchem die korrekten Größen der Amplifikatprodukte mit zugehörigem KIR-Protein angegeben sind. In allen Reaktionsproben gibt es eine interne Kontrollbande, welche die spezifische Reaktion der Taq-Polymerase bestätigt. Verschwindet sie oder ist sie nur sehr schwach erkennbar, kann die Probe unter Umständen nicht ausgewertet werden und muss in einem erneuten Durchgang wiederholt werden. In der Kontaminations- bzw. Negativkontrolle in der letzten Position des Streifens (Nr. 27) darf dagegen keine Bande erscheinen.

\subsection{Sequenzierung der KIR-Gene KIR2DL1 und KIR3DL1}

Für die Untersuchung der genetischen Basenabfolge der für die Forschungsarbeit relevanten zwei Rezeptoren, KIR2DL1 und KIR3DL1, wurde eine Polymerase-Ketten-Reaktion (engl.: polymerase chain reaction, PCR) nach Sanger durchgeführt. Dadurch konnten spenderspezifischen Basenabweichungen identifiziert werden, welche als Basis für die spätere Klassifikation in bestimmte KIR-Allele dienten. Da für dieses Verfahren reine Erbsubstanz, also Desoxyribonukleinsäure (DNA) der Spender benötigt wird, wurde diese im Vorfeld aus Spenderblut isoliert ( $\rightarrow$ vgl. Abschitt 4.1). Zur Bestimmung der relevanten 
Genabschnitte wurde mit spezifischen Primerpaaren gearbeitet. In der ersten Amplifikation wurde das gesamte KIR-Gen in kleinere Genabschnitte geteilt und diese vervielfacht (Abschnitt 4.8.2). Im Anschluss daran wurde nach Gelelektrophorese und Aufreinigung der PCR-Amplifikate eine zweite Sequenzier-PCR einzelner Exonen durchgeführt (Abschnitt 4.8.5) und die gewonnenen Basensequenzen weiter analysiert.

\subsubsection{Erste Sequenzier-PCR: Amplikation exonischer Gensequenzabschnitte}

Wie in Abbildung 3 der Einleitung gezeigt, besitzen verschiedenen KIR-Rezeptoren einen auffallend ähnlichen strukturellen Aufbau. Dies spiegelt sich auch in der Anordnung der Genabschnitte innerhalb der einzelnen KIR-Gene wider (Abb. 13).

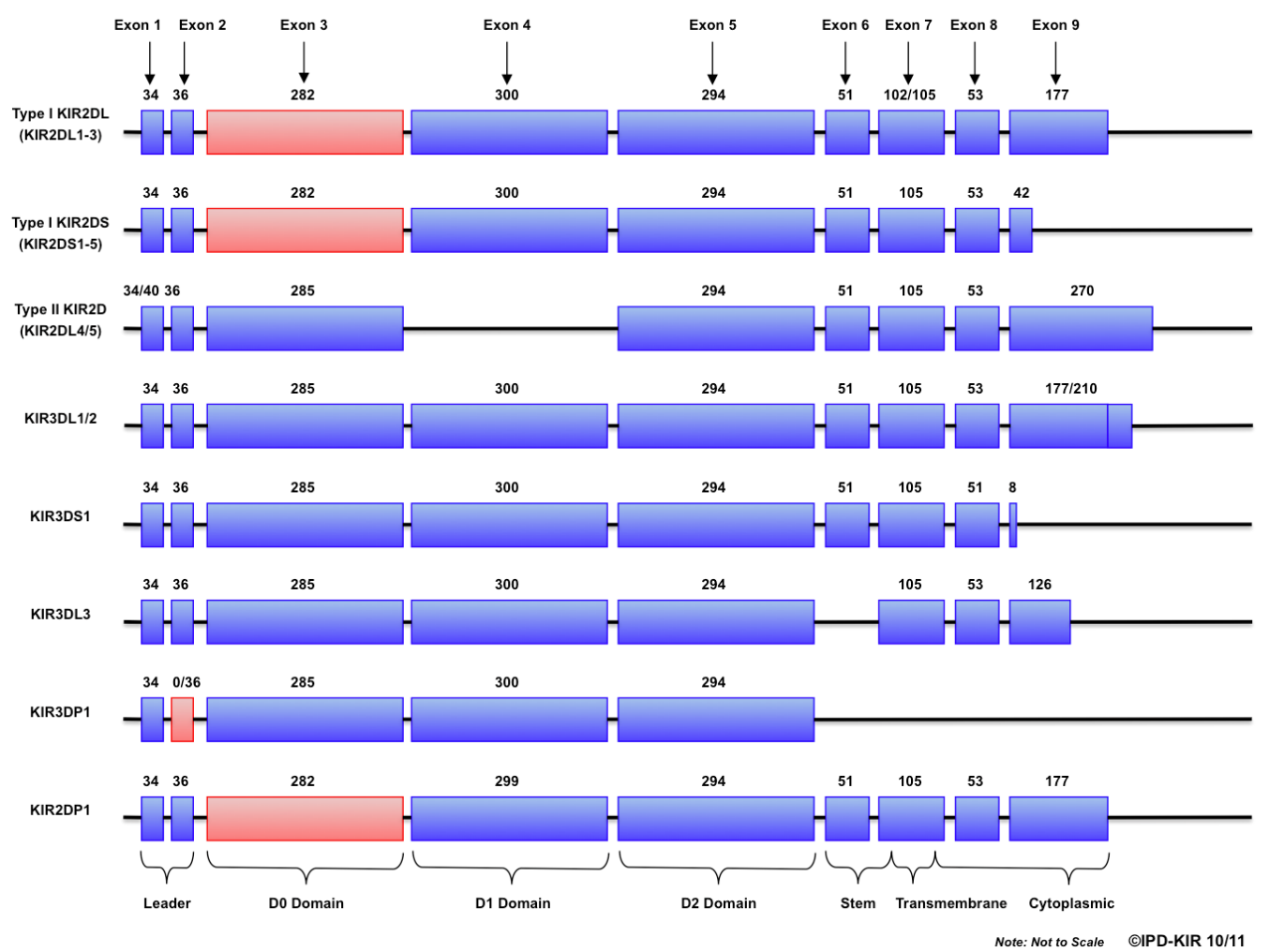

Abbildung 13 Darstellung der strukturellen Organisation einzelner KIR-Gene. Die kodierenden Regionen eines Exons sind in blau dargestellt, darüber ihre Größe in Basenpaaren (Bp). Das Pseudoexon 3 und die Exon 2- Deletion in KIR3DP1 sind dahingegen rot gekennzeichnet. Die Klammern unten in der Abbildung zeigen welche Exone für welche Proteindomäne oder -region im KIR-Rezeptor kodieren. [Quelle: IPD Datenbank, https://www.ebi.ac.uk/ipd /kir/genes.html]

Bei den allermeisten KIR-Genen handelt es sich um verhältnismäßig große Gene, KIR2DL1 mit 14,1 Kilobasen $(\mathrm{Kb})$ und KIR3DL1 mit sogar insgesamt 15,3 Kilobasen (Kb). Dies macht ein angepasstes Sequenzierungsvorgehen mit insgesamt zwei 
Amplifikationsdurchgängen methodisch notwendig. Als Exon (engl.: expressed region) werden alle Teile eines eukaryotischen Gens bezeichnet, welche bei der Transkription eines Gens, also beim Prozess der Umwandlung von DNA in mRNA, nicht aus dem Gen herausgespleißt werden. Das Spleißen (engl.: splicing) verkürzt das Gen enorm durch die Entfernung der sogenannten Introns (engl.: intragenic regions). Die verbleibenden Exone können kodierend, teilweise kodierend oder nicht kodierend sein. Als Pseudoexone, wie im Falle von Exon 3 bei KIR2DL1, bezeichnet man potentielle exonische Genabschnitte in intronischen premRNA Regionen, welche die Charakteristika eines Exons zwar erfüllen, allerdings nicht vom zellulären Splicing-Apparat als solches erkannt werden und deshalb nicht mehr in der reifen mRNA (engl.: mature RNA) zu finden sind.

Eines der Routineverfahren im klinischen Alltag ist die Polymerase-Ketten-Reaktion (PCR) nach Sanger (Sanger-Sequenzierung). Pro Sequenzierungsansatz wird hierfür jeweils ein vorwärtslaufender F-Primer (engl.: forward oder sense primer) und ein rückwärtslaufender RPrimer (engl:: reverse oder antisense primer) verwendet, der nach dem Entwinden des doppelsträngigen DNA-Strangs in zwei Einzelstränge an einem der beiden bindet und einen an den linearen Matrizenstrang angelehnten einzelsträngigen Komplementärstrang erzeugt. Die dafür benötigten Bausteine nennt man Desoxynukleosidtriphosphate (dNTPs) und Didesoxynukleosidtriphosphate (ddNTPs), welche den PCR-Ansätzen im Vorfeld in einem ausreichenden Mischungsverhältnis der vier Basen Adenin, Guanin, Cytosin und Thymidin künstlich zugesetzt werden müssen. Die einzelnen Basen sind hierbei mit verschiedenen Fluorochrom-Farbstoffen konjugiert, die ihrerseits als Dye Terminatoren bezeichnet werden und aufgrund unterschiedlicher Strahlungseigenschaften durch den Laser des Sequezierungsgeräts erkannt und voneinander differenziert werden können. Die Dokumentation der Basenreihenfolge erfolgt mittels einer eingebauten CCD-Kamera (engl.: charge-coupled device camera). Im Gegensatz zu dNTPs besitzen die ddNTPs keine 3'-HydroxylGruppe in ihrer chemischen Struktur, weshalb sie nach Einbau in den Komplementärstrang zu einem spontanen Kettenabbruch führen. Auf Grund dieses Mechanismus spricht man bei der Sanger-Sequenzierung auch von einer Kettenabbruch-Synthese. Da die ddNTPs prinzipiell an jeder Stelle des DNA-Strangs eingebaut werden können, resultieren folglich nach Ablauf der Sequenzierung zahlreiche unterschiedlich lange DNA-Fragmente eines Gens. Der Sequenzer kann anschließend mittels sogenannter Kapillarelekrophorese die Größe der einzelnen DNA-Fragmente bestimmen und durch Anregung der Fluorochrome in einem entsprechenden Wellenlängenbereich die Reihenfolge der einzelnen Basen erfassen und dokumentieren. Die Kombination aus Fragmentlängenmessung und Anregung der 
Fluorochrome ermöglicht durch diverse Überlagerungen in der Basenreihenfolge eines Genabschnitts die Entschlüsselung des relevanten Gens.

Unter Verwendung geeigneter Primerpaare wurden mittels Sanger-Sequenzierung bestimmte exonische DNA-Abschnitte der KIR-Gene KIR2DL1 und KIR3DL1 amplifiziert und ihre Kopien vervielfältigt. Das generelle Prinzip der PCR basiert auf drei aufeinanderfolgenden Schritten: Denaturierung (D), Anheftung (A; engl.: annealing) und Elongation $(\mathbf{E})$. Durch Zufuhr hoher Hitze kommt es zur Auftrennung aller doppelsträngigen DNA-Helices in jeweils zwei Einzelstränge (D), an welche sich im nächsten Schritt bei niedrigerer Temperatur sequenzspezifische Primer über das freie 5'-Ende anheften können (A). Für den nächsten Schritt werden freie dNTPs und ddNTPs, sowie eine thermostabile DNA-Polymerase gebraucht. Thermostabile DNA-Polymerasen sind DNA-Polymerasen, die meist von thermophilen Bakterien oder seltener Archaeenarten stammen und daher hitzeresistent sind. Bakterielle thermostabile DNA-Polymerase, wie die für die Sequenzierung verwendet, besitzt sowohl eine 5 ' $\rightarrow$ 3'-Polymerase-Aktivität, welche einen komplementären Einzelstrang synthetisiert (E), als auch eine zusätzliche 5 ' $\rightarrow$ 3'Exonuklease-Aktivität, die am 3'-Ende des neu erzeugten Komplementärstranges einen Adenosin-Überhang (engl.: sticky ends) erzeugt. Der D-A-E-Vorgang wird solange wiederholt (25 bis 30 Zyklen) bis nach Beendigung der ersten Sequenzier-PCR ausreichend Kopien der Gen-Abschnitte für die zweite Sequenzier-PCR ( $\rightarrow$ vgl. Abschnitt 4.3.4) vorhanden sind.

Wie der Abbildung 14 auf der nachfolgenden Seite $\mathrm{zu}$ entnehmen ist, wurde die Amplifikation des KIR2DL1-Gens in dieser Forschungsarbeit mithilfe von insgesamt drei überlappenden Genabschnitten, angeleht an die Sequenzierungsstrategie von Hou et al., realisiert. ${ }^{201}$ Pro Amplifikat wurden jeweils ein F- und ein R-Primer verwendet. Die neue Aufteilung des KIR2DL1-Gens besteht aus einem 5,6 Kilobasen (kB) großen Amplifikat A, dass den Bereich von Exon 1 bis 4, inklusive des Pseudoexons 3, umfasst, sowie einen Teil von Exon 5. Das KIR2DL1 Amplifikat B1 $(7,8 \mathrm{kB})$ dient der Amplifikation der mittelständigen Exone 4, 5 und 6, während Amplifikat B2 (0,5 kB) die Exone 7 bis 9 abdeckt. Das KIR3DL1-Gen, welches kein Pseudoexon besitzt, wird mit insgesamt vier überlappenden Sequenzabschnitten amplifiziert. Amplifikat A umfasst hierbei die Exone 1 bis $3(2,1 \mathrm{kB})$, Amplifikat B (2,3 kB) die zwei folgenden größeren Exone 4 und 5. Für Exon 6 sind keinerlei polymorphe Positionen beschrieben, damit ist dieser Genabschnitt für die 
Subtypisierung von KIR3DL1 unrelevant. Amplifikat C1 (0,5 kB) entspricht dem Exon 5, während Amplifikat C2 $(1 \mathrm{kB})$ die endständigen Exone 7 bis 9 repräsentiert.

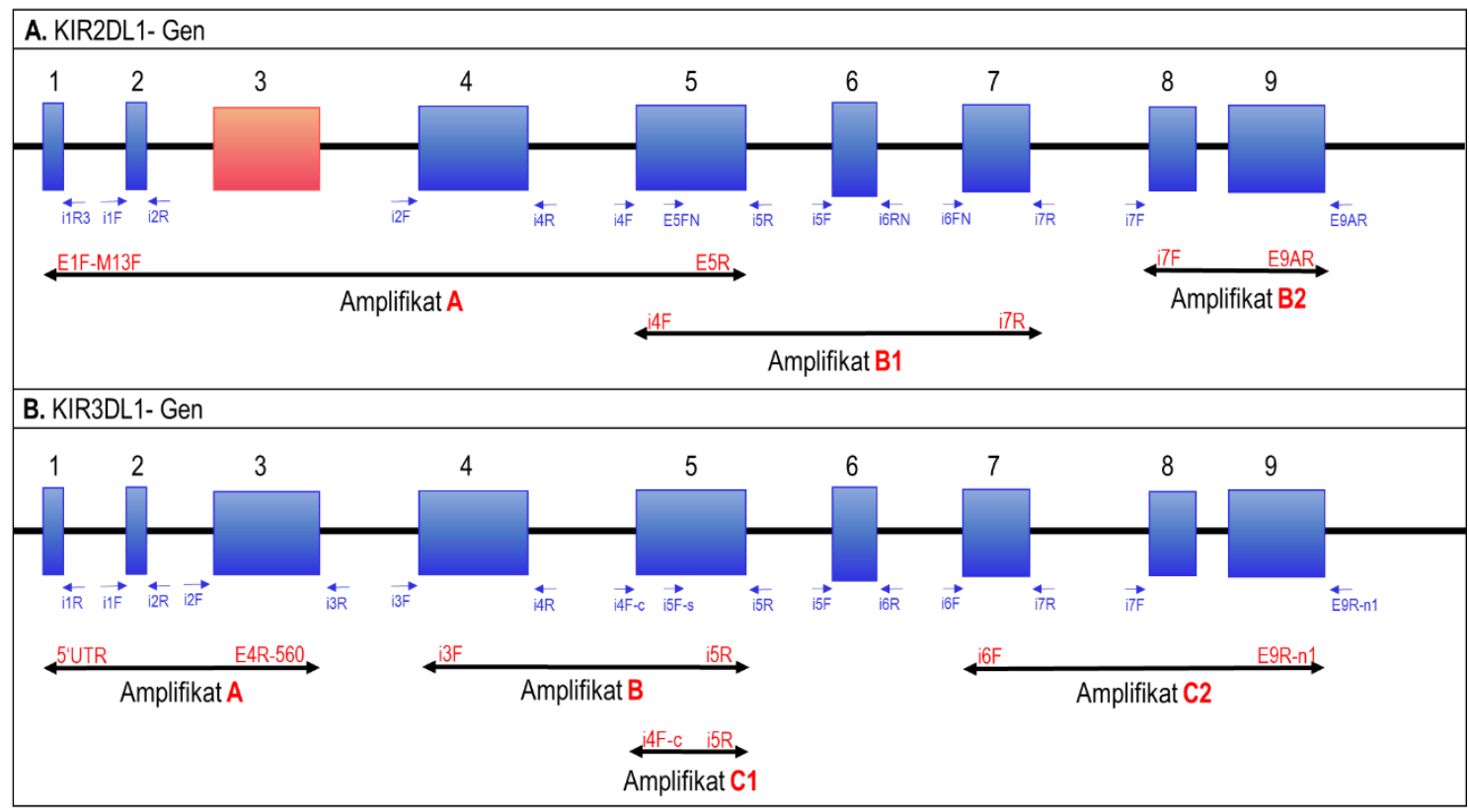

Abbildung 14 Amplifikationsstrategie der ersten Sequenzier-PCR des KIR2DL1-Gens von Exon 1 bis 9 (A; oben) und des KIR3DL1-Gens von Exon 1 bis 9 (B; unten). Die roten Ziffern zeigen die Primerpaare, die für die erste Sequenzier-PCR verwendet wurden. Die drei Amplifikate für KIR2DL1 und die vier Amplifikate für KIR3DL1 wurden anschließend mit Hilfe der in blauen Ziffern angegebenen Primerpaare exonisch sequenziert ( $\rightarrow$ vgl. Abschnitt 4.3.4).

Für die Amplifikation des großen Amplifikats A des KIR2DL1-Gens wurde dem Studienprotokoll von Hou et al. (2007) folgend die Platinum ${ }^{\text {TM }}$ High-Fidelity Taq DNA Polymerase (Invitrogen) belassen. ${ }^{201}$ Bei den Amplifikate B1 und B2 wurde die SequenzierPCR nach entsprechenden Versuchen durch eine Phusion High-Fidelity DNA Polymerase (Thermo Fisher Scientific) deutlich optimiert. Für die Amplifikation des gesamten KIR3DL1-Gens wurde das Long Range PCR Kit (Quiagen) gewählt. Die verwendeten Primer für die Amplikation und Sequenzierung von KIR3DL1 stammen aus den Publikationen von Belle et al. (2008). ${ }^{202}$

Um eine vollständige Sequenzierung des Exons 9 innerhalb des KIR3DL1-Gens zu realisieren, wurde ein neuer Primer 3DL1-E9R-n1 entworfen. 3DL1-E9R-n1 bindet im Bereich der intronischen DNA und nicht inmitten der relevanten polymorphen Positionen im Exon 9 ( $\rightarrow$ siehe Abb. 48, Anhang). Durch diese Verfahrensoptimierung konnten die Basenpaare 76 bis 177 des Exons 9 genaustmöglich sequenziert werden. 
Die genauen Angaben zu den Bezeichnungen und spezifischen Basenabfolgen der verwendeten Primer des ersten Amplifikationdurchgangs für die Gene KIR2DL1 und KIR3DL1 befinden sich in Tabelle 5 zusammengestellt.

Tabelle 5 Auflistung der für die Generierung der Amplifikate von KIR2DL1 und KIR3DL1 verwendeten Primer und deren spezifische Größe (Kilobasen(Kb)-Länge). Mit * versehen sind alle Primer, die in veränderter 1:100 Verdünnung, in der späteren Sequenzier-PCR Anwendung erneut verwendet wurden.

\begin{tabular}{|c|c|c|c|c|c|c|c|}
\hline \multirow{2}{*}{$\begin{array}{l}\text { Amplifikatbezeichnung } \\
\text { (KIR2DL1-Gen) }\end{array}$} & \multirow{2}{*}{ Größe } & \multirow{2}{*}{ Strang } & \multicolumn{5}{|c|}{ Verwendete Primer } \\
\hline & & & Bezeichnung & Länge (bp) & Verdünnung & Nukleotidsequenz & \\
\hline \multirow{2}{*}{ A } & \multirow{2}{*}{$5,6 \mathrm{~kb}$} & sense & 2DL1-E1F-M13F & 19 & 1:10 & 5'- GGC AGC ACC ATG TCG CTC T & $-3^{\prime}$ \\
\hline & & antisense & 2DL1-E5R & 20 & 1:10 & 5'- CAAGCAGTG GGT CAC TTG AC & $-3^{\prime}$ \\
\hline \multirow{2}{*}{ B1 } & \multirow{2}{*}{$7,9 \mathrm{~kb}$} & sense & 2DL1-i4F & 20 & 1:10 & 5'- AAG ATC CTC CCT GAG GAAAC & $-3^{\prime}$ \\
\hline & & antisense & 2DL1-i7R & 20 & 1:10 & 5'- AGG GAC CAT CCT GTT TGT GA & $-3^{\prime}$ \\
\hline \multirow{2}{*}{ B2 } & \multirow{2}{*}{$\sim 0,5 \mathrm{~kb}$} & sense & 2DL1-i7F & 20 & 1:10 & 5'- AAATGAGGACCC AGAAGT GC & $-3^{\prime}$ \\
\hline & & antisense & 2DL1-E9AR & 20 & 1:10 & 5'- TGT TGT CTC CCT AGAAGACG & $-3^{\prime}$ \\
\hline
\end{tabular}

\begin{tabular}{|c|c|c|c|c|c|c|c|}
\hline \multirow{2}{*}{\begin{tabular}{|l|} 
Amplifikatbezeichnung \\
(KIR3DL1-Gen)
\end{tabular}} & \multirow{2}{*}{ Größe } & \multirow{2}{*}{ Strang } & \multicolumn{5}{|c|}{ Verwendete Primer } \\
\hline & & & Bezeichnung & Länge (bp) & Verdünnung & Nukleotidsequenz & \\
\hline \multirow{2}{*}{ A } & \multirow{2}{*}{$2,1 \mathrm{~kb}$} & sense & 3DL1/S1- 5'UTR & 19 & $01: 10$ & 5'- TGT CT G CAC CGG CAG CAC C & $-3^{\prime}$ \\
\hline & & antisense & 3DL1- E4R-560 & 19 & $01: 10$ & 5'- TAG GTC CCT GCAAGG GCAA & $-3^{\prime}$ \\
\hline \multirow{2}{*}{ B } & \multirow{2}{*}{$2,3 \mathrm{~kb}$} & sense & 3DL1-i3F & 21 & $01: 10$ & 5'- GAT GCC TTC TAAACT CAC AAC & $-3^{\prime}$ \\
\hline & & antisense & 3DL1-i5R & 20 & $01: 10$ & 5'- TGC ATC TGT CCATGC TTT TC & $-3^{\prime}$ \\
\hline \multirow{2}{*}{ C1 } & \multirow{2}{*}{$0,5 \mathrm{~kb}$} & sense & 3DL1-i4F-c & 20 & $01: 10$ & 5'- GGT CAT AGA GCA GGG GAG TG & $-3^{\prime}$ \\
\hline & & antisense & 3DL1-i6R & 20 & $01: 10$ & 5'- CCC TTT CAC TGT TGG AGT GT & $-3^{\prime}$ \\
\hline \multirow{2}{*}{$\mathrm{C} 2$} & \multirow{2}{*}{$1,0 \mathrm{~kb}$} & sense & 3DL1-i6F & 20 & 01:10 & 5'- AGG GGT CAAACATCT CAACT & $-3^{\prime}$ \\
\hline & & antisense & 3DL1- E9R & 17 & $01: 10$ & 5'- GCC TCT GAG AAG GGC GA & $-3^{\prime}$ \\
\hline
\end{tabular}

PCR-Reaktionen beider Gene erfolgten in Eppendorf-Reaktionsgefäßen (8-er PCR Stripes). Eine Zusammenstellung der Reaktionsansätze für KIR2DL1 und KIR3DL1 findet sich in Tabelle 25, die vollständig aufgelisteten Thermocycler-Parametern in Tabelle 26 des Anhangs. Bis zur Überprüfung der Amplifikation mittels Gelelekrophorese und deren Aufreinigung wurden die PCR-Amplifikate im Thermocycler und anschließend im Kühlschrank bei $4^{\circ} \mathrm{C}$ zwischengelagert.

\subsection{2 Überprüfung der Amplifikation über Gelelektrophorese}

Zur Überprüfung der Größe (Kilobasen (Kb)-Länge) der Amplifikate und Bestätigung des Erfolgs der ersten Sequenzier-PCR wurde das PCR-Produkt auf ein Agarosegel geladen. Um eine gute Gelqualität zu erzielen, wurden die für die Gelelektrophorese verwendeten 1\%igen Agarose-Gele stets frisch angesetzt und vor jedem Durchgang nach 20-minütiger Aushärtung in eine mit TRIS-Borat-EDTA(TBE)-Puffer (1x) befüllte Gelelektrophoresekammer gelegt. Je höher der Agarose-Anteil im Gel gewählt wird, desto engmaschiger wird das Netz, wodurch es für größere Fragmente schwieriger wird nach 
Ansetzen der elektrischen Spannung in Richtung Anode zu wandern. Abhängig von den Eigenschaften des angesetzten Agarosegels sowie der Fragmentlänge wandern die Amplifikate demnach in gleicher Zeit unterschiedlich weit durch die Gelektrophoresekammer im Gel. Die Gelelektrophorese lief für $30 \mathrm{~min}$ bei einer Stromstärke von 130 Ampere und einer elektrischen Spannung von 60 Volt. Bei der Durchführung wurde zu je $5 \mu$ der Amplifikat-Probe jeweils $1 \mu$ l Ladepuffer (LoadingDye 6x) in eine Mischplatte gegeben und durch auf- und ab-Pipettieren gemischt sowie anschließend präzise in eine Geltasche des Agarosegels gegeben (Abb. 15). Der Ladepuffer fungiert dabei als „Probenbeschwerer“ und verhindert das frühzeitige Herausdiffundieren der Probe. Der zusätzlich enthaltene Farbstoff erleichtert dem Untersuchenden die Wanderung der Probe im Gel optisch zu überprüfen. Ein im Gel mitlaufender Standardlängen-Marker, welcher ebenfalls mit $1 \mu \mathrm{l}$ Ladepuffer (LoadingDye 6x) und $4 \mu \mathrm{l}$ RNase-freiem Wasser verdünnt in eine Geltasche pipettiert wird, enthält DNA-Fragmente definierter Größe und ermöglicht als Genleiter (engl.: gene ladder) das Ablesen der

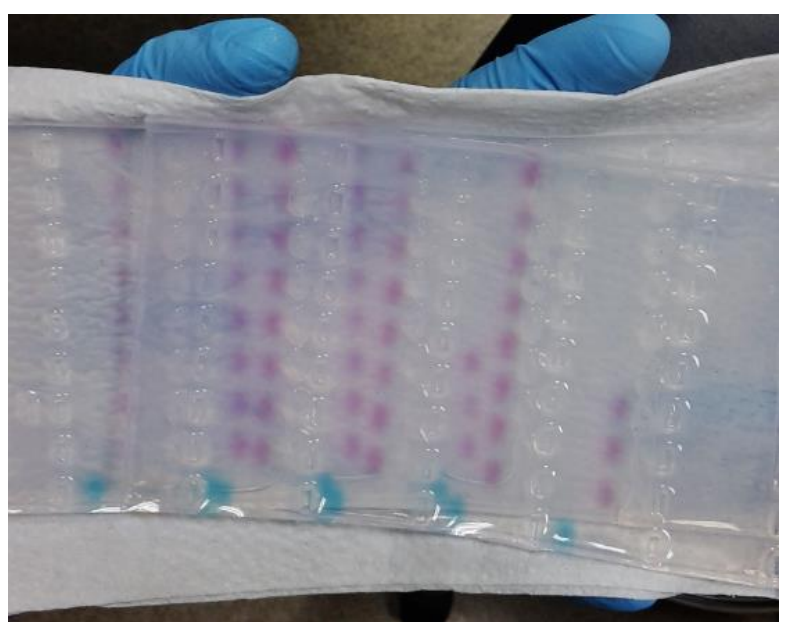

Abbildung 15 Darstellung eines Agarosegels nach abgeschlossener Gelelektrophorese der ersten Sequenzier$P C R$. In die Geltaschen wurden die Amplifikat-Proben mit jeweils $1 \mu \mathrm{l}$ Ladepuffer (rötlich) pipettiert und pro Reihe der Standardlängen-Marker (blau) mitgeführt.
Fragmentlänge der zu untersuchenden Probe nach Anfärbung des Gels. Nach beendeter Gelelektrophorese wird das Gel in einem 1\%igen Ethidiumbromidbecken für 15 min inkubiert und anschließend zur Sichtbarmachung der Banden unter eine UV-Lampe platziert. Die nun aufleuchtenden spezifischen Gelbanden werden computergesteuert eingescannt. Das erzeugte Bild kann ausgedruckt $(\rightarrow$ vgl. Abb. 12, Abschnitt 4.2) und die KbLängen der DNA-Proben mit Hilfe der Genleiter abgeglichen werden.

\subsubsection{Verdünnung und Aufreinigung der amplifizierten DNA-Abschnitte}

Nach Bestätigung der korrekten Amplifikation der gewünschten DNA-Abschnitte mittels Gelelektrophorese wurde die DNA-Konzentration der Amplifikat-Proben am Nanodrop2000 ${ }^{\mathrm{TM}}$ (Thermo Fisher Scientific) bestimmt und mit Hilfe von RNase-freiem Wasser auf eine Konzentration von $50 \mathrm{ng} / \mu \mathrm{l}$ eingestellt. Die Probenaufreinigung erfolgte 
mittels eines speziellen Kits von Thermo Fisher Scientific bestehend aus Fast-AP (Thermosensitive Alkaline Phosphatase) und einer Exonuklease I. Zu je $5 \mu$ des Amplifikats wurden $1 \mu \mathrm{l}$ Fast-AP $(1 \mathrm{U} / \mu \mathrm{l})$ und $0,5 \mu \mathrm{l}$ Exonuklease I $(20 \mathrm{U} / \mu \mathrm{l})$ gegeben und für $15 \mathrm{~min}$ bei $37^{\circ} \mathrm{C}$ inkubiert. Anschließend wurde die Reaktion nach weiteren $15 \mathrm{~min}$ im Thermocycler bei $85^{\circ} \mathrm{C}$ gestoppt. Die Proben wurden bis zur weiteren Verwendung erneut bei $4^{\circ} \mathrm{C}$ im Kühlschrank gelagert.

\subsubsection{Zweite Sequenzier-PCR: Generierung spezifischer Exon-Amplifikate}

Nach Aufreinigung der auf $50 \mathrm{ng} / \mu \mathrm{l}$ verdünnten DNA-Amplifikate erfolgte die spezifische Exon-Sequenzierung mittels BigDye ${ }^{\mathrm{TM}}$ Terminator v3.0 Ready Reaction Kit (Thermo Fisher Scientific). Die Durchführung erfolgte nach Herstelleranleitung mit den in Tabelle 6 aufgeführten Thermocycler-Parametern.

Tabelle 6 Thermocycler-Parameter für die zweite Sequenzier-PCR zur Generierung spezifischer Exon-Amplifikate der KIR2DL1- und KIR3DL1-Gene.

\begin{tabular}{|c|c|c|c|c|}
\hline KIR2DL1 / KIR3DL1 & Zeit & $\begin{array}{c}\text { Temperatur } \\
\left({ }^{\circ} \mathrm{C}\right)\end{array}$ & Wiederholungen & $\begin{array}{c}\text { Programmname } \\
\text { (individuell) }\end{array}$ \\
\hline Initiation & $1 \mathrm{~min}$ & 96 & & \\
\hline Denaturierung & $10 \mathrm{~s}$ & 96 & & \\
\hline Annealing & $5 \mathrm{~s}$ & 50 & $25 x$ & SEQ-PCR \\
\hline Extension & $4 \mathrm{~min}$ & 6 & & \\
\hline Ende & $10 \mathrm{~min}$ & 4 & & \\
\hline
\end{tabular}

Das Reaktionsendvolumen betrug $10 \mu$ l. Pro PCR-Ansatz wurde in diesem Durchgang nur ein Primer, anstelle von zwei Primern verwendet, um ausschließlich Kopien von jeweils einem der beiden DNA-Einzelsträngen zu generieren. Die verwendeten Primer wurden von ihrer Basenabfolge so konstruiert, dass sie gerade noch in der Intronregion unmittelbar vor oder nach dem KIR-Exon binden. Auf diese Weise ist das Exon mit seiner gesamten Länge exakt in dem Sequenzierungsbereich eingeschlossen und das entstehende Amplifikat gleichzeitig minimal lang. Durch die Konstruktion eines neuen Primers für Exon 9 des KIR3DL1-Gens, abweichend von dem Protokoll von Belle et al. ( $\rightarrow$ siehe Abb. 48, Anhang), gelang die Sequenzierung des gesamten Exons. Für die zweite Sequenzier-PCR wurden teilweise Primer verwendet, die bereits in höherer Konzentration zur Amplifikation der exonischen Gensequenzabschnitte von KIR2DL1 und KIR3DL1 verwendet wurden. Eine komplette Auflistung aller verwendeten Primer zeigt Tabelle 27 des Anhangs. 


\subsubsection{Aufreinigung der Sequenzierungsprodukte}

Die Aufreinigung der Sequenzierungsamplifikate erfolgte mit Hilfe einer EthanolAufreinigung. Ziel ist es überschüssiges Sequenziermaterial, allen voran nicht eingebaute ddNTPs, vom BigDye ${ }^{\mathrm{TM}}$ Terminator v3.0 Ready Reaction Kit (Thermo Fisher Scientific) zu entfernen. Hierbei wird hochgerechnet auf die Anzahl der Proben (pro Amplifikat jeweils 2 $\mu \mathrm{l}$ Natriumacetat $(\mathrm{NaOAc}) /$ EDTA-Puffer mit $25 \mu \mathrm{l}$ 96\%igem Ethanol (EtOH)) eine Gebrauchslösung angesetzt und gut durchmischt. Je $25 \mu \mathrm{l}$ der fertigen, milchig-trüben Puffer-Ethanol-Lösung wird zu jedem $10 \mu$ l DNA-Amplifikat hinzugegeben und mindestens 1 min auf dem Vortexer stark geschüttelt. Anschließend wurden die Amplifikatproben mittels Mehrkanalpipette auf eine 96-Mikrotiterplatte (engl.: microwell plate) überführt und bei $2000 \mathrm{rpm}$ für $30 \mathrm{~min}$ (mit Bremse) zentrifugiert. Nach abgelaufener Zeit wurden die Proben auf einem zugeschnittenen Papiertuch bei $<500 \mathrm{rpm}$ für $<1$ min über Kopf zentrifugiert, mit $50 \mu \mathrm{l}$ 80\%igem EtOH überschichtet und bei $2000 \mathrm{rpm}$ erneute 5 min erneut zentrifugiert. Zur Waschung der Proben wurde die Über-Kopf-Zentrifugation $<1$ min wiederholt. Als Abschluss wurde jeder Schacht der 96-Well-Platte mit $15 \mu$ l Formamid befüllt, die Proben am Vortexer gemischt und danach kurz anzentrifugiert, um Luftbläschen vor der 96-Kanal Sequenzierung aus dem Reaktionsansatz zu entfernen.

\subsubsection{6-Kanal Sequenzierung}

Der finale Sequenzierungsschritt der entstandenen einzelsträngigen, linearen DNAAmplifikate erfolgte in einem 96-Kanal Sequenziergerät (Genetic Analyzer ${ }^{\circledR}$ 3130xl von Applied Biosystems) im Institut für Transfusionsmedizin und Immunhämatologie des DRKBlutspendedienstes. Wie bereits im Abschnitt 4.3.2 beschrieben, beruht die Sequenzierung auf dem Einbau fluoreszenzmarkierter dNTPs und ddNTPs folgend der Kettenabbruchmethode nach Sanger. Dadurch entstehen unterschiedlich lange fluoreszenzmarkierte DNA-Sequenzierungsabschnitte, welche über eine Kapillarelekrophorese der Länge nach zunächst aufgetrennt und mit Hilfe eines gerätinternen Kamerasystems (ABI Prism 3730xl Genetic Analyzer) auf ihre charakteristische photophysikalische Leuchterscheinung bei Bestrahlung mit ultraviolettem Licht hin untersucht werden. Längenmessung und Fluoreszenzemission werden durch den Genetic Analyzer parallel und vollautomatisch prozessiert, sodass die Sequenzen nach etwa einer Stunde in Form von Computerdateien zur weiteren Analyse zur Verfügung stehen. Durch eine geeignete Software wurde die Gensequenz anschließend systematisiert und im 
Anschluss manuell ausgewertet. Die dabei ermittelten Gemeinsamkeiten und Unterschiede, im Vergleich zur definierten Referenzsequenz des KIR-Gens, wurden tabellarisch dokumentiert. Die vollständige Gensequenzierung ermöglichte eine allelische Subtypisierung der Spender für KIR2DL1 und KIR3DL1. Die bei der Sequenzierung im Genetic Analyzer 3130xl verwendeten Protokoll-Parameter sind in Tabelle 7 zusammengefasst.

Tabelle 7 Protokoll-Parameter bei der Sequenzierung von KIR2DL1 und KIR3DL1 mittels Genetic Analyzer 3130xI (Applied Biosystems®).

\begin{tabular}{|l|l|}
\hline $\begin{array}{l}\text { Ausgewähltes } \\
\text { Protokoll }\end{array}$ & Auswahlbezeichnung \\
\hline $\begin{array}{l}\text { Instrument-Protokoll } \\
\text { Analyse-Protokoll }\end{array}$ & $\begin{array}{l}\text { StdSeq36_POP7_BDver1 } \\
\text { 3730BDTv1_KB-DeNovo-v5.2 }\end{array}$ \\
\hline
\end{tabular}

\subsubsection{Auswertung der KIR-Gensequenzen}

Zur Ermittlung der spenderspezifischen Basenabfolge der KIR-Sequenzdateien wurde die GeneSearch-Software (Version 4.1) von PhenoSystems verwendet. Sie ermöglicht die Gegenüberstellung von Sequenzabschnitten von KIR-Exonen mit denen eines Referenzgens. Auf diese Weise lassen sich veränderte Basenabfolgen innerhalb einzelner Exone untersuchen. Für KIR2DL1 wurde das Allel KIR2DL1*001 als Referenzgen gewählt, für KIR3DL1 das Allel KIR3DL1*0010101. Es ist bereits bekannt, dass KIR-Gene hochpolymorph sind, sodass alleine für KIR2DL1 insgesamt 66 Allele bekannt sind. Für KIR3DL1 sind sogar 150 Allele derzeit bekannt (Stand Januar 2019). Die große Anzahl sich ergebeneder Allelvarianten erschwert die maschinelle Typisierung mittels Software. Zur Erleichterung der Auswertung wurden alle bislang in der Immuno Polymorphism Database (IPD) bestätigten Allele inklusive ihrer genetischen „Mismatch-Positionen“ für beide KIRGene chronologisch in jeweils eine Excel-Tabelle kopiert. Danach wurden nach manueller Auswertung der Sequenzen für jeden der 20 Spender, die vom Referenzgen abweichenden Nukleotidpositionen in der exonischen DNA sowie die stattdessen auftretende Base in die Auswertungstabelle eingefügt. Diese umfangreiche Tabelle wurde zur Bestimmung der Spenderallele verwenden, sowie zum Vergleich der polymorphen Positionen innerhalb der KIR-Sequenzen herangezogen. Unter Abschnitt 8.2 sind die verwendeten KIRAuswertungstabellen zur Bestimmung der KIR-Subtypen der Spenderproben abgebildet $(\rightarrow$ Abschnitt 8.3 (Anhang); KIR2DL1 auf Seite 125, KIR3DL1 auf den Seiten 127-133). Unterschiede in der Basenabfolge innerhalb der DNA-Abschnitte (Exon 1 bis 9) einzelner 
Spender wurden mittels Ausschlussverfahren nach Sequenzvergleich mit den Datensätzen bereits bekannter KIR-Allele ermittelt. Sequenzvariationen innerhalb der kodierenden DNAAbschnitte können nach der Übersetzung der Basentriplets (Translation) in veränderten Aminosäuren ( $\rightarrow$ siehe Tabelle 28, Anhang) im Genprodukt, hier dem fertigen KIRRezeptor, resultieren und seine letztliche Funktion beeinflussen. ${ }^{203-205}$ Die Abbildung 16 zeigt die relevanten Abschnitte des KIR-Rezeptors mit den dazugehörigen Exonen 1-9 des KIR-Gens.

\begin{tabular}{|c|c|c|c|c|c|c|c|}
\hline Exon $1-2$ & Exon 3 & Exon 4 & Exon 5 & Exon 6 & Exon 7 & Exon 8 & Exon 9 \\
\hline $\begin{array}{l}\text { (Signal-) } \\
\text { Sequenz } \\
\text { "Leader"- } \\
\text { Domäne }\end{array}$ & $\begin{array}{c}\text { D0- } \\
\text { Domäne }\end{array}$ & $\begin{array}{c}\text { D1- } \\
\text { Domäne }\end{array}$ & $\begin{array}{c}\text { D2- } \\
\text { Domäne }\end{array}$ & $\begin{array}{l}\text { Stamm- } \\
\text { Domäne; } \\
\text { "Linker" }\end{array}$ & $\begin{array}{c}\text { Transmembran } \\
\text { (TM)- } \\
\text { Bereich }\end{array}$ & \multicolumn{2}{|c|}{$\begin{array}{c}\text { Zytoplasmatische (ZYT)- } \\
\text { Domäne }\end{array}$} \\
\hline
\end{tabular}

Abbildung 16 Darstellung der Exone 1 bis 9 mit dem dazugehörigen Ig-Rezeptor-Bereich, unterteilt in Domänen, welche für alle zwei Domänen bzw. drei Domänen KIRs gleichermaßen zutrifft. Einzige Ausnahme stellt Exon 3 dar, dass nur in Form der D0-Domäne bei KIR3DL kodiert wird. 206

\subsection{Isolierung von peripheren mononukleärer Zellen aus Vollblutproben}

Das Heparin-Vollblut der Spender wurde im ersten Schritt der Isolierung unter sterilen Bedingungen mit vorgewärmtem RPMI 1640-Medium 1:1 vorverdünnt. Diese Suspension wurde auf jeweils mit mindestens $15 \mathrm{ml}$ Lymphodex (Ficoll ${ }^{\circledR}$ ) vorbefüllte $50 \mathrm{ml}$ FalconRöhrchen vorsichtig aufpipettiert. Dabei wurde auf eine reine Überschichtung ohne Mischung zwischen Blut und Ficoll ${ }^{\circledR}$ geachtet. Ficoll ${ }^{\circledR}$ ist ein synthetisches Polymer aus Saccharose-Epichlorhydrin-Molekülen, welches als Auftrennungsmaterial bei der Dichtezentrifugation zur Trennung und Isolierung von Blutbestandteile verwendet wird. Im nächsten Schritt wurde der Inhalt der 50 ml-Falcon-Röhrchen bei 2000 rpm (engl:: rounds per minute) für 20 min ohne Bremse zentrifugiert. Nach Ablauf der Zeit ließen sich 4 Phasen voneinander unterscheiden (Abb. 17). 

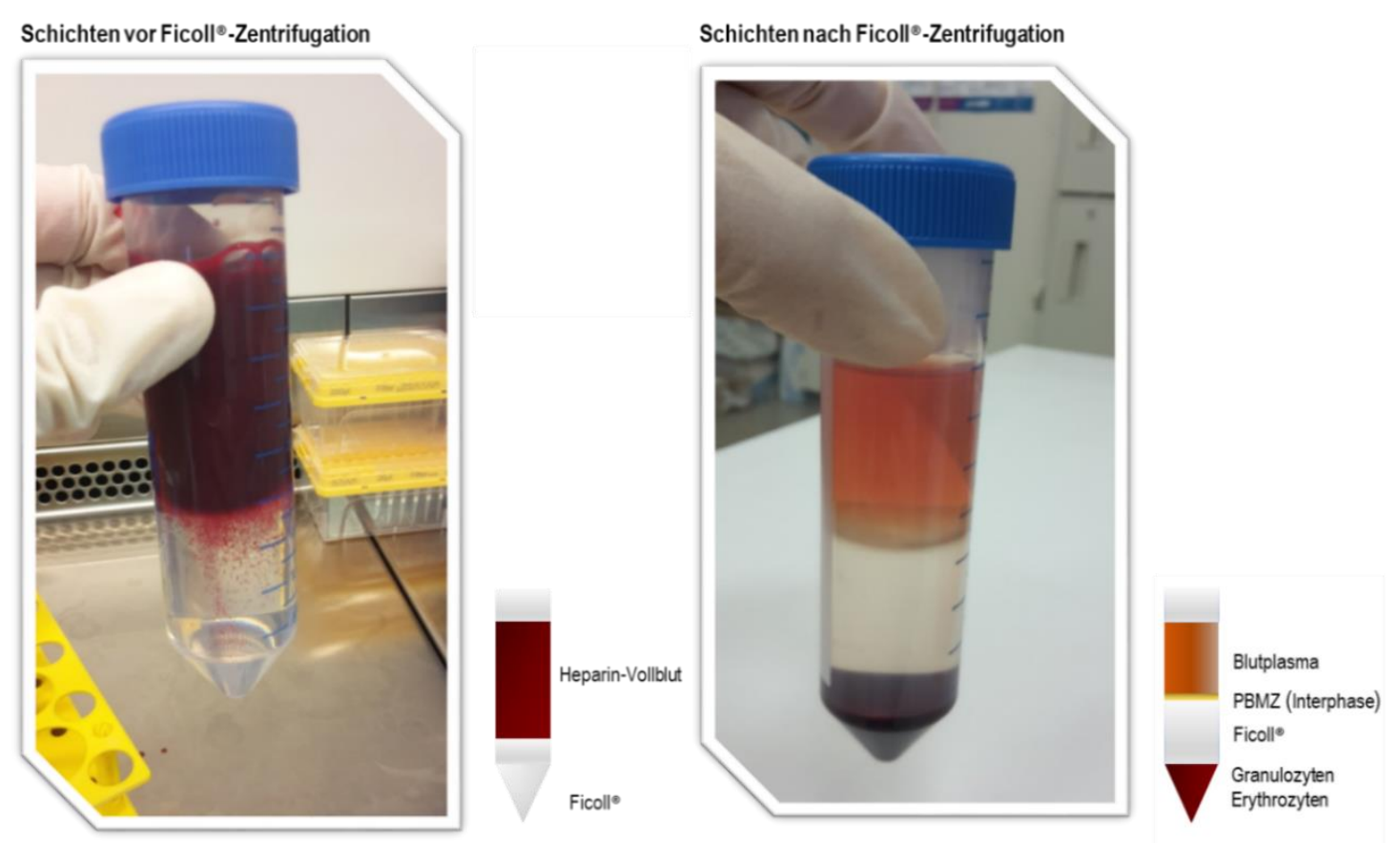

Abbildung 17 Phasenbildung einer Heparin-Vollblutprobe nach Ficoll-Überschichtung vor (links) und nach (rechts) Dichtezentrifugation. Die oberste, rötliche Phase nach der Trennungszentrifugation des Röhrchens enthält das Blutplasma des Spenders. Die darunter milchig aussehende Phase wird (aus dem Englischen) als „Buffy-Coat" bezeichnet. Dieser besteht hauptsächlich aus peripheren mononukleären Blutzellen (PBMZ) und macht nur etwa ein Prozent der Blutprobe aus. Darunter befindet sich das transparente Ficoll und abschließend ein dunkelrotes Sediment aus Granulozyten und Erythrozyten.

Die in der Interphase enthaltenen peripheren mononukleären Blutzellen (PBMZ) bilden den sogenannten Buffy-Coat und beinhalten neben Blutplättchen (Thrombozyten) auch alle Lymphozyten einschließlich der NK-Zellen. Durch den vorsichtigen Einsatz einer manuellen Pipette wurde der Buffy-Coat herausgelöst und in ein neues $50 \mathrm{ml}$ FalconRöhrchen überführt. Dabei wurde darauf geachtet möglichst keine Verwirbelungen zwischen den Phasen zu erzeugen. Nun erfolgte eine erneute Verdünnung mit X-Vivo10 ${ }^{\circledR}$-Medium auf 50 ml. Die Suspension wurde durch 2-3-malige Inversion des Röhrchens vermischt. Danach wurde eine zweite Zentrifugation bei $1900 \mathrm{rpm}$ für $12 \mathrm{~min}$ mit Bremse angeschlossen. Dadurch trennten sich die Thrombozyten aus dem Leukozytenverband heraus und wurden als Überstand verworfen. Das verbleibende Zellpellet wurde in $10 \mathrm{ml}$ frisches X-Vivo10 ${ }^{\circledR}$ Medium aufgenommen und mittels Pipette vermischt. Für die anschließende Isolierung der NK-Zellen wurde die Zellzahl der gewonnenen PBMZ mittels Trypanblaufärbung und Zählkammer pro $\mathrm{ml}$ Medium ermittelt. 


\subsection{NK-Zellisolierung aus Proben mit peripheren mononukleärer Zellen}

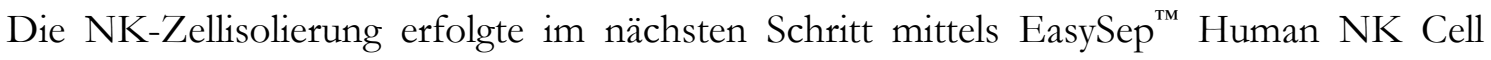
Enrichment Kit (STEMCELL Technologies) nach Angaben des Herstellers. Der im Kit enthaltene Antikörper-Mix beinhaltet Glycophorin A, CD3, CD4, CD14, CD19, CD20, CD36, CD66b, CD123 und HLA-DR, als spezifische Antikörper gegen bestimmte Oberflächenmoleküle humaner hämatopoetischer Zellen ( $\rightarrow$ siehe Tabelle 29, Anhang). Die genannten monoklonale Antikörper werden durch Crosslinking an magnetische Beads zu

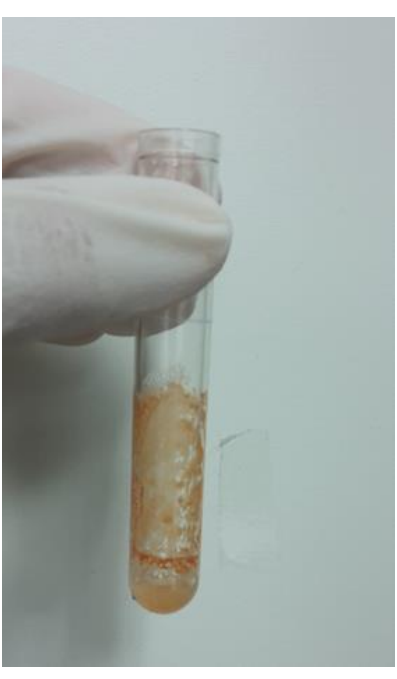

Abbildung 18 Versuchsröhrchen aus dem Magnetständer nach Abkippen der NK-Zell-Suspension. tetramerischen Antikörper-Komplexen gekoppelt, sodass die daran gebundenen Zellen über einen Tischmagneten an der Röhrchenwand festgehalten werden können (Abb. 18). Dies entspricht dem Prinzip einer Negativ-Selektion, sodass unerwünschte Zellen aus der Buffy-Coat Lösung per Magnet herausgelöst werden können. Anschließend wird das im Magnet stehende Röhrchen durch eine dosierte Kippbewegung in ein neues Röhrchen überführt. Die gewonnene Zellsuspension wird erneut zentrifugiert, der Überstand verworfen, das NK-ZellSediment mit Zellmedium auf eine Konzentration von $5 \times 10^{5}$ Zellen pro ml NK-Zell-Zellmedium gebracht und die isolierten Zellen in einem Wärmeinkubator bis zur weiteren Verwendung inkubiert.

\subsection{Zellzählung nach Trypanblaufärbung}

Zur Einschätzung und Dokumentation der qualitativen Vitalität der isolierten Zellen erfolgte die Zellzählung in der Neubauerkammer mittels Trypanblau (Abb. 19). Trypanblau, auch Benzaminblau genannt, ist ein anionischer Diazofarbstoff, welcher Zellmembranen geschädigter und/oder toter Zellen durchdringen kann. Tote Zellen färbten sich rasch einheitlich blau an, während lebende Zellen mit intakter Lipiddoppelmembran ungefärbt bleiben. 
Durch diese Charakteristik kann Trypanblau als Vitalitätsparameter herangezogen werden und den Lebendzellanteil von dem Totzellanteil der Gesamtzellzahl visuell darstellen. Zunächst wurden $10 \mu \mathrm{l}$ der Zellsuspension mit $40 \mu \mathrm{l}$ Trypanblau (1:5) verdünnt, mittels Pipette mehrmals resuspendiert und für etwa 2 - 3 min bei Raumtemperatur inkubiert. Anschließend wurde die gefärbte Probe in der Zählkammer betrachtet. Bei zu hoher zellulärer Dichte und dadurch eingeschränkter Zählbarkeit wurde eine höhere Verdünnung angesetzt $(1: 10)$.
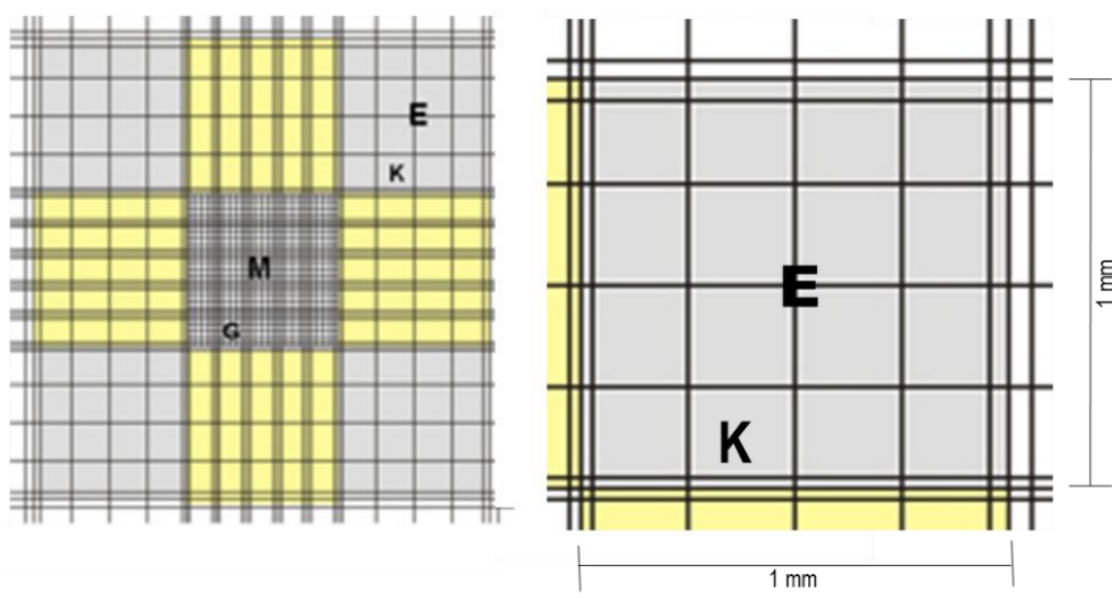

\author{
E: Eckquadrat \\ K: Kleinquadrat \\ $E=16 \times K$ \\ M: Mittelquadrat \\ G: Gruppenquadrat \\ $\mathbf{G}=16 \times \mu$ Quadrate \\ $M=25 \times G$ \\ $\mathbf{M}=25 \times 16 \mu$ Quadrate
}

Abbildung 19 Schematische Darstellung einer Neubauer-Zählkammer (links) mit allen vier Eckquadraten (E) und dem Mittelquadrat (M). Zusätzliche vergrößerte Darstellung eines Eckquadrat-Abschnitts der Zählkammer (rechts) bestehend aus 16 Kleinquadraten (K).

Da Trypanblau zelltoxische Eigenschaften besitzt, sollten gefärbten Proben nicht länger stehen gelassen werden, da es dadurch zu falsch-positiven Ergebnissen kommen kann. Nach geeigneter Verdünnung wurden jeweils $8 \mathrm{ml}$ der kombinierten Suspension in eine Neubauerkammer überführt und die Anzahl der ungefärbten Zellen von insgesamt 4 Großquadranten ausgewertet. Zur Ermittlung der Lebendzell-Gesamtzahl pro ml Zellkultur wurde die nachfolgende Formel 2 verwendet:

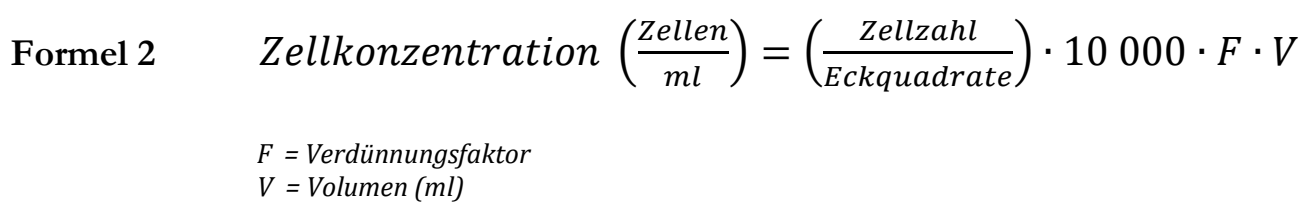

Analog dazu, wurde zusätzlich der Totzell-Anteil aller Quadranten ermittelt und berechnet, sowie Lebend- und Totzell-Anteile zu der Gesamtzellzahl addiert. 


\subsection{Zellkulturtechniken}

\subsubsection{Aliquotierung und Kyrokonservierung von Zellen}

Zur quantitativen Aufrechterhatung wurden Zellchargen aller vier L721.221-Zelllinien strategisch in regelmäßigen Zeitabständen eingefroren. Während die Lagerung von Zellkulturen bei $-80^{\circ} \mathrm{C}$ längerfristig keine gute Zellqualität gewährleistet, kann durch die Kryokonservierung von Proben in flüssigem Stickstoff bei $-196^{\circ} \mathrm{C}$ eine nahezu zeitlich unbegrenzte Lagerungsdauer erreicht werden. Vor der Kyrokonservierung wurden die L721.221-Zielzellen durch Zentrifugation bei $1500 \mathrm{rpm}$ für $5 \mathrm{~min}$ mit Bremse von ihrem jeweiligen Kulturmedium separiert. Danach wurde das Medium vorsichtig abgesaugt. Da das Einfrieren durch die Bildung von zahlreichen Eiskristallen einen strapaziösen Vorgang auf Zellebene darstellt, wurde während des Einfriervorgangs ein spezielles Zellmedium verwendet, um die zu konservierenden Zellen bestmöglich zu schützen. Es handelt sich um ein 1:1 Gemisch aus hitzeinaktiviertem fetalen Kälberserum (engl.: fetal calf serum, FCS) und einem mit 10\%iges sterilem Dimethylsulfoxid (DMSO) zugesetzten X-Vivo10-Medium. Das nach Zentrifugation verbleibende Zellsediment wird jeweils in $1 \mathrm{ml}$ des Schutzmediums resuspendiert. und schließlich auf die 1,8 $\mathrm{ml}$ Ampullen verteilt. Jede Ampulle besitzt danach ein Endvolumen von $1 \mathrm{ml}$ der jeweiligen Zellkultur. Die Ampullen wurden detalliert beschriftet und in einer geeigneten Kühlkiste für 1 Woche bei $-80^{\circ} \mathrm{C}$ gelagert. Danach wurden die Probeampullen für die Langzeitlagerung in einen Stickstofftank überführt.

\subsubsection{Auftauen kyrokonservierter Zellen}

Nach Entnahme der kyrokonservierten Probe aus dem Stickstofftank wurde die Ampulle mittels Handwärme aufgetaut. Bei dem Auftauen mehrerer Proben wurde alternativ ein $37^{\circ} \mathrm{C}$ Wasserbad verwendet, jedoch streng darauf geachtet, dass der Deckel der Ampullen dabei oberhalb des Flüssigkeitsspiegels blieb, um eine Kontamination der Probe zu vermeiden. Die flüssige Probe wurde mit $10 \mathrm{ml} \mathrm{FCS}$ in ein $15 \mathrm{ml}$ Falcon-Röhrchen gegeben und bei 1500 rpm für 10 min mit Bremse zentrifugiert. Das Auftauen von Zellen sollte möglichst rasch erfolgen, da das beim Einfrieren verwendete Frostschutzmittel DMSO in aufgetautem Zustand stark zelltoxisch wirkt. Während der Zentrifugation werden $25 \mathrm{~cm}^{2}$ CELLSTAR $^{\circledR}$ Zellkulturflaschen mit $5 \mathrm{ml}$ des spezifischen Kulturmediums vorbereitet und in das warme Wasserbad gestellt. Das Einfriermedium wird nach der Zentrifugation als Überstand 
verworfen. Das verbleibende Zellpellet kann in $1 \mathrm{ml}$ des Kulturmediums resuspendiert werden und in die vorbereiteten Kulturflaschen mit vorgewärmtem Medium überführt werden. Die Zellkulturflaschen werden anschließend in einen dafür vorgesehenen $37^{\circ} \mathrm{C}$ Inkubator mit 5\% $\mathrm{CO}_{2}$ bis zur weiteren Verwendung kultiviert.

\subsubsection{Kultivierung der L721.221-Zelllinien}

Nach dem Auftauen der L721.221-Zelllinien aus Stickstoff-Proben wurden die Zellen zunächst in $5 \mathrm{ml}$ (Selektions-)Medium in $25 \mathrm{~cm}^{2}$ CELLSTAR $^{\circledR}$ Zellkulturflaschen mit Standardschraubverschluss aufgenommen und für bis zu 1 Woche hochkant im Brutschrank kultiviert. Erst nachdem deutliche Stoffwechselaktivität und zahlenmäßiges Wachstum lichtmikroskopisch erkennbar war, erfolgte die Überführung der Suspensionskulturen in größere $75 \mathrm{~cm}^{2}$ CELLSTAR ${ }^{\circledR}$ Zellkulturflaschen mit einem Endvolumen von $20 \mathrm{ml}$. Wöchentlich wurde nun 1-2 Mal jede Zellkultur 1:5 gesplittet, wobei jeweils 16 ml der Kultur verworfen und durch frisches Tumor-Medium ersetzt wurden. In regelmäßigen Abständen wurden HLA-Oberflächenfärbungen durchgeführt, um die Qualität der Zellkulturtechnik zu kontrollieren (Abb. 20).
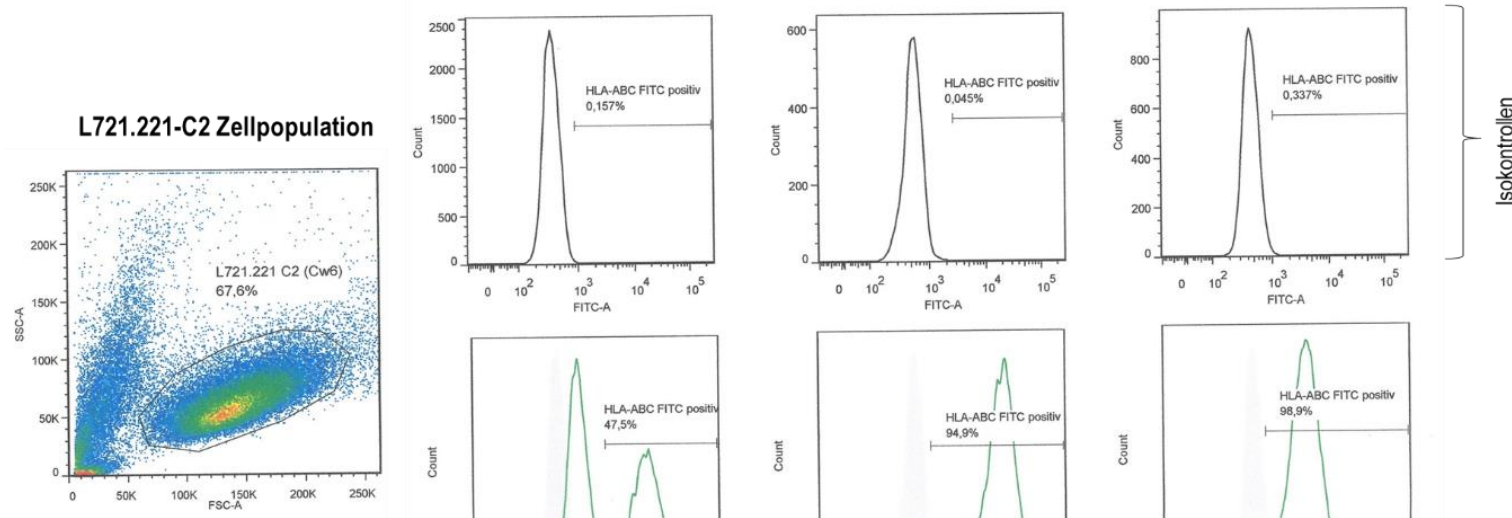

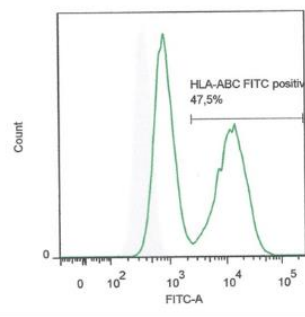

- $\operatorname{Tag} 1$ -

Zellkultur ohne Hygromycin $\mathrm{B}^{\circledast}$

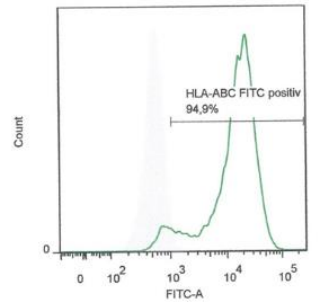

Tag 5 -

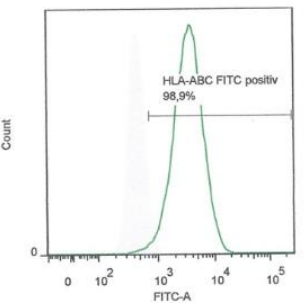

- Tag 10 -

Zellkultur nach Hygromycin $\mathrm{B}^{\circledR}$-Substitution

Abbildung 20 HLA-Oberflächenfärbung der verwendeten L721.221- C2 Zellkultur. Exemplarisch gezeigt ist die HLAOberflächenfärung der Zelllinie L721.221-C2 über den zeitlichen Verlauf von 10 Tagen während der Kultivierung. Erst nach Hinzugabe von Hygromycin $B^{\circledR}$ zu dem Basis-Tumormedium kommt es zur Selektionierung, sodass sich lediglich HLA-C positive Zielzellen in der durchflusszytometrischen Messung bestimmen lassen. 
Um während der Kultivierung sicherzustellen, dass die jeweiligen Zelllinien jeweils nur ein spezifisches HLA-Merkmal exprimierten, enthielten die dafür vorgesehenen Zellkulturmedien teilweise ein spezifisches Antibiotikum zur Zellselektion. Konkret wurde für die Zelllinie L721.221-Cw1 (HLA-C1) Geneticin ${ }^{\circledR}$ (G418-Sulfat), ein Gentamicin verwandtes, jedoch stärker antibiotisch wirksames Aminoglykosid, verwendet, während für die Zelllinie L721.221-Cw6 (HLA-C2) Hygromycin B ${ }^{\circledR}$, ein weiteres AminoglykosidAntibiotikum, als Selektionsmarker eingesetzt wurde. Vermittelt durch ein NeomycinGeneticin-Resistenzgen (Neor) bzw. E.coli Hygromycin-Resistenzgen (hyg or hph) wirkt die Selektion einer Vermehrung nicht transformierter Zellen in der Zellkultur entgegen. Aminoglykoside wirken über die Hemmung der Proteinbiosynthese von Zellen. Die für die Resistenzen gegen Geneticin ${ }^{\circledR}$ bzw. Hygromycin B ${ }^{\circledR}$ verantwortlichen Genregionen kodieren für sogenannte Aminoglykosid-Phosphotransferasen (APT). Diese phosphorylieren Aminoglykosid-Antibiotika an den Hydroxygruppen und unterdrücken damit ihre Wirkung. Die Zelllinien L721.221-ØHLA und L721.221-Bw4 wurden beide in dem BasisTumormedium kultiviert.

\subsubsection{Kultivierung der primären NK-Zellen}

Unmittelbar nach der Isolierung primärer NK-Zellen aus PBM-Zellen der Spenderblutproben wurden diese durch Hinzugabe von NK-Zellmedium auf eine Verdünnung von $5 \times 10^{5}$ Zellen pro $\mathrm{ml}$ in einem $50 \mathrm{ml}$ Falcon-Röhrchen eingestellt und für maximal 2 Tage bei $37^{\circ} \mathrm{C}$ und $5 \% \mathrm{CO}_{2}$ im Brutschrank inkubiert. Die NK-Zellen wurden am Isolationstag selbst oder am darauffolgenden Tag für den CD107-Degranulationsassay verwendet.

\subsection{Durchflusszytometrische Messungen}

Die Durchflusszytometrie beschreibt ein quantitatives Verfahren, das zur Analyse von physikalischen Zelleigenschaften sowohl für einzelne Zellen, als auch durch die Analyse von einer großen Anzahl von Zellen zur Unterscheidung verschiedener Zellpopulationen innerhalb einer Zellsuspension herangezogen werden kann. Mit Hilfe des Durchflusszytometers (engl:: flow cytometer) können Zellen durch Eigenfluoreszenz häufiger jedoch gekoppelt an fluoreszierende Trägerstoffe, anhand charakteristischer Eigenschaften voneinander unterschieden werden. Die fluoreszendierenden Antikörper binden hierbei an 
zelltypische Oberflächenmarker oder an intrazellulären Strukturen, was eine maschinelle Differenzierung ermöglicht. Für die vorliegende Forschungsarbeit wurde ein BD LSRFortessa $^{\mathrm{TM}}$ Cell Analyzer (Beckton Dickinson) als Durchflusszytometer verwendet, welcher über 4 Laser (blau / violett / rot / gelb) sowie 13 Filter im Aufbau verfügt. Die Abbildung 49 im Anhang zeigt die Emissionsspektren der verwendeten Fluorochrome und eine Auflistung des Laser-Detektionsarms des verwendeten Durchflusszytometers. Zur Darstellung und Abgrenzung verschiedener Zellpopulationen wurden monoklonale, Fluoreszenz-gekoppelte Antikörper (Tabelle 8) für extrazelluläre Färbungen verwendet.

Tabelle 8 Alphabetische Auflistung der verwendeten Fluorochrome für die Antikörperfärbungen und durchfusszytometrischen Messungen. [Quelle: Herstellerangaben von Beckmann Coulter Miltenyi Biotec, BD Pharmingen und $R+D$ Systems]

\begin{tabular}{|l|l|c|c|c|}
\hline $\begin{array}{l}\text { Fluorochrom } \\
\text { Bezeichnung }\end{array}$ & Abk. & $\begin{array}{c}\text { max. Absorption } \\
(\mathbf{n m})\end{array}$ & $\begin{array}{c}\text { max. Emission } \\
(\mathbf{n m})\end{array}$ & $\begin{array}{c}\text { Exzitation des Lasers } \\
(\mathbf{n m})\end{array}$ \\
\hline Allophycocyanin & APC & 650 & 661 & $633,635,647$ \\
Fluorescein-5-Isothiocyanat & FITC & 490 & 525 & 488 \\
Pacific Blue & PB & 410 & 455 & 405,407 \\
Phycoerythrin & PE & 490,565 & 578 & 488 \\
Phycoerythrincyanin & PE-Cy7 & 496,546 & 578 & 488 \\
\hline
\end{tabular}

$\mathrm{nm}: \quad$ Nanometer

Der Messvorgang während der Durchflusszytometrie kann im Hochdurchsatz bis zu 200.000 Ereignisse pro Sekunde registrieren. Die in dem Zellgemisch befindlichen losen Zellen können anhand ihrer charakteristischen Zellparameter einzelnen Zellpopulationen zuverlässig zugeornet werden und werden dabei gezählt. Die fluoreszenzmarkierten Zellen fließen in hoher Geschwindigkeit durch eine dünne Messkammer, die sogenannte Flusszelle (engl.: flow cell) des Durchflusszytometers, welche neben den Fluoreszenzdetektoren zusätzlich einen Vibrator zur Unterteilung des Flüssigkeitsstroms in kleine Tröpfchen beinhaltet. Dieser Prozess wird hydrodynamische Fokussierung genannt. Die eingestellte Tröpfchengröße ist dabei so klein gewählt, dass gerade eben eine vereinzelte Zelle hineinpasst (Abb. 21). Auf diese Weise entsteht maschinell forciert ein feiner Strom einzeln hintereinander aufgereihter Zellen, welcher mittels Laser angestrahlt wird (Polarisation) und ein charakteristisches Streulicht abgibt. Das Vorwärtsstreulicht (engl.: forward scatter, FSC) ist ein $\mathrm{Maß}$ für die Beugung des Lichtes im flachen Winkel und hängt maßgeblich vom Zellvolumen ab. Je voluminöser eine Zelle ist, desto größer ist das entstehende „flache“ Streulicht. Das Seitwärtsstreulicht (engl.: side scatter, SSC) ist dagegen ein Maß für die Brechung des Lichtes im rechten Winkel und nimmt, je differenzierter die Strukturen 
im Zytoplasma einer Zelle sind, zu. Dies betrifft neben der Größe und Beschaffenheit des Zellkerns, auch die Granularität der Zelle, sowie die Anzahl sich dort befindlicher Zellvesikel. Andere Geräte bieten als zusätzliche Option Zellen nicht nur zu messen, sondern auch räumlich zu ordnen, d.h. sie während des Messvorgangs je nach Färbung in unterschiedliche Reagenzgefäße zu sortieren. Ein Durchflusszytometer, welches mit dieser Funktion

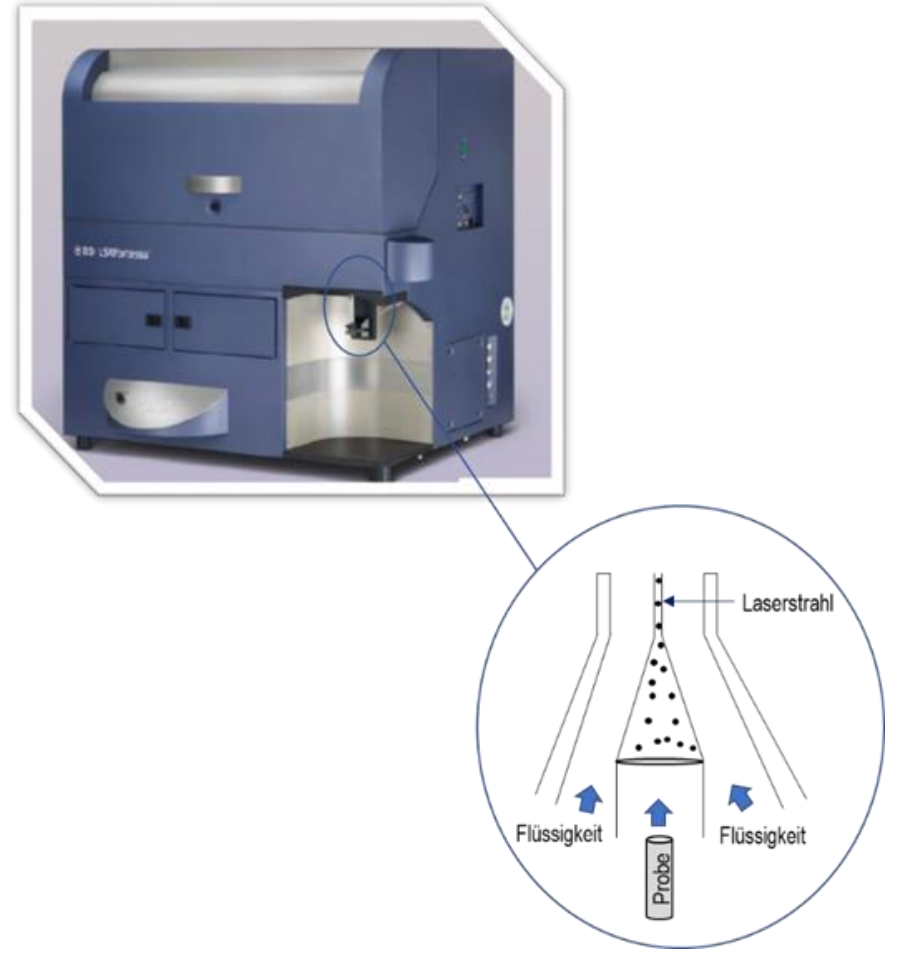

Abbildung 21 Darstellung des BD LSRFortessaTM Cell Analyzer mit seiner Flusszelle (blau umkreist). ausgestattet ist, nennt man auf Englisch „flow sorter“ oder „fluorescence-activated cell sorter“ (FACS). Beiden Gerätvarianten gemeinsam ist es, dass sie mindestens 50.000 bis 100.000 Zellen in wenigen Sekungen messen können und auf Grundlage der Zuordnung der Emissionswellenlängen mithilfe verschiedener Filter Fluoreszenzfarben messen und dann zellspezifischen Oberflächenmarkern zuordnen. Die Auswertung der ermittelten Daten erfolgte mittels FlowJo ${ }^{\circledR}$-Software.

\subsubsection{Oberflächenfärbung der L721.221-Zelllinien}

Durch die Verwendung spezifischer monoklonaler, Fluoreszenz-gekoppelter Antikörper wurden die verschiedenen L721.221-Zelllinien und die primären NK-Zellen experimentell auf die Anwesenheit von zellulären Oberflächenmarkern analysiert. Bei den L721.221Zelllinien wurde mittels Durchflusszytometrie die regelrechte HLA-Merkmalsausprägung auf der Zelloberfläche ( $\rightarrow$ vgl. Abschnitt 5.5) überprüft. Für die durchflusszytometrischen Anfärbungen wurden pro Ansatz jeweils 100.000 Zellen aus der Suspensionskultur entnommen und nach Überführung in ein Polypropylen (PP)-Rundboden-Röhrchen jeweils mit $500 \mu \mathrm{l}$ FACS-Puffer versehen bei $1500 \mathrm{rpm}$ für 5 min zentrifugiert. Der Überstand der gewaschenen Probe wurde verworfen und die Zellen in den im Röhrchen verbleibenden 100 $\mu \mathrm{l}$ FACS-Puffer resuspendiert. Anschließend wurde $1 \mu \mathrm{l}$ eines FITC-konjugiertem 
Antikörpers, je nach individueller Fragestellung, hinzupipettiert. Nach Antikörperzugabe wurde die Zellsuspension erneut gut durchmischt und in Dunkelheit für $30-45$ min bei $4^{\circ}$ C, bis zur erneuten Waschung bei 1500 rpm für 5 min, inkubiert. Durch Zugabe von 200 $300 \mu \mathrm{l}$ konservierender, 1\%iger Paraformaldehyd-PBS-Lösung konnten die gefärbten Zellen dunkel bis zu zwei Tagen bei $4^{\circ} \mathrm{C}$ bis zur Messung im Laborkühlschrank lichtgeschützt zwischengelagert werden.

Der Antikörper-Ansatz zur Analyse der Expression von HLA-Merkmalen ist in Tabelle 9 auf der nachfolgenden Seite zusammengefasst und beinhaltete neben einem Antikörper, der an alle HLA-Klasse-I-Moleküle bindet, einen weiteren Antikörper zur spezifischen Unterscheidung der serologischen HLA-B Untergruppe mit Bw4-Epitop. Letzterer sollte bei der HLA-Oberflächenmarkerprüfung lediglich bei der Zelllinie L721.221-Bw4 entsprechend positiv sein.

Tabelle 9 Auflistung der verwendeten Fluorochrom-konjugierten Antikörper für die Oberflächenfärbung der L721.221Zelllinien und Erläuterungen zu den erwarteten HLA-Oberflächenmerkmalen.

\begin{tabular}{|l|l|c|c|c|}
\hline Bezeichnung & HLA - & Verwendete & \multicolumn{2}{|c|}{ Erwartetes Ergebnis } \\
\cline { 4 - 5 } & Merkmal & Antikörper & 1 & 2 \\
\hline L721.221- $\varnothing$ HLA & kein HLA & Anti-HLA-ABC-Fitc 1 & negativ & negativ \\
\cline { 3 - 5 } L721.221- Bw4 & HLA-B & positiv & positiv \\
L721.221- Cw1 & HLA-C1 & & positiv & negativ \\
\cline { 3 - 5 } L721.221- Cw6 & HLA-C2 & Anti-HLA-Bw 4-Fitc 2 & positiv & negativ \\
\hline Negativ kontrolle & jew eils mit & Anti-Maus-IgG1-Fitc & & \\
\hline
\end{tabular}

\subsubsection{Immunphänotypisierung der Spender NK-Zellen}

Analog wurde bei den primären NK-Zellen der Spender mittels Oberflächenfärbung die prozentuale KIR-Expression bestimmt ( $\rightarrow$ vgl. Abschnitt 5.6). Zur Erleichterung der Abgrenzung verschiedener Lymphozytenpopulationen im NK-Zellisolat jedes Spenders, wurden in den durchflusszytometrischen Messungen zellspezifische Marker wie CD3, welches charakteristisch für T-Lymphozyten ist, und CD56 als Positivmarker für NK-Zellen, jeweils Fluorochrom-gekoppelt mitgeführt. Durch computergestützte Signaleingrenzung (engl.: gating) von Fluoreszenzsignalen während der durchflusszytometrischen Messung konnten innerhalb der $\mathrm{CD}_{5} 6^{+} \mathrm{NK}$-Zellen einerseits NK-Zellpopulationen mit diversen KIR-Rezeptoren (Total-KIR positiv), andererseits Populationen mit ausschließlich einem einzigen inhibitorischen KIR-Rezeptortyp auf der Zelloberfläche (Single-KIR positiv) 
differenziert werden. Die zur Analyse der KIR-Expression verwendeten Antikörper finden sich in Tabelle 10 aufgelistet.

Tabelle 10 Auflistung der verwendeten Fluorochrom-konjugierten Antikörper zur Analyse der KIR-Expression auf der Zelloberfläche der primären Spender NK-Zellen. Angaben für 100.000 Zellen/100 $\mu$ l: $1 \mu$ l Anti-CD3-PB, jeweils $5 \mu l$ KIRPE/APC-Antikörper, Anti-CD56-PE-Cy7 oder Anti-Maus-IgG1-PE.

\begin{tabular}{|l|l|}
\hline \multicolumn{1}{|c|}{ Merkmal } & \multicolumn{1}{|c|}{ Verwendete Antikörper } \\
\hline KIR2DL1,S1 & Anti-CD3-PB, Ant-CD56-APC, KIR2DL1,S1-PE \\
KIR3DL1,S1 & Ant-CD3-PB, Ant-CD56-APC, KIR3DL1,S1-PE \\
KIR2DL2,L3,S2 & Anti-CD3-PB, Ant-CD56-APC, KIR2DL2,L3,S2-PE \\
\hline Total-KIR2DL1+ & Anti-CD3-PB, Ant-CD56-APC, KIR2DL1-PE \\
Total-KIR3DL1+ & Ant-CD3-PB, Ant-CD56-APC, KIR3DL1-PE \\
Single-KIR2DL1+ & Ant-CD3-PB, Ant-CD56-PE-Cy7,KIR2DL2,L3,S2-PE, KIR3DL1-PE, KIR2DL1-APC \\
Single-KIR3DL1+ & Anti-CD3-PB, Ant-CD56-PE-Cy7,KIR2DL2,L3,S2-PE, KIR2DL1-PE, KIR3DL1-APC \\
\hline Negativkontrolle & Anti-CD3-PB, Ant-CD56-APC, Ant-Maus-IgG1-PE \\
\hline
\end{tabular}

Zur Immunphänotypisierung der primären NK-Zellen wurden 1 x $10^{6} / \mathrm{ml}$ der Zellsuspension eines Spenders nach Antikörperzugabe gut gemischt, mit Aluminium-Folie zur Verdunkelung abgedeckt und anschließend für $30-45$ min bei $4^{\circ} \mathrm{C}$ inkubiert. Danach folgten zwei Waschungen mit FACS-Puffer, jeweils für 5 min bei 1500 rpm. Der Überstand wurde verworfen und durch frischen FACS-Puffer ersetzt. Zuletzt wurden die Proben in etwa $300 \mu \mathrm{l}$ 1\%iger Paraformaldehyd-PBS-Lösung aufgenommen und bis zur Messung dunkel und bei $4^{\circ} \mathrm{C}$ gekühlt gelagert.

\subsubsection{CD107-Degranulationsassay}

Eine der Schlüsseleigenschaften von zytotoxischen Immunzellen, einschließlich $\mathrm{CD} 16^{+} \mathrm{CD} 56_{\text {dim }} \mathrm{NK}-$ Zellen, ist die Anwesenheit von intrazellulär vorgeformten lytischen Vesikeln mit zytotoxischen Granula. Auf ihrer inneren Membranseite befinden sich lysosomal-assoziierte Membranproteine, wie CD107a (LAMP-1) ${ }^{207}$ und CD107b (LAMP2) ${ }^{208}$, sowie der exosomalen Marker CD63 (LAMP-3, Granulophysin, Tetraspanin-30). ${ }^{209}$ Nach kontaktabhängiger Aktivierung von NK-Zellen durch Rezeptorinteraktion werden krankhaft-veränderte Zielzellen zur Lyse freigegeben. Intrazelluläre Vesikel werden entlang von Schienen aus Mikrotubuli in Richtung Zielzelle mobilisiert und unter Ausbildung einer sogenannten immunologischen Synapse nach extern freigesetzt (Exozytose). Bei dem Proteintransport des Golgi-Apparates und dem Sortierprozess von sekretorischen Lysosomen und zytolytischen Vesikeln spielen hierbei LYST und AP-3 eine wichtige Rolle. Kurz vor der zytotoxischen Degranulation fusioniert die Vesikelmembran mit der äußeren 
Plasmamembran der Effektorzelle. Dadurch werden die CD107-Moleküle zu einem vorrübergehenden Bestandteil der äußeren NK-Zellmembran und können methodisch auf der Oberfläche der Effektorzelle mittels spezifischer Antikörper angefärbt werden. Der Vorgang ist in Abbildung 22 detailliert dargestellt.

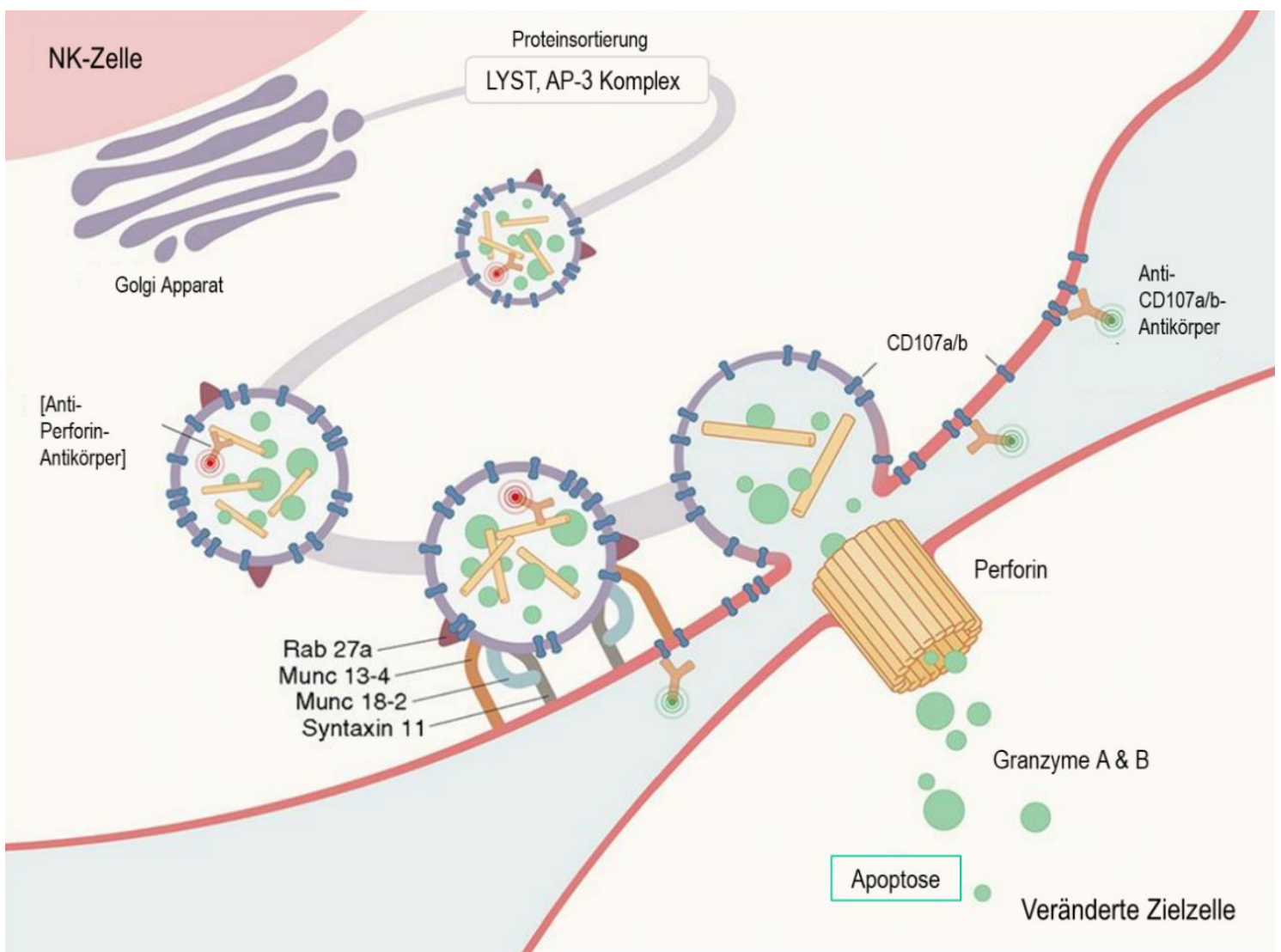

Abbildung 22 Schematische Darstellung des Degranulationsprozesses bei NK-Zellen nach Zielzellkontakt.. Die Vesikel-Exozytose führt zu einer vorrübergehenden Expression der Vesikelproteine CD107a (LAMP-1)- und -b (LAMP2) auf der äußeren NK-Zellmembran. Freigesetztes Perforin bildet eine porenartige Struktur an der Membran der Zielzelle, durch die Granzyme durchtreten und den Zelltod (Apoptose) vermitteln. Rab27a unterstützt den Transport und das Andocken von beladenen Vesikeln an die NK-Zellmembran. Munc18-2 und Syntaxin 11 ermöglichen die Fusion und Freisetzung von Granulatanteilen nach Priming durch Munc13-4. [Abbildung übersetzt mit Genehmigung von Hines, Nichols et al. (2017) $\left.{ }^{210}\right]$

Aufgrund der leichten Durchführbarkeit stellt der CD107-Degranulationsassay eine beliebte, nicht-radioaktive Methode dar und hat sich zur Messung der Effektorstärke von degranulierenden NK-Zellen etabliert. Unter den LAMPs macht CD107a den größten Anteil aus und stellt damit den wichtigsten Degranulationsmarker für die durchflusszytometrische Aktivitätsmessung dar. In den nachfolgenden funktionellen Untersuchungen wurde deshalb der CD107-Degranulationsassay als Messmethode gewählt und zum Vergleich der Allorekativität verschiedener Spender NK-Zellen herangezogen. 
Die für die Durchführung des CD107-Assays verwendeten fluoreszenzmarkierten Antikörper sind in Tabelle 11 übersichtlich zusammengefasst.

Tabelle 11 Auflistung der verwendeten Fluorochrom-konjugierten Antikörper zur Durchführung des CD107Degranulationsassays.

\begin{tabular}{|c|c|c|c|}
\hline $\begin{array}{l}\text { Verwendete } \\
\text { Antikörper }\end{array}$ & \multicolumn{2}{|c|}{$\begin{array}{l}\text { Fluorochrom- } \\
\text { bezeichnung }\end{array}$} & $\begin{array}{l}\text { Volumen- } \\
\text { angabe }\end{array}$ \\
\hline Anti-CD107a & \multicolumn{2}{|l|}{ FITC } & $4 \mu \mathrm{l}$ \\
\hline Anti-CD107b & \multicolumn{2}{|l|}{ FITC } & $4 \mu \mathrm{l}$ \\
\hline Anti-CD3 & \multicolumn{2}{|l|}{ PB } & $1 \mu \mathrm{l}$ \\
\hline Anti-CD56 & \multicolumn{2}{|c|}{ PE-Сy7 } & $5 \mu l$ \\
\hline Anti-KIR2DL1 & PE & APC & $4 \mu \mathrm{l}$ \\
\hline Anti-KIR3DL1 & PE & APC & $4 \mu l$ \\
\hline Anti-KIR2DL2,3/S2 & \multicolumn{2}{|l|}{ PE } & $1 \mu \mathrm{l}$ \\
\hline
\end{tabular}

Da die Kontaktstelle zwischen NK-Effektor- und Zielzelle nur vorübergend besteht und die LAMPs nach erfolgter Degranulation kontinuierlich in Form eines „Vesikelrecyclings“ reinternalisiert werden muss die Messung rasch und ohne Verzögerung erfolgen. Deshalb wurden Start- und Endzeitpunkt der Reaktion methodisch möglichst genau eingehalten, um eine Vergleichbarkeit der Proben zu ermöglichen. Die zeitliche Abfolge des Experimentes ist in Abbildung 23 nachzuvollziehen.

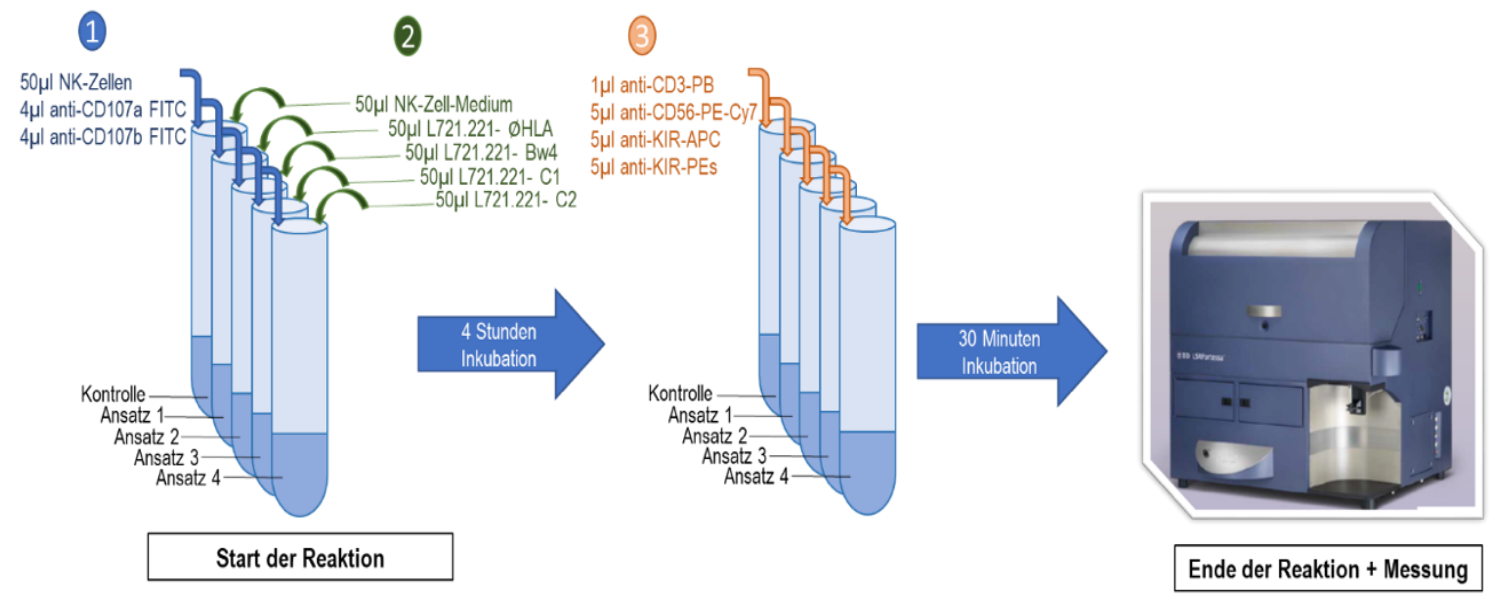

Abbildung 23 Darstellung der zeitlichen Abfolge bei der Durchführung des CD107-Degranulationsassays mit der NKZell-Probe eines Spenders. Die Hinzugabe spezifisch HLA-exprimierender Zellreihen der Linie L721.221 (Schritt (2)) markiert den Startzeitpunkt des Assays. Insgesamt erfolgen bis zur Messung zwei Antikörper-Färbungen (Schritt (1) und(3), welche durch ein vierstündiges Inkubationsintervall voneinander getrennt sind.

Für jeden der untersuchten Spender wurden 5 Rundboden-Röhrchen mit je $50 \mu \mathrm{l}$ NK-Zellen befüllt. Durch die Zugabe von je $4 \mu$ l fluoreszenzmarkierter Antikörper gegen CD107a und 
CD107b pro NK-Zell-Ansatz wurden die CD107-Moleküle nach vierstündiger Inkubation mit verschiedenen Zielzellen der Linie L721.221 im Brutschrank bei $37^{\circ} \mathrm{C}$ an der Oberfläche von aktivierten NK-Zellen markiert. Vor Ende der Inkubationszeit wurde die Zentrifuge auf $4^{\circ} \mathrm{C}$ heruntergekühlt. Vor dem Hereinstellen der Proben wurde ein direkter Reaktionsstopp durch Hinzugabe von $500 \mu \mathrm{l}$ eisgekühltem FACS-Puffer pro Ansatz herbeigeführt. Die Proben wurden dann bei $1500 \mathrm{rpm}$ für $5 \mathrm{~min}$ zentrifugiert. Anschließend wurde der Überstand verworfen, um die Probe von überschüssigen Antikörpern der ersten Färbung zu reinigen. Um die NK-Zellpopulation später von T-Lymphozyten abgrenzen zu können, wurden die Versuchszellen während der zweiten Färbung (Schritt 3; Abb. 23) mit CD3- und CD56-Antikörper behandelt. Der Ansatz wurde mit allen fluoreszenzmarkierten Antikörpern erneut für 30 min inkubiert. Nach erneuter $4^{\circ} \mathrm{C}$ Zentrifugation der Proben bei $1500 \mathrm{rpm}$ für $5 \mathrm{~min}$ wurde der Überstand mittels Saugpipette entfernt. Das gefärbte Zellpellet wurde in mindestens $200 \mu$ Paraformaldehyd aufgenommen und vorsichtig resuspendiert. Anschließend wurde die Probe bis zur Messung abgedunkelt kühl gelagert. Die Messung der Zellen erfolgte zeitnah durchflusszytometrisch im LSRFortessa $^{\text {TM }}$ Zellscanner. Bei den Messungen der CD107a/b-FITC-Fluoreszenzintensitäten der einzelnen Probeansätze ergaben sich charakteristische Aktivitätskurven, die als proportionales Maß die NK-Zell-Degranulation zu deuten waren. Die anschließende Auswertung erfolgte mittels FACS-basierter Methode nach Alter et al. ${ }^{211}$

\subsubsection{Auswertung der ermittelten FACS-Daten mittels FlowJo ${ }^{\circ}$-Software}

Die aufgenommenen Primärsignale der Durchflusszytometrie wurden in Form eines Streudiagramms dargestellt und softwaregestützt weiter systematisiert. Als Negativkontrollen wurden alle Proben mit Isotyp-Kontrollantikörper ohne Spezifität parallel mitgeführt, um Hintergrundsignale der verwendeten fluoreszenzmarkierten Antikörper aufzuzeigen und dadurch Messfehler zu minimieren. Der ermittelte Störwert wurde bei der Berechnung dem Endwert abgezogen. Die durchflusszytometrisch aufgenommenen Zellen wurden zunächst als Punktwolkendiagramm in einem orthogonalen Koordinatensystem dargestellt, bei dem die Ordinatenachse mit SSC gegen die Abszissenachse mit FSC aufgetragen wurde. Zur Identifizierung der $\mathrm{CD}_{5} 6^{+} \mathrm{NK}$-Zellen und Abgrenzung von insbesondere $\mathrm{CD}^{+} \mathrm{T}$ Lymphozyten wurden spezifische Marker-Antikörper verwendet $(\rightarrow$ vgl. Tabelle 11, Abschnitt 4.8.3). Durch das Setzen verschiedener Selektionsgrenzen (engl.: gating) konnten verschiedene Zellpopulationen in Bezug auf ihre Größe bzw. Granularität und im Anschluss 
infolge der An- oder Abwesenheit zuvor definierter Oberflächenproteine identifiziert und räumlich getrennt voneinander dargestellt werden. Diese selektive Eingrenzung ermöglichte im Falle der NK-Zellexperimente schließlich die Messung der Aktivitätslevel verschiedener NK-Zell-Populationen innerhalb der gespendeten NK-Zellen. Die Aktivitätsanalyse nach CD107-Degranulationsassay der jeweiligen NK-Zell-Proben erfolgte für drei Populationskriterien: 1. Aktivitätsanalyse der gesamten Spender NK-Zellen, 2. Degranulation von Total-KIR positiver NK-Zellen und 3. Degranulation von Single-KIR positiver NK-Zellen. Alle durchflusszytometrisch ermittelten Daten nach Kontakt der NKZell-Popultionen mit den verschiedenen L721.221-Zielzellen wurden im Anschluss mit Hilfe der FlowJo ${ }^{\circledR}$-Software (Version 10.5.0) analysiert und ausgewertet.

Zur besseren Übersicht findet sich in Abbildung 24 die grundlegende Auswertungsstrategie, exemplarisch für die Total-KIR2DL1 ${ }^{+}$positiven NK-Zell-Population einer Spenders ohne Kontakt mit einer L721.221-Zielzelle, dargestellt.
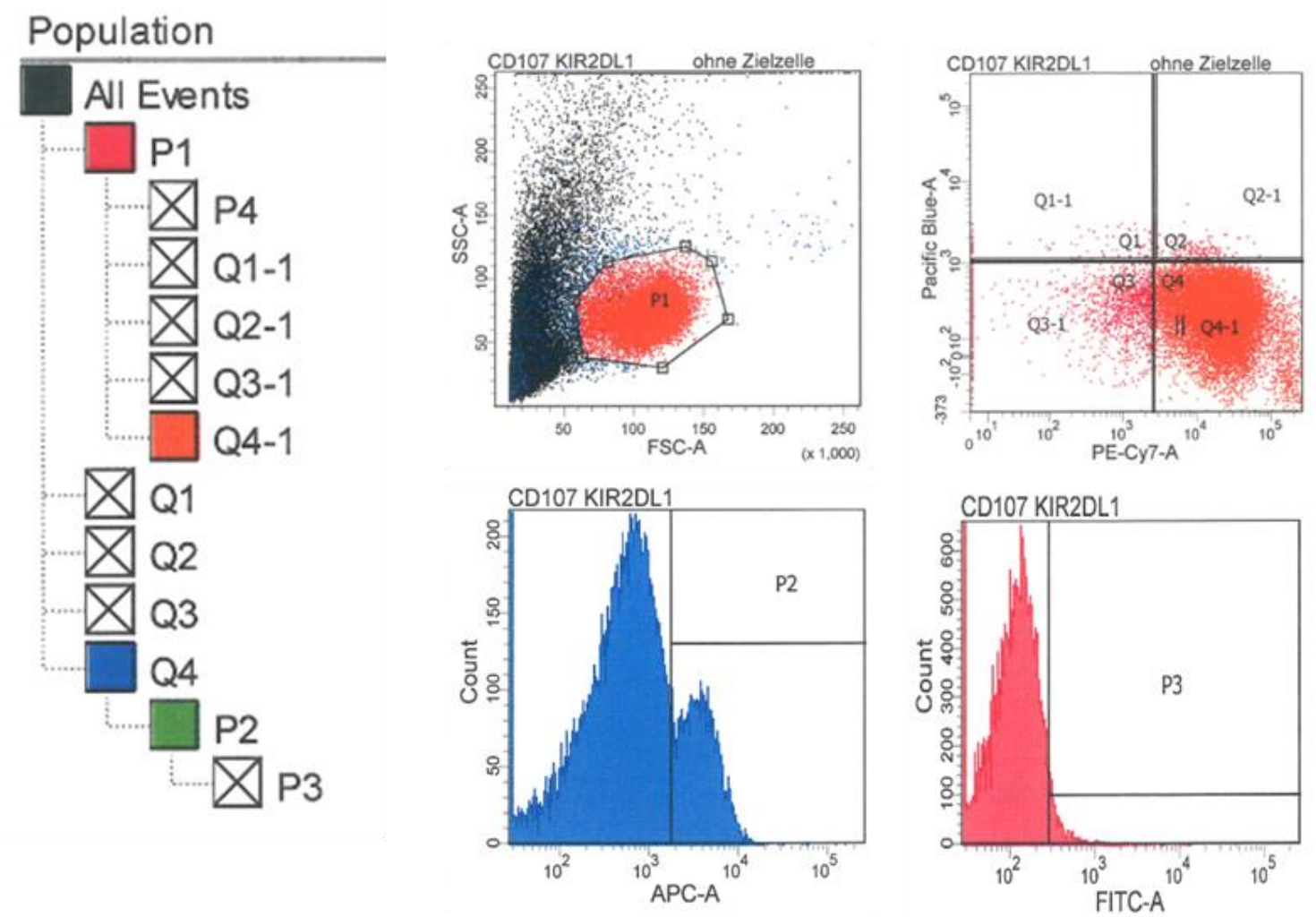

Abbildung 24 Darstellung der allgemeinen Gating-Strategie während der FACS-Messungen, am Beispiel von Spender 9. Der eingegrenzte Bereich (P1) innerhalb des Punktwolkendiagramms zeigt die vitale Immunzell-Fraktion nach NKZell-Isolation aus PBMZs ( $\rightarrow$ vgl. Abschnitt 4.5). Quadrant Q4 entspricht den davon CD3-/ CD56+ Lymphozyten, welche der Population der gesamte NK-Zellen entspricht. Mittels APC-Färbung lassen sich daraus in der Histogrammansicht die Total-KIR2DL1 positiven NK-Zellen (P2) eingrenzen, welche innerhalb der Isokontrolle (ohne Zielzellkontakt), wie erwartet, keine CD107a-FITC-Aktivität (P3) zeigten. 


\section{Ergebnisse}

\section{Teil 1: Ergebnisse der KIR- und HLA-Typisierung der NK-Zell-Spender}

\subsection{KIR-Genotypisierung mittels KIR-SSP}

Zur Genotypisierung wurde mittels SSP-Technik der genetische KIR-Umfang der 20 NKZell-Spender untersucht. Das Verfahren entscheidet dabei anhand einer Binominalverteilung, ob kodierende genetische Information für einen KIR-Rezeptor vorliegen (KIR positiv; $\mathrm{KIR}^{+}$) oder nicht (KIR negativ; KIR) ist. Tabelle 12 zeigt eine übersichtliche Zusammenstellung der KIR-SSP Ergebnisse der 20 Spender. Mit Ausnahme von Spender 13, zeigen alle Spenderprofile ein positives Ergebnis für beide in der Studie untersuchten Killerzell-Immunoglobulin-ähnlichen-Rezeptoren KIR2DL1 und KIR3DL1. Auffallend ist, dass die Gene für KIR2DL5A, KIR2DS1 und KIR2DS5 im untersuchten Kollektiv selten mit einer Wahrscheinlichkeitsfrequenz von $15 \%$ auftreten, KIR3DS1 sogar nur in 10\% der Fälle (2 von 20 Spendern).

Tabelle 12 Übersicht der Ergebnisse des KIR-Profils (KIRom) von Spender 1 bis 20. Bei Spender 10 zeigen sich beispielsweise, bis auf einiger Allele des aktivierenden Rezeptors KIR2DS4, alle weiteren KIRs genetisch ausgeprägt. Die in der vorliegenden Arbeit untersuchten KIR-Gene sind farbig hinterlegt. [Abkürzungen: männlich (m) und weiblich (w)]

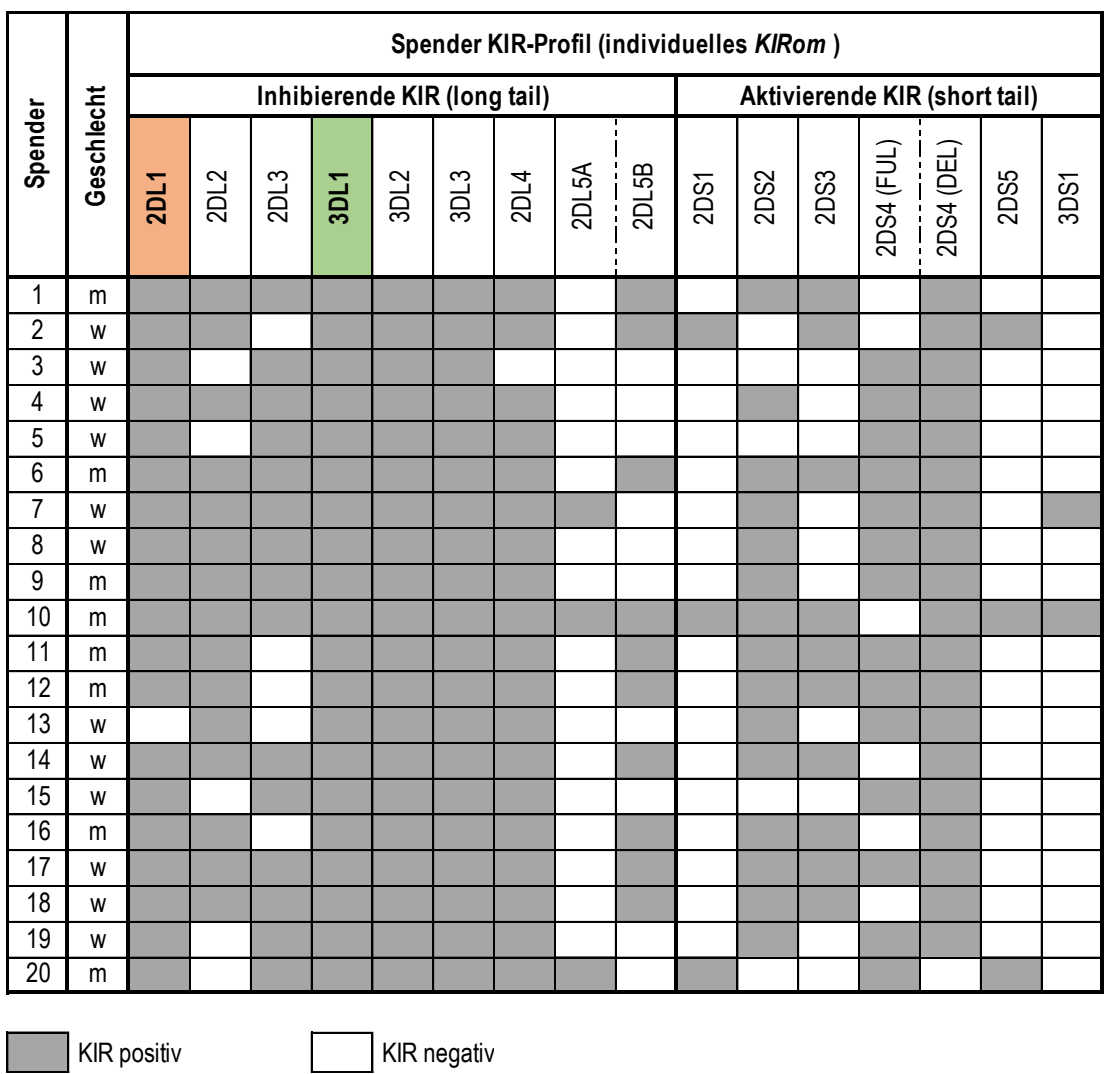




\subsubsection{Haplotyp-Bestimmung}

Anhand der KIR-Genotypisierung konnte das genetische KIR-Repertoire, d.h. die An- oder Abwesenheit von KIR-Genen, der 20 Spender untersucht werden. Im Anschluss wurden die Spender einem der beiden vordefinierten Haplotypen AA oder Bx zugeordnet. Die Sequenzdiversität innerhalb einzelner Haplotypen variiert zwischen der zentromerischen und telomerischen Hälfte des KIR-Genlocus. Die Gene für KIR2DL5, -2DS5 und -2DS3 bilden Ausnahmen, da sie sich sowohl zentromerisch als auch telomerisch innerhalb des Genlocus befinden können ( $\rightarrow$ vgl. Abb. 5, Abschnitt 1.3.2). Spender mit identischem Haplotypen können sich sowohl vom Geninhalt als auch durch abweichende, polymorphe KIR-Allele innerhalb der einzelnen Genabschnitte voneinander unterscheiden. Die HaplotypBestimmung (Haplotypisierung) der Spender ergab von 20 Spendern insgesamt $n=3$ mit einem Haplotyp der Gruppe AA und n=17 mit einem Haplotyp der Gruppe Bx (Tabelle 13).

Tabelle 13 Anhand des Genumfangs aktivierender KIRs (aKIRs) wurde der Haplotyp der Spender 1 - 20 bestimmt $(\rightarrow$ vgl. Abschnitt 1.3.2). Haplotyp-AA Spender besitzen ausschließlich Gene, die dem Haplotypen A zugeordnet werden. Haplotyp-Bx Träger dagegen mindestens ein nicht zu Haplotyp-AA passendes KIR-Gen.

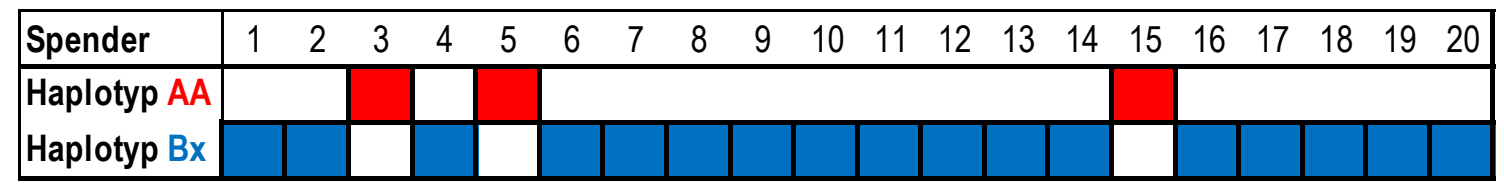

\subsection{Selektive HLA-Typisierung der Spender}

HLA-Moleküle der Klasse I (MHC-I) fungieren als Liganden für KIR2DL1 und KIR3DL1 und können anhand von epitopischen Motiven in HLA-C Gruppe C1 (Ser77/Asn80), HLAC Gruppe C2 (Asn77/Lys80) sowie in die HLA-B Gruppen Bw4 und Bw6 eingeteilt werden. Die Unterschiede ergeben sich hierbei jeweils aus der Aminosäurenstruktur der $\alpha 1$-Helix der HLA-Moleküle ( $\rightarrow$ vgl. Tabelle 2, Abschnitt 1.3.3). KIR2DL1 erkennt HLA-C C2 mit einem Asparagin an Aminosäuren(AS)-Position 77 und einem Lysin an der AS-Position 80. ${ }^{98,100}$ KIR3DL1 bevorzugt die Bindung an die $\alpha_{1}$-Kette eines Bw4-Epitop tragenden HLA-A beziehungsweise vornehmlich HLA-B Moleküls ( $\rightarrow$ vgl. Abb. 7, Abschnitt 1.3.3).

Die Spender MHC-I-Umwelt, in der KIRs exprimiert werden, scheint Einfluss auf die Ausbildung, d.h. Reifung und Lizensierung der jeweiligen NK-Zellen im Organismus zu nehmen. ${ }^{109,212,213}$ Da dies auch die spätere NK-Zell-Effektivität in der Erkennung und Abtötung verschiedener Fremdzellen bedingen könnte, wurden die Ergebnisse der selektiven 
HLA-Typisierung der Genloci für HLA-A, -B und -C in der funktionellen Analyse mitberücksichtigt. Tabelle 14 zeigt eine Übersicht der im Spenderorganismus exprimierten MHC-I-Liganden nach der HLA-Typisierung der 20 Studienteilnehmer. Für die spätere funktionelle Analyse wurden die NK-Zell-Spender entsprechend ihrer HLA-Allele einem spenderspezifischen MHC-I-Profil zugeordnet.

Tabelle 14 Ergebnisse der selektiven HLA-Typisierung (Genloci für HLA-A, -B und -C) der 20 untersuchten Spender, welche Liganden von KIR2DL1 und KIR3DL1 darstellen.

\begin{tabular}{|c|c|c|c|}
\hline MHC-I-Ligand & $\mathrm{C} 2 / \mathrm{C2}$ & $\mathrm{C} 1 / \mathrm{C} 2$ & $\mathrm{C} 1 / \mathrm{C} 1$ \\
\hline \multirow{8}{*}{ 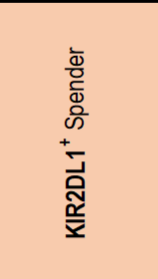 } & 8 & 1 & 2 \\
\hline & 11 & 3 & 5 \\
\hline & 17 & 4 & 6 \\
\hline & 20 & 9 & 7 \\
\hline & & 10 & 12 \\
\hline & & 14 & 16. \\
\hline & & 16 & 15 \\
\hline & & 18 & 19 \\
\hline
\end{tabular}

\begin{tabular}{|c|c|c|c|}
\hline MHC-I-Ligand & Bw4/Bw4 & Bw4/Bw6 & Bw6/Bw6 \\
\hline \multirow{8}{*}{ 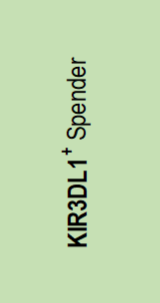 } & 1 & 4 & 2 \\
\hline & 3 & 5 & 6 \\
\hline & 8 & 9 & 7 \\
\hline & 20 & 10 & 11 \\
\hline & & 14 & 12 \\
\hline & & 16 & 13 \\
\hline & & 17 & 15 \\
\hline & & 15 & 19 \\
\hline
\end{tabular}

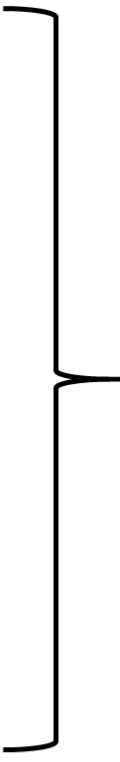

\begin{tabular}{|c|l|l|l|}
\hline $\begin{array}{c}\text { Spenderspezifisches } \\
\text { MHC-I- Profil }\end{array}$ & Kriterium & $\begin{array}{l}\text { Spender- } \\
\text { anzahl }\end{array}$ & Gesamt \\
\hline C2- & $(\mathrm{C} 1 / \mathrm{C} 1)$ & $\mathrm{n}=7$ & $\mathrm{n}=7$ \\
\hline $\mathrm{C} 2+$ & $(\mathrm{C} 1 / \mathrm{C} 2)$ & $\mathrm{n}=8$ & $\mathrm{n}=12$ \\
$(\mathrm{C} / \mathrm{C} 2)$ & $\mathrm{n}=4$ & \\
\hline Bw4+ & $\begin{array}{l}(\mathrm{Bw} 4 / \mathrm{Bw} 4) \\
(\mathrm{Bw} 4 / \mathrm{Bw} 6)\end{array}$ & $\mathrm{n}=4$ & $\mathrm{n}=6$ \\
\hline Bw4- & $(\mathrm{Bw6} / \mathrm{Bw6})$ & $\mathrm{n}=8$ & $\mathrm{n}=8$ \\
\hline
\end{tabular}

Spender 14 trägt das KIR3DL1-Gen, zeigt aber keine Oberflächenexpression. Für Spender 18 liegen keine funktionellen Daten vor.

Die selektive HLA-Typisierung zeigt bei insgesamt 4 Spendern homozygote HLA-C Allele (C2/C2) sowie 8 weitere Spender, die heterozygot C2 positiv sind (C1/C2). Damit gehören insgesamt 12 Spender dem MHC-I-Profil C2+ (positiv) an. Die restlichen 7 KIR2DL1+ Spender werden der Ligandengruppe HLA-C2- (C2 negativ, C1/C1) zugezählt. Bezogen auf die Expression von Bw4 ist die Mehrheit der Spender ( $\mathrm{n}=10)$ von ihrem MHC-I-Profil Bw4+, die verbleibenden 8 Spender zeigen ein Bw4 negatives MHC-I-Profil. Das spenderspezifische MHC-I-Profil wurde in funktionellen Experimenten dafür verwendet, die alloreaktiven CD107-Aktivitätsergebnisse der Studienteilnehmer unter dem Aspekt der MHC-I-abhängigen Ausbildung der verwendeten NK-Zellen zu untersuchen $(\rightarrow$ vgl. Abschnitt 5.8.2). Eine umfassendere Tabelle mit Aufführung der spenderspezifischen HLAA, -B und -C Allele befindet sich in der Tabelle 30 des Anhangs. 


\subsection{Ergebnisse der allelischen KIR2DL1-Subtypisierung}

Die KIR2DL1-Allele der ausgewählten 20 Spender wurden mittels PCR nach Sanger ermittelt. Die für die Vervielfältigung der Nukleotidsequenzen verwendeten Primerpaare sind in Tabelle 27 des Anhangs aufgeführt. Zum Ausschluss möglichst vieler Ambiguitäten wurden die Sequenzierung aller 8 kodierenden Exone des KIR2DL1-Gens gewählt (Abb. 25). Aktuell sind für das KIR2DL1-Gen 66 Allele, inklusive 2 Nulllallele, bekannt.

\begin{tabular}{|c|c|c|c|c|c|c|c|c|c|}
\hline KIR2DL1 & Exon 1 & Exon 2 & Exon 3 & Exon 4 & Exon 5 & Exon 6 & Exon 7 & Exon 8 & Exon 9 \\
\hline Länge (bp) & $\begin{array}{ll}5^{\prime} & 34\end{array}$ & 36 & 282 & 300 & 294 & 51 & 102 & 53 & $1773^{\prime}$ \\
\hline $\begin{array}{l}\text { Variable } \\
\text { Positionen }\end{array}$ & 1 & 0 & 0 & 14 & 12 & 2 & 6 & 3 & 7 \\
\hline
\end{tabular}

\begin{tabular}{|lc|}
\hline \multicolumn{2}{|c|}{ KIR2DL1-Gen } \\
\hline Polymorphismen & 45 \\
Allele & 64 \\
Nullallele & 2 \\
Proteine & 36 \\
\hline
\end{tabular}

Abbildung 25 Aufreihung der Genabschnitte (Exon 1 - 9) des NK-Rezeptors KIR2DL1, inklusive Basenpaar(bp)-Länge und Anzahl bisher bekannter variabler Stellen (Polymorphismen) in Bezug zum Referenzallel KIR2DL1*0010101. Je länger der Genabschnitt ist, desto mehr variable Stellen sind bisher beschrieben. Exon 3, als Pseudogenabschnitt, wurde hierbei vernachlässigt (gestrichelte Markierung). [Stand Januar 2019, Quelle: https://www.ebi.ac.uk/ipd//kir ]

Die Entdeckung neuer KIR-Allele wird ganzjährlich online in der Immuno Polymorphism Database (IPD) veröffentlicht. Sie wird von dem EMBL-EBI mit Sitz in Cambridge (UK), als Teil des European Molecular Biology Laboratory, verwaltet. Zur Erleichterung der Auswertung wurden alle bislang in der IPD bestätigten Allele inklusive ihrer genetischen „Mismatch-Positionen“ für beide KIR-Gene chronologisch in jeweils eine Excel-Tabelle kopiert ( $\rightarrow$ siehe Tabelle 33, Anhang). Danach wurden nach manueller Auswertung der Sequenzen, die zum Referenzgen abweichenden Nukleotidpositionen in die Tabelle für jeden Spender eingetragen. Mittels Ausschlussverfahren wurden nachfolgend die zwei möglichen Allele pro Spender ermittelt.

In Tabelle 15 auf der nachfolgenden Seite finden sich die Ergebnisse der Allelbestimmung der 20 Spender zusammengefasst. Spender 5 zeigte differente Positionen in Exon 5 (Positionen 179, 180, 238) und Exon 9 (Position 37) und konnte keinem bekannte Allel eindeutig zuordnen werden. Für die Auswertung wurden bei 4 abweichenden Polymorphismen die Allele KIR2DL1*00302/*00602 mit größtmöglicher Ähnlichkeit gewählt. Die genetische Sequenzierung bei Spender 13 ergab bei negativer KIR-SSP und bestätigter fehlender KIR2DL1-Oberflächenexpression eine nicht beschriebene KIR2DL1*02201/*023-ähnliche Nullallelvariante. Insgesamt zeigten sich 9 abweichenden Positionen in 3 unterschiedlichen Exonen (Exon 5: Positionen 34, 84, 179, 212, 214; Exon 7: Positionen 9, 10, 98; Exon 8: Position 32). 
Teil 1: Ergebnisse der KIR- und HLA-Typisierung der NK-Zell-Spender

Tabelle 15 Auflistung der gefundenen KIR2DL1-Allele, sowie deren Allelfrequenz innerhalb der Studiengruppe. (Detailierte Ansicht mit den Abweichungen zu dem Referenzallel KIR2DL1*0010101 in Tabelle 34 des Anhangs)

\begin{tabular}{|c|l|l|}
\hline \multicolumn{3}{|c|}{ KIR2DL1 [Referenzallel: $\left.2 \mathrm{DL} 1^{*} 0010101\right]$} \\
\hline Spender & \multicolumn{2}{|c|}{ Spenderallele } \\
\hline 1 & $2 \mathrm{DL} 1^{*} 00403$ & $2 \mathrm{DL} 1^{*} 005$ \\
\hline 2 & $2 \mathrm{DL} 1^{*} 00401$ & $2 \mathrm{DL} 1^{*} 00403$ \\
\hline 3 & $2 \mathrm{DL} 1^{*} 001$ & $2 \mathrm{DL} 1^{*} 00201$ \\
\hline 4 & $2 \mathrm{DL} 1^{*} 00201$ & \\
\hline 5 & $2 \mathrm{DL} 1^{*} 00302^{4}$ & $2 \mathrm{DL} 1^{*} 00602^{4}$ \\
\hline 6 & $2 \mathrm{DL} 1^{*} 00403$ & $2 \mathrm{DL} 1^{*} 00302$ \\
\hline 7 & $2 \mathrm{DL} 1^{*} 00403$ & $2 \mathrm{DL} 1^{*} 00401$ \\
\hline 8 & $2 \mathrm{DL} 1^{*} 00301$ & $2 \mathrm{DL} 1^{*} 00302$ \\
\hline 9 & $2 \mathrm{DL} 1^{*} 00601$ & $2 \mathrm{DL} 1^{*} 001$ \\
\hline 10 & $2 \mathrm{DL} 1^{*} 01101$ & $2 \mathrm{DL} 1^{*} 005$ \\
\hline 11 & $2 \mathrm{DL} 1^{*} 00403$ & $2 \mathrm{DL} 1^{*} 00401$ \\
\hline 12 & $2 \mathrm{DL} 1^{*} 00403$ & $2 \mathrm{DL} 1^{*} 00401$ \\
\hline 13 & $2 \mathrm{DL} 1^{*} 02201 \mathrm{~N}^{\text {neu }}$ & $2 \mathrm{DL} 1^{*} 023 \mathrm{~N}^{\text {neu }}$ \\
\hline 14 & $2 \mathrm{DL} 1^{*} 01101$ & $2 \mathrm{DL} 1^{*} 00602$ \\
\hline 15 & $2 \mathrm{DL} 1^{*} 00302$ & $2 \mathrm{DL} 1^{*} 00201$ \\
\hline 16 & $2 \mathrm{DL} 1^{*} 00601$ & $2 \mathrm{DL} 1^{*} 001$ \\
\hline 17 & $2 \mathrm{DL} 1^{*} 017$ & $2 \mathrm{DL} 1^{*} 00403$ \\
\hline 18 & $2 \mathrm{DL} 1^{*} 00401$ & $2 \mathrm{DL} 1^{*} 00201$ \\
\hline 19 & $2 \mathrm{DL} 1^{*} 01201$ & $2 \mathrm{DL} 1^{*} 001$ \\
\hline 20 & $2 \mathrm{DL} 1^{*} 00302$ & $2 \mathrm{DL} 1^{*} 01201^{\text {neu }}$ \\
\hline & & \\
\hline
\end{tabular}

\begin{tabular}{|l|c|}
\hline $\begin{array}{c}\text { KIR2DL1 } \\
\text { Allele }\end{array}$ & Allelfrequenz (\%) \\
\hline $2 \mathrm{DL} 1^{*} 001$ & $20 \%$ \\
\hline $2 \mathrm{DL} 1^{*} 00201$ & $20 \%$ \\
\hline $2 \mathrm{DL} 1^{*} 00301$ & $5 \%$ \\
\hline $2 \mathrm{DL} 1^{*} 00302$ & $25 \%$ \\
\hline $2 \mathrm{DL} 1^{*} 00401$ & $25 \%$ \\
\hline $2 \mathrm{DL} 1^{*} 00403$ & $35 \%$ \\
\hline $2 \mathrm{DL} 1^{*} 005$ & $10 \%$ \\
\hline $2 \mathrm{DL} 1^{*} 00601$ & $10 \%$ \\
\hline $2 \mathrm{DL} 1^{*} 00602$ & $10 \%$ \\
\hline $2 \mathrm{DL} 1^{*} 01101$ & $10 \%$ \\
\hline $2 \mathrm{DL} 1^{*} 01201$ & $5 \%$ \\
\hline $2 \mathrm{DL} 1^{*} 01201^{\text {neu }}$ & $5 \%$ \\
\hline $2 \mathrm{DL} 1^{*} 017$ & $5 \%$ \\
\hline $2 \mathrm{DL} 1^{*} 02201 \mathrm{~N}^{\text {neu }}$ & $5 \%$ \\
\hline $2 \mathrm{DL} 1^{*} 023 \mathrm{~N}^{\text {neu }}$ & $5 \%$ \\
\hline
\end{tabular}

$\Delta=$ abweichende Nukleotidsequenz; größte Ähnlichkeit zu den Allelen KIR2DL1*00302/*00602.

Eine detaillierte Auflistung der Referenz-Abweichungen der untersuchten KIR2DL1-Allele findet sich in Tabelle 34 des Anhangs tabellarisch zusammengefasst.

\subsubsection{Untersuchung auf relevante KIR2DL1-Polymorphismen}

Arbeiten aus dem Jahr 2009 von Bari et al. untersuchten erstmals verschiedene KIR2DL1Polymorphismen hinsichtlich funktioneller Aspekte. Die Untersuchungen postulierten, dass ein allelischer Polymorphismus an der Aminosäuren(AS)-Position 245 (Exon 7) des KIR2DL1-Gens eine mögliche signifikante Rolle für die Funktion des zugehörigen Rezeptors haben könnte. ${ }^{203}$ Die AS-245 befindet sich strukturell in der Transmembrandomäne des fertigen KIR2DL1-Rezeptors. In weiteren Arbeiten zeigte sich, dass ein Arginin-Rest an dieser Position Vorteile nach der allogenen HSZT für betreffende Empfänger hatte. ${ }^{214}$ 
Die in der vorliegenden Arbeit bestimmten Allele wurden deshalb nach der Aminosäurenposition 245 gruppiert (Abb. 26) und im zweiten Teil der Forschungsarbeit funktionell untersucht $(\rightarrow$ vgl. Abschnitt 5.8.3).
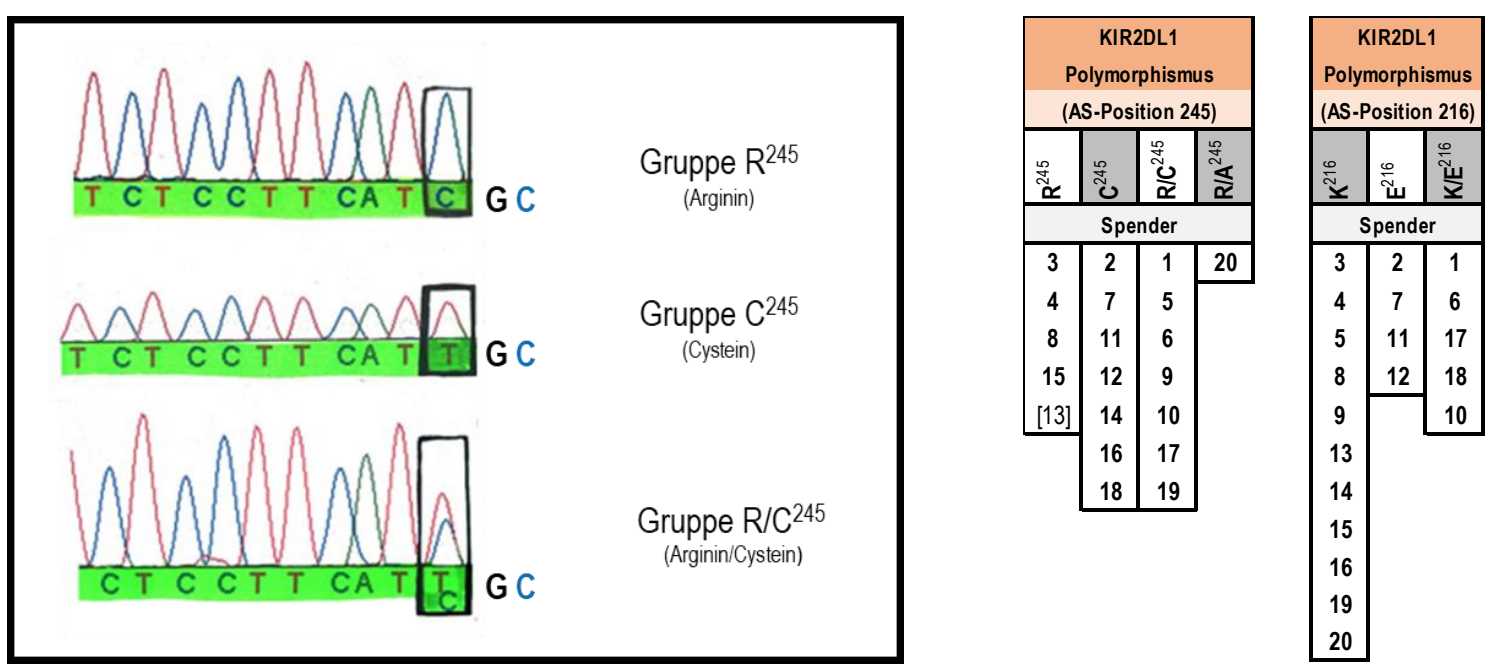

Abbildung 26 Dargestellt sind Beispiele für DNA-Sequenzen für den 245-Polymorphismus (links). Die Buchstaben entsprechen den vier DNA-Basen Adenin (A), Guanin (G), Cytosin (C) und Thymidin (T). Daneben sind die gruppierten Ergebnisse der Spender 1- 20 bezogen auf beide durch Bari et al. beschriebene KIR2DL1- Polymorphismen dargestellt (rechts). Der eckig umklammerte Spender 13 exprimiert kein KIR2DL1 auf seiner Zelloberfläche.

Obwohl die Mehrheit der bis dato entdeckten KIR2DL1-Allele ( $\mathrm{n}=59$ ) die Aminosäure (AS) Arginin an AS-Position $245\left(\mathrm{R}^{245}\right)$ exprimieren und gerade mal 13 Allele die AS Cystein $\left(\mathrm{C}^{245}\right)$, zeigte sich in der Kohorte der 20 untersuchten Spendern ein ausgewogenes Verhältnis von $\mathrm{R}^{245}$-Allelen ( $\left.\mathrm{n}=5\right) \mathrm{zu} \mathrm{C}^{245}$-Allelen $(\mathrm{n}=5)$. Der größte Teil der Spender zeigten Allele für $\mathrm{R} / \mathrm{C}^{245}(\mathrm{n}=8)$. Spender $20\left(2 \mathrm{DL} 1 * 00301 / * 01201^{\text {new }}\right)$ zeigte eine neue heterozygote Variante $(\mathrm{C} / \mathrm{G}$ statt $\mathrm{C} / \mathrm{T}$ ) in Exon 7 (Nukleotidposition 81), resultierend in einer Kombination der basischen AS Arginin mit der hydrophoben AS Alanin (R/A $\left.\mathrm{A}^{245}\right)$.

Auch die Einteilung der Spender hinsichtlich eines weiteren durch Bari et al. beschriebenen Polymorphismus an Aminosäurenposition 216 wird in Abbildung 26 (siehe oben) dargestellt. Die Aminosäure 216 befindet sich in der membrannahen Stammdomäne des Rezeptors und ist genetisch im Exon 6 kodiert. Dieser Polymorphismus wurde bei der Auswertung der NK-Aktivitätsmessungen jedoch vernachlässigt, da für diesen Polymorphismus in der Literatur keine signifikanten Funktionalitätsunterschiede beschrieben sind. Dennoch fällt bei der Betrachtung beider durch Bari et al. beschriebenen Polymorphismen auf Allelebene eine interessante Homogenität in der allelischen Verteilung auf. Bei der Gegenüberstellung der bekannten KIR2DL1-Allele in Hinblick auf die Polymorphismen $C^{245}$ (Cystein) und $\mathrm{E}^{216}$ (Glutaminsäure), wie in Tabelle 16 dargestellt, fällt auf, dass nur drei Allele auf beiden Seiten, nämlich 2DL1*00601, *0060, *010, *028, *035 
*036, dieser Kongruenzbeziehung widersprechen. Alle untersuchten Spender mit K/E ${ }^{216}{ }_{-}$ Polymorphismus in der Gruppe R/C $\mathrm{C}^{245}$ wieder. Gleiches gilt für sämtliche Spender der $\mathrm{E}^{216}$ Gruppe in Bezug auf den $C^{245}$-Polymorphismus, sowie immerhin 5 von 11 Spendern der $\mathrm{K}^{216}$-Gruppe in Bezug auf den $\mathrm{R}^{245}$-Polymorphismus.

Tabelle 16 Darstellung der allelischen Kongruenzbeziehung der Polymorphismen an den AS-Positionen 245 und 216 des KIR2DL1Gens. Die Überlappungen hinsichtlich der Polymorphismen C245 (Cystein) und $E^{216}$ (Glutaminsäure) sind durch die rote Markierung sichtbar gemacht. Allele, welche einen singulären Polymorphismus zeigen, bilden die Minderheit und sind in der Tabelle orange gekennzeichnet.

Untersuchte KIR2DL1-Polymorphismen

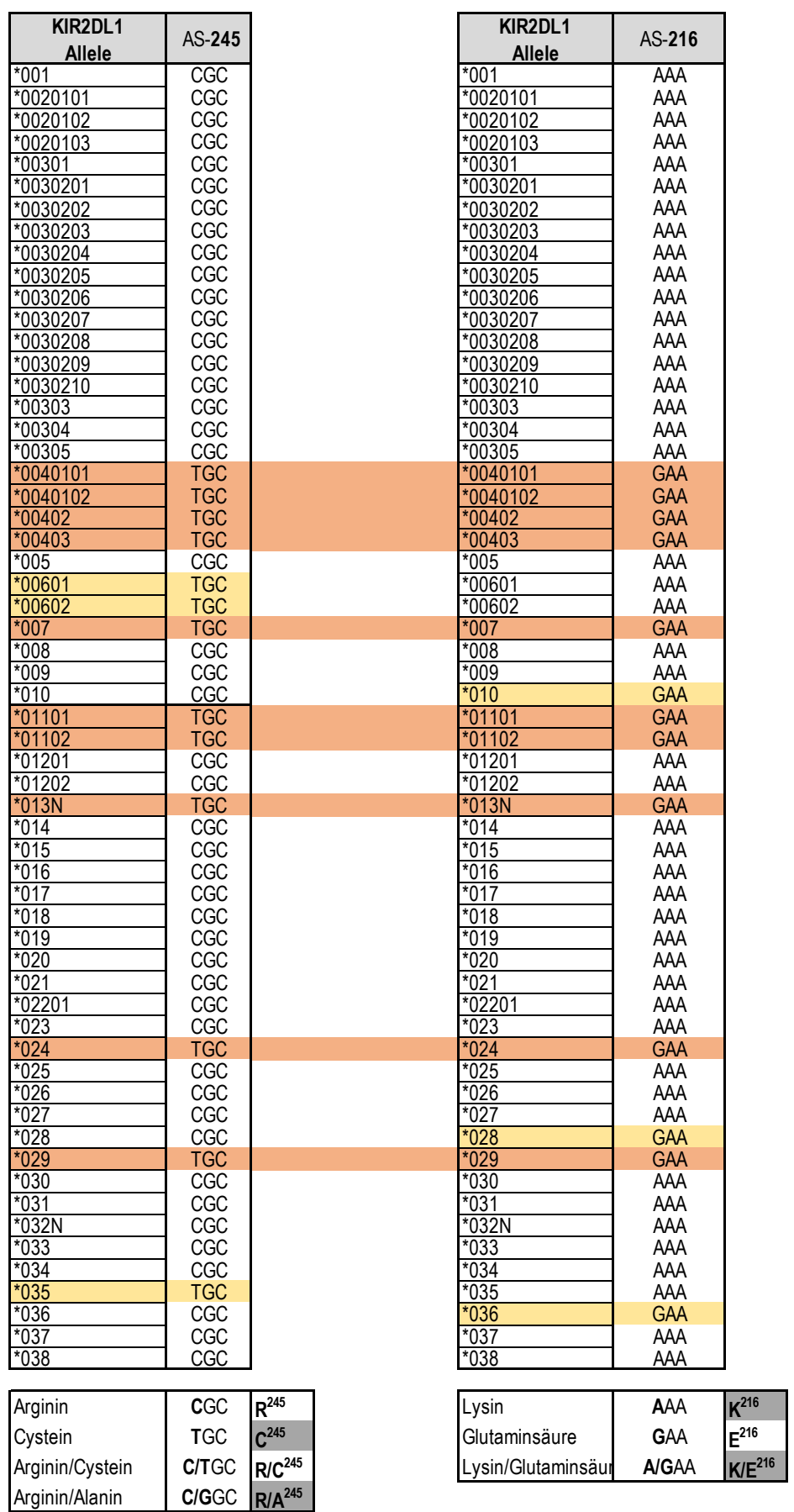




\subsection{Ergebnisse der allelischen KIR3DL1-Subtypisierung}

Unter Verwendung angepasster Primerpaare ( $\rightarrow$ siehe Tabelle 27, Anhang) wurden alle kodierenden Exone 1 bis 9 von KIR3DL1 auf Chromosom 19 untersucht. Als Referenzallel wurde KIR3DL1*0010101 verwendet. Das Gen ist mit insgesamt 1.335 kodierenden Basenpaaren (bp) exakt 288 bp länger als das KIR2DL1-Gen (Abb. 27). Genetisch präsentiert KIR3DL1 fast doppelt so viele variable Positionen. Derzeit sind 150 Allele, inklusive 3 Nullallele, bekannt (Stand Januar 2019).

\begin{tabular}{|lccccccccc|c|}
\hline KIR3DL1 & Exon 1 & Exon 2 & Exon 3 & Exon 4 & Exon 5 & Exon 6 & Exon 7 & Exon 8 & Exon 9 \\
\cline { 1 - 2 } & $5^{\prime}$ & 34 & 36 & 285 & 300 & 294 & 51 & 105 & 53 & 177 \\
$\begin{array}{l}\text { Variable } \\
\text { Positionen }\end{array}$ & 2 & 3 & 29 & 25 & 20 & 0 & 11 & 12 & 22 \\
\hline
\end{tabular}

\begin{tabular}{|lc|}
\hline \multicolumn{2}{|c|}{ KIR3DL1-Gen } \\
\hline Polymorphismen & 124 \\
Allele & 147 \\
Nullallele & 3 \\
Proteine & 91 \\
\hline
\end{tabular}

Abbildung 27 Aufreihung der Genabschnitte (Exon 1 - 9) des NK-Rezeptors KIR3DL1, inklusive Basenpaar(bp)Länge und Anzahl der untersuchten Polymorphismen (variable Stellen) in Relation zu dem Referenzallel KIR3DL1*0010101. [Stand Januar 2019, Quelle: https://www.ebi.ac.uk/ipd/kir ]

Nach Auswertung der „Mismatch-Positionen“ der sequenzierten Nukleotidabfolge wurden mittels Ausschlussverfahren die jeweiligen KIR3DL1-Allele aus der Immuno Polymorphism Database (IPD) für die 20 Spender ermittelt ( $\rightarrow$ siehe Tabelle 35, Anhang). Die Ergebnisse der KIR3DL1-Subtypisierung sind in Tabelle 17 auf der nachfolgenden Seite zusammengefasst. 
Teil 1: Ergebnisse der KIR- und HLA-Typisierung der NK-Zell-Spender

Tabelle 17 Auflistung der gefundenen KIR3DL1-Allele, sowie deren Allelfrequenz innerhalb der Studiengruppe. (Detailierte Ansicht mit den Abweichungen zu dem Referenzallel KIR3DL 1*0010101 in Tabelle 36 des Anhangs)

\begin{tabular}{|c|c|c|c|}
\hline \multicolumn{4}{|c|}{ KIR3DL1 [Referenzallel 3DL1*0010101] } \\
\hline Spender & & Spenderallele & \\
\hline 1 & $3 \mathrm{DL} 1{ }^{*} 008$ & $3 \mathrm{DL} 1^{*} 069^{\Delta}$ & \\
\hline 2 & $3 \mathrm{DL} 1^{*} X^{\text {neu }}$ & $3 \mathrm{DL} 1^{*} X^{\text {neu }}$ & \\
\hline 3 & $3 D L 1 * 002$ & $3 \mathrm{DL} 1{ }^{*} 087$ & \\
\hline 4 & $3 D L 1 * 00101$ & $3 \mathrm{DL} 1{ }^{*} 002$ & \\
\hline 5 & $3 D L 1 * 087$ & $3 \mathrm{DL} 1 * 097$ & \\
\hline 6 & 3DL1*01501 & $3 D L 1 * 00701$ & \\
\hline 7 & 3DL1*00101 & $3 \mathrm{DL} 1{ }^{*} 054$ & \\
\hline 8 & $3 D L 1 * 00101$ & $3 \mathrm{DL} 1{ }^{*} 076$ & \\
\hline 9 & 3DL1*01702 & $3 D L 1 * 095$ & \\
\hline 10 & $3 \mathrm{DL} 1{ }^{*} 087$ & $3 D L 1 * 109$ & \\
\hline 11 & $3 \mathrm{DL} 1{ }^{*} 002$ & 3DL1*00402 & \\
\hline 12 & $3 D L 1 * 068$ & $3 D L 1 * 097$ & \\
\hline 13 & $3 D L 1 * 00103$ & $3 \mathrm{DL} 1{ }^{*} 076$ & \\
\hline 14 & $3 D L 1 * 0040101$ & $3 D L 1^{*} 00501^{\Delta}$ & \\
\hline 15 & 3DL1*00101 & 3DL1*099 & $3 \mathrm{DL} 1{ }^{*} 016$ \\
\hline 16 & 3DL1*00402 & $3 D L 1 * 01501$ & $3 \mathrm{DL} 1{ }^{*} 0310102$ \\
\hline 17 & $3 \mathrm{DL} 1{ }^{*} 087$ & $3 \mathrm{DL} 1{ }^{*} 021$ & \\
\hline 18 & $3 D L 1 * 019$ & 3DL1*00501 & \\
\hline 19 & $3 \mathrm{DL} 1{ }^{*} 008$ & 3DL1*00101 & \\
\hline 20 & 3DL1*009 & $3 \mathrm{DL} 1^{*} 054$ & \\
\hline
\end{tabular}

\begin{tabular}{|c|c|}
\hline $\begin{array}{l}\text { KIR3DL1 } \\
\text { Allele }\end{array}$ & Allelfrequenz $(\%)$ \\
\hline $3 \mathrm{DL1} 1^{*} 00101$ & $25 \%$ \\
\hline $3 \mathrm{DL} 1^{*} 00103$ & $5 \%$ \\
\hline 3DL1*002 & $15 \%$ \\
\hline 3DL1*0040101 & $5 \%$ \\
\hline $3 \mathrm{DL} 1^{*} 00402$ & $10 \%$ \\
\hline 3DL1*00501 & $10 \%$ \\
\hline 3DL1*00701 & $5 \%$ \\
\hline 3DL1*008 & $10 \%$ \\
\hline 3DL1*009 & $5 \%$ \\
\hline 3DL1*01501 & $10 \%$ \\
\hline $3 D L 1 * 016$ & $5 \%$ \\
\hline 3DL1*01702 & $5 \%$ \\
\hline 3DL1*019 & $5 \%$ \\
\hline $3 \mathrm{DL} 1 * 021$ & $5 \%$ \\
\hline $3 D L 1 * 0310102$ & $5 \%$ \\
\hline 3DL1*054 & $10 \%$ \\
\hline 3DL1*068 & $5 \%$ \\
\hline $3 \mathrm{DL1} 1{ }^{*} 069$ & $5 \%$ \\
\hline $3 D L 1 * 076$ & $10 \%$ \\
\hline $3 \mathrm{DL1} 1 * 087$ & $20 \%$ \\
\hline 3DL1*095 & $5 \%$ \\
\hline $3 \mathrm{DL1} 1{ }^{*} 097$ & $10 \%$ \\
\hline 3DL1*099 & $5 \%$ \\
\hline $3 \mathrm{DL}^{*}{ }^{* 109}$ & $5 \%$ \\
\hline $3 \mathrm{DL} 1 * X^{\text {neu }}$ & $5 \%$ \\
\hline $3 D L 1 * X^{\text {neu }}$ & $5 \%$ \\
\hline
\end{tabular}

$\Delta=$ abweichende Nukleotidsequenæ; größte Äbnlichkeit zu den Allelen KIR3DL1*069 und *00501.

Bei der KIR3DL1-Sequenzierung zeigten sich bei Spender 1 insgesamt 10 heterozygote Abweichungen der Nukleotidsequenz von der Referenzsequenz. Für die Auswertung wurden neben dem Allel 3DL1*008 das Allel 3DL1*069 mit größtmöglicher Ähnlichkeit ausgewählt. Ebenfalls zu erwähnen ist das Sequenzierungsergebnis von Spender 14 mit insgesamt 4 homozygoten Referenzabweichungen, eine davon im Exon 8 (Position 44), weitere drei im Bereich von Exon 9 (Positionen 22, 121, 145). Bei Spender 2 ergaben sich dagegen die mit Abstand meisten homozygote Abweichungen im Vergleich zur Referenzsequenz 3DL1*00101, insbesondere im Bereich der Exone 3 bis 5. Bei diesem Spender ist die Kombination neuer KIR3DL1-Allele wahrscheinlich. Für das hochpolymorphe Exon 5 des KIR3DL1-Gens sind derzeit 18 variable Positionen in der IPD beschrieben, von denen 12 nach Translation der Gentriplets zu veränderten Aminosäuren führen. 
Zur Demonstration zeigt Abbildung 28 einen Auszug aus der Sequenzierung von Exon 5 bei Spender 2. Die sich aus den Basentriplets ergebenden Aminosäuren sind zur Vereinfachung mit dem sogenannten Einbuchstabencode darin wiedergegeben. Erklärungen zur verwendeten Aminosäuren-Nomenklatur befinden sich in Tabelle 28 des Anhangs.

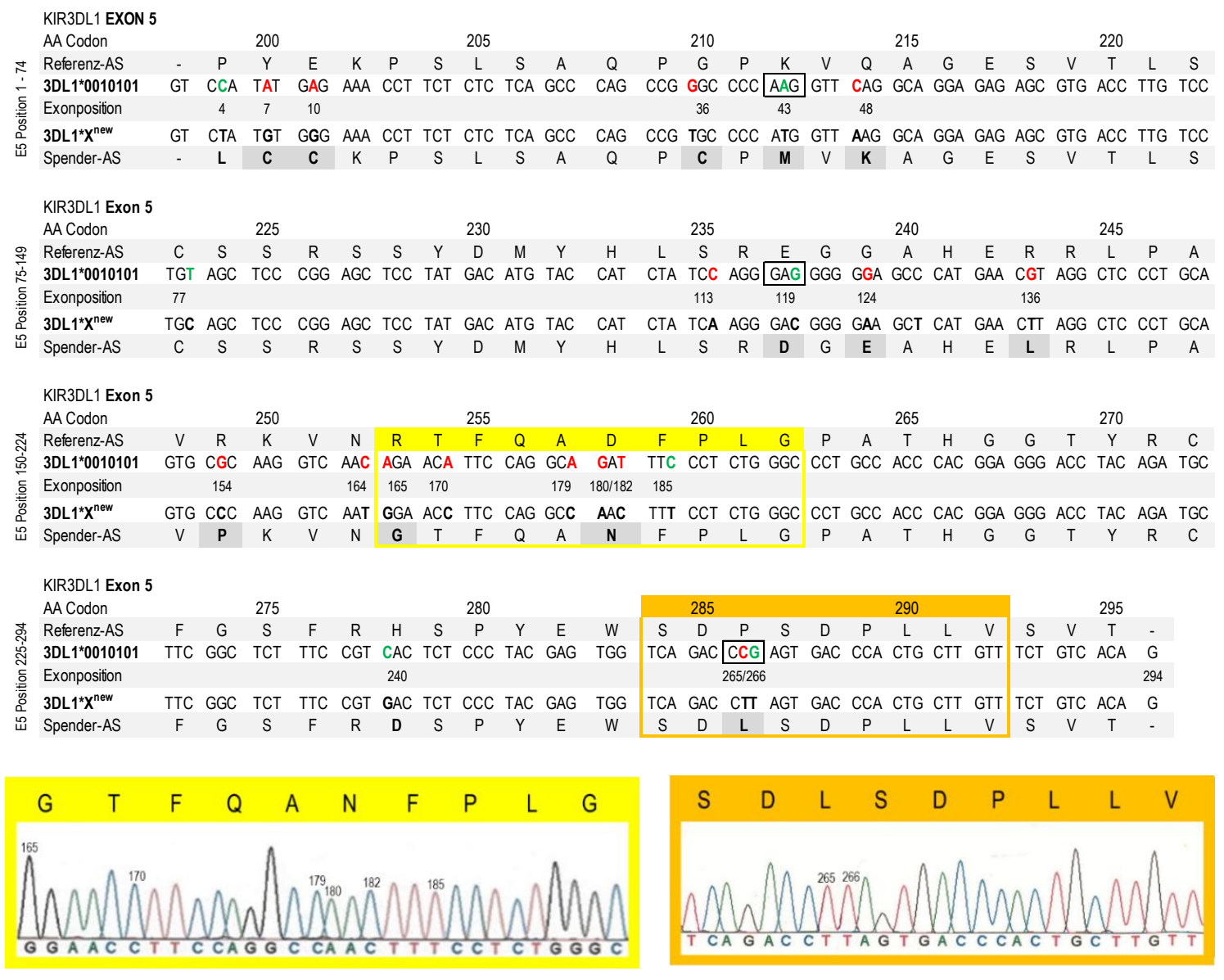

Abbildung 28 Analyse der Nukleotidsequenz bei Spender 2 im Bereich des Exons 5 innerhalb des KIR3DL1-Gens. Bereits bekannte Polymorphismen sind in fett grün dargestellt, solche die bisher nicht beschrieben sind dagegen in fett rot in der Referenzsequenz 3DL1*0010101 gekennzeichnet. Die aus den Polymorphismen sich ergebenden Aminosäurenabweichnungen sind unter Verwendung des Einbuchstabencodes in fett schwarz hervorgehoben. Aminosäuren, die durch einen bisher unbekannten Polymorphismus zustande kommen, sind zusätzlich dunkler-grau hinterlegt. Zusätzlich sieht man im unteren Teil der Abbildung zwei ausgewählte Abschnitte der Nukleotidsequenz (gelber und orangener Kasten). Darin werden insgesamt drei von der Referenz abweichenden Aminosäuren an den Positionen 253, 258 und 286 dargestellt. Eine entsprechende Legende zu dem Einbuchstabencode bei der Aminosäurennomenklatur befindet sich im Anhang (Tabelle 28).

Eine detaillierte Auflistung der Referenz-Abweichungen der untersuchten KIR3DL1-Allele findet sich in Tabelle 36 des Anhangs tabellarisch zusammengefasst. 


\subsubsection{Spendergruppierung anhand von KIR3DL1-Expressionsmustern}

In der Literatur wurden nach Zellexperimenten Expressions- und Affinitätsunterschiede von KIR3DL1-Rezeptoren auf NK-Zell-Populationen bereits beschrieben. ${ }^{205,215-218}$ Sowohl oberflächlich durch Durchflusszytometrie als auch allelisch durch Sequenzierung, wurden in diesen Arbeiten funktionelle Unterschiede beobachtet, welche zu einer unterschiedlichen Rezeptoreffizienz bei der Bindung von Bw4-Epitopen führen. Die Bindungsstärke beeinflusst wiederherum die Hemmung der Zellfunktion von NK-Zellen. Beobachtungen von Gardiner et al. (2001) legten nahe, dass eine Unterscheidung in „low“, „high“ und „zero“ KIR3DL1-Expressionsmuster sinnvoll ist, um allelische Funktionalität präklinisch, beispielsweise vor einer Transplantion, kategorisieren zu können. ${ }^{215}$ Eine Zusammenstellung der in der Literatur bisher hinterlegten allelischen Expressionsmuster ist in Tabelle $18 \mathrm{zu}$ sehen.

Tabelle 18 Überblick der in der Literatur 2001 - 2015 beschriebenen allelische Expressionsstärken des inhibitorischen KIR3DL1-Rezeptors. ${ }^{205,215-218}$ Bei allen in den Tabellen nicht aufgeführten Allelen handelt es sich um unknown-Allele („3DL1-U“), welche in der bisherigen Literatur keine Erwähnung finden. Sie entsprechen 65\% der KIR3DL1-Allele.

\begin{tabular}{|c|c|}
\hline \multicolumn{2}{|c|}{$\begin{array}{c}\text { KIR3DL1 } \\
\text { high -Allele („,3DL1-h“) }\end{array}$} \\
\hline${ }^{*} 0010102$ & *0150207 \\
\hline *0010103 & *0150208 \\
\hline${ }^{*} 00102$ & *0150209 \\
\hline${ }^{*} 00103$ & *0150210 \\
\hline *00104 & *0150211 \\
\hline *00105 & *0150212 \\
\hline${ }^{*} 002$ & *01503 \\
\hline *008 & *01504 \\
\hline *009 & *01505 \\
\hline *0150101 & *01506 \\
\hline *0150102 & ${ }^{*} 016$ \\
\hline *0150103 & *0200101 \\
\hline *0150201 & *0200102 \\
\hline *0150202 & \\
\hline *0150203 & \\
\hline *0150204 & \\
\hline *0150205 & \\
\hline *0150206 & \\
\hline
\end{tabular}

\begin{tabular}{|l|}
\hline KIR3DL1 \\
low -Allele $\left(, 3 D L 1-I^{\prime \prime}\right)$ \\
\hline${ }^{*} 0050101$ \\
${ }^{*} 0050102$ \\
${ }^{*} 0050103$ \\
${ }^{*} 0050104$ \\
${ }^{*} 0050105$ \\
${ }^{*} 00502$ \\
${ }^{*} 00503$ \\
${ }^{*} 00504$ \\
${ }^{*} 00505$ \\
${ }^{*} 006$ \\
${ }^{*} 0070101$ \\
${ }^{*} 0070102$ \\
${ }^{*} 0070103$ \\
${ }^{*} 0070104$ \\
${ }^{*} 053$ \\
${ }^{*} 054$ \\
\hline
\end{tabular}

\begin{tabular}{|l|}
\hline KIR3DL1 \\
zero-Allele $(, 3 D L 1-n “)$ \\
\hline${ }^{*} 0040101$ \\
${ }^{*} 0040102$ \\
${ }^{*} 0040103$ \\
${ }^{*} 00402$ \\
${ }^{*} 00403$ \\
${ }^{*} 00404$ \\
\hline
\end{tabular}

Die Expressionsstärke ist jedoch nur für 53 der 150 KIR3DL1-Allele untersucht worden, sodass derzeit für 65\% der KIR3DL1-Allele keine Daten zur Expressionsstärke vorliegen (Stand Januar 2019). Die in der Kohorte von 20 Spendern ermittelten 27 KIR3DL1-Allele wurden basierend auf beschriebenen Daten zum Expressionsniveau und der Bw4-Spezifität in funktionelle Hauptgruppen eingeordnet. Für die vorliegende Forschungsarbeit wurde die 
Gruppierung in low- (,3DL1-l“), high- (,3DL1-b") und zero- (,3DL1-n“, wie null) Expressionsmuster gewählt. Aufgrund der hohen Anzahl nicht untersuchter Allele wurde eine vierte Hauptgruppe der unknown-(,3DL1-u“) -Expression hinzugefügt. Allelisch ergaben sich nach Zuordnung abschließend 5 Untersuchungsgruppen: high/high-Spender

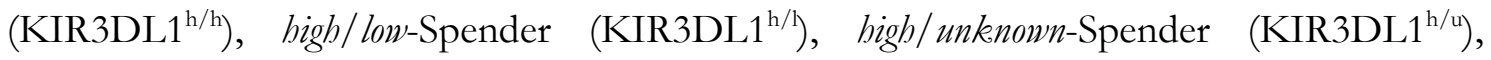
high/null-Spender $\left(\right.$ KIR3DL1 $\left.{ }^{\mathrm{h} / \mathrm{n}}\right)$ und unknown/unknown-Spender (KIR3DL1 ${ }^{\mathrm{u} / \mathrm{u}}$ ). Die Ergebnisse der 20 Spender sind in Tabelle 19 dargestellt. Die größte Untersuchungsgruppe bildeten Spender mit KIR3DL1 ${ }^{\mathrm{u} / \mathrm{u}}$ Allelkonstellationen.

Tabelle 19 Gruppierungsübersicht der 20 Spender anhand der 5 Untersuchungsgruppen high/high (KIR3DL 1h/h), high/low (KIR3DL1h/l), high/unknown (KIR3DL1h/u), high/null (KIR3DL1h/n) mit unterschiedlicher RezeptorExpressionsstärke.

\begin{tabular}{|c|c|c|c|c|}
\hline \multirow{2}{*}{ Spender } & \multicolumn{3}{|c|}{ Allele KIR3DL1 } & \multirow{2}{*}{ Expressionsmuster } \\
\hline & Allel 1 & Allel 2 & Allel 3 & \\
\hline 4 & ${ }^{*} 00101$ & *002 & & \multirow{2}{*}{$\begin{array}{c}\text { high/high- Expression } \\
\left(\text { KIR3DL1 }{ }^{\text {h/h }}\right)\end{array}$} \\
\hline 19 & ${ }^{*} 008$ & *00101 & & \\
\hline 1 & ${ }^{*} 008$ & ${ }^{*} 069$ & & \multirow{4}{*}{$\begin{array}{l}\text { high/low- Expression } \\
\left.\text { (KIR3DL1 }{ }^{\text {h/l/1}}\right)\end{array}$} \\
\hline 6 & *01501 & *00701 & & \\
\hline 7 & $* 00101$ & *054 & & \\
\hline 20 & ${ }^{*} 009$ & *054 & & \\
\hline 3 & ${ }^{*} 002$ & *087 & \multirow[b]{4}{*}{${ }^{*} 016^{h}$} & \multirow{4}{*}{$\begin{array}{c}\text { high/unknown- Expression } \\
\left.\text { (KIR3DL1 }{ }^{\text {h/u }}\right)\end{array}$} \\
\hline 8 & *00101 & *076 & & \\
\hline 13 & $* 00103$ & *076 & & \\
\hline 15 & $* 00101$ & $* 099$ & & \\
\hline 11 & ${ }^{*} 002$ & *00402 & & high/null- Expression \\
\hline 16 & *00402 & *01502 & ${ }^{*} 0310102^{\mathrm{u}}$ & $\left(\mathrm{KIR} 3 \mathrm{DL} 1^{\mathrm{h} / \mathrm{n}}\right)$ \\
\hline 2 & ${ }^{*} X^{\text {neu }}$ & ${ }^{*} X^{\text {neu }}$ & & \multirow{6}{*}{$\begin{array}{l}\text { unknown/unknown- } \\
\text { Expression } \\
\text { (KIR3DL1 }^{\text {u/u })}\end{array}$} \\
\hline 5 & *087 & *097 & & \\
\hline 9 & *01702 & *095 & & \\
\hline 10 & ${ }^{*} 087$ & *109 & & \\
\hline 12 & ${ }^{*} 068$ & $* 097$ & & \\
\hline 17 & ${ }^{*} 087$ & *021 & & \\
\hline 14 & ${ }^{*} 0040101$ & ${ }^{*} 00501$ & & low/null- Expression" \\
\hline 18 & ${ }^{*} 019$ & *00501 & & low/unknown-Expression \\
\hline
\end{tabular}

Spender 14 exprimiert keinen KIR3DL1-Rezeptor auf seiner Zelloberfläche.

- Spender 18 ist grau hinterlegt, da für diesen Spender keine funktionellen Datensätze erhoben werden konnten (Abschnitt 5.8.2).

Die Sequenzanalyse bei Spender 14 mit positiver KIR3DL1-SSP bei negativer Rezeptorexpression in der Oberflächenfärbung ( $\rightarrow$ vgl. Abschnitt 5.6$)$ zeigte erwartungsgemäß das in der englischen Literatur als „zero-expression“-Allel beschriebene 3DL1*0040101. ${ }^{215}$ Weitere Allelvarianten von 3DL1*004 fanden sich in Form von 
3DL1*00402 ebenfalls bei den Spendern 11 und 16. Sie gingen jedoch nicht mit einer negativen KIR3DL1-Oberflächenexpression einher. Stattdessen zeigten beide Spender KIR3DL1-Expressionsstärken von $10 \%$ bei der Oberflächenanfärbung mit dem antiKIR3DL1-APC-Antikörper ( $\rightarrow$ vgl. Abb. 31, Abschnitt 5.6). Pando et al. zeigte in einer Studienarbeit, dass innerhalb der extrazellulären D0- und D1-Domäne des KIR3DL1Rezeptors die Substitution eines Glycins an der Position 44 (Glycin-44) die Rezeptorexpression erhöht, während die AS-Substitution an Position 86 durch Alanin oder Leucin die Oberflächenexpression des Rezeptors gänzlich verhindert. ${ }^{216}$ Sequenzvarationen in den Aminosäuren des fertigen Proteinrezeptors zeigt maßgeblichen Einfluss auf den NKZell-Phänotypen. Wie komplex die durch Polymorphismen veränderten Aminosäurenpositionen sich dabei auf die Funktion des KIR3DL1-Rezeptors auswirken, versucht die Tabelle $32 \mathrm{im}$ Anhang zu verdeutlichen. Angeleht daran wurden die drei Spender 11, 14 und 16 mit den ermittelten KIR3DL1*004 Nullallelvarianten zusätzlich mit speziellem Fokus auf Polymorphismen der D0- und D1-Domänen untersucht. Spender 14 zeigte hierbei den Polymorphismus zugunsten des Glycin-44 (G/G) sowie den Leucin-86 (L/L) Polymorphismus und in Konsequenz eine KIR3DL1-Expression von nahezu 0\% in der KIR-Oberflächenfärbung. Bei den Spendern 14 und 18 konnte dagegen eine Substitution von Serin anstelle von Prolin an AS-Position 182 (P182S) identifiziert werden, dass auch bei den ,low-expressing“ Allelen 3DL1*005 und *053 beschrieben ist. 


\section{Teil 2: Ergebnisse der durchflusszytometrischen Messungen}

\subsection{HLA-Oberflächenfärbung der verwendeten Zielzelllinien}

Um die Expression der für die NK-Zell-Experimente verwendeten vier transgenen L721.221-Zielzelllinien zu überprüfen, wurden innerhalb des Experimentzeitraums in regelmäßigen Abständen HLA-Oberflächenfärbungen durchgeführt. Für die Qualitätskontrollen wurden zwei Fluoreszenz-gekoppelte Antikörper, Anti-HLA-A,B,CFITC und Anti-HLA-Bw4-FITC, verwendet, die jeweils an die exprimierten HLA-Merkmale der Zielzellpopulation bilden. Abbildung 29 zeigt die Auswertung der L721.221 Oberflächenfärbung nach Durchflusszytometrie und damit auch das Ergebnis einer gelungenen Zellkulturtechnik. Zur Selektionierung ist bei den Zielzellinien L721-221-C1 und -C2 ein antibiotisches Zusatzmedium während der Kultivierung verwendet worden $(\rightarrow$ vgl. Abschnitt 4.7.3).
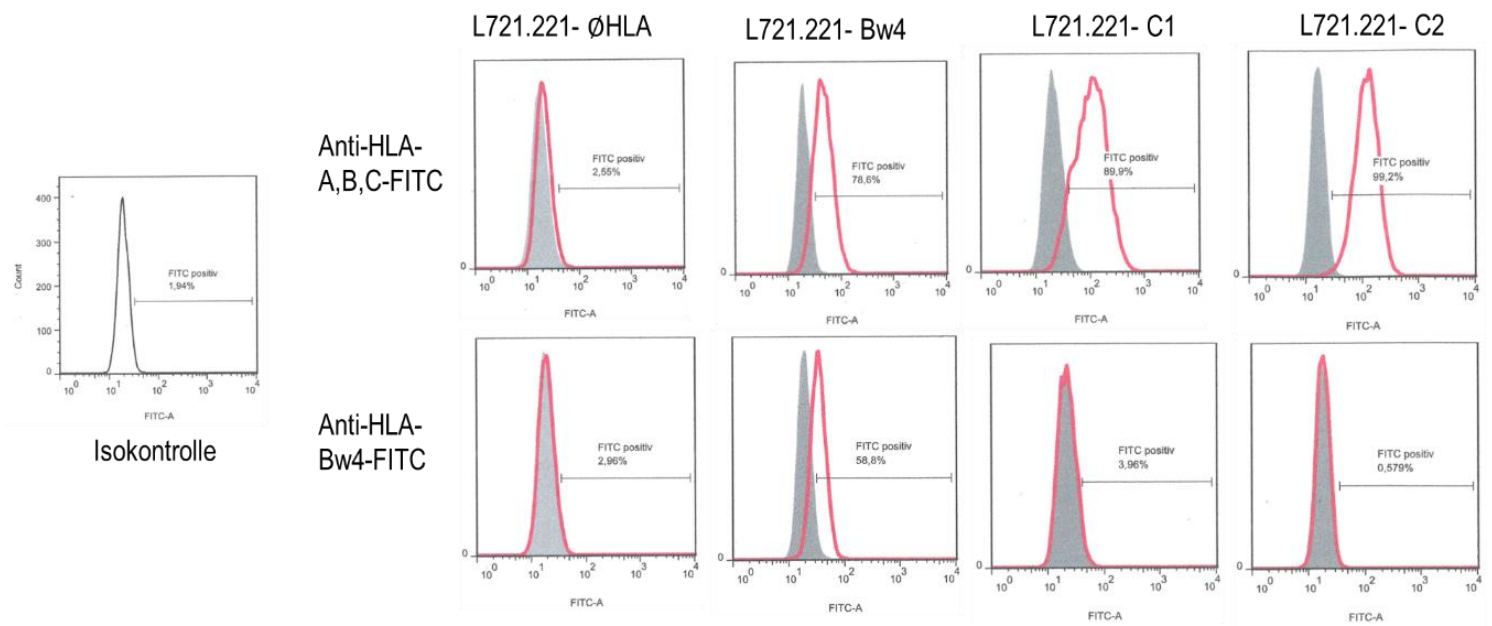

Abbildung 29 Analyse der Zelloberflächenmerkmale (HLA) der kultivierten Zelllinien L721.221-ØHLA. L721.221-Bw4, L721.221-C1, und L721.221-C2 mittels Durchflusszytometrie nach Inkubation mit den Fluoreszenz- gekoppelten Antikörper Anti-HLA-A,B,C-FITC und Anti-HLA-Bw4-FITC zur stetigen Qualitätskontrolle.

\subsection{KIR2DL1- und KIR3DL1-Oberflächenexpression der NK-Zell-Spender}

Nach der Geno- und Haplotypisierung der Spender wurde zur weiteren Differenzierung der KIR-Rezeptorausprägung eine antikörpervermittelte Oberflächenfärbung der Spender NKZellen (quantitative KIR-Typisierung) durchgeführt. Dazu wurden die isolierten Spender NK-Zellen mit APC-konjugierten KIR-Antikörper inkubiert und die erzielte Oberflächenbindung anschließend mittels Durchflusszytometer untersucht. 
Die FACS-gestützte Messung der Oberflächenexpression ermöglicht die Untersuchung prozentuale Anteile einzelner auf der Oberfläche exprimierter KIR-Rezeptoren (Abb. 30).

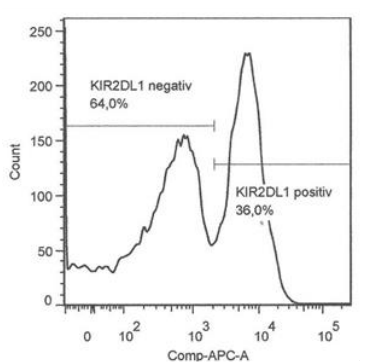

Spender 3

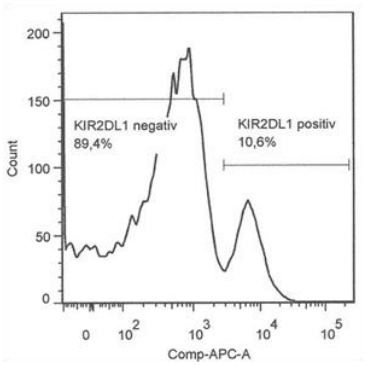

Spender 15

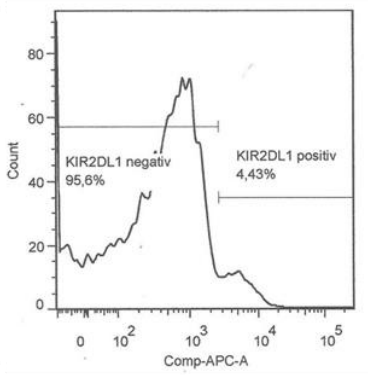

Spender 5

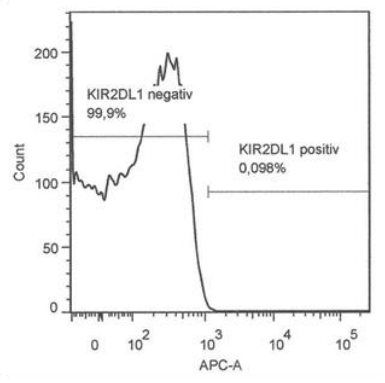

Spender 13

Abbildung 30 Exemplarische Darstellung unterschiedlich starker Expressionsmuster am Beispiel des KillerzellImmunoglobulin-ähnlichen Rezeptors KIR2DL1 von vier NK-Zell-Spendern mittels Durchflusszytometrie. Für die Anfärbung der NK-Zellen wurde ein anti-KIR2DL1-APC Antikörper verwendet.

Bei dem Großteil der Spender ( $\mathrm{n}=18$ ) lag sowohl KIR2DL1, als auch KIR3DL1 genetisch vor. Jedoch ergaben sich spenderspezifische Unterschiede in Hinblick auf die RezeptorExpressionsdichte der zwei inhibitorischen KIRs. Die Expressionsanteile aller 20 untersuchten Spender für KIR2DL1 und KIR3DL1 sind tabellarisch und graphisch zusätzlich in Abbildung 31 dargestellt.

\begin{tabular}{|c|c|c|}
\hline Spender & $\begin{array}{l}\text { KIR2DL1- } \\
\text { Rezeptor }\end{array}$ & $\begin{array}{l}\text { KIR3DL1- } \\
\text { Rezeptor }\end{array}$ \\
\hline 1 & $12,5 \%$ & $13,9 \%$ \\
\hline 2 & $6,1 \%$ & $24,5 \%$ \\
\hline 3 & $36,0 \%$ & $13,6 \%$ \\
\hline 4 & $11,6 \%$ & $34,7 \%$ \\
\hline 5 & $4,4 \%$ & $3,0 \%$ \\
\hline 6 & $11,7 \%$ & $20,6 \%$ \\
\hline 7 & $6,0 \%$ & $9,8 \%$ \\
\hline 8 & $14,3 \%$ & $33,2 \%$ \\
\hline 9 & $12,9 \%$ & $43,3 \%$ \\
\hline 10 & $6,0 \%$ & $13,1 \%$ \\
\hline 11 & $10,4 \%$ & $9,9 \%$ \\
\hline 12 & $21,4 \%$ & $28,1 \%$ \\
\hline 13 & $0,0 \%$ & $40,9 \%$ \\
\hline 14 & $16,4 \%$ & $0,0 \%$ \\
\hline 15 & $10,6 \%$ & $20,4 \%$ \\
\hline 16 & $4,8 \%$ & $10,0 \%$ \\
\hline 17 & $8,9 \%$ & $13,5 \%$ \\
\hline 19 & $15,3 \%$ & $7,2 \%$ \\
\hline 20 & $19,2 \%$ & $13,4 \%$ \\
\hline 18 & $16,0 \%$ & \\
\hline
\end{tabular}

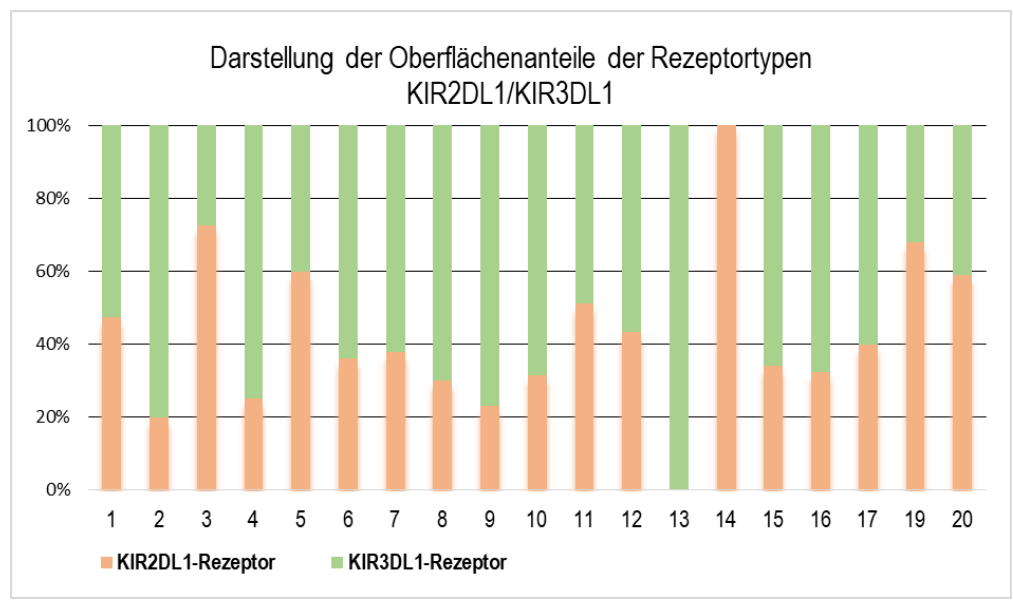

Abbildung 31 Auflistung (links) und graphische Darstellung (rechts) der prozentualen Anteile der KIR2DL1 und KIR3DL1-Oberflächenexpression nach Anfärbung der Spender NK-Zellen mit Anti-KIR2DL1- und Anti-KIR2DL1-APCAntikörper und Messung im Durchflusszytometer. Spender 13 zeigt keinerlei KIR2DL1-Oberflächenexpression bei negativer KIR-SSP, Spender 14 fällt analog durch seine fehlende KIR3DL1-Oberflächenexpression auf. Spender 18 wurde graphisch nicht berücksichtigt, da der KIR3DL1-Oberflächenanteil nicht untersucht wurde. 
Die Ergebnistabelle für den KIR2DL1-Rezeptor zeigt bei Spender 3 die vergleichsweise stärkste KIR-Oberflächenexpression mit rund 36\%, während Spender 13, wie erwartet bei negativer KIR-SSP, keine KIR2DL1-Oberflächenexpression zeigt. Bezogen auf KIR3DL1 zeigt Spender 9 mit 45\% die stärkste Oberflächenexpression. Spender 14 zeigt dahingegen keine nachweisbare KIR3DL1-Oberflächenexpression trotz doppelt positiver Rezeptor-SSP $\left(2 \mathrm{DL} 1^{+} / 3 \mathrm{DL}^{+}\right)$. Dieses Ergebnis wurde in zwei weiteren Durchläufen bestätigt. Die KIR2DL1 ${ }^{+}$bzw. KIR3DL1 ${ }^{+}$Spender NK-Zellen wurden, wie im nächsten Abschnitt beschrieben, auch in Hinblick auf ihre Total-KIR positive und Single-KIR positive Zellpopulationen weiter untersucht.

\subsection{Untersuchung der Total-KIR / Single-KIR ${ }^{+}$NK-Zell-Populationen}

Die Differenzierung der isolierten Spender NK-Zellen in Single-KIR ${ }^{+}$und Total-KIR ${ }^{+}$ Zellpopulationen erfolgte durchflusszytometrisch nach entsprechender Antikörperbehandlung der Proben $(\rightarrow$ vgl. Tabelle 10, Abschnitt 4.8.2) unter anderem mit anti-KIR2DL1 bzw. anti-KIR3DL1-APC-Antikörpern. Abbildung 32 zeigt die Eingrenzung der Single-KIR ${ }^{+}$NK-Zellen (Q3) nach der FACS-Messung der Total-KIR ${ }^{+}$ NK-Zellen, welche mit 36\% in der Histogrammansicht für Spender 3 angeben ist.
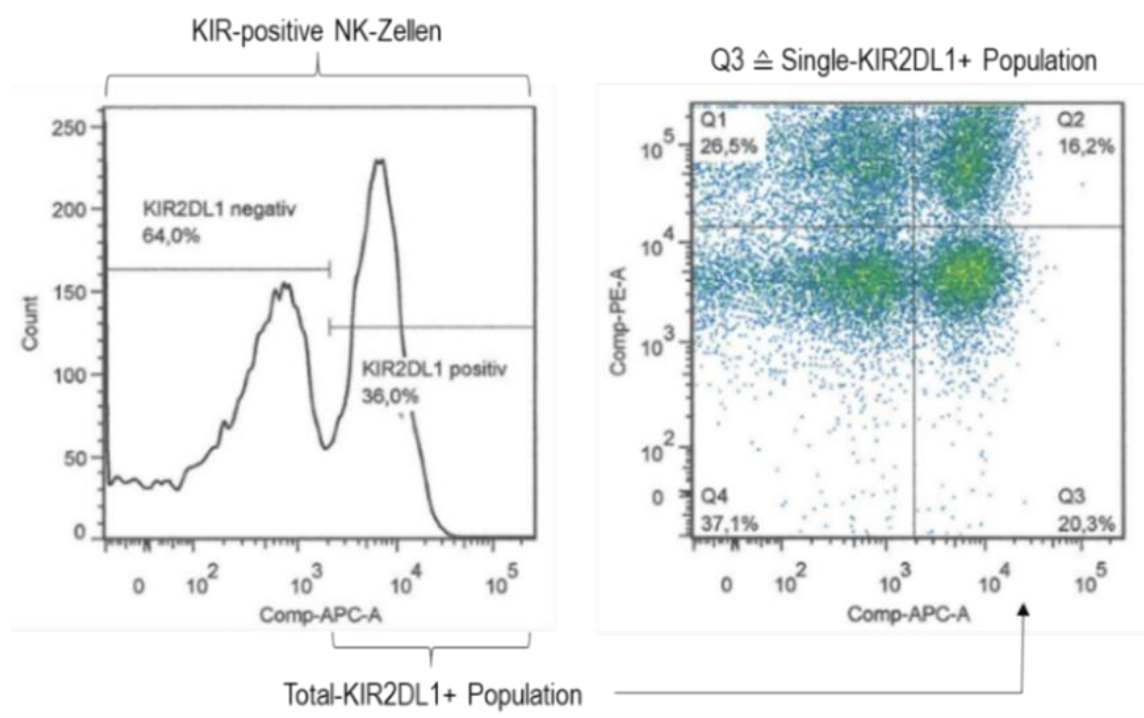

Abbildung 32 Gatingstrategie zur Unterscheidung zwischen Total-KIR+ und Single-KIR+ NK-Zellen. Die NKZelpopulationen wurden selektiv verwendet, um die Alloreaktivitätsmessungen auf definierte HLA-Liganden innerhalb einzelner Individuen experimentell vergleichen zu können. Die im Feld Q3 FACS-definierte Single-KIR2DL1+ Population (KIR-PE negativ/ KIR2DL1-APC positiv) eignen sich im Folgenden zur Untersuchung der anteiligen Wirkung einzelner Rezeptortypen auf die gesamte NK-Zell-Alloreaktivität. 
Als Single-KIR2DL1 ${ }^{+}$Population wurden NK-Zellen definiert, die KIR2DL1 exprimieren, während weitere inhibitorischen Killerzell-Immunoglobulin-ähnliche Rezeptoren, wie KIR2DL2, KIR2DL3 und KIR3DL1 sowie der aktivierende KIR2DS2, auf der Oberfläche fehlen. Total-KIR2DL1 ${ }^{+}$NK-Populationen exprimieren demgegenüber ein diverses Set an iKIRs, inklusive KIR2DL1.

Die Abbildung 33 zeigt die Auswertung der relativen Anteile der Single-KIR2DL1 ${ }^{+}$NKZellfraktion von der Total-KIR2DL1 ${ }^{+}$NK-Zellpopulation der untersuchten Spender. Der Großteil der Spender zeigt eine KIR2DL1-Single/Total-Ratio von $\leq 10 \%$, während die Spender 3, 11, 14, 17 und 20 deutlich höhere relative Single-KIR2DL1 ${ }^{+}$Anteile zwischen 16 - 24\% zeigen. Zwei Spender der $C^{245}$-Gruppe zeigen ebenfalls Single-KIR2DL1 ${ }^{+}$Anteile von $>25 \%$, Spender $20\left(\mathrm{R} / \mathrm{A}^{245}\right)$ sogar mit 31,9\% die größte Fraktion an Single-KIR2DL1 ${ }^{+}$ NK-Zellen überhaupt. Bei der $\mathrm{R}^{245}$-Gruppe zeigt Spender 3 den größten Anteil mit 20,3\%, unter den $\mathrm{R} / \mathrm{C}^{245}$-Spendern ist es Spender 17 mit anteilig 30,7\% Single-KIR2DL1 ${ }^{+} \mathrm{NK}$ Zellen.

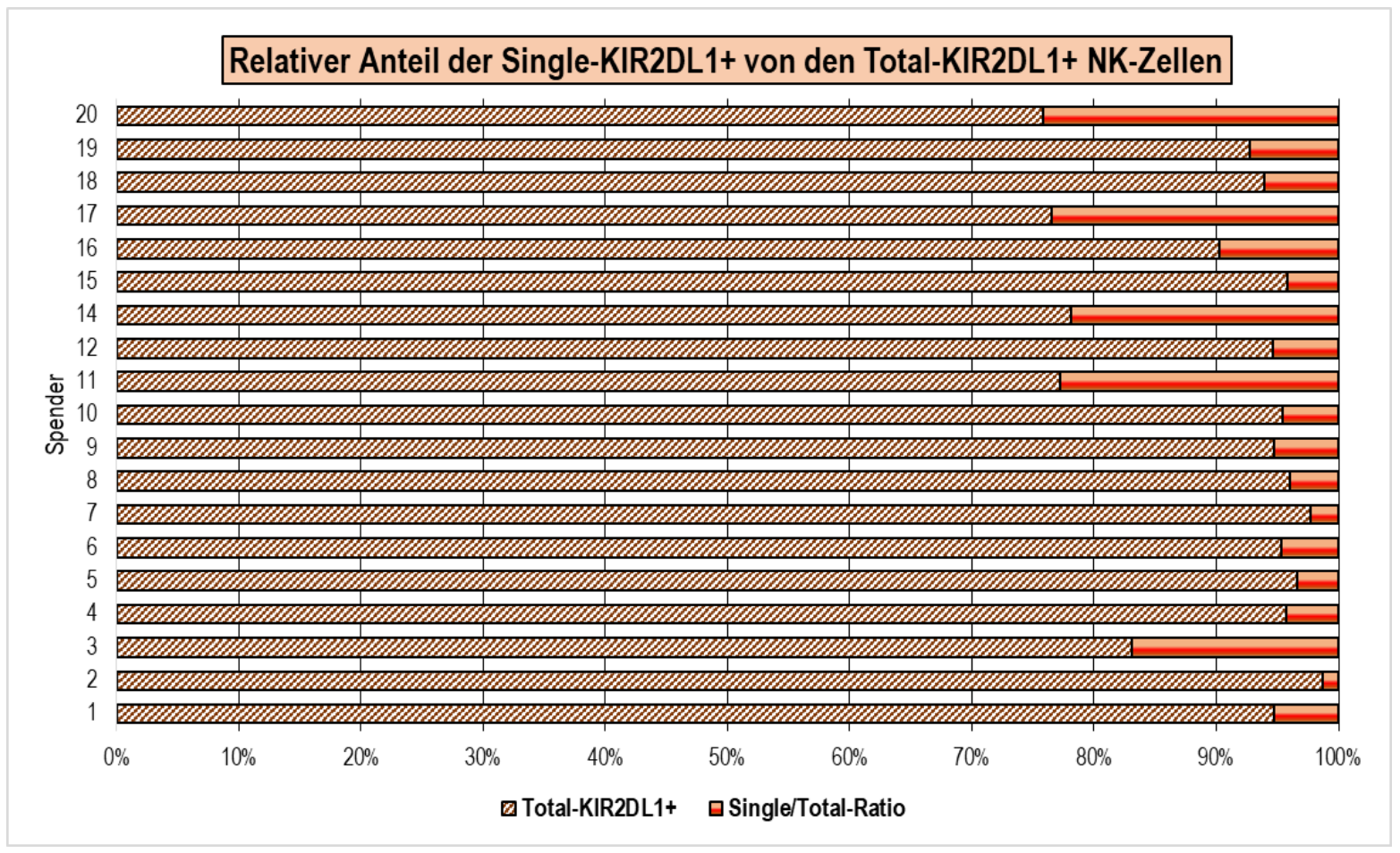

Abbildung 33 Optische Darstellung der relativen Anteile der Single-KIR2DL1+ NK-Zellfraktion von der Total-KIR2DL1+ NK-Zellpopulation der untersuchten Spender. Der Spender 13 zeigt keine KIR2DL1-Expression und ist nicht mit dargestellt

Die Abbildung 34 auf der nachfolgenden Seite zeigt die Auswertung der KIR3DL1Single/Total-Ratios der untersuchten Spender. Für die Mehrheit der untersuchten Spender ergibt sich analog zum KIR2DL1 Rezeptor eine Single/Total-Ratio $<10 \%$. Lediglich ein 
Viertel der Spender ( $\mathrm{n}=5$ ) zeigt Werte über 10\% (11,3 - 20,4\%). Davon gehören drei Spender (Spender 2, 9 und 10) der Expressionsgruppe KIR3DL1 ${ }^{\mathrm{u} / \mathrm{u}}$ an. Spender 9 zeigt mit 20,4\% die größte Fraktion aller untersuchten NK-Zellen an Single-KIR3DL1 ${ }^{+}$NK-Zellen. Weitere zwei Spender (Spender 8 und 13) sind Teil der Expressionsgruppe KIR3DL1 ${ }^{\mathrm{h} / \mathrm{u}}$ und zeigen anteilig $>15 \%$ Single-KIR3DL1 ${ }^{+}$NK-Zellen. Spender 4 ist einziger Vertreter der Expressionsgruppe KIR3DL1 ${ }^{\mathrm{h} / \mathrm{h}}$ mit einem Anteil an KIR3DL1 ${ }^{+}$NK-Zellen von 18,2\%.

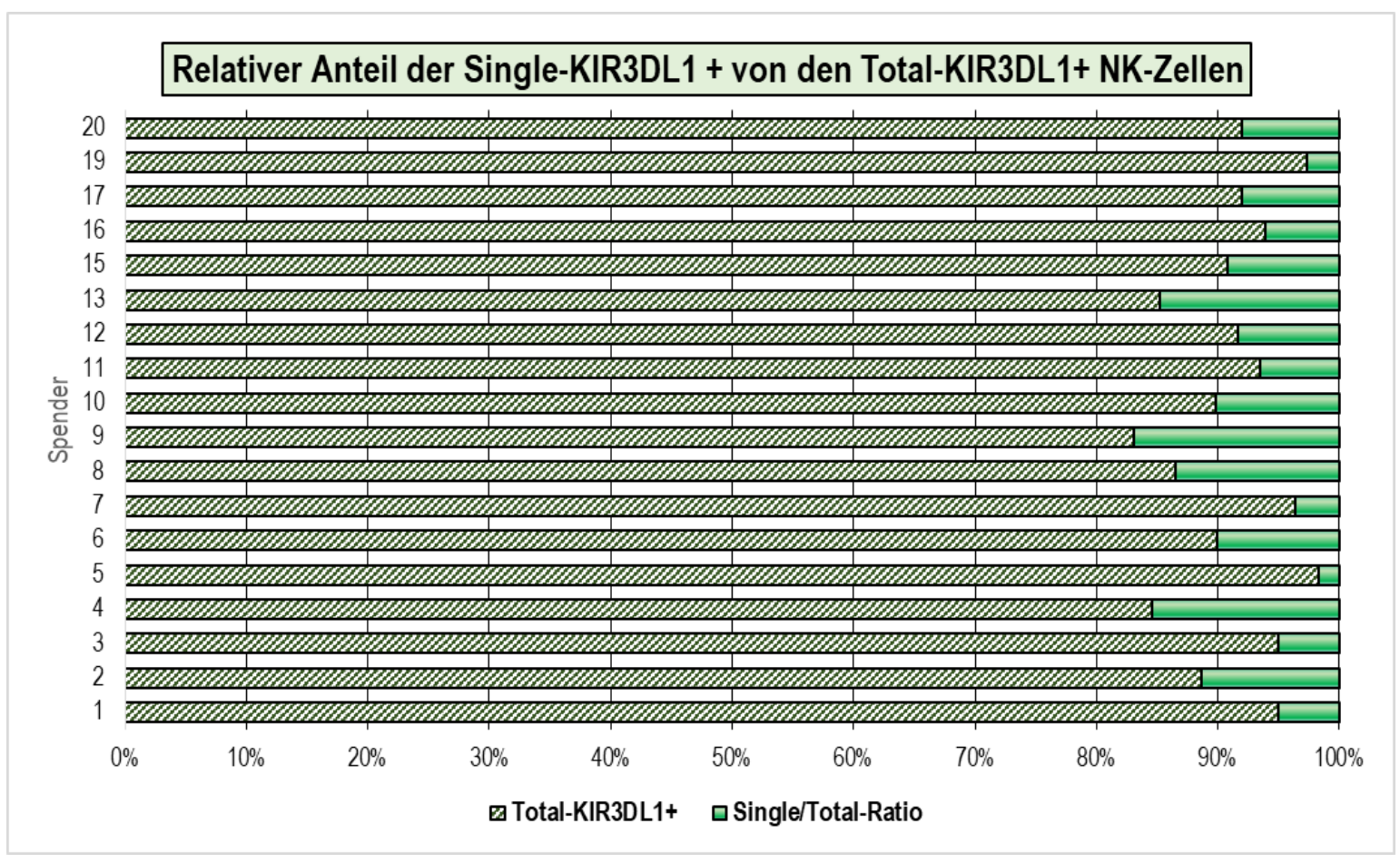

Abbildung 34 Optische Darstellung der relativen Anteile der Single-KIR3DL1+ NK-Zellfraktion von der Total-KIR3DL1+ NK-Zellpopulation. Die Spender 14 und 18 sind nicht mit dargestellt.

Diese zelluläre Unterscheidung wurde bei den späteren funktionellen Aktivitätsmessungen verwendet, um NK-Zell-Populationen hinsichtlich ihrer Alloreaktivität auf verschiedenen transgenen L721.221-Zielzellen genauer zu studieren. Die zugrundeliegende Fragestellung war also, ob es bei Betrachtung der Alloreaktivität einzelner iKIRs (Single-KIR ${ }^{+}$NK-Zellen) zu verstärkten Degranulationsreaktionen gegen ihrer spezifischen HLA-Liganden kommt und als Konsequenz Single-KIR ${ }^{+} \mathrm{NK}-$ Zellen, bspw. für eine Transplantation, bevorzugt werden sollten.

\subsection{Ergebnisse des funktionellen CD107-Degranulationsassays}

Für die ex vivo Funktionsanalyse der 20 NK-Zell-Spender wurden vier verschiedene transgenen L721.221-Zielzellen verwendet. Dabei besitzt jede Zielzelle ein definiertes Profil 
von HLA-Klasse-I-Molekülen (MHC-I) auf ihrer Zelloberfläche. Für die Quantifizierung der Aktivitätslevel wurde das CD107-Degranulationsassay gewählt. Das Verfahren misst den Grad der NK-Zell-Aktivität anhand der resultierenden Oberflächenexpression bestimmter Membranfusionsproteine nach Zielzellkontakt. Nach Zusammentreffen mit einer Zielzelle kommt es zur Degranulation der NK-Zellen und Freisetzung zytotoxischer Vesikel. Dafür fusionieren die Vesikel mit der äußeren NK-Zellmembran. Die bei dem CD107Degranulationsassay eingesetzten Antikörper binden an solche lysosomal assoziierte Membranglykoproteine (LAMPs), einschließlich CD107a (LAMP-1) und CD107b (LAMP2), welche dann kurzzeitig auf der NK-Zell-Oberfläche exprimiert werden. Durch die Kopplung der Anti-CD107a/b-Antikörper an ein FITC-Fluorochrom können mittels Durchflusszytometer spender- oder gruppenspezifischen Aktivitätskurven der NK-Zellen aufgezeichnet und verglichen werden.

\subsubsection{Funktionelle Untersuchung des Haplotyps-AA und -Bx}

Nach der Haplotyp-Zuordnung der 20 untersuchten Spender ( $\rightarrow$ vgl. Abschnitt 5.1.1) wurden vergleichende Funktionsanalysen mittels CD107-Degranulationsassay durchgeführt. Dabei wurde die funktionelle Aktivität der NK-Zell-Spender des Haplotyps-AA und des Haplotyps-Bx für ihre gesamten NK-Zellen sowie ihre Total- und Single-KIR2DL1 ${ }^{+}$bzw. KIR3DL1 ${ }^{+}$NK-Zellpopulationen separat untersucht und ausgewertet.

Im Nachfolgenden werden die Ergebnisse des CD107-Degranulationsassays für HaplotypAA ( $n=3)$ und -Bx ( $n=17)$ präsentiert. Dabei zeigt Abbildung 35 die Aktivitätsspanne, d.h. die minimale und maximale prozentuale CD107-Aktivität, der gesamten NK-Zellen der gruppierten Haplotyp-AA und -Bx Spender nach Stimulation mit einer der vier transgenen L721.221-Zelllinien. Die in der Abbildung integrierte Tabelle zeigt die dafür zugrundeliegenden Einzeldaten für die Spender 1 bis 20. Bei dem Aktivitätsvergleich der haplotypisierten Spender fällt auf, dass die Gesamt-NK-Zellpopulation des Haplotyps-AA eine geringe Aktivitätsspanne und damit vergeichsweise hohe CD107-Aktivität gegenüber L721.221-ØHLA (zwischen 46\% und 70\%) aufweist. Auch gegenüber der Zellllinie L721.221-Bw4 zeigt sich bei Spendern des Haplotyps-AA ein ähnliches Bild mit einer Aktivitätsspanne zwischen 40\% und 70\%. Ein solches Ergebnis zeigt sich für keine weitere Kombination von NK-Haplotyp und L721.221-Zielzelle. 


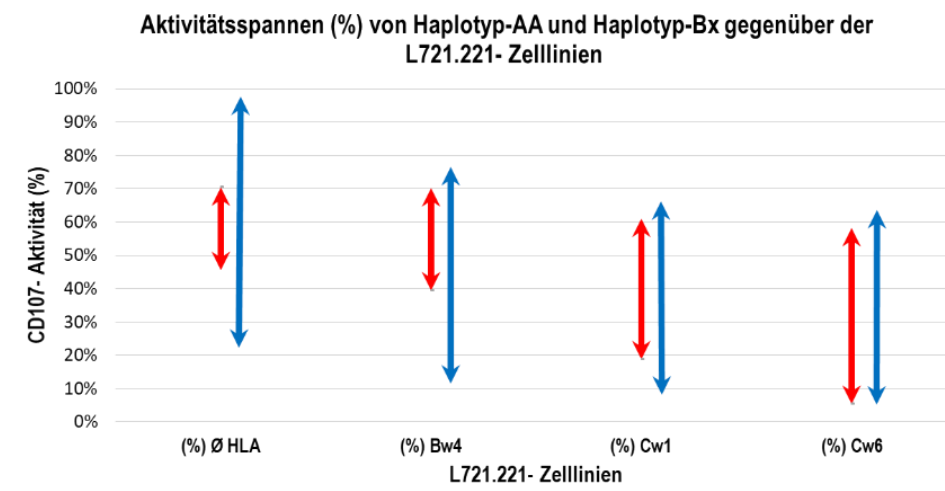

\begin{tabular}{|c|c|c|c|c|c|c|}
\hline \multirow{3}{*}{$\begin{array}{l}\bar{\Phi} \\
\text { क्षे } \\
\text { के }\end{array}$} & \multirow{2}{*}{\multicolumn{2}{|c|}{$\begin{array}{l}\text { 옹 } \\
\frac{0}{2} \\
\text { ㅍㅗㅗ }\end{array}$}} & \multicolumn{4}{|c|}{$\begin{array}{c}\text { Haplotyp-Vergleich } \\
\text { - gesamte NK-Zellen- }\end{array}$} \\
\hline & & & \multicolumn{4}{|c|}{ CD107-Aktivität (\%) gegen } \\
\hline & $\mathrm{AA}$ & $B x$ & $\begin{array}{c}\text { L721.221 } \\
\text {-ØHLA }\end{array}$ & \begin{tabular}{|c|}
721.221 \\
$-B w 4$
\end{tabular} & $\begin{array}{l}\text { L721.221 } \\
- \text { CW1 }\end{array}$ & \begin{tabular}{|c|} 
L721.221 \\
- Cw6 \\
\end{tabular} \\
\hline 1 & & & $74 \%$ & $21 \%$ & $51 \%$ & $30 \%$ \\
\hline 2 & & & $36 \%$ & $24 \%$ & $16 \%$ & $26 \%$ \\
\hline 3 & & & $69 \%$ & $70 \%$ & $61 \%$ & $58 \%$ \\
\hline 4 & & & $69 \%$ & $20 \%$ & $19 \%$ & $36 \%$ \\
\hline 5 & & & $46 \%$ & $49 \%$ & $30 \%$ & $13 \%$ \\
\hline 6 & & & $57 \%$ & $25 \%$ & $19 \%$ & $38 \%$ \\
\hline 7 & & & $23 \%$ & $21 \%$ & $15 \%$ & $27 \%$ \\
\hline 8 & & & $97 \%$ & $43 \%$ & $45 \%$ & $55 \%$ \\
\hline 9 & & & $60 \%$ & $59 \%$ & $25 \%$ & $51 \%$ \\
\hline 10 & & & $65 \%$ & $55 \%$ & $65 \%$ & $27 \%$ \\
\hline 11 & & & $51 \%$ & $16 \%$ & $13 \%$ & $10 \%$ \\
\hline 12 & & & $59 \%$ & $58 \%$ & $25 \%$ & $31 \%$ \\
\hline 13 & & & $33 \%$ & $13 \%$ & $9 \%$ & $6 \%$ \\
\hline 14 & & & $31 \%$ & $63 \%$ & $41 \%$ & $15 \%$ \\
\hline 15 & & & $70 \%$ & $40 \%$ & $19 \%$ & $5 \%$ \\
\hline 16 & & & $66 \%$ & $18 \%$ & $9 \%$ & $5 \%$ \\
\hline 17 & & & $80 \%$ & $75 \%$ & $55 \%$ & $62 \%$ \\
\hline 18 & & & $31 \%$ & $27 \%$ & $23 \%$ & $21 \%$ \\
\hline 19 & & & $53 \%$ & $37 \%$ & $13 \%$ & $19 \%$ \\
\hline 20 & & & $69 \%$ & $58 \%$ & $31 \%$ & $60 \%$ \\
\hline
\end{tabular}

Abbildung 35 Aktivitätsspanne, definiert nach minimaler und maximaler CD107-Aktivität (in Prozent) gegen die vier verwendeten L721.221-Zielzelllinien, für Haplotyp-A (rot) und Haplotyp-Bx (blau). Die integrierte Tabelle zeigt die dafür verwendeten Einzelergebnisse der haplotypisierten NK-Zell-Spender. Die geringste Aktivitätsspanne zeigt Haplotyp-AA gegenüber den Zelllinien L721.221-øHLA und -Bw4.

Die sich anschließende Auswertung bezieht sich auf die Durchschnittswerte der Aktivitätsergebnisse der Total-KIR2DL1 ${ }^{+}$und Single-KIR2DL1 ${ }^{+}$Zellpopulationen (Abb. 36, Diagramme 1 und 2) nach Kontakt mit den vier Zielzellinien. Die stärkste Inhibition

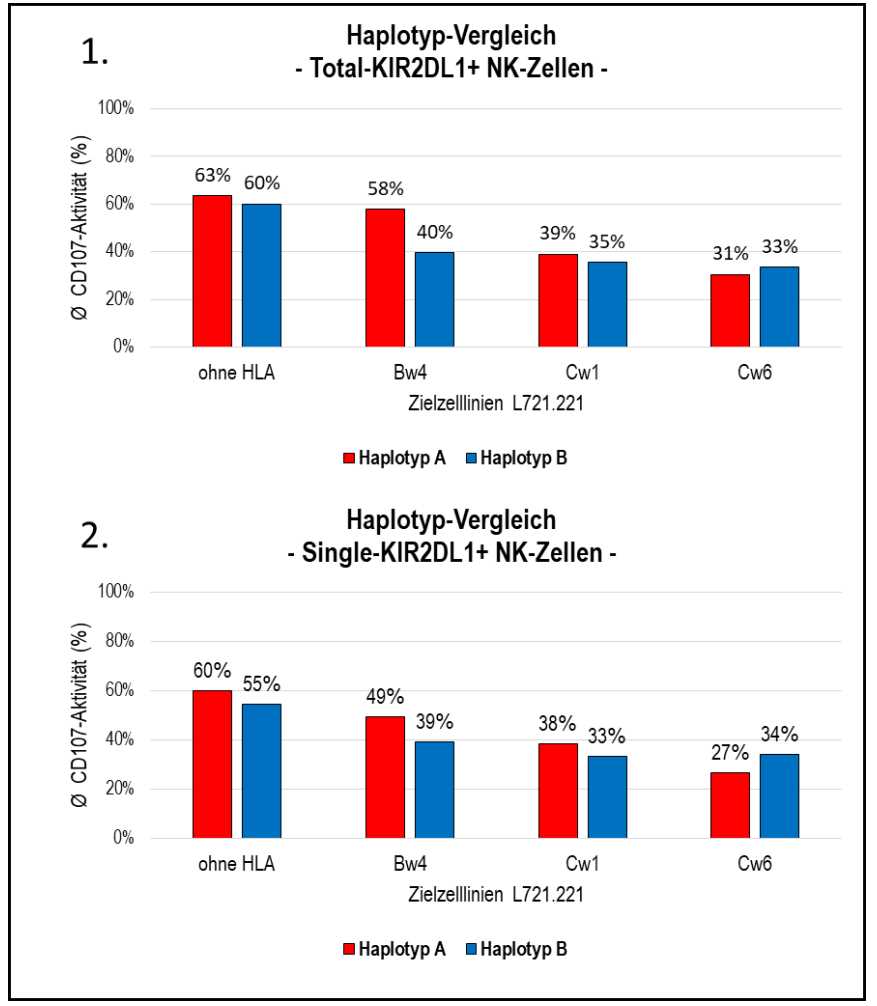

Abbildung 36 Säulendiagrammdarstellung des durchschnittlichen prozentualen aktiven NK-Zell-Anteils der Total-KIR2DL1+ (1.; oben) und Single-KIR2DL1+ (2.; unten) der Spender Haplotyp-AA Gruppe (rot, $n=3)$ und der Haplotyp-Bx Gruppe (blau, $n=17)$. Alle Prozentwerte wurden für die Darstellung auf- bzw. abgerundet. und damit geringste CD107Aktivität wurde gegen die Zielzellen mit dem spezifischen Liganden $\mathrm{Cw} 6$, als Vertreter der HLA-C2 Gruppe, erwartet. Der KIR-HLA-mismatch Theorie folgend, zeigen die NKZellen beider Haplotypen in beiden Diagrammen hierbei tatsächlich die im Durchschnitt höchste Aktivität gegen die Zielzelllinie mit fehlendem HLA-Liganden (L721.221-ØHLA). Die Total-KIR2DL1 ${ }^{+}$NK-Zellen des Haplotyps-AA zeigen eine höhere durchschnittliche CD107Aktivität gegenüber L721.221$\varnothing$ HLA, -Bw4 und -Cw1 verglichen mit den Aktivitätsdaten der Spender des Haplotyps-Bx. Bei Haplotyp-Bx 
Spendern zeigt sich im direkten Vergleich eine zusätzlich stärkere Aktivität gegenüber dem HLA-Liganden $\mathrm{Cw6}$, als Zeichen einer unterlegenen Hemmung der NK-Zellfunktion. In den Diagrammen 1 (Total-KIR2DL1 ${ }^{+}$) und 2 (Single-KIR2DL1 ${ }^{+}$) der Abbildung 36 beträgt die durchschnittliche prozentuale Haplotyp-A/B-Differenz ohne HLA-Liganden 3\%, mit Bw4-Liganden 18\% und mit Cw1-Liganden 4\%. In Bezug auf den HLA-Liganden Cw6 zeigt sich bei der Total-KIR2DL1 ${ }^{+}$Population des Haplotyps-AA eine Haplotyp-A/B-Differenz von $2 \%$, bei der Single-KIR2DL1 ${ }^{+}$Population von 7\%. Bei der Interaktion mit den Zielzelllinien L721.221-Bw4 und -Cw1, ohne spezifischen Liganden für KIR2DL1, zeigen stimulierte Spender des Haplotyps-AA bezogen auf die CD107-Aktivität der Single- und Total-KIR2DL1 ${ }^{+}$NK-Zellpopulationen erhöhte durchschnittliche Aktivitätslevel. Die durchschnittliche Haplotyp-AA Aktivität gegenüber dem HLA-Liganden Bw4 überstieg in den NK-Zellpopulationen dabei deutlich die der Haplotyp-Bx Vergleichsgruppe. Es zeigte sich ein Haplotyp-A/B-Differenzmaximum von 18\% in der Population der TotalKIR2DL1 ${ }^{+}$NK-Zellen. Bezogen auf die durchschnittliche Haplotyp-AA Aktivität gegenüber dem HLA-Liganden Cw1 ergaben sich lediglich Differenzwerte zwischen 4 - 5\%.

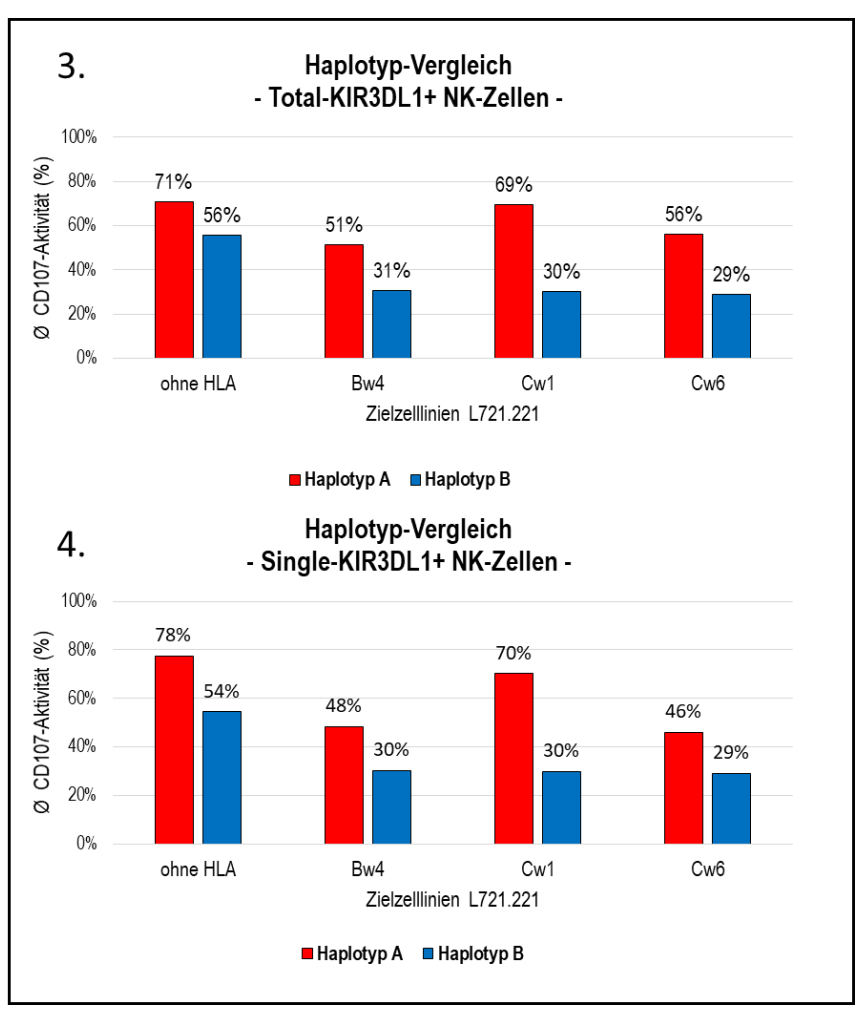

Abbildung 37 Säulendiagrammdarstellung des durchschnittlichen prozentualen aktiven NK-Zell-Anteils der gesamten NKZellpopulation (A), Total-KIR3DL1+ (3.; oben) und Single-KIR3DL1+ (4.; unten) der Spender Haplotyp-AAGruppe (rot, $n=3$ ) und der Haplotyp-Bx Gruppe (blau, $n=17$ ). Alle Prozentwerte wurden für die Darstellung auf- bzw. abgerundet.
Die Abbildung 37 zeigt die Auswertung bezogen auf die Durchschnittswerte der Aktivitätsergebnisse der SingleKIR3DL1 $^{+}$und Total-KIR3DL1+ Zellpopulationen

(Abb. 37, Diagramme 3 und 4) nach Kontakt mit den vier Zielzelllinien. Beim Haplotyp-Vergleich bezogen auf den KIR3DL1-Rezeptors zeigt die Untersuchung eine höhere durchschnittliche Aktivität der Total-

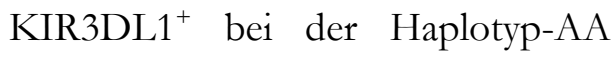
Gruppe verglichen mit der der SingleKIR3DL1 ${ }^{+}$NK-Zellen. In der unterlegenen Haplotyp-B Gruppe variieren die gemessene Aktivität gegenüner der HLA-Liganden Bw4, Cw1 und Cw6 nur geringfügig (0,7 - 
2,1\%) untereinander und zeigen deshalb graphisch nahezu ein Aktivitätsplateau. Die größten Haplotyp-A/B-Differenzen zeigen sich in Bezug auf die Zielzelllinien L721.221-Cw1 und Cw6, welche beide keinen spezifischen Liganden für KIR3DL1 darstellen. Beim Vergleich der Aktivität gegen L721.221-øHLA der Total-KIR3DL1 ${ }^{+}$mit der Single-KIR3DL1 ${ }^{+}$NKZell-Population zeigt die Single-KIR3DL1 ${ }^{+}$Population der Haplotyp-AA Spender die größte Aktivitätsdifferenz von rund 29\%. Die Total-KIR3DL1 ${ }^{+}$Haplotyp-AA Zellpopulation zeigt dagegen die geringste Inhibitionsleistung mit etwa 19\%. Die Total- und Single-KIR3DL1+ Spenderpopulationen des Haplotyps-Bx zeigen in diesem Vergleichsmodell als Ergebnis eine durchschnittliche prozentuale Aktivitätsdifferenz von $24,5 \%$.

\subsubsection{Funktionelle Untersuchung des spenderspezifischen MHC-I-Profils}

Mehrere wissenschaftliche Arbeiten konnten zeigen, dass die individuelle Ausstattung an MHC-I Molekülen (MHC-I-Profil) Einfluss auf die Erlangung der funktionellen Kompetenz von NK-Zellen nimmt. ${ }^{109,212,213}$ Wenn ein Individuum den Killerzell-Immunoglobulinähnlichen Rezeptor KIR2DL1 und gleichzeitig den spezifischen C2-Liganden auf der Oberfläche seiner NK-Zellen exprimiert, werden die NK-Zellen dieser Hypothese folgend anders funktionell ausgebildet und sind damit potenziell kompetenter in der Erkennung krankhaft-veränderter Körperzellen. Im Umkehrschluss bedeutet dies aber auch, dass KIR2DL1 ${ }^{+}$Individuen, die in ihrem HLA-Repertoire ausschließlich C1+ HLA-Liganden oder analog KIR3DL1 ${ }^{+}$Individuen ausschließlich Bw6+ HLA-Liganden exprimieren, weniger gut ausgebildete NK-Zellen besitzen müssten.

Die NK-Zell-Spender wurden entsprechend ihrer HLA-Typisierungsergebnisse bezogen auf die 4 relevanten Ligandepitope C1, C2, Bw4 und Bw6 gruppiert und einem der MHC-IProfile C2+, C2-, Bw4+ oder Bw4- zugeordnet ( $\rightarrow$ vgl. Tabelle 14, Abschnitt 5.2). Die Abbildung 38 zeigt auf der nachfolgenden Seite die Ergebnisse des CD107Degranulationsassays der MHC-I gruppierten Total-KIR2DL1+ ${ }^{+}$KK-Zellen. 


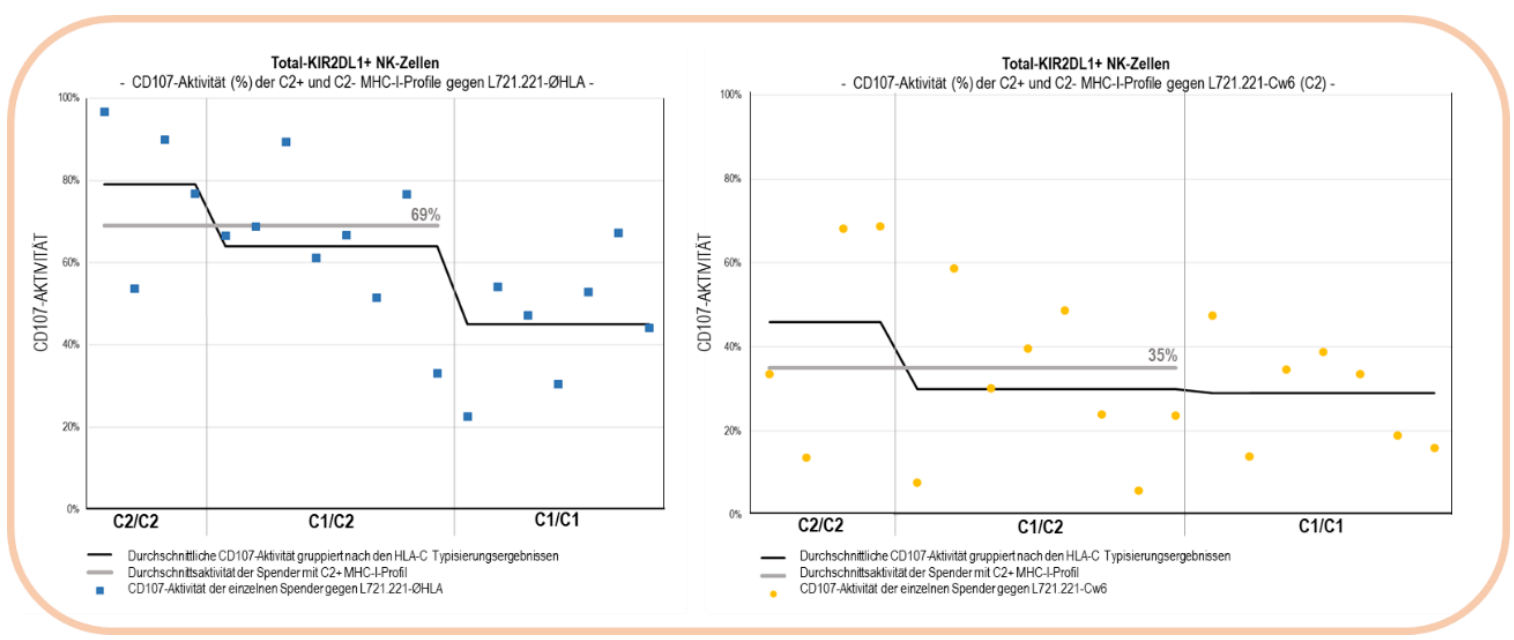

Abbildung 38 Auswertung des CD107-Degranulationsassays der nach MHC-I gruppierten KIR2DL1+ Spender NKZellen. Die abgebildeten Punkte entsprechen den Aktivitäten der einzelnen Spender (links) gegen L721.221-ØHLA und (rechts) gegen L721.221-Cw6 (А HLA-C C2). Die schwarze Linie zeigt die durchschnittliche CD107-Aktivität der nach ihren HLA-C Typisierungsergebnissen gruppierten Spender. Die graue Linie repräsentiert die Durchschnittsaktivität der Spender mit C2+ MHC-I-Profil, d.h. C2/C2 oder C1/C2 MHC-I-Ligand.

Die Spender mit homozygoten C2/C2-Allelen $(\mathrm{n}=4)$ sowie heterozygoten C1/C2-Allelen $(n=8)$ repräsentieren das C2+ MHC-I-Profil und zeigen im CD107-Degranulationsassay gegen die Zellinie L721.221-ØHLA eine durchschnittlich höhere prozentuale Aktivität (69\%) verglichen mit Spendern des C2- MHC-I-Profils (45\%). Bei der Erkennung der C2 tragenden Zelllinie L721.221-Cw6 zeigen die Spender der MHC-I-Ligandengruppen C1/C2 und C1/C1 nahezu identische Aktivitätslevel und damit eine stärkere Inhibition der NKZellfunktion.

Die Auswertung der Ergebnisse des CD107-Degranulationsassays der MHC-I gruppierten Total-KIR3DL1 ${ }^{+}$NK-Zellen zeigt, wie in Abbildung 39 dargestellt, ein abweichendes Ergebnis. Im CD107-Degranulationsassay gegen die Zellinie L721.221-ØHLA zeigen die Spender mit Bw4+ MHC-I-Profil $(\mathrm{n}=10)$ mit durchschnittlich 57\% ein kaum von dem Rest der Spender abweichendes Ergebnis. Bei dem Inhibitionsvergleich der MHC-I gruppierten Total-KIR3DL1 ${ }^{+}$NK-Zellen nach Kontakt mit der korrespondieren Zelllinie L721.221-Bw4 zeigen Spender des Bw4- MHC-I-Profils Bw6/Bw6 ( $\mathrm{n}=8)$ die geringste durchschnittliche CD107-Aktivität (28\%). Die Spendergruppe des Bw4+ MHC-I-Profils ( $\mathrm{n}=10)$ zeigt dagegen eine durchschnittliche prozentuale Aktivität von 39\%. 


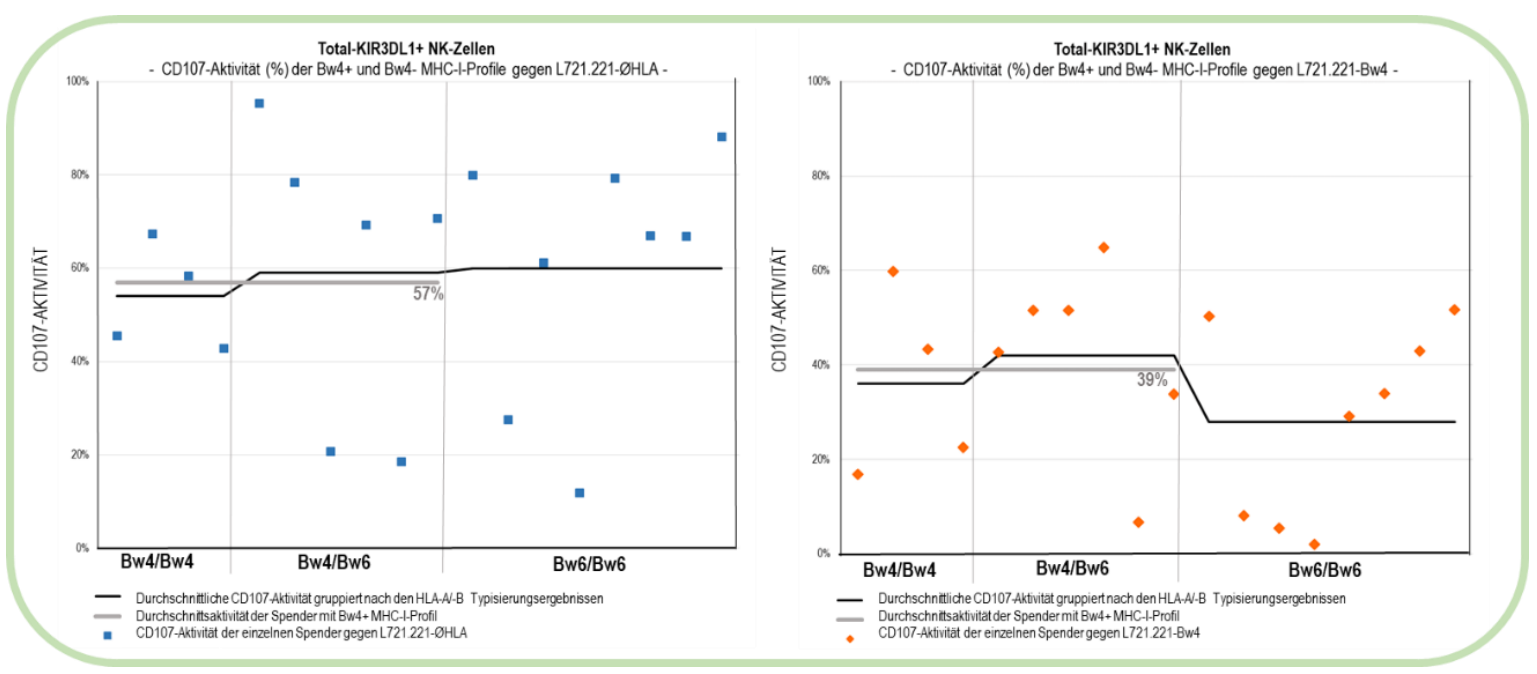

Abbildung 39 Auswertung des CD107-Degranulationsassays der nach MHC-I gruppierten KIR3DL1+ Spender NKZellen. Die abgebildeten Punkte entsprechen den Aktivitäten der einzelnen Spender (links) gegen L721.221-ØHLA und (rechts) gegen L721.221-Bw4. Die schwarze Linie zeigt die durchschnittliche CD107-Aktivität der nach ihren HLA-A/-B Typisierungsergebnissen gruppierten Spender. Die graue Linie repräsentiert die Durchschnittsaktivität der Spender mit Bw4+ MHC-I-Profil.

\subsubsection{NK-Zellaktivität der subtypisierten KIR2DL1-Spender}

Nach der Gruppierung der Spender anhand eines im Paper von Bari et al. für KIR2DL1 beschriebenen relevanten allelischen Polymorphismus an Aminosäuren-Position $245 \mathrm{im}$ Exon 7 des Rezeptorgens in $\mathrm{R}^{245}, \mathrm{C}^{245}$ und $\mathrm{R} / \mathrm{C}^{245}$ ( $\rightarrow$ vgl. Abschnitt 5.3.1) wurden Messungen der NK-Zellaktivität mittels CD107-Degranulationsassay durchgeführt. Spender 20 $\left(2 \mathrm{DL} 1 * 00301 /{ }^{*} 01201^{\text {neu}}\right)$ zeigte eine neue heterozygote Variante an der Nukleotidposition 81, resultierend in einer Kombination der basischen AS Arginin mit der hydrophoben AS Alanin $\left(\mathrm{R} / \mathrm{A}^{245}\right)$. Für die Aktivitätsmessungen wurden vier transgene L721.221-Zielzellen verwendet. Die funktionelle Aktivität wurde für die Single-KIR2DL1 ${ }^{+}$und Total-KIR2DL1 ${ }^{+}$ NK-Zellpopulationen bei den Spendern separat untersucht und verglichen.

Analog der KIR-HLA-mismatch Theorie zeigten sowohl die Total-KIR2DL1 ${ }^{+}$als auch die Single-KIR2DL1 ${ }^{+}$NK-Zellen der allermeisten Spender die höchste CD107-Aktivität gegenüber der L721.221-Zielzelllinie mit fehlendem HLA-Liganden (Abb. 40). Die TotalKIR2DL1 ${ }^{+}$NK-Zell-Population der $\mathrm{R}^{245}$-Gruppe zeigt die im Durchschnitt das stärkste Aktivitätspotenzial (81\%), gefolgt von der R/C $\mathrm{C}^{245}$-Gruppe (61\%) und der $\mathrm{C}^{245}$-Gruppe (46\%). Die durchschnittlich stärkste NK-Zell-Inhibition zeigt sich ebenfalls in der $\mathrm{R}^{245}$ Gruppe ( $>\mathrm{R} / \mathrm{C}^{245}$ Gruppe $>\mathrm{C}^{245}$-Gruppe). Einzige Ausnahmen bildeten die Spender 2 und 7 der $C^{245}$-Allelgruppe, deren gemessene CD107-Aktivitäten nach Stimulation mit L721.221Cw6 prozentual höher lagen, als mit L721.221-ØHLA ( $\rightarrow$ vgl. Tabelle 20). 
Total-KIR2DL1+ NK-Zellen

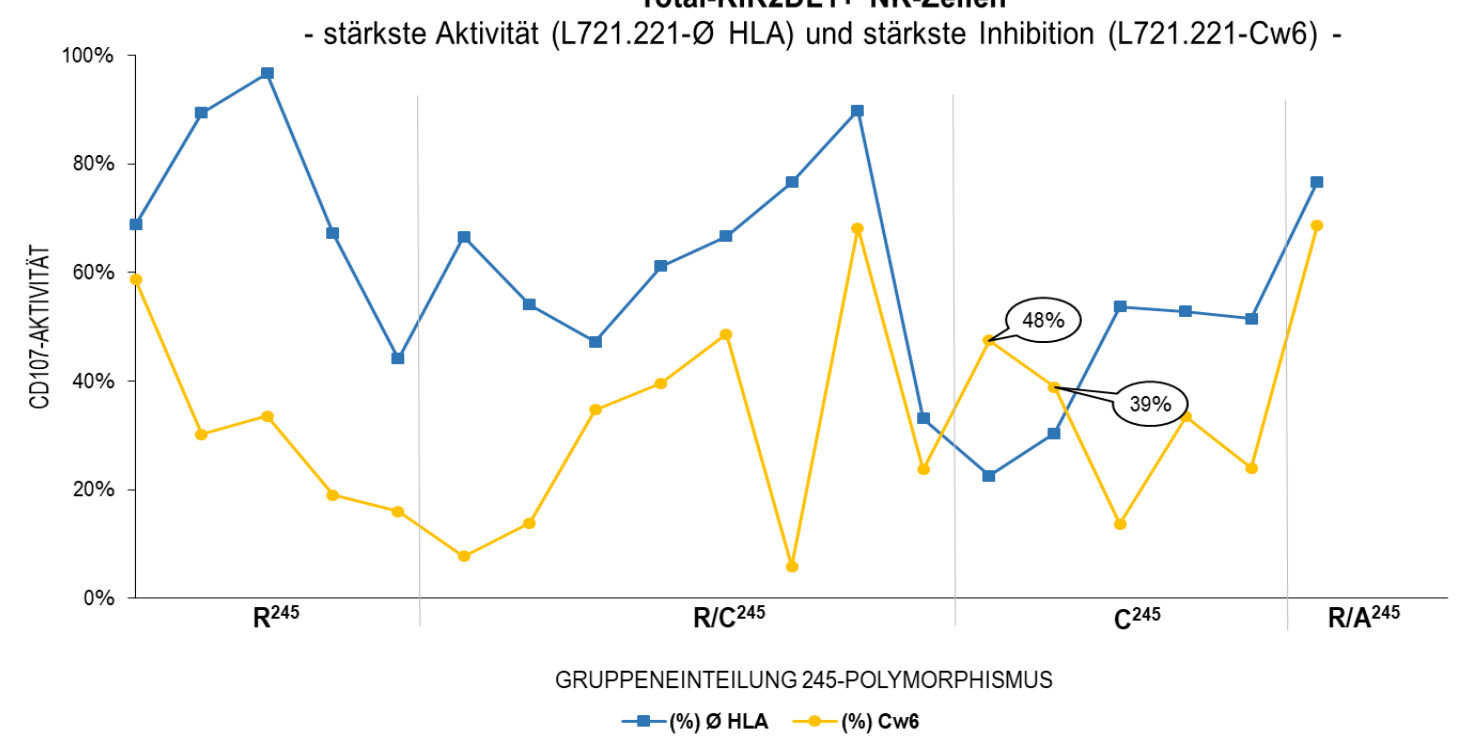

Abbildung 40 Überblick der gruppierten 20 Spender beim Vergleich der Aktivität der gruppierten Total-KIR2DL1+NKZellen gegen L721.221 ohne HLA-Ligand (= erwartete stärkste Aktivierung) mit der Aktivität bei Interaktion mit dem rezeptorspezifischen HLA-C2 Liganden Cw6 (= erwartete stärkste Inhibition).

Die restlichen Spender zeigten dem KIR2DL1-spezifischen HLA-Gruppe C2 Liganden gegenüber die stärkste NK-Zell-Inhibition. Bei der Untersuchung des KIR2DL1-Rezeptors des Spenders 20 (R/A ${ }^{245}$-Gruppe) zeigten sich gegenüber den beiden Zelllinien L721.221$\varnothing$ HLA und -Bw4 nahezu identische Prozentsätze zwischen 74\% und 77\%. Statt der stärksten NK-Zell-Inhibition nach Interaktion mit L721.221-Cw6, als KIR2DL1 korrespondierender HLA-C2 Ligand, zeigte sich die stärkste Hemmung mit 38\% nach Stimulation der Spender NK-Zellen mit HLA-C1.

Tabelle 20 Abweichende Spender beim Aktivitätsvergleich gegenüber verschiedenen Zielzellinien. Wichtige Messwerte zum Verständnis der Abbildungen 40 und 41 wurden in fett hervorgehoben.

\begin{tabular}{|c|c|c|c|c|c|c|c|}
\hline Donor & \multicolumn{2}{|c|}{ Allele } & 245-Gruppe & $\begin{array}{l}\text { KIR2DL1 (+) Total } \\
(\%) \text { ohne HLA }\end{array}$ & \begin{tabular}{|c} 
KIR2DL1 (+) Total \\
$(\%)$ Cw6
\end{tabular} & $\begin{array}{l}\text { KIR2DL1 (+) Total } \\
\text { (\%) Cw1 }\end{array}$ & $\begin{array}{l}\text { KIR2DL1 (+) Total } \\
\text { (\%) Bw4 }\end{array}$ \\
\hline 6 & ${ }^{*} 00302$ & ${ }^{*} 00403$ & $R / C$ & $47 \%$ & $35 \%$ & $27 \%$ & $14 \%$ \\
\hline 2 & ${ }^{*} 00401$ & ${ }^{*} 00403$ & C & $23 \%$ & $48 \%$ & $24 \%$ & $37 \%$ \\
\hline 7 & ${ }^{*} 00401$ & ${ }^{*} 00403$ & & $30 \%$ & $39 \%$ & $22 \%$ & $34 \%$ \\
\hline
\end{tabular}

Abbildung 41 auf der nachfolgenden Seite zeigt den Vergleich der CD107-Aktivität der Total-KIR2DL1 ${ }^{+}$Spender NK-Zellen gegen L721.221 ohne HLA-Ligand und beim Zusammentreffen mit den HLA-C Liganden Cw3 (HLA-C1) und Bw4 (HLA-A/B). Hierbei zeigt Spender 2 die geringste Aktivität gegenüber L721.221-ØHLA, verglichen mit den Aktivitätslevel gegenüber der Zielzelllinien L721.221-Bw4 und -Cw1. Spender 7 zeigt die niedrigste Aktivität gegenüber dem Liganden HLA-C1 ( $\rightarrow$ vgl. Tabelle 20). 


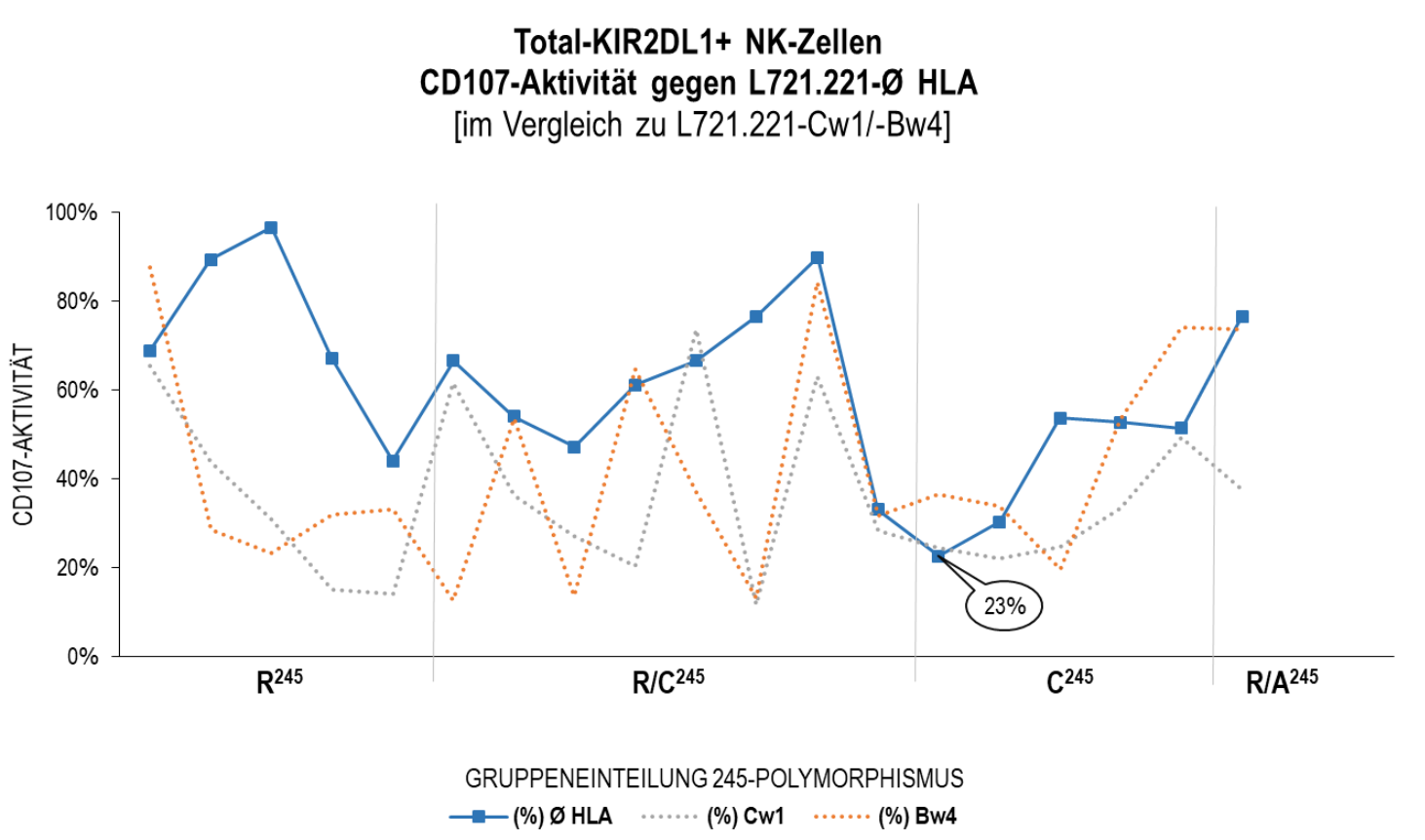

Abbildung 41 Überblick der gruppierten 20 Spender beim Vergleich der Aktivität der gruppierten Total-KIR2DL1+ NKZellen gegen L721.221 ohne HLA-Ligand mit höchster NK-Zell-Aktiviät verglichen mit der gemessenen CD107Aktivität bei Interaktion mit den Liganden Cw3 (HLA-C1) und Cw6 (HLA-C2) Liganden.

Weitere Abweichungen fanden sich beim Vergleich der Aktivitätslevel der Spender gegen L721.221-Bw4 und -Cw1 verglichen mit L721.221-Cw6 (Abb. 42).

Total-KIR2DL1+ NK-Zellen

CD107-Aktivität gegen L721.221-Cw6

[im Vergleich zu L721.221-Cw1/-Bw4]

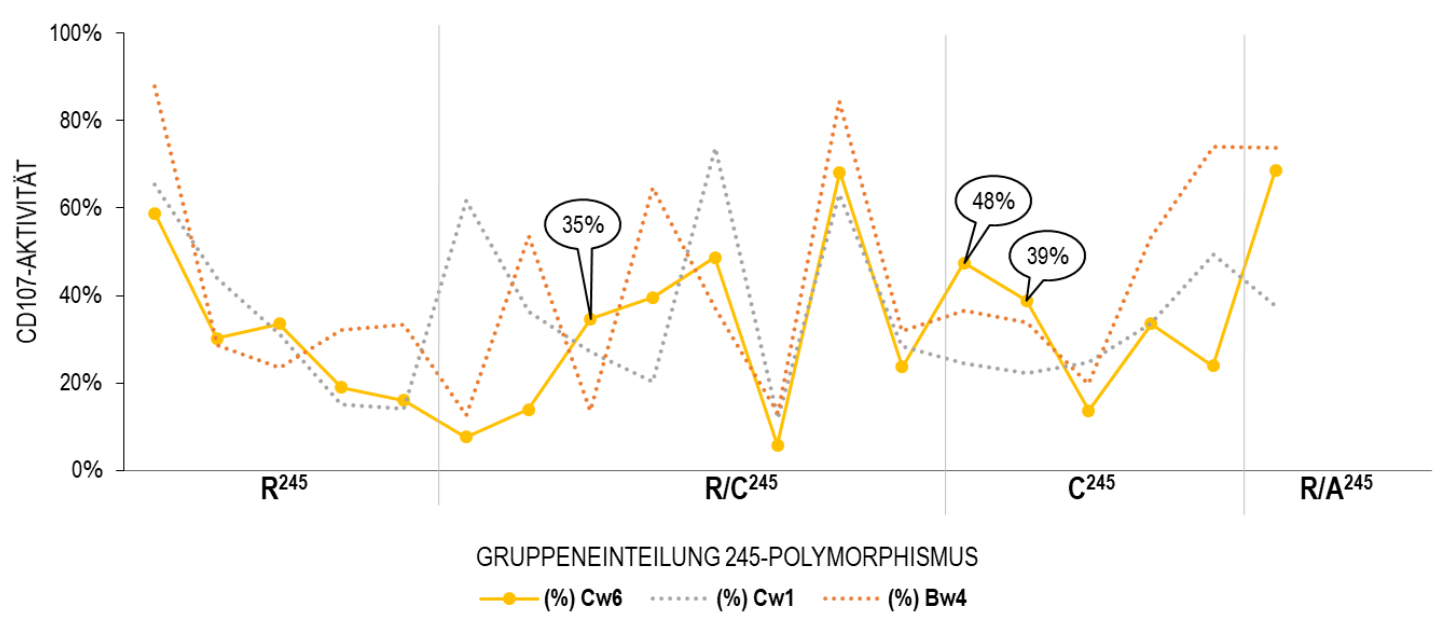

Abbildung 42 Spender 2 ( $C^{245}$ ) fiel in allen Vergleichsabbildungen gleichermaßen durch eine auffällig hohe Aktivität gegenüber L721.221-Bw4 und -Cw6 Zielzellen auf. Auch Spender 7 (C245), sowie Spender 6 aus der R/C245 -Gruppe zeigten dem HLA-C2 Liganden Cw6 gegenüber ein signifikant vermindertes inhibitorisches Potenzial.

Der rezeptorspezifischen (maximalen) Inhibition widersprachen drei Spender (Spender 2 und 7 der $C^{245}$-Allelgruppe und Spender $6 \operatorname{der} \mathrm{R} / \mathrm{C}^{245}$-Allelgruppe). Trotz unterschiedlicher 
Gruppenzugehörigkeit, zeigten diese drei Spender als gemeinsames Merkmal eine heterozygote Allelkombination mit dem KIR2DL1*00403-Allel, welches gleichzeitig innerhalb der untersuchten 20 Spender nach Subtypisierung mit 35\% das häufigste Allel darstellte ( $\rightarrow$ vgl. Tabelle 15, Abschnitt 5.3).

Bei dem Vergleich der Aktivität der Single-KIR2DL1 ${ }^{+}$Zellpopulation aller fünf Spender der alloreaktiv stärksten KIR2DL1-Allelgruppe $\mathrm{R}^{245}$ mit der Aktivität ihrer Total-KIR2DL1+ NK-Zellen zeigt sich kein relevanter Unterschied. Abbildung 43 zeigt zur Veranschaulichung dieses Ergebnisses eine nahezu spiegelbildliche Verteilung der Aktivitätniveaus nach Inkubation mit den vier transgenen L721.221-Zelllinien.

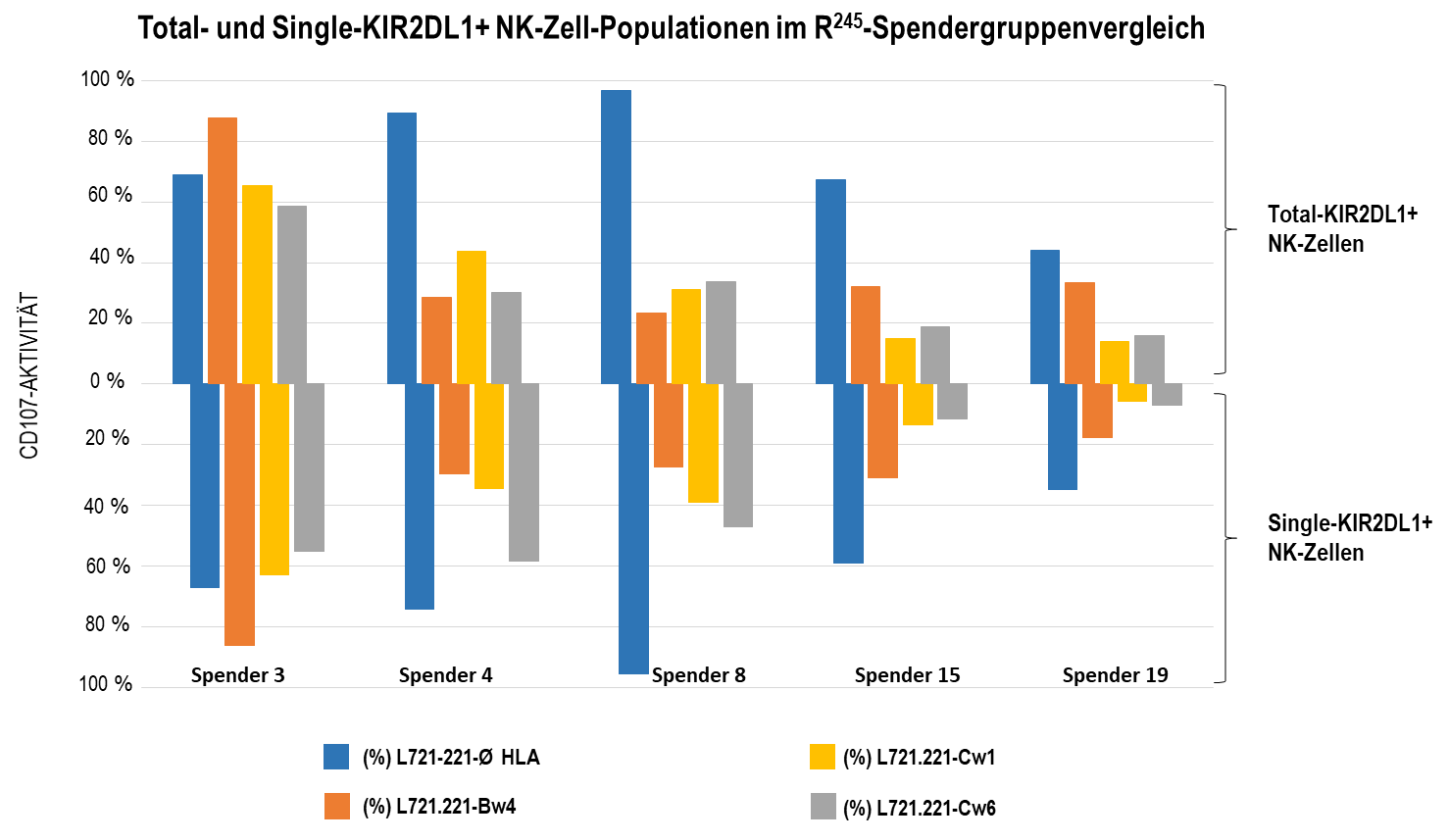

Abbildung 43 Übersicht über die CD107-Aktivitätsmessungen der NK-Zellpopulationen Total-KIR2DL1+ und der Single-KIR2DL1+ innerhalb der $\left.R^{245-S p e n d e r g r u p p e ~(~} n=5\right)$. Es zeigen sich nahezu identische Ergebnisse (in \%) bei der Aktivitätsmessung gegenüber den vier L721.221-Zelllinien. 


\subsubsection{NK-Zellaktivität der subtypisierten KIR3DL1-Spender}

Die KIR3DL1 ${ }^{+}$NK-Zell-Spender wurden, wie zuvor beschrieben, entsprechend der Einteilung von Gardiner et al. in low-, high- und zero- Expressions- und Affinitätsmuster eingeteilt. $^{215}$ Zusätzlich wurden die Spender mit unbekannter Allelzuordnung der Expressionsgruppe KIR3DL1-unknown zugeordnet. Nach allelischer Subtypisierung ergaben sich daraus 5 Untersuchungsgruppen: high/high-Spender (KIR3DL1 ${ }^{\mathrm{h} / \mathrm{h}}$ ), high/low-Spender

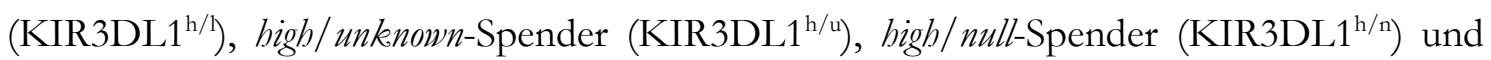
unknown/ unknown-Spender (KIR3DL1 ${ }^{\mathrm{u} / \mathrm{u}}$ ). Wie in Abbildung 44 gezeigt, konnten spezifische Expressionsmuster der KIR3DL1 ${ }^{+}$Spender NK-Zellen im Durchflusszytometer nach Anfärbung mit anti-KIR3DL1-APC-Antikörpern eindeutig optisch sichtbar gemacht werden. Exemplarisch wird die KIR3DL1 ${ }^{1 / u}$-Expressionsgruppe mit aufgeführt.
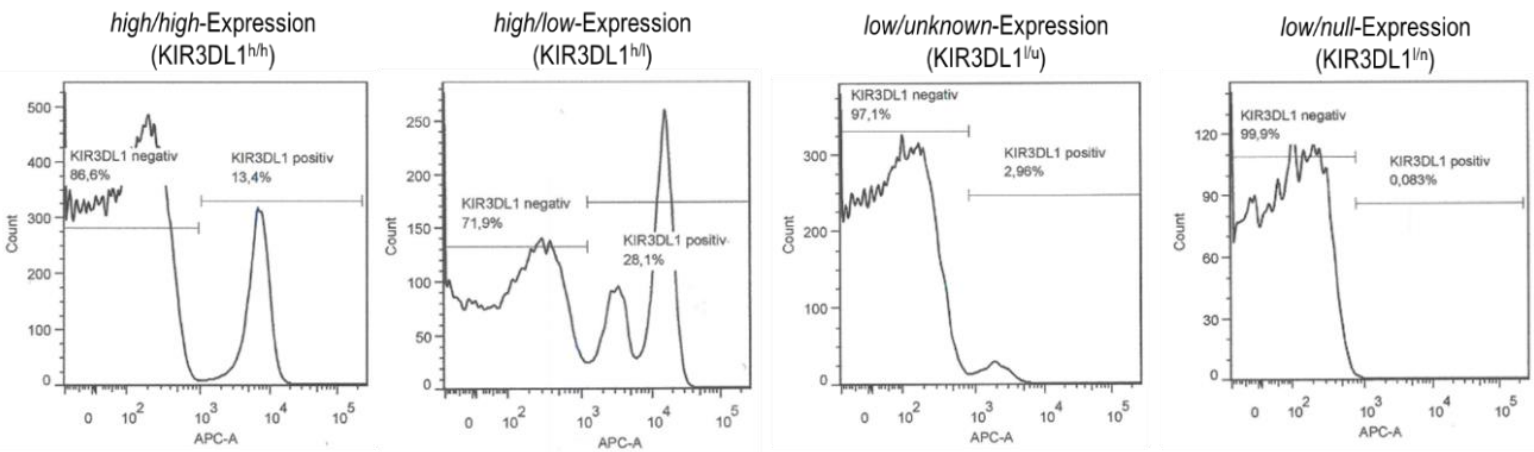

Abbildung 44 Exemplarische Darstellung von Rezeptorhistogrammen mit unterschiedlich starker Expressionsmuster der Spendergruppen high/high (KIR3DL1h/h), high/low (KIR3DL1h/l), low/unknown (KIR3DL1/u) und low/null (KIR3DL1/n) mittels Durchflusszytometrie. Für die Anfärbung der NK-Zellen wurde ein anti-KIR3DL1-APC Antikörper verwendet.

Die 5 Untersuchungsgruppen ( $\rightarrow$ vgl. Abschnitt 5.4.1) wurden in Hinblick auf ihre funktionelle Aktivität gegen vier transgene L721.221-Zielzellen im CD107Degranulationsassay miteinander verglichen wurden. Die Alloreaktivität der Spender NKZellen wurde dabei für ihre Single-KIR2DL1 ${ }^{+}$und Total-KIR2DL1 ${ }^{+}$NK-Zellpopulationen separat untersucht und verglichen.

Abbildung 45 auf der nachfolgenden Seite zeigt die Ergebnisse des CD107Degranulationsassays der 20 gruppierten KIR3DL1 ${ }^{+}$NK-Zell-Spender. Darin sind auch die Expressionsgruppen-determinierenden Spender-Allele mit aufgeführt. Analog der KIRHLA-mismatch Theorie zeigten sowohl die Total-KIR3DL1 ${ }^{+}$als auch die Single-KIR3DL1 ${ }^{+}$ NK-Zellen gegenüber der L721.221-ØHLA Zelllinie bei der mehrheitlichen Anzahl der 
Spender die höchste CD107-Aktivität, davon abweichend zeigen sich insgesamt vier Studienteilnehmer (Spender 3, 8, 9 und 20).

\section{CD107-Aktivität (\%) der KIR3DL1+ NK-Zellen - alle Spender im Überblick -}

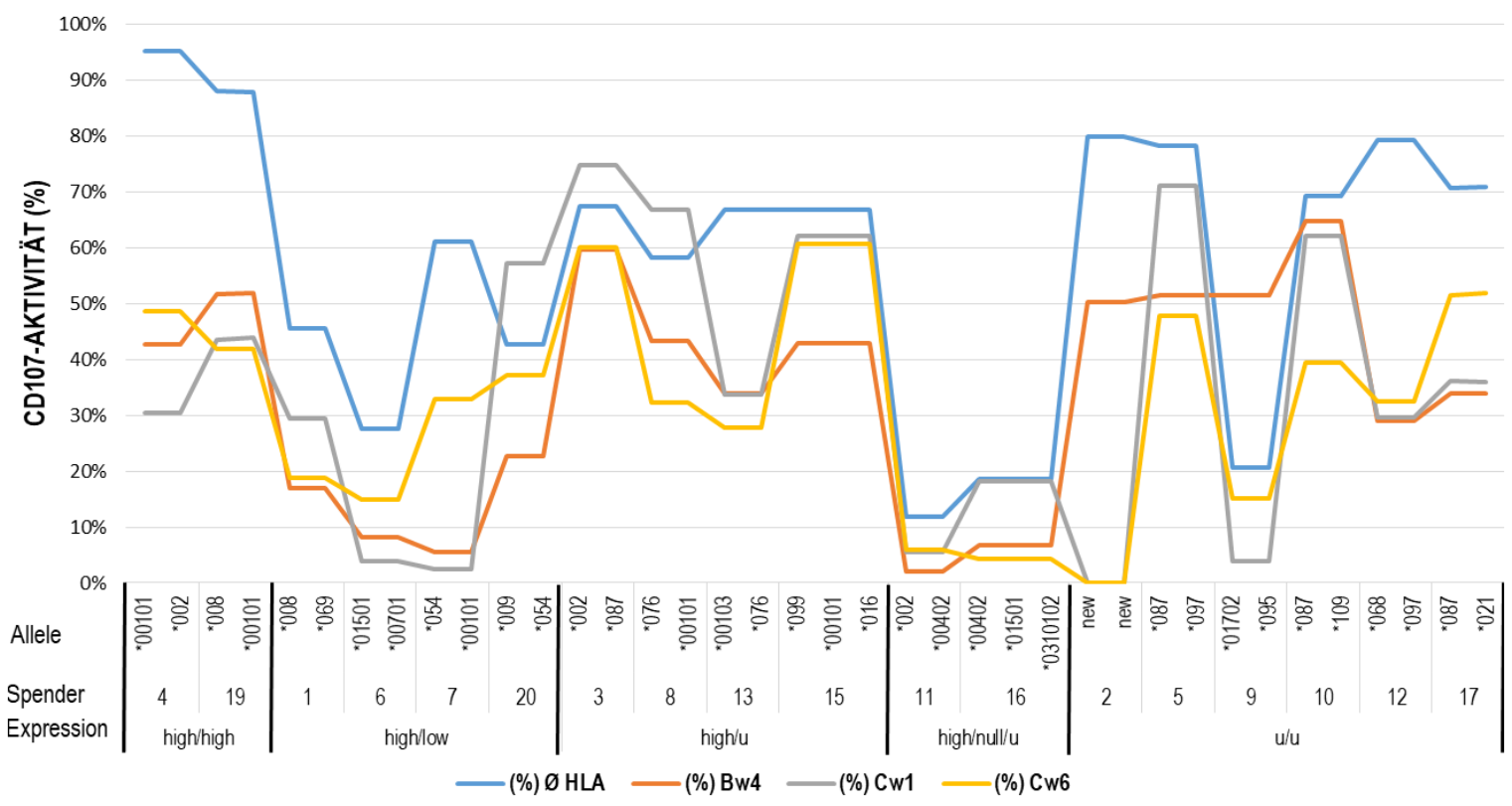

Abbildung 45 Exemplarische Darstellung von Rezeptorhistogrammen mit unterschiedlich starker Expressionsmuster der Spendergruppen high/high (KIR3DL1h/h), high/low (KIR3DL1h/), low/unknown (KIR3DL 1/lu) und low/null (KIR3DL1//n) mittels Durchflusszytometrie. Für die Anfärbung der NK-Zellen wurde ein anti-KIR3DL1-APC Antikörper verwendet.

Zur besseren Übersicht zeigt die nachfolgende Abbildung 46 die Ergebnisse des CD107Degranulationsassays für die Total-KIR3DL1 ${ }^{+}$NK-Zellen aller gruppierten Spender in Form eines Punktdiagramms nach Stimulation mit den Zelllinien L721.221-ØHLA und Bw4. Die gestrichelte Linie gibt darin den Durchschnitt der Aktivitätswerte für die NK-ZellSpender der jeweiligen Expressionsgruppe wieder. Die dazugehörige Tabelle 21 gibt die einzelnen prozentualen Aktivitätswerte des CD107-Assays wieder. 


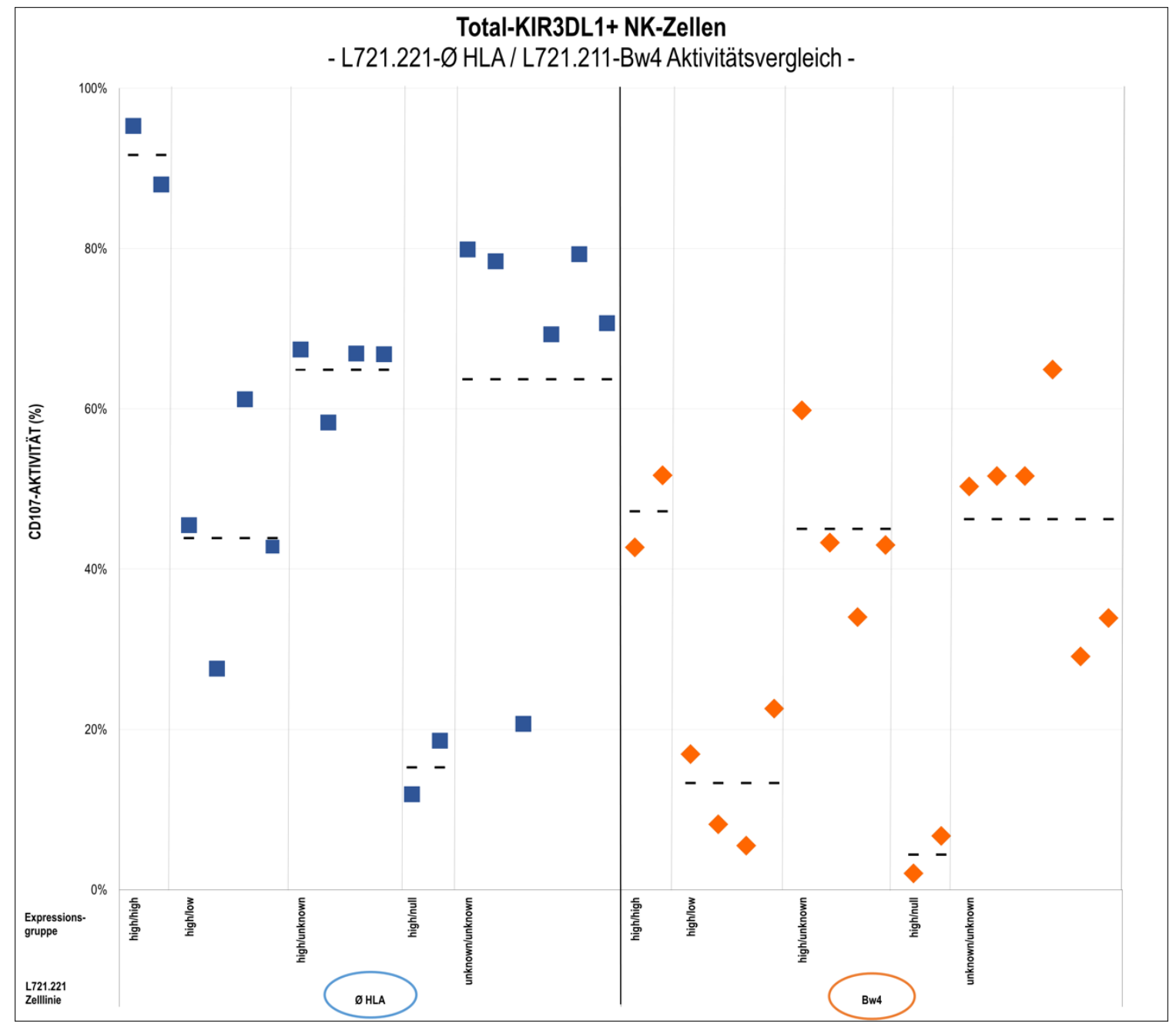

Abbildung 46 Überblick der gruppierten KIR3DL1+ Spender beim Vergleich der Aktivität gegen L721.221 ohne HLALigand (= erwartete stärkste Aktivität) mit der Aktivität bei Interaktion mit dem rezeptorspezifischen Liganden HLA-B mit Bw4 Epitop (= erwartete stärkste Inhibition). Die gestrichelte Linie stellt den Durchschnitt der Aktivitätswerte für die Spender der jeweiligen Expressionsgruppe dar.

Bei dem ØHLA-Aktivität/Bw4-Inhibition-Vergleich (Tabelle 21) zeigen Spender 4 und 19 der high/high-Expressionsgruppe (KIR3DL1 ${ }^{\mathrm{h} / \mathrm{h}}$ ) bei fehlendem HLA-Liganden mit einem maximalen Aktivitätsdurchschnitt von $92 \%$ die höchste Alloreaktivität innerhalb der gesamten Studiengruppe. Des Weiteren zeigen 5 von 6 Spendern der KIR3DL1 ${ }^{\mathrm{u} / \mathrm{u}}-$ Expressionsgruppe auffallend hohe Alloreaktivitätslevel (Durchschnitt 65\%), wie die Spender der KIR3DL1 ${ }^{\mathrm{h} / \mathrm{u}}-$ Gruppe mit durchschnittlich 66\%. Lediglich Spender 20 der KIR3DL1 ${ }^{\mathrm{h} /}$-Gruppe, Spender 3 und 8 der KIR3DL1 ${ }^{\mathrm{h} / \mathrm{u}}-$ Gruppe und Spender 9 der KIR3DL1 ${ }^{\mathrm{u} / \mathrm{u}}$-Expressionsgruppe präsentieren von der KIR-HLA-mismatch Theorie abweichende Ergebnisse. Bei den ersten drei genannten zeigt sich die stärkste Alloreaktivität nach Stimulation mit L721.221-Cw1, bei Spender 9 (3DL1*01702/*095) gegenüber der Zelllinie L721.221-Bw4. In Hinblick auf die zu erwartende Inhibition der NK-Zellen zeigen sich die niedrigsten Aktivitätslevels gegenüber L721.221-Bw4 für Spender der KIR3DL1 ${ }^{\mathrm{h} / \mathrm{n}_{-}}$ 
Expressionsgruppen mit durchschnittlich 15\%, gefolgt von low/high-Spendern mit durchschnittlich 44\%. Die high/unknown (KIR3DL1/u) -Gruppe mit 4 Spendern und unknown/unknown (KIR3DL1/u ) -Gruppe mit 6 Spendern zeigen ein annähernd gleich hohes Aktivitätsprofil (Durchschnitt 65,5\%). In Hinblick auf die Interaktion mit L721.221Bw4 zeigte sich die verhältnismäßig stärkste durchschnittliche Inhibition bei high/nullSpendern mit durchschnittlich 4\% gefolgt von Spendern der KIR3DL1 ${ }^{\mathrm{h} / 1}$ Expressionsgruppe mit durchschnittlich 13\%. Der prozentuale Durchschnitt der Alloreaktivität der verbleibenden Spender innerhalb der drei Expressionsgruppen high/high, high/unknown und unknown/unknown beträgt 45 - 47\%.

Tabelle 21 Messergebnisse des CD107-Assays der Total-KIR3DL1+ NK-Zellen nach Stimulation mit den Zellinien L721.221-ØHLA und $-B w 4$.

\begin{tabular}{|c|c|c|c|c|c|}
\hline \multirow{2}{*}{ Spender } & \multirow{2}{*}{$\begin{array}{c}\text { KIR3DL1- } \\
\text { Expressionsgruppe }\end{array}$} & \multicolumn{2}{|c|}{ L721.221-Ø HLA } & \multicolumn{2}{|c|}{ L721.221-Bw4 } \\
\hline & & $\begin{array}{l}\text { CD107- } \\
\text { Aktivität }\end{array}$ & Mittelwert & $\begin{array}{l}\text { CD107- } \\
\text { Aktivität }\end{array}$ & Mittelwert \\
\hline 4 & \multirow{2}{*}{$\begin{array}{c}\text { high/high } \\
\left(\text { KIR3DL1 }^{\text {h/h }}\right)\end{array}$} & $95 \%$ & \multirow{2}{*}{$92 \%$} & $43 \%$ & \multirow{2}{*}{$47 \%$} \\
\hline 19 & & $88 \%$ & & $52 \%$ & \\
\hline 1 & \multirow{4}{*}{$\begin{array}{c}\text { high/low } \\
\left(\text { KIR3DL1 }{ }^{\text {h/l }}\right)\end{array}$} & $46 \%$ & \multirow{4}{*}{$44 \%$} & $17 \%$ & \multirow{4}{*}{$13 \%$} \\
\hline 6 & & $28 \%$ & & $8 \%$ & \\
\hline 7 & & $61 \%$ & & $5 \%$ & \\
\hline 20 & & $43 \%$ & & $23 \%$ & \\
\hline 3 & \multirow{4}{*}{$\begin{array}{l}\text { high/unknown } \\
\left(\mathrm{KIR} 3 \mathrm{DL} 1^{\mathrm{u} / \mathrm{u}}\right)\end{array}$} & $67 \%$ & \multirow{4}{*}{$65 \%$} & $60 \%$ & \multirow{4}{*}{$45 \%$} \\
\hline 8 & & $58 \%$ & & $43 \%$ & \\
\hline 13 & & $67 \%$ & & $34 \%$ & \\
\hline 15 & & $67 \%$ & & $43 \%$ & \\
\hline 11 & \multirow{2}{*}{$\begin{array}{c}\text { high/null } \\
\left(\text { KIR3DL1 }{ }^{\text {h/u }}\right)\end{array}$} & $12 \%$ & \multirow{2}{*}{$15 \%$} & $2 \%$ & \multirow{2}{*}{$4 \%$} \\
\hline 16 & & $19 \%$ & & $7 \%$ & \\
\hline 2 & \multirow{6}{*}{$\begin{array}{l}\text { unknown/unknown } \\
\qquad\left(\mathrm{KIR} 3 \mathrm{DL} 1^{\mathrm{u} / \mathrm{u}}\right)\end{array}$} & $80 \%$ & \multirow{6}{*}{$66 \%$} & $50 \%$ & \multirow{6}{*}{$47 \%$} \\
\hline 4 & & $78 \%$ & & $52 \%$ & \\
\hline 9 & & $21 \%$ & & $52 \%$ & \\
\hline 10 & & $69 \%$ & & $65 \%$ & \\
\hline 12 & & $79 \%$ & & $29 \%$ & \\
\hline 17 & & $71 \%$ & & $34 \%$ & \\
\hline
\end{tabular}




\section{Diskussion}

\subsection{KIRom-basierte NK-Zell-Spenderauswahl}

Natürliche Killerzellen (NK-Zellen) haben die einzigartige Eigenschaft leukämische Blastenzellen zu erkennen und diese über gezielte Degranulation zu zerstören. ${ }^{219}$ Dabei helfen ihnen unter anderem die an HLA bindenden inhibierenden KillerzellImmunoglobulin-ähnliche Rezeptoren (KIRs). Die Anzahl aktivierender und inhibierender KIRs ist im menschlichen Genom festgelegt. Einige Autoren sprechen deshalb in diesem Zusammenhang von dem menschlichen KIRom. Je nach genetischer Ausstattung, das heißt der An- oder Abwesenheit von KIR-Genabschnitten, lassen sich Individuen in einen aktivierenden Haplotyp-AA oder inhibierenden Haplotyp-Bx genotypisieren. ${ }^{56,81}$ Der genetische KIR-Umfang jedes Spenders wurde in der vorliegenden Arbeit mittels KIR-SSP ermittelt.

Die Mehrheit der 20 NK-Zell-Spender wurden dem Haplotyp-Bx ( $\mathrm{n}=17)$ zugeordnet. Die Spender 3, 5 und 15 zeigten als Ergebnis den Haplotyp-AA. In der Literatur werden den Haplotypen unterschiedliche Rollen bei der Steuerung der Effektorfunktionen von NKZellen, wie der Degranulationsstärke, zugesprochen. ${ }^{81}$ Bereits die Arbeitsgruppe von Cooley et al. (2009) konnte zeigen, dass die KIR-Ausstattung der Spender eine wichtige Rolle für das Ergebnis nach haploidentischer hämatopoetischer Stammzelltransplantation (HSZT) bei Patienten mit akuter myeloischer Leukämie (AML) spielt. ${ }^{220}$ In einer großen Studie mit 448 eingeschlossenen Patienten zeigte sich nach drei Jahren ein besseres Gesamtüberleben nach Stammzellspende von KIR Bx-Individuen. Gleichzeitig zeigte sich keine erhöhte Inzidenz für eine akute Graft-versus-Host $(\mathrm{GvH})$-Reaktion bzw. Therapie-assoziierte Mortalität. ${ }^{220}$ Diese Daten legen nahe, dass der Haplotyp-Bx zu einem signifikanten Überlebensvorteil für AML-Patienten nach myeloablativer Konditionierung bei nicht verwandter Spende hämatopoetischer Stammzellen führt. Dieser Effekt ließ sich in der Studie jedoch nicht für Patienten mit akuter lymphatischer Leukämie (ALL) bestätigen. Auch bleibt unklar, welche aktivierenden oder inhibierenden B-Haplotyp-definierende KIR-Gene diesen Effekt ausmachen. Bisher konnte kein spezifisch exprimierter KIR identifiziert werden, der allein für das signifikant verbesserte Ergebnis nach HSZT verantwortlich ist. So bleiben die genauen Mechanismen, welche den Haplotyp-Bx im Rahmen der HSZT klinisch begünstigen, weitestgehend unerforscht. Sarah Cooleys Erkenntnisse zeigen dennoch eindeutig, weshalb die Bestimmung des KIR-Genotyps ein wichtiges Kriterium für die 
Spenderauswahl ist. Mittlerweile wird aus diesem Grund die KIR-Genotypisierung, neben der HLA-Typisierung, in vielen deutschen Instituten standardisiert durchgeführt.

Zur Untersuchung der Alloreaktivität der haplotypisierten Spender wurden in der vorliegenden Arbeit funktionelle NK-Zell-Analysen durchgeführt. Methodisch wurde dafür das CD107-Degranulationsassay gewählt. Die funktionelle Auswertung ergab, dass die Gruppe der gesamten NK-Zellen der Haplotyp-AA Spender gegenüber allen L721.221Zelllinien eine deutlich stärkere Aktivität zeigte. Obwohl der Stichprobenumfang mit 20 NK-Zell-Spendern sicherlich begrenzt ist und zudem eine zahlenmäßige Diskrepanz in der Gruppenverteilung von Haplotyp-AA und -Bx Spendern besteht, zeigen die Ergebnisse eine Tendenz an, die weiterer Forschung bedarf. Auch kleine Datensätze können als Teil zukünftiger Metaanalysen helfen, den Ansatz der KIR-Genotypisierung als wichtigen Parameter der NK-Spender-Auswahl zu bestärken.

Neben der Bedeutung funktioneller Haplotypen im Kontext der HSZT wurden in verschiedenen Arbeiten weiterführende Hypothesen über die potenziellen Vorteile von zytotoxischen NK-Zellen beider Haplotypen aufgestellt. Eine weit verbreitete Annahme ist, dass KIR A-Haplotypen prädisponiert sind Infektionskrankheiten zu bekämpfen, während KIR B-Haplotypen insbesondere Erfolge im Bereich der Reproduktion und nach Transplantationen zeigen. ${ }^{221,222}$ Dafürsprechende Studien konnten zeigen, dass homozygote KIR Haplotyp-AA Individuen messbar höhere Degranulationsraten ihrer NK-Zellen nach Kontakt mit virusinfizierten Zellen aufweisen. Daraus folgt, dass der Haplotyp-AA zu einer besseren Heilungsrate nach Hepatitis C-Infektion führt. Khakoo et al. (2004) konnte zeigen, dass sich insbesondere beim Fehlen des HLA-Bw4 Liganden (KIR-HLA-mismatch) von Individuen eine gesteigerte antivirale NK-Zell-Aktivität zeigt. Dies lässt auf die wichtige Rolle von respondierenden KIR3DL1-exprimierenden NK-Zellen im Rahmen der Hepatitisinfektion rückschließen. ${ }^{90}$ In anderen Publikationen konnte die Anwesenheit des aktivierenden KIR3DS1-Rezeptors in Zusammenhang mit einem langsameren Fortschreiten von AIDS nach einer HIV-Infektion gebracht werden. ${ }^{223,224}$ HIV- und Hepatitis C-infizierte Patienten mit KIR Haplotyp-AA sind gegenüber denen mit Haplotyp-Bx damit im Vorteil. ${ }^{225}$ Demgegenüber zeigen homozygote KIR Haplotyp-Bx Individuen einen natürlichen Schutz gegen schwangerschaftsassoziierte Komplikationen wie beispielsweise der Präeklampsie. ${ }^{226,227}$ 


\subsection{Allel-basierte NK-Zell-Spenderauswahl}

Im gleichen Jahr in dem Cooley et al. ihre Ergebnisse veröffentlichte ${ }^{220}$, folgten wichtige Forschungsarbeiten von Rafijul Bari, der sich der optimierten KIR-Spenderauswahl auf allelischer Ebene näherte. Im Unterschied zu Cooley et al. untersuchte er neben der genetischen An- oder Abwesenheit von KIR-Genen (spenderspezifisches KIRom) gezielt Veränderungen der Nukleotidsequenzen einzelner KIR-Genabschnitte. ${ }^{203}$ Bari et al. (2009) konnte dabei zeigen, dass bestimmte Polymorphismen der KIR-Allele zu signifikanten Unterschieden in der Alloreaktivität der Spender NK-Zellen führen. Dieser Hypothese folgend teilte er die ermittelten KIR2DL1-Allele in unterschiedliche Gruppen ein. Die Einteilung erfolgte abhängig von dem Auftreten exonischen Polymorphismen bzw. der Aminosäurenlokalisation in den strukturellen Domänen des fertigen Rezeptors. Insbesondere Allele der Gruppe 1 zeigten in den durchgeführten Funktionsanalysen eine verstärkte Alloreaktivität bei Interaktion mit ihren korrespondierende HLA-Liganden. ${ }^{203}$ In späteren Forschungsarbeiten wurden weitere Punktmutationen innerhalb inhibierender KIRs identifiziert, welche interindividuell die NK-Zellfunktion beeinflussen. ${ }^{204,205}$ Boudreau et al. (2017) postulierte, dass spenderspezifische KIR-Gen-Polymorphismen maßgeblich Einfluss auf das HSZT-Ergebnis bei transplantierten Patienten nehmen. ${ }^{228}$ Nach Bari et al. bildet die Spenderauswahl anhand des allelischen KIR-Subtyps der Spender eine weitere Möglichkeit der Optimierung des Einsatzes von NK-Zellen in der Medizin. Seine Beobachtungen zeigen, dass es nicht nur von Interesse ist im Vorfeld zu wissen welche KIRs ein Spender besitzt, sondern auch welche allelische KIR-Variante er vererbt bekommen hat.

Diese Bestrebungen wurden in der vorliegenden Forschungsarbeit aufgegriffen. So bestand das primäre Ziel darin ein optimiertes Subtypisierungsverfahren, ähnlich der hochauflösenden HLA-Typisierung, für die KIR-Allele der Gene KIR2DL1 und KIR3DL1 zu etablieren. Als Sequenzierungsmethode wurde die PCR nach Sanger gewählt, mit der die vollständige genetische Basenreihenfolge beider inhibitorischer KIRs von 20 gesunden, nicht verwandten Spendern ermittelt wurde. Für die Amplifikation der KIR-Gene wurden Primer aus den Publikationen von Hou et al. (2007) und Belle et al. (2008) verwendet. ${ }^{201,202}$ Für die Bestimmung der KIR2DL1- und KIR3DL1-Allele wurden die DNA-Amplifikate zunächst mittels 96-Kanal-Sequenzierung in eine kodierte Basensequenz übersetzt. Anschließend die von der Referenzsequenz abweichenden Basen identifiziert und als polymorphe Positionen innerhalb der Nukleotidsequenz markiert. Die Sequenzierungsergebnisse wurden in einer eigens dafür erstellten Excel-Tabelle zusammengefasst $(\rightarrow$ siehe Tabellen 33 und 35, 
Anhang). Bei der überschaubaren Anzahl beschriebener Allele für KIR2DL1 gestaltete sich die Eingrenzung methodisch nahezu problemlos. Die 19 untersuchten KIR2DL1 positiven NK-Spender konnten 12 bereits beschriebenen Allelen zugeordnet werden. Dafür wurde die Immuno Polymorphism Database (IPD) verwendet. Lediglich Spender 5 zeigte differente Positionen in Exon 5 (Positionen 179, 180, 238) und Exon 9 (Position 37) und konnte keinem der bisher beschriebenen Allelen eindeutig zuordnen werden. Für die Auswertung wurden die Allele KIR2DL1*00302/*00602 mit größtmöglicher Ähnlichkeit ausgewählt. Spender 20 zeigte neben dem Allel 2DL1*00302 eine neue Variante des Allels 2DL1*01201 mit Abweichungen in zwei Positionen innerhalb von Exon 7.

Das KIR3DL1-Gen besitzt im Gegensatz zu KIR2DL1 eine extrazelluläre D0-Domäne, kodiert durch Exon 3. Für diesen Drei-Domänen-Rezeptor sind mehr als doppelt so viele KIR-Allele in der IPD bereits hinterlegt. Im April 2013 waren insgesamt 69 KIR3DL1-Allele bekannt, 2019 waren es bereits 150, im Folgejahr 2020 sogar 186 Allelvarianten. Die große Anzahl an möglichen Punktmutationen innerhalb des KIR-Gens erhöht die Wahrscheinlichkeit für das Auftreten von Ambiguitäten bei der allelischen Subtypisierung. Dies spiegelt sich auch in dem Sequenzierungsergebnis der KIR3DL1 positiven Spender 15 und 16 wider. Bei beiden war eine Eingrenzung auf unter drei mögliche Allele mittels Doppelstrangsequenzierung methodisch nicht eindeutig möglich. Da in den nächsten Jahrzehnten mit einem stetigen Anstieg von KIR-Allelvariationen zu rechnen ist, ist die Umstellung auf ein einheitliches Einzelstrangverfahren zur genauen Eingrenzung der Allele der hochpolymorphen KIR-Gene sinnvoll. Next-Generation Sequencing (NGS)-Systeme haben dabei den Vorteil als moderne Sequenzierungsmethode in kürzester Zeit eine Vielzahl von DNA-Proben lückenlos und ambiguitätsfrei analysieren zu können. ${ }^{229} \mathrm{Um}$ die Zuordnung bestimmter Allele zu erleichtern, werden zudem geeignete Software-Programme benötigt, die große Datensätze zuverlässig prozessieren können. Durch die Zusammenführung der gewonnenen Informationen vieler untersuchter Individuen, wäre es denkbar Statistiken zur weltweiten Häufigkeitsverteilung von KIR-Allelen zu erstellen und für medizinische Zwecke zu nutzen.

Die Subtypisierung der 20 NK-Zell-Spender anhand ihrer allelspezifischen Polymorphismen wurde in der vorliegenden Forschungsarbeit dafür verwendet potenziell stärkere alloreaktive Allel- und Expressionsgruppen innerhalb von KIR2DL1 - und 3DL1 zu identifizieren. Dabei wurde für die Funktionsanalysen des KIR2DL1-Rezeptors ein Polymorphismus der Allelgruppe 1 nach Bari et al. (2009) mit Aminosäuren (AS)-Veränderungen an Position 245 
gewählt. AS-245 befindet sich in der späteren Transmembrandomäne des Rezeptors und zeigte in der Arbeit von Bari et al. (2009) signifikante Funktionsunterschiede bei der Interaktion mit verschiedenen Zielzellen. ${ }^{203}$ Obwohl die Mehrheit der bis dato entdeckten KIR2DL1-Allele $(\mathrm{n}=59)$ Arginin an AS-Position $245\left(\mathrm{R}^{245}\right)$ des Exons 7 exprimiert und nur 13 Allele die AS Cystein $\left(C^{245}\right)(\rightarrow$ vgl. Tabelle 16, Abschnitt 5.3.1) zeigen, fanden sich bei der durchgeführten Untersuchung zu gleichen Anteilen ( $\mathrm{n}=5)$ Spender mit $\mathrm{R}^{245}$-Allelen und $C^{245}$-Allelen. Die größte Allelgruppe bildeten jedoch Spender mit R/C $C^{245}$-Allelen ( $\left.n=8\right)$. Spender 20 zeigte eine neue heterozygote Variante an AS-Position 245, die eine Kombination der basischen AS Arginin mit der hydrophoben AS Alanin $\left(\mathrm{R} / \mathrm{A}^{245}\right)$ ergab. Der Arginin/Alanin-245-Polymorphismus des KIR2DL1-Gens bestätigte sich im Rahmen wiederholter Sequenzierungsdurchgänge und sollte in nachfolgenden Forschungsarbeiten eingehender untersucht werden.

Auch bei der Bestimmung von KIR3DL1-Allelen konnten in bisherigen Forschungsarbeiten zahlreiche Polymorphismen gefunden werden, die Einfluss auf die Funktion des KIR3DL1Rezeptors zu haben scheinen (Tabelle 22). Pando et al. (2003) zeigte unter anderem, dass Substitutionen an der Position 44, aber vornehmlich an der Position 86 mit Leucin in der extrazellulären Ig-Domäne D0 für eine veränderte Proteinfaltung und intrazelluläre Retention verantwortlich sein könnten. ${ }^{216}$ Glycin-44 erhöhte hingegen die oberflächliche Rezeptorexpression. Die Forschungsgruppe bestätigte durch die Untersuchung des KIR3DL1*004-Allels, bei dem die AS-Substitution an Position 86 durch Alanin oder Leucin die Oberflächenexpression des Rezeptors verhindert, dass im Umkehrschluss das Vorhandensein der Aminosäure Serin-86 eine entscheidende Rolle für die Proteinfaltung und Verankerung in der Oberflächenmembran spielt. Auch der Leucin-Rest (L182P) an ASPosition 182 in der D1-Domäne scheint an der Entstehung eines nicht funktionellen KIR3DL1-Phänotyps beteiligt zu sein. Die Forscher zeigten, dass es bei Prolin-182 Substitution mit Alanin bei 3DL1*002 zu einer signifikanten Reduktion der Oberflächenexpression kommt, wohingegen diese Manipulation bei 3DL1*004 keinen Effekt zeigt. Die Anwesenheit von Prolin-182 scheint damit zwar untergeordnet, aber dennoch einen relevanten Einfluss auf die finale Expressionsdichte zu nehmen. Carr et al. (2005) beschrieb drei weitere funktionelle Polymorphismen in der extrazellulären D2Domäne (AS-Position 238; Exon 5), Transmembran-Region (AS-Position 320; Exon 7), sowie zytoplasmatischen Schwanzregion (AS-Position 372; Exon 9). ${ }^{221}$ Diese können als „genetische Markerpositionen“ der HLA-Bw4 Affinität angesehen werden. 
Tabelle 22 Tabellarische Übersicht relevanter KIR3DL1-Polymorphismen aus den Arbeiten von Pando et al. (2003)216 und Carr et al. (2005)221.

\begin{tabular}{|c|c|c|c|c|c|c|c|}
\hline Domäne & AS-Position & $\begin{array}{l}\text { entsprechende } \\
\text { Exonposition }\end{array}$ & \begin{tabular}{|l} 
kodierendes \\
Triplet
\end{tabular} & \begin{tabular}{|l} 
AS-Sequenzen \\
reifen KIR3DL1
\end{tabular} & teine & Kommentar & Literatur \\
\hline \multirow{2}{*}{ D0 } & 44 & \begin{tabular}{|l} 
Exon 3 \\
Pos. 123 \\
\end{tabular} & $\begin{array}{l}{[\mathrm{AGA}]} \\
{[\mathrm{GGA}]}\end{array}$ & $\begin{array}{l}\text { 3DL1*0010101 } \\
\text { 3DL1*00X }\end{array}$ & $\begin{array}{c}44 \\
\text { K E D R I H I } \\
\ldots-\text { - G - - } \\
\end{array}$ & $\begin{array}{c}\text { Glycin-44 erhöht die } \\
\text { KIR3DL1-Oberflächenexpression } \\
\text { bei 3DL1*002, jedoch nicht bei }\end{array}$ & \multirow{3}{*}{ Pando et al. (2003) } \\
\hline & 86 & \begin{tabular}{|l} 
Exon 3 \\
Pos. 250/251
\end{tabular} & $\begin{array}{l}{[\text { TCG }]} \\
{[\text { TTG }]_{250}[\text { TCA }]_{251}}\end{array}$ & $\begin{array}{l}\text { 3DL1*0010101 } \\
\text { 3DL1*00X }\end{array}$ & $\begin{array}{c}86 \\
\text { T G W S AP S } \\
\cdots-\text { L - . } \\
\end{array}$ & $\begin{array}{l}\text { Veränderte Proteinfaltung } \\
\text { (beschädigtes WSXPS-Motiv) }\end{array}$ & \\
\hline D1 & 182 & \begin{tabular}{|l} 
Exon 4 \\
Pos. 252
\end{tabular} & $\begin{array}{l}{[\mathrm{CCC}]} \\
{[\mathrm{TCC}][\mathrm{ACC}]}\end{array}$ & $\begin{array}{l}\text { 3DL1*0010101 } \\
\text { 3DL1*00X }\end{array}$ & $\begin{array}{c}182 \\
T H T P Y Q L \\
-\cdots\end{array}$ & $\begin{array}{l}\text { Reduzierte Oberflächenexpression bei } \\
\text { Prolin-Substitution mit Serin oder Alanin. }\end{array}$ & \\
\hline D2 & 238 & \begin{tabular}{|l} 
Exon 5 \\
Pos. 120 \\
\end{tabular} & $\begin{array}{l}{[G G G]} \\
{[C G G]} \\
\end{array}$ & $\begin{array}{l}\text { 3DL1*0010101 } \\
\text { 3DL1*00X }\end{array}$ & $\begin{array}{c}238 \\
\text { SRE G G A H } \\
\text { - - R - . - } \\
\end{array}$ & \multirow{2}{*}{$\begin{array}{l}\text { Polymorphismus an dieser Stelle erhöht } \\
\text { das } \\
\text { inhibitorische Potenzal von high/high - } \\
\text { Allellen [3DL1*002 > 3DL1*007] }\end{array}$} & \multirow{3}{*}{ Carr et al. (2005) } \\
\hline TM & 320 & \begin{tabular}{|l} 
Exon 7 \\
Pos.21 \\
\end{tabular} & $\begin{array}{l}\text { [ATT] } \\
\text { [GTT] } \\
\end{array}$ & $\begin{array}{l}\text { 3DL1*0010101 } \\
\text { 3DL1*00X }\end{array}$ & $\begin{array}{c}320 \\
\text { H L H I L I G } \\
\ldots-\ldots \text { - . - } \\
\end{array}$ & & \\
\hline CYT & 373 & $\begin{array}{l}\text { Exon } 9 \\
\text { Pos. } 22\end{array}$ & $\begin{array}{l}{[\mathrm{GAG}]} \\
{[\mathrm{CAG}]}\end{array}$ & $\begin{array}{l}\text { 3DL1*0010101 } \\
\text { 3DL1*00X }\end{array}$ & $\begin{array}{c}373 \\
\text { Q D P E E V T } \\
\ldots-\text { Q - - }\end{array}$ & \begin{tabular}{|c|}
$\begin{array}{c}\text { Mutationen in AS-Position } 373 \text { hatten } \\
\text { bei den Allelen } 3 \mathrm{DL} 1^{*} 002 \text { oder } 3 \mathrm{DL} 1^{*} 007 \\
\text { keinen funktionellen Effekt. }\end{array}$
\end{tabular} & \\
\hline
\end{tabular}

Im Anhang befindet sich eine eigens erarbeitete Zusammenfassung wichtiger polymorpher Positionen innerhalb des KIR3DL1-Gens mit genauer Lokalisationsangabe und dazugehöriger Literaturreferenz ( $\rightarrow$ Tabelle 32, Anhang). Andere Forscher wie Gardiner et al. (2001) untersuchten NK-Zellen hinsichtlich ihrer KIR-Oberflächenkonzentration/dichte mittels eines KIR3DL1-bindenden DX9-Antikörpers. Dabei zeigte sich, dass drei Typen von KIR3DL1-Allelen existieren, solche mit einer hohen Oberflächenkonzentration (3DL1*001, *002 und *008), mit einer niedrigeren (3DL1*005 und *009) oder keiner Rezeptorexpression (3DL1*004) existieren. ${ }^{215,230,231}$

Nach der Subtypisierung wurden die KIR3DL1 positiven NK-Zell-Spender in der vorliegender Arbeit entsprechend ihrer ermittelten Allele nach Gardiner et al. in low-, highund zero- KIR3DL1-Expressionsallele ( $\rightarrow$ vgl. Tabelle 18, Abschnitt 5.4.1) kategorisiert. ${ }^{215}$ Da bisher lediglich 53 von 150 bekannten KIR3DL1-Allelen einer Expressionsgruppe zugeordnet wurden, besteht auf diesem Gebiet weiterhin Forschungsbedarf. Deshalb wurde eine vierte Gruppe für noch nicht zugeordnete Allelvarianten ergänzt und als unknownKIR3DL1-Expressionsgruppe bezeichnet. In dieser Kategorie befanden sich zum einen die Allele 3DL1*009, *01702,*021,*068,*087,*095,*097,*099 und *109, zum anderen die Allele des Spenders 2, dessen Nukleotidsequenz zahlreiche homozygote Abweichungen zu allen bisher beschriebenen Allelreferenzen zeigte. Insgesamt drei der subtypisierten Studienteilnehmer mit zero- 3DL1*004-Allelvarianten wurden in Hinblick auf relevante Polymorphismen innerhalb der Nukleotidsequenz ihrer extrazellulären D0- und D1Domänen näher untersucht. Lediglich Spender 14 mit Glycin-44 (G/G) und Leucin-86 (L/L) zeigte als Träger des Nullallels 3DL1*0040101, passend zur negativen KIR3DL1-SSP, 
eine tatsächlich fehlende Oberflächenexpression des KIR3DL1-Rezeptors. Spender 11 und 16 als Träger des Allels 3DL1*00402 zeigten in der KIR-Oberflächenfärbung dagegen eine nachweisbare KIR3DL1-Expression zwischen 4,8 - 10,4\%. Die Allele 3DL1*00401 und *00402 unterscheiden sich dabei genetisch betrachtet lediglich in den Nukleotidpositionen 85, 123 und 250 des Exons 3 ( $\rightarrow$ siehe Tabelle 31, Anhang). Dies bestärkt, dass die tatsächliche Oberflächenexpression des KIR3DL1-Rezeptors maßgeblich von der Beschaffenheit seiner D0-Domäne, kodiert durch Exon 3, abhängig ist ( $\rightarrow$ vgl. Abb. 16, Abschnitt 4.3.7).

\subsubsection{Alloreaktivität der subtypisierten Spender NK-Zellen}

Die alloreaktive Antwort zur Einleitung der Zelllyse fremdartiger Zellen wird verstärkt, wenn KIR2DL1 oder KIR3DL1 ihren spezifischen HLA-Liganden im Organismus nicht finden. ${ }^{190,183}$ Diese Konstellation wird als KIR-HLA-mismatch bezeichnet. Zur Objektivierung der Wirkstärke (Alloreaktivität) der isolierten NK-Zellen wurden die Spender, wie bereits erwähnt, zunächst in KIR2DL1-Allelgruppen bzw. KIR3DL1-Expressionsgruppen zusammengefasst. Anschließend wurden die Spender NK-Zellen durch die Hinzugabe von HLA-differenten Zielzellen funktionell untersucht. Die spenderspezifische Alloreaktivität wurde experimentell unter Verwendung von vier B-lymphoblastoiden L721.221-Zelllinien mittels CD107-Degranulationsassay im Durchflusszytometer gemessen. Ziel dieses Spendervergleichs war es festzustellen, ob alloreaktive Unterschiede bei der Erkennung und Degranulationsstärke gegenüber einzelner Zielzellen existieren und ob es einen Zusammenhang zu ihrer allelischen Gruppenzugehörigkeit gibt.

Trotz der kleinen Stichprobe von 20 untersuchten Spendern unterschied sich die Alloreaktivität der KIR2DL1 ${ }^{+}$bzw. KIR3DL1 ${ }^{+}$NK-Zellen in großem Maße. So zeigte die Total-KIR2DL1 ${ }^{+}$NK-Zell-Population der $\mathrm{R}^{245}$-Gruppe die im Durchschnitt stärkste Aktivität (81\%) gegenüber der Zelllinie L721.221-ØHLA, gefolgt von der R/C ${ }^{245}$-Gruppe $(61 \%)$ und der $\mathrm{C}^{245}$-Gruppe (46\%). Diese Ergebnisse decken sich mit den publizierten Daten von Bari et al. (2009) und zeigen, dass bei der Spenderauswahl Allelträger der $\mathrm{R}^{245}$-Gruppe, gefolgt von der heterozygoten $\mathrm{R} / \mathrm{C}^{245}$-Allelgruppe, bevorzugt werden sollten.

Vier Spender zeigten abweichende Ergebnisse. Spender 20 der R/A ${ }^{245}$-Allelgruppe zeigte eine geringe Spezifität gegenüber L721.221-øHLA, -Bw4 und -Cw6 und stärkste Inhibition gegenüber HLA-C1. Auch zwei weitere Spender der $C^{245}$-Allelgruppe (Spender 2 und 7) 
zeigten nicht wie erwartet gegenüber L721.221-ØHLA die stärkste alloreaktive Antwort sondern nach Stimulation mit dem Ligand HLA-C2. Beide trugen, wie auch Spender 11 und 12 der $C^{245}$-Gruppe, die Allelkombination 2DL1*00401/*00403. Aus diesem Grund kann das abweichende Ergebnis nicht auf allelischer Ebene erklärt werden. Um diesen Unterschied zu verstehen, bedarf es weiteren Untersuchungen in Hinblick auf interindividueller Faktoren. Gleiches betrifft den Spender 6 mit der Allelkombination 2DL1*00302/*00403 bei dem sich eine auffällig hohen Alloreaktivität gegenüber der Zelllinie L721.221-Cw6 in der Untersuchung zeigte.

Auch die Ergebnisse des CD107-Degranulationsassays für die Total-KIR3DL1 ${ }^{+}$NK-Zellen zeigten bei fehlendem HLA-Liganden mehrheitlich die stärkste NK-Zell-Aktivierung. Spender 4 und 19 der high/high-Gruppe (KIR3DL1 ${ }^{\mathrm{h} / \mathrm{h}}$ ) wiesen dabei mit durchschnittlich 92\% die stärkste KIR-HLA-mismatch Aktivität auf. Im Gruppenvergleich zeigten beide nach Stimulation mit ihrem spezifischen HLA-Bw4 Liganden jedoch bei Weitem nicht die stärkste Inhibition auf. Diese war bei Spendern der KIR3DL1-Expressionsgruppen high/null $\left(K_{I R 3 D L 1}{ }^{\mathrm{h} / \mathrm{n}}: 4 \%\right)$ und high/low (KIR3DL1 ${ }^{\mathrm{h} / 1}: 13 \%$ ) ausgeprägter zu beobachten. Ein weiterer Aspekt der funktionellen Untersuchungen war, dass alle Spender der unknown/unknown (KIR3DL1 ${ }^{\mathrm{u} / \mathrm{u}}$ )- und der high/unknown (KIR3DL1 ${ }^{\mathrm{h} / \mathrm{u}}$ )-Gruppe, bis auf Spender 9 (3DL1*01702/*095), eine mit 65\% überdurchschnittlich hohe Alloreaktivität zeigten. Mit diesem Ergebnis konnten die bisher keiner Expressionsgruppe zugeordneten unknown-Allele 3DL1*009, *021, *068,*076, *087,*097, *099 und *109 eher einem high Expressions- und Affinitätsmuster zugeordnet werden.

Im Verlauf der Experimente stellte sich die Frage, ob es einen Zusammenhang zwischen der Alloreaktivität der als potent identifizierten NK-Zell-Spender und der tatsächlichen Dichte des KIR3DL1-Rezeptors auf ihrer NK-Zelloberfläche gibt. Wenngleich auf den ersten Blick einleuchtend, bestätigte sich diese Hypothese nicht. Zur Veranschaulichung dieses Sachverhaltes wurde Abbildung 47 (siehe unten) erstellt. Bereits bei den high/highSpendern zeigte sich bei ähnlicher prozentualer Alloreaktivität gegenüber L721.221-ØHLA ein Unterschied in der prozentualen KIR3DL1-Oberflächendichte von über 27\%. Ähnlich verhielt es sich in den Expressionsgruppen KIR3DL1 ${ }^{\mathrm{u} / \mathrm{u}}$ und KIR3DL1 ${ }^{\mathrm{h} / \mathrm{u}}$, wo die Oberflächendichte des Rezeptors zwischen 3\% bis 43\% variierte. Innerhalb der unknownSpendergruppe zeigte Spender 9 als Träger der Allele KIR3DL1*01702 und *095 die geringste Aktivität im CD107-Degranulationsassay. Interessanterweise zeigte dieser Spender dabei gleichzeitig die höchste KIR3DL1-Oberflächenexpression (43\%) von allen 
untersuchten NK-Zell-Spendern. Die prozentuale Oberflächenexpression des KIR3DL1Rezeptors scheint somit in keinem direkten Zusammenhang mit der Alloreaktivität gegenüber HLA zu stehen. Schlussfolgernd bedeutet dies, dass die Bestimmung der prozentualen Rezeptordichte der gespendeten NK-Zellen mittels KIR-Oberflächenfärbung, anders als die KIR-Typisierung, kein zuverlässiges Werkzeug bei der Auswahl eines potenten Spenders darstellt.

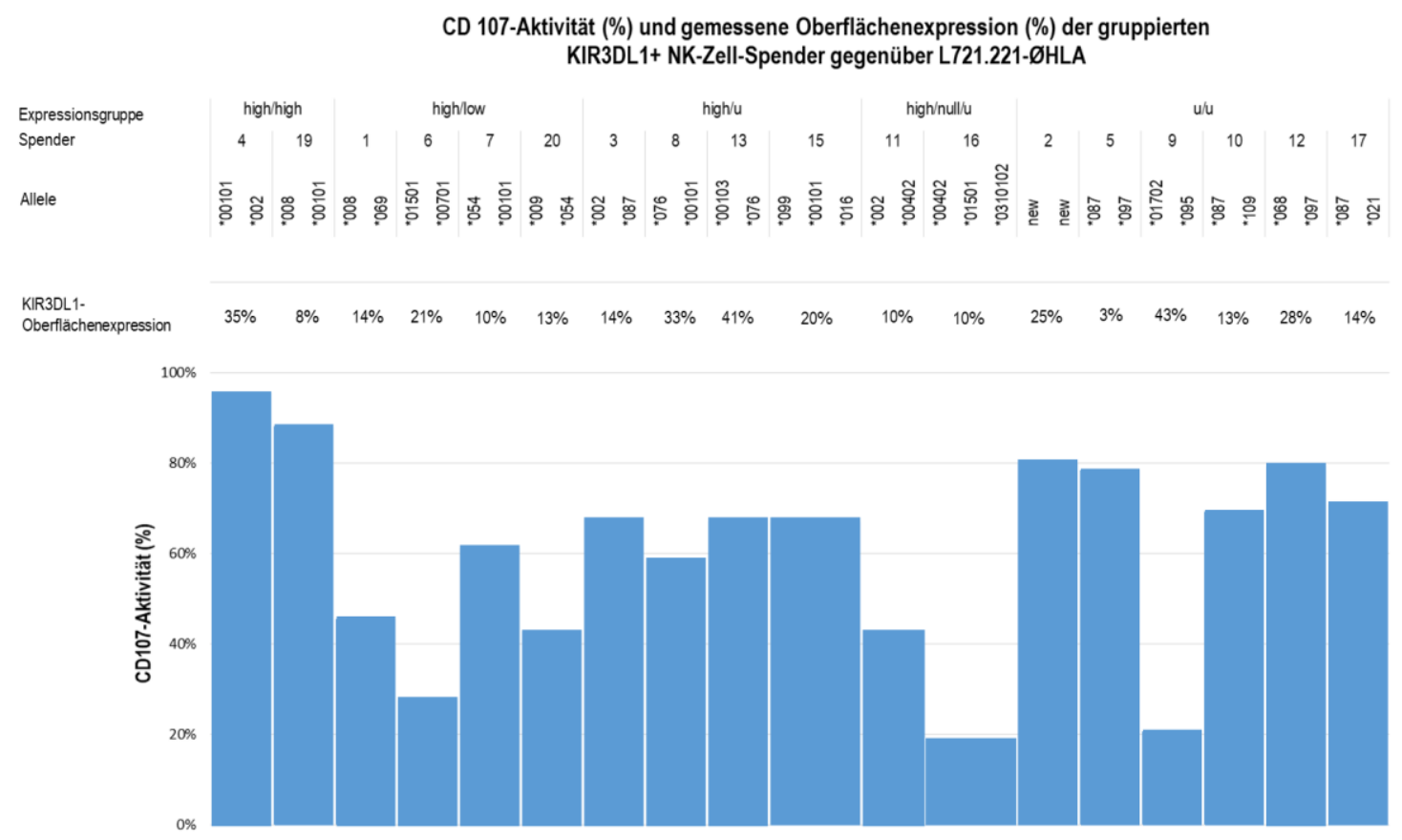

Abbildung 47 Das Säulendiagramm zeigt die alloreaktive CD107-Aktivität (\%) der gruppierten KIR3DL1+ NK-ZellSpender gegenüber L721.221-ØHLA mit der zugehörigen prozentualen Oberflächenexpression des KIR3DL1Rezeptors. Eine hohe KIR3DL1-Rezeptordichte in der KIR-Oberflächenfärbung steht in keinem direkten Verhältnis zur resultierenden Reaktivität der NK-Zellen.

Bezogen auf das gewählte CD107-Degranulationsassay zur Quantifizierung der spenderspezifischen NK-Zell-Aktivität ist zu erwähnen, dass diese Art der Aktivitätsmessung lediglich extrazelluläre Veränderungen der NK-Zell-Oberflächenproteine berücksichtigt. Neben der Entwicklung von Methoden zur Messung granulärer Zytotoxizität, gibt es ebenfalls intrazelluläre Färbemethoden. Bei dem ELISpot-Assay wird beispielsweise die Zytokinsekretion von IFN- $\gamma$ gemessen und als $\mathrm{Maß}$ für die immunologische Effektorantwort herangezogen. Die Anwendung kombinierter Verfahren bei der Aktivitätsbestimmung von NK-Zellen kann demnach eine sinnvolle Ergänzung sein, um interindividuelle Unterschiede der Spender umfassender darzustellen. Außerdem muss das Immunsystem als komplexes und dynamisches Konzept verstanden werden. In weiteren Forschungsbestrebungen sollten immunmodulatorischen Variablen durch die Erhöhung der Durchläufe der Aktivitätsmessungen deshalb strenger mitberücksichtigt werden. Mögliche 
Variabilitäten machen es auch schwieriger Aussagen zur Auswahl geeigneter NK-ZellSubpopulationen zu treffen. Die in der Arbeit erhobenen Daten konnten nicht bestätigen, dass Single-KIR ${ }^{+}$NK-Zellen alloreaktiver sind als die Total-KIR ${ }^{+}$NK-Zell-Population. Stattdessen waren die Aktivitätslevel im CD107-Degranulationsassay nahezu identisch $(\rightarrow$ vgl. Abb. 43, Abschnitt 5.8.3). Die Auswahl und Expansion geeigneter NK-ZellSubpopulationen stellt ungeachtet dessen einen Schwerpunkt aktueller Forschung bei der Optimierung der NK-Zell-basierten Immuntherapie dar.

\subsection{Einfluss der KIR-HLA-Spezifität und des MHC-I-Profils der Spender auf die NK-Zell-Alloreaktivität}

Bei der Erlangung funktioneller NK-Zell-Kompetenz scheint die Ausstattung an HLAKlasse-I-Proteinen im Organismus (MHC-I-Profil) eine entscheidende Rolle zu spielen. ${ }^{109,212,213}$ Die zelluläre Ausbildung von reifen NK-Zellen im Immunsystem wird dabei maßgeblich durch die Expression und Interaktion einzelner inhibitorischer NKZellrezeptoren mit MHC-I-Molekülen verwirklicht. ${ }^{48}$ Die NK-Zell-Ausbildung (engl. education) beinhaltet dabei zum einen den Prozess der funktionellen Reifung und zum anderen die Entwicklung einer Selbsttoleranz. Da weiterhin unklar ist, ob ein aktivierendes Signal für die NK-Zellausbildung erforderlich ist, geht die Mehrheit der Wissenschaftler von einer dominierenden Rolle der inhibitorischen Rezeptoren im Reifungsprozesses der NK-Zellen aus. $^{232,59}$ Diese Sichtweise wird auch häufig damit begründet, dass NK-Zellen in ihrer Reaktionsfähigkeit hyporesponsiv verbleiben, wenn sie einem Dauerstimulus an aktivierenden Signalen - oder anders formuliert - von keinerlei inhibierenden Signalen umgeben sind. ${ }^{49}$ Die inhibitorischen Rezeptoren KIR2DL1 und KIR3DL1 binden an spezifische Epitope der klassischen MHC-I-Moleküle HLA-A, -B und -C im eigenen Organismus. HLA-C-Allele werden abhängig von den AS-Positionen 77 und 80 der MHC-I $\alpha_{1}$-Helix in HLA-C1 oder HLA-C2 eingeteilt. Dagegen können HLA-A und HLA-B-Allele anhand ihres Bw4- oder Bw6-Epitops (AS-Positionen 77 bis 83) klassifiziert werden (Tabelle 2, Abschnitt 1.3.3). Epidemiologische Studien konnten eine signifikante Heterogenität spezifischer KIR- und HLA-Genotypkombinationen bezogen auf Krankheitsprozesse und -verläufe bei Tumorerkrankungen ${ }^{206}$ und der Bekämpfung von viralen Infektionen zeigen. Beispielsweise ist die Vererbung des hemmenden KIR2DL3 und seines spezifischen HLA-C1 Liganden mit einer erhöhten Heilungsrate des Hepatitis-CVirus verbunden. ${ }^{90}$ Bei dem Fortschreiten des invasiven Zervixkarzinoms zeigt sich ein 
gewisser Schutz bei Individuen, die einen KIR2DL1 $^{+}$und KIR3DL1 ${ }^{+}$Genotyp in Kombination mit dem Vorhandensein der entsprechenden HLA-Bw4 und HLA-C2 Liganden besitzen. ${ }^{233}$ Dem KIR3DL1 ${ }^{+} / \mathrm{Bw}^{+}$-Genotyp wird außerdem ein signifikant langsameres Fortschreiten bei einer HIV-Infektion zu AIDS zugerechnet. ${ }^{234,235}$

Je nachdem ob der entsprechende HLA-Ligand im jeweiligen Individuum vorhanden ist, ergeben sich bei den 20 untersuchten NK-Zellen in der vorliegenden Arbeit entsprechende Alloreaktivitätsunterschiede gegenüber der HLA-transgenen Zelllinien. Die HLATypisierung ergab für 4 KIR2DL1+ Spender homozygote C2/C2 Allelvarianten. Von den 19 KIR3DL1 + Spendern zeigten ebenfalls 4 Spender homozygote Bw4/Bw4 MHC-I-Allele. Lediglich zwei Individuen (Spender 8 und 20) zeigten Homozygotie für beide MHC-ILiganden C2/C2 und Bw4/Bw4. Die 6 homozygoten Spender (Spender 1, 3, 8, 11, 17 und 20) konnten nach allelischer Subtypisierung insgesamt 6 unterschiedlichen KIR2DL1-Allelund KIR3DL1-Expressionsgruppen zugeordnet werden. Bezogen auf KIR2DL1 kam auf jede untersuchte AS245-Allelgruppe ein homozygoter C2/C2 Spender, bei KIR3DL1 dagegen verteilte es sich auf die high/low-Expressionsgruppe (Spender 1 und 20) und die high/unknown-Expressionsgruppe (Spender 3 und 8). Die funktionelle Analyse mittels CD107-Degranulationsassays zeigte konsequenterweise ein ebenfalls gemischtes Verteilungsmuster der NK-Zell-Aktivität. In anderen Worten bedeutet dies, dass die zuvor als besonders potent identifizierten KIR3DL1 $^{+}$high/high-Spender 4 und 19 nicht homozygot für ihren spezifischen Liganden waren, sondern dem MHC-I-Profil Bw4/Bw6 bzw. Bw6/Bw6 zugehörten. Bei den KIR2DL1 ${ }^{+}$Spendern zeigten die Spender der $\mathrm{R}^{245}$ Gruppe ( $\mathrm{n}=4$ ) eine heterogene Verteilung innerhalb der Ligandengruppen C2/C2 (Spender 8), C1/C2 (Spender 3 und 4) sowie C1/C1 (Spender 15). Es konnte kein Zusammenhang zwischen der Potenz subtypisierten NK-Zell-Spender und der Anwesenheit eines spezifischen MHC-I-Liganden im Spenderorganismus sicher erkannt werden. Damit ist basierend auf die gewählte Stichprobe keine eindeutige Zuordnung zu dem klassischen HLALiganden-Modell möglich.

Mittlerweise gibt es zunehmende Beweise, dass bei der Ausbildung und Lizensierung von NK-Zellen nicht nur die klassischen MHC-I-Moleküle sondern auch nicht-klassische MHCI- und sogar Nicht-MHC-I-Moleküle beteiligt sind. ${ }^{236}$ Thomas et al. (2013) fand heraus, dass die Lizensierung von NK-Zellen mit einer erhöhten Bindungsstärke (NK-Zellhaftung) an Zielzellen verbunden ist. ${ }^{212}$ Als möglicher Erklärungsansatz gilt das sogenannte „confiningModell“. Dieses geht von zwei Kriterien aus, erstens die räumliche Begrenzung (engl. 
confinement) der Rezeptorverteilung auf der NK-Zelloberfläche und zweitens von bestimmten zellulären Adhäsionssignalen, welche unverzichtbar für die NK-Zellausbildung sind. Insbesondere das $\beta 2$-Integrin LFA-1, dass zu einer Rezeptor-Kompartimentierung auf der NK-Zelloberfläche führt, wird für eine stabilere Konjugatbildung zur Zielzelle verantwortlich gemacht. ${ }^{237,238}$ LFA-1 wird zu den Nicht-MHC-I-Molekülen gezählt und begünstigt über die Bildung einer Art „Kommunikatiosbrücke“ den Dialog zwischen dem NK-Zell-Innerem (intrazellulären Zytoskelett) und der Außenwelt (Plasmamembran/Peripherie) bilden. Demnach zeichnen sich unlizenzierte NK-Zellen durch weniger stabile Konjugate mit ihren Zielzellen aus, da sie nach Thomas et al. (2013) über eine deutlich reduzierte Signalvermittlung in Form eines „Inside-Out-Signaling“ via LFA-1 verfügen. Ein weiteres in diesem Zusammenhang gut untersuchtes Protein ist der Kostimulator CD226 (DNAM-1). CD226 ist an der Bildung der immunologischen Synapse zwischen NK- und Zielzelle beteiligt und moduliert damit die NK-Zell-vermittelte Zytotoxizität gegenüber krebstransformierter oder virusinfizierter Zellen. Die Synergie zwischen LFA-1 und CD226 wurde von Hou et al. (2014) als wichtiger Parameter für die Förderung und Regulation der NK-Zellreaktivität gehandelt. ${ }^{239}$ Als zusätzliches Kriterium bei der NK-Zellausbildung werden cis- und trans-Eigenschaften der KIR-Bindungsproteine diskutiert. Boudreau et al. (2016) untersuchten dafür die Interaktionseigenschaften von „Selbst“-HLA-Klasse-I-Moleküle bei der Ausbildung menschlicher NK-Zellen. ${ }^{240}$ Ihre Arbeitsgruppe untersuchte durch Experimente an MHC-I-transgenen Mäusen dabei genauer, ob die direkte Bindung der HLA-Klasse-I-Moleküle an die NK-Zelle (cis) oder an benachbarte Zellen (trans) ausschlaggebend für die Förderung sowie Aufrechterhaltung der Reaktionsfähigkeit der NK-Zellpopulation ist. Die Ergebnisse offenbaren eine mögliche wichtige Rollenverteilung der cis- und trans-HLA-Interaktionen bei der Ausbildung von reifen NK-Zellen. Die intrinsische cis-Interaktion führte vor allem zur Lizensierung zytotoxischer NK-Zellen und der nachhaltigen Förderung der NK-Zellreaktivität gegenüber Fremdzellen in den Experimenten. Der zellextrinsische Kontakt (trans) mit MHC-I ermöglichte demgegenüber die Aufrechterhaltung der erlernten Kompetenz und Bewahrung der Selbsttoleranz gegenüber gesunder Körperzellen.

Per Definition gelten NK-Zellen ohne spezifischen MHC-I-Liganden für ihre hemmenden KIRs als ungebildet und sind damit nicht in der Lage erkrankte Zielzellen suffizient zu töten. Boudreau et al. (2016) zeigte in einem Xenograft-Modell darüber hinaus, dass auch ungebildeten NK-Zellen eines Spenders durch exprimierte „Selbst“-HLA-Klasse-I-Moleküle im Wirt funktionelle Kompetenz nachträglich erwerben können. Dieses Phänomen konnte 
in weiteren Arbeiten bestätigt werden, bei denen reife NK-Zellen von MHC-defizienten Mausindividuen, die hypofunktional waren, ihre funktionelle Kompetenz zurückerlangten, als sie in einen MHC-kompetenten Empfänger übertragen wurden. Nach Transplantation von hämatopoetischen Stammzellen von $\mathrm{Bw} 4+$ und Bw4- Spendern in transgene Mäuse, wurden unterschiedliche Niveaus an NK-Zell-Ausbildung beobachtet. Es zeigte sich, dass diejenigen KIR3DL1 ${ }^{+}$NK-Zellen am wenigsten ausgebildet waren, denen sowohl auf der Spender als auch auf der Empfängerseite der HLA-Bw4 Ligand fehlte. Umgekehrt verringert sich die Reaktionsfähigkeit von potenziell reaktiven NK-Zellen, wenn sie in eine MHC-IMangelumgebung übertragen wurden. ${ }^{241,242}$ Um die möglichen Auswirkungen von HLA-BPolymorphismen auf die Aktivierung von NK-Zellen zu untersuchen, betrachtete die

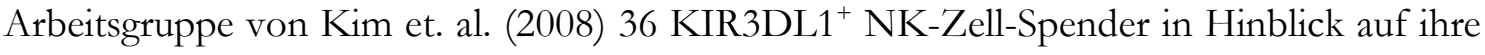
spezifischen HLA-Genotypen. ${ }^{109}$ Hierbei wurden drei Gruppen unterteilt: HLA-Bw4/Bw4Homozygote $(\mathrm{n}=11)$, HLA-Bw4/Bw6 Heterozygote $(\mathrm{n}=12)$ und HLA-Bw6/Bw66 Homozygote $(\mathrm{n}=13)$. Zur Untersuchung der Spender-NK-Zellen wurden sie mit MHCdefizienten L721.221-Tumorzellen inkubiert und auf intrazelluläres IFN- $\gamma$ analysiert. Die KIR3DL1+ Spender mit zwei HLA-Bw4-Genen zeigten eine höhere Reaktionsfähigkeit auf Tumorstimulation im Vergleich zu den Studienteilnehmern mit nur einem oder keinen Bw4Gen. Im Gegensatz dazu zeigten NK-Zellen ohne KIR3DL1 keine Unterschiede.

Die erhobenen Daten deuten darauf hin, dass bestimmte KIR/HLA-Allelkombinationen mit reaktionsfreudigeren NK-Zellen in Verbindung gebracht werden können und damit Einfluss auf Krankheitsverläufe nehmen. Möglicherweise erklären HLA-Polymorphismen auch die interindividuellen Unterschiede in der NK-Zell-Potenz allelisch identischer Spender. Neben der Qualität der Rezeptor-Ligand-Interaktion scheinen zudem modulierende ZytokinSignale ${ }^{243}$, insbesondere nach Interaktion mit Dentritischen Zellen, die NK-Zellausbildung mitzubeeinflussen. ${ }^{244}$ Zusammenfassend lässt sich sagen, dass HLA-Klasse-I-Moleküle, die von hämatopoetischen Spenderzellen präsentiert werden, die NK-Zellbildung maßgeblich beeinflussen. Damit rücken mögliche erfolgsversprechende KIR/HLA-Konstellationen als wichtiger Parameter der Spenderauswahl in den Vordergrund. Das Kriterium der NKZellausbildung und der damit verbundenen Reaktivität gegenüber leukämischer Krebszellen nach Stammzelltransplantation hätte damit auch Einfluss auf mögliche Behandlungsergebnisse von HSZT- oder adoptiven NK-Zelltherapien. Bei der Spenderauswahl sollte neben dem KIR-HLA-mismatch zwischen Spender und Empfänger nach Genotypisierung, auch der für die Reifung und Ausbildung der NK-Zellen förderliche KIR-HLA-match im Spenderorganismus zur Maximierung der NK-Zellreaktivität 
mitberücksichtigt werden. Die Erforschung der genauen Mechanismen, inwiefern die zelluläre Umgebung auf die zelltypspezifische Ausbildung effektiver NK-Zellen auswirkt, würde wertvolle therapeutische Ansätze im Themengebiet der Tumorinvasionen und Virusinfektionen ergänzen.

Als weiterer Aspekt soll im Folgenden auf Subtyp-abhängige Abweichungen der KIR3DL1Affinität und -Spezifität für Bw4+ Liganden eingegangen werden. ${ }^{218,96,245}$ O'Connor et al. (2007) hatte in diesem Zusammenhang bereits festgestellt, dass es für diverse KIR3DL1Subtypen eine Hierarchie in der Erkennung Bw4-tragender HLA-Moleküle gibt. So konnte er in seiner Arbeit zeigen, dass das Bw4-Epitop von HLA-B*51:01 besser erkannt wird als bei anderen HLA-B-Molekülen $(B * 38: 01>B * 58: 01>B * 27: 05) .{ }^{246}$ Das es trotz fehlender Unterschiede in der Aminosäurenregion 77-83 des Bw4-Epitops ( $\rightarrow$ vgl. Tabelle 2, Abschnitt 1.3.3) zu einer Differenzierung bei der Erkennung und Affinität von HLA-BMolekülen kommt, legt nahe, dass sich die KIR3DL1-Bindungsstelle über die HLA- $\alpha_{1}$-Helix hinaus erstrecken muss. ${ }^{247}$ In Experimenten mit NK-Zell-Klonen und rekombinanten KIRs konnte demonstriert werden, dass beide KIR3DL1-Subtypen 3DL1*001 und 3DL1*002 in der Lage sind B*51:01 erkennen. Im Gegensatz dazu bindet das Allel 3DL1*001 kaum an $\mathrm{B} * 27: 05$ und das Allel KIR3DL1*002 nahezu gar nicht an B*58:01. Um die isolierten NKZellen in der vorliegenden Arbeit funktionell zu untersuchen, wurde das Bw4-Epitop des HLA-B*51:01 Moleküls verwendet ( $\rightarrow$ vgl. Tabelle 4, Abschnitt 3.2.1). Betrachtet man die Ergebnisse der Untersuchung durch O'Connor et. al. (2007) lässt sich diskutieren, ob sich das Ergebnis der Funktionsanalyse der subtypisierten Spender 3, 4 und 11 als Träger des 3DL1*002-Allels valide auswerten lässt. Sollte dies nicht der Fall sein, könnte es zumindest erklären, weshalb bei diesen drei Spendern die Spezifität ihres KIR3DL1-Rezeptors für HLA-Bw4 mit dem des nicht-korrespondierenden HLA-C1 (HLA-C*01:02) vergleichbar ist. Auch andere Spender zeigten einen ähnlichen Zusammenhang bei dem Vergleich der Alloreaktivität gegenüber L721.221-Bw4 und -Cw6 (HLA-C2). In einer Folgearbeit wäre es demnach interessant die KIR3DL1-Allele der Spender 1, 5, 9, 12, 16 und 19, konkreter bezüglich ihrer spezifischen HLA-B*51:01-Affinität zu untersuchen $(\rightarrow$ vgl. Abb. 45, Abschnitt 5.8.4). Thananchai et al. (2007) konnte in einer weiteren Studie beweisen, dass zwar mehrere KIR3DL1-Subtypen das an HLA-A*24:02 gebundene Bw4-Epitop binden können, jedoch lediglich Träger des 3DL1*005-Allels zusätzlich mit B*57:01 interagieren. ${ }^{248}$ Folglich sollten bei zukünftigen Funktionsuntersuchungen subtypisierter NK-Zellen verstärkt mit unterschiedlichen Bw4-tragenden HLA-Molekülen gearbeitet werden und zusätzlich ebenfalls Bw6-tragenden Zelllinie als in der Regel nicht-korrespondierende 
KIR3DL1-Liganden miteingeschlossen werden. In einer 2008 veröffentlichten Publikation wurde die Interaktion der HLA-B*5101 und -B*1513 mit KIR3DL1 verglichen. Hierbei erwiesen sich zwei Aminosäuren Substitution innerhalb des Bw4-Epitops als relevant für die Funktionalität des Bw4-Motivs. Sanjanwala et. al. (2008) fand heraus, dass die Mutagenese an der AS-Position 83 Voraussetzung für die Interaktion mit KIR3DL1 ist. Auch die Substitution der Aminosäure Leucin mit Arginin an der Position 82 war relevant und resultierte in einem Funktionsverlust für HLA-B*5101, jedoch nicht für HLA-B*1513. Zusätzlich zeigte sich in der Arbeit, dass die AS-Position 67 der $\alpha_{1}$-Domäne, die AS-116 der $\alpha_{2}$-Domäne sowie die AS-194 der $\alpha_{3}$-Domäne Einfluss auf die KIR-HLA-Interaktion nehmen. ${ }^{96}$

Mulrooney et al. (2015) konnte ergänzend eine bessere Erkennung von HLA-B*4403 durch KIR3DL1*005, im Gegensatz zu 3DL1*001 und 3DL1*009, nachweisen. ${ }^{231}$ Die Untersuchungen an dem KIR3DL1-Rezeptor legten außerdem nahe, dass die unterschiedlich starke Erkennung von Bw4+ HLA-Liganden zusätzlich von der KIR3DS1-Expression mitbeeinflusst wird. KIR3DS1 ist ein stimulierender Rezeptortyp der seinem inhibitorischen Pendant strukturell sehr ähnlich ist und gemeinsam mit ihm im selben Gen-Locus (KIR3DL1/S1) kodiert wird. Die Arbeitsgruppe erforschte daraufhin KIR3DS1-spezifische Polymorphismen in der extrazellulären D0-Domäne, welche zu Störungen der Wechselwirkung zwischen KIR3DL1 und Bw4+ HLA-Molekülen führen. Seine erhobenen Daten identifizierten zwei Polymorphismen an AS-Position 58 (S58G) und 92 (V92M) im KIR3DS1-Gen, welche in kombinierter Form zu einer signifikant verringerten KIR3DL1Bw4-Interaktion führen. Obwohl Methionin-92 dabei nicht direkt mit HLA interagiert, zeigten Analysen an KIR3DL1*009 eine 92M-bedingte sterische Hinderung der molekularen Interaktion. Diese wurde auf eine minimale Konformationsänderung innerhalb der D1Domäne des KIR-Rezeptors zurückgeführt. Stattdessen wurde für den KIR3DS1Polymorphismus Glycin-58 eine effektverstärkende Wirkung nachgewiesen. ${ }^{231}$ Bereits frühere Untersuchungen hatten zeigen können, dass Polymorphismen der D0-Domäne bei der Interaktion mit Bw4+ HLA-Liganden einen „Enhancer“-Effekt besitzen. ${ }^{249,250}$

In der vorliegenden Arbeit wurde eine KIR-SSP gestützten Genotypisierung der 20 Spender durchgeführt. Hierbei zeigten ausschließlich Spender 7 und 10 eine positive KIR-SSP für KIR3DL1 und -S1. In Folgearbeiten sollte mit größerer Studiengruppe die genotypische Koexpression in der funktionellen Auswertung mitberücksichtigt werden. Um den 
letztlichen Einfluss des anwesenden KIR3DS1-Gens zu untersuchen, ist eine Sequenzierung des Rezeptors auf obengenannte Polymorphismen obligat.

Tabelle 23 Überblick der KIR-SSP Genotypisierungsergebnisse der 20 NK-Zell-Spender hinsichtlich ihres inhibierenden und aktivierenden KIR3D-Rezeptors. Spender 14 zeigte trotz positiver KIR-SSP bei bekanntem 3DL1*0040101 Nullallel entsprechend keine Oberflächenexpression des KIR3DL1-Rezeptors (gestrichelt).

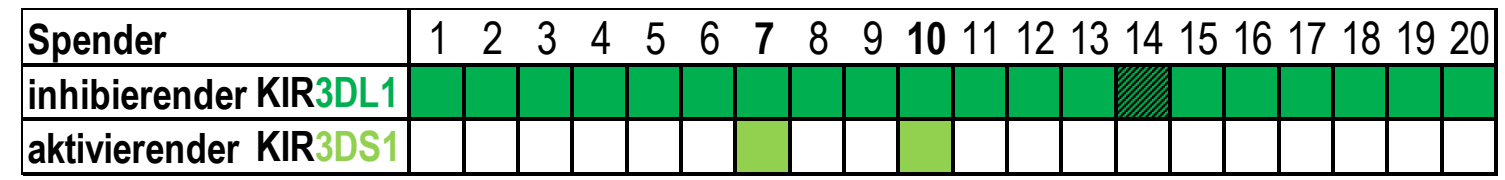

Boyington et al. (2002) stellte fest, dass neben der KIR-Oberflächendichte und den funktionellen AS-Änderungen innerhalb der KIR- und HLA-Proteine, auch die Art des gebundenen Peptids zu Affinitätsschwankungen gegenüber Bw4-Varianten führen. ${ }^{251}$ Dabei scheinen vor allem die Aminosäurenresten P7 und P8 des gebundenen Peptids von besonderer Relevanz für die KIR-HLA-Bindungsqualität zu sein. ${ }^{249}$ Die Erkenntnis, dass unterschiedliche Peptide ihrerseits Einfluss auf die Konformation des Bw4-tragenden HLAKlasse-I-Moleküls nehmen, führte zu intensiver Forschung weiterer Zusammenhänge im Gebiet der medizinischen Infektiologie und Mikrobiologie. Experimentell zeigten sich beispielsweise virusinfizierte Körperzellen einzelner Individuen weniger zugänglich für NKZell-vermittelte Zytotoxizität. Fadda et al. (2011) fand heraus, dass die Affinität von KIR3DL1*001 gegenüber HLA-B*57:01 und $-A * 24: 02$ von unterschiedlichen HLAassoziierten Peptiden des Humanen Immundefizienz-Virus (HIV-1) in herausragendem Maße beeinflussbar ist. ${ }^{252}$ Dies erklärt möglicherweise, weshalb virusinfizierte Zellen, die im Zweifelsfall nur ein begrenztes Repertoire an viralen Peptiden exprimieren, von dem KIR3DL1-Rezeptor nicht gut erkannt werden.

\subsection{Zukunftsvisionen NK-Zell-basierter Therapieansätze}

Zunehmend wird deutlich, dass NK-Zellen nicht nur selbst an vielen immunologischen Prozessen beteiligt sind, sondern eines der wichtigsten Bindeglieder zwischen dem angeborenen und dem erworbenen Immunsystem darstellen. NK-Zellen zeigen dies durch ihre klinische Relevanz in der Pathogenese vieler Erkrankungen. So können sie nachweislich zur Verschlechterung, aber auch zur Limitation von Autoimmunkrankheiten beitragen. ${ }^{253,254}$ Sie zeigen eine Beteiligung an Hypersensitivitätsreaktionen ${ }^{255}$ und haben eine tragende Funktion bei der Bekämpfung viraler Infektionen und der Erlangung einer adaptiven Immunität. ${ }^{256}$ Ebenfalls erforscht werden funktionelle Aspekte körpereigener NK-Zellen im 
Fachgebiet der Gynäkologie und Geburtsmedizin, beispielsweise bei der Entstehung der materno-fetalen Toleranz ${ }^{257}$ oder Ätiologie der Präeklampsie ${ }^{258,259}$ und Endometriose. ${ }^{260}$ Wenngleich auf dem Gebiet der NK-Zell-basierten Immuntherapie noch viele Fragen offen sind, wird der nachweislich protektive Effekt im Rahmen der hämatopoetischen Stammzelltransplantation (HSZT) bereits klinisch genutzt. NK-Zellen spielen nach Organund Knochenmarktransplantationen eine entscheidende Rolle im Kampf gegen verbleibende Tumorzellen im Empfängerorganismus. Sie fördern sie den positiv zu wertenden Graftversus-Leukemia (GvL)-Effekt und unterdrücken die Transplantat-gegen-Wirt-Krankheit (engl.: Graft-versus-Host Disease, GvHD). ${ }^{178}$

Aufgrund der Vielzahl pathogenetischer Mechanismen in Bereich der Onkologie wurde in den letzten Jahren verstärkt an der Entwicklung gezielter Tumorstrategien gearbeitet. Innovative CAR-T-Zellen (engl.: cbimeric antigen receptor, CAR) sind genetisch veränderte TLymphozyten, die zusätzlich zu ihren natürlichen T-Zell-Rezeptoren andere Oberflächenmerkmale tragen, welche über selektive Tumorepitope spezifisch an Malignomzellpopulationen binden. Im September 2019 wurden in Europa zwei CAR-T-ZellProdukte, Tisagenlecleucel $\left(\mathrm{Kymriah}^{\circledR}\right)$ und Axicabtagene Ciloleucel (Yescarta ${ }^{\circledR}$ ) in der klinischen Versorgung zugelassen. ${ }^{195}$ Beide Zelltherapeutika binden an die Zielstruktur CD19. Wenngleich derzeit noch wenige Daten zu Behandlungsergebnissen zahlreicher onkologischer Erkrankungen existieren, zeigen CAR-T-Zellen vielversprechende therapeutische Ergebnisse bei der Behandlung von großzelligen B-Zell-Lymphomen (DLBZCL). Auch bei der ALL wurden Komplettremissionen beschrieben, die zumindest kurzfristig für bis zu 24 Monate anhalten. Nach Angaben der Deutschen Gesellschaft für Hämatologie und Medizinische Onkologie (DGHO) sind in Deutschland derzeit 24 Zentren für die Therapie mit CARs zertifiziert (Stand Oktober 2019). Zelltherapeutisch können transfizierte CARs ex vivo kultiviert, eingefroren und dem Patienten zum passenden Zeitpunkt reinfundiert werden. Entgegen aller Euphorie bleibt die Anwendung von CAR-TZellprodukten komplex und risikoreich. Die Sterblichkeit damit behandelter Patienten wird auf bis zu 15\% geschätzt. Hierbei zählt das Zytokinfreisetzungssyndrom (engl.: cytokine release syndrom, CRS) und das Enzephalopathiesyndrom (engl.: immune effector cell-associated neurotoxicity syndrom, ICANS) zu den schwerwiegensten Nebenwirkungen.

Hier treten NK-Zell-basierte Konzepte in den Vordergrund wissenschaftlichen Interesses. CAR-NK-Zellen haben gegenüber CAR-T-Zellen mehrere Vorteile. Sie besitzen eine angeborene intrinsische Fähigkeit, Tumorzellen über ihre nativen Rezeptoren zu erkennen, 
zudem wurden nach jetzigem Stand kaum lebensbedrohliche Zwischenfälle nach der Anwendung von CAR-NK-Zellen beschrieben. Da NK-Zellen nachweislich keine GvHD verursachen, können sie xenotransplantiert werden. Dies macht CAR-NK-Zelltherapien zu medizinischen Universalprodukten. ${ }^{261}$ Trotz klinischer Erfolge und neuer Strategien zur Verbesserung der Sicherheit und Wirksamkeit der NK-basierter Zelltherapien, bleibt der derzeitige administrative, medizinische und finanzielle Aufwand weiterhin hoch. Auf allen Ebenen besteht somit noch Optimierungsbedarf. Zu klärende zentrale Fragestellungen bleiben: Welche Eigenschaften müssen NK-Zelltherapeutika besitzen, um dem Patienten bestmöglich zu dienen? Wie lässt sich das Verhältnis an erwünschter Wirkung zu unerwünschter Nebenwirkung maximal optimieren? Wie kann die Wirtschaftlichkeit angewendeter Immunzelltherapien verbessert werden? Ein für die Zukunft denkbares Konzept wäre, dass Immuntherapie-akkreditierte Institutionen CAR-NK-Zelltherapeutika als autologe Zellprodukte für ihre Patienten selbst herstellen und ihnen dann therapeutisch zu Verfügung stellen. Langfristig könnte ein nationales CAR-NK-Zell-Register zur besseren Übersicht allogener Anwendungen erstellt werden. 


\section{Zusammenfassung}

\subsection{Deutsch}

In Deutschland erkranken pro Jahr bis zu 12.000 Menschen neu an Leukämie. Leukämie ist eine schwere onkologische Erkrankung, bei der reifes Knochenmarkgewebe in Folge von Mutationen unreifer und defekter Vorläuferzellen (leukämischen Blasten) verdrängt wird. Dies führt zu einer zunehmend eingeschränkten Blutbildung. Akute Leukämieformen können unbehandelt innerhalb von wenigen Wochen zum Tode führen und erfordern deshalb eine umgehende Diagnostik sowie einen raschen Therapiebeginn. Heilungschancen bestehen dann, wenn durch die Transplantation von gesunden hämatopoetischen Stammzellen (HSZT) das erkrankte Knochenmark ausreichend ersetzt wird. Leider sind Abstoßungsreaktionen des Spendermaterials (engl.: Graft-versus-Host-Disease, GvHD) keine Seltenheit.

Natürliche Killerzellen (NK-Zellen) stellen die kleinste Lymphozytenpopulation im menschlichen Blut dar und werden dem angeborenen Immunsystem zugerechnet. Sie wurden erstmals 1975 durch die Forscher Kiessling, Klein et al. entdeckt. ${ }^{17}$ Aufgrund ihrer Fähigkeit bestimmte Tumorzellen in vitro zu töten, wächst das Interesse an der Erforschung ihrer aktivierenden und inhibierenden Oberflächenrezeptoren. Die Killer-ZellImmunoglobulin-ähnlichen Rezeptoren (KIRs) bilden dabei eine besonders diverse NKZell-Rezeptorfamilie. Lokalisiert auf Chromosom 19 liegen bis zu 17 hochpolymorphe KIRGene. Die genetische Ausstattung und Oberflächenexpression variiert von Individuum zu Individuum und bildet die Voraussetzung für die vorhandene Diversität KIR-exprimierender NK-Zellen. NK-Zellen besitzen die Fähigkeit, Gewebezellen in „körpereigen“ oder „fremd“ zu kategorisieren. Inhibitorische Killer-Immunoglobulin-ähnliche Rezeptoren (iKIR) nutzen dazu HLA-Klasse-I-Proteine (MHC-I) auf der Oberfläche gesunder Zellen. Diese schützen sie vor einem zytotoxischen NK-Zell-Angriff. NK-Zellen durchlaufen im Vorfeld einen komplexen Ausbildungssprozess ${ }^{48}$, an dessen Ende lizensierte Effektorzellen stehen. Diese können mittels gezielter Zytolyse krebstransformierte, zellulär-gestresste, sowie viralinfizierte Zellen im intakten Organismus erkennen und abtöten. ${ }^{49}$

Die Spenderauswahl ist ein wichtiger Faktor für den Erfolg einer Stammzelltransplantation. Infundierte Spender NK-Zellen schützen das Transplantat, indem sie als wirksame Effektorzellen verbleibende Leukämiezellen aktiv eliminieren. Diese wünschenswerte 
Nebenwirkung wird als Graft-versus-Leukämie (GvL)-Effekt bezeichnet. Ruggeri et al. konnte zeigen, dass insbesondere Transplantationsstrategien, die auf KIR-LigandFehlpaarungen (engl.: KIR-HLA-mismatch) basieren, zu weniger Rückfällen, weniger GvHD und einem besseren Gesamtüberleben bei Patienten mit akuter myeloischer Leukämie (AML) nach HSZT führt. Der KIR-HLA-mismatch wird mittlerweile aufgrund ausreichender Datenlage bei der Auswahl passender NK-Zell-Spender berücksichtigt und die Untersuchung auf die An- bzw. Abwesenheit bestimmter KIR-Gene (Haplotypisierung) mittlerweile neben der HLA-Typisierung standardisiert in vielen Instituten durchgeführt. Daneben finden sich immer mehr Hinweise dafür, dass bereits einzelne allelische Polymorphismen innerhalb der KIR-Gene einzelner Spender großen Einfluss auf die Funktionalität ihrer NK-Zellen nehmen. ${ }^{204,205}$ Die allelische Subtypisierung von KIRs stellt aufgrund stetig steigender Zahlen neu entdeckter Allele eine Herausforderung dar. Im Januar 2019 sind für KIR2DL1 bereits 66 Allele beschrieben und für KIR3DL1 sogar 150 Allele in der Immuno Polymorphism Database (IPD) hinterlegt.

Die vorliegende Arbeit präsentiert ein praktikables Subtypisierungsverfahren, um allelische Unterschiede innerhalb der Genloci der NK-Zell-Rezeptoren KIR2DL1 und KIR3DL1 zu untersuchen. Für die Experimente wurden NK-Zellen von 20 gesunden Spendern funktionell untersucht und KIR-genetisch analysiert. Ziel war es innerhalb dieser Individuen besonders potente NK-Zellspender $\mathrm{zu}$ identifizieren und diese anhand bestimmter Polymorphismen und/ oder der Expression von KIR-Rezeptoren zu charakterisieren.

Bei der Subtypisierung der KIR2DL1-Gene konnten 12 verschiedene, bereits bekannte KIR2DL1-Allele bestimmt werden. Die häufigsten Allele waren dabei 2DL1*001, *00201, $* 00302, * 00401$ und $* 00403.5$ der 20 Spender konnten der funktionell hochpotenten $\mathrm{R}^{245}$ Allelgruppe (AS Arginin an Pos. 245) zugeordnet werden. ${ }^{203}$ Spender 13 zeigte bei negativer KIR2DL1-SSP eine vermeintlich neue Nullallelvariante, Spender 20 eine neue heterozygote Variante, resultierend in der Kombination eines Arginin mit Alanin $\left(\mathrm{R} / \mathrm{A}^{245}\right)$. Bei der allelischer Subtypisierung von KIR3DL1 wurden 25 verschiedene, bereits bekannte KIR3DL1-Allele bei den 20 Spendern bestimmt. Spender 2 zeigt zahlreiche, vorwiegend homozygote Abweichungen von der Referenzfrequenz, insbesondere im Exon 5, und wurde als neue Allelvariante gewertet. Die häufigsten KIR3DL1-Allele waren 3DL1*00101, *002 und *087. Mittels durchflusszytometrischer Messung konnte gezeigt werden, dass das bekannte Nullallel 3DL1*0040101 bei Spender 14 zu keiner Oberflächenexpression des Rezeptors führt ${ }^{215}$, während Spendern 11 und 16 als Träger des 3DL1*00402 Allels eine 
Oberflächenexpression von rund $10 \%$ präsentierten. Um die Spender NK-Zellen der gebildeten Gruppen funktionell zu testen, wurden die NK-Zellen experimentell mit vier unterschiedlichen transgenen L721.221-Zelllinien stimuliert. Die funktionelle Potenz der gespendeten NK-Zellen wurde mittels eines CD107-Degranulationsassays gemessen. Nach aktuellem Stand sind nur für 53 der 150 KIR3DL1-Allele die allelischen Expressionsmuster untersucht worden. Dies bedeutet im Umkehrschluss, dass für rund 65\% der bekannten KIR3DL1-Allele Daten zur Funktionalität fehlen, und damit der größte Anteil der ermittelten Allele von 6 Spendern der unknown-Expression (KIR3DL1 ${ }^{\mathrm{u} / u}$ ) Gruppe zugeordnet wurde. Die Spender 4 und 19 der high-Expressiongruppe (KIR3DL1 ${ }^{\mathrm{h} / \mathrm{h}}$ ), sowie Spender 5 und 10 der KIR3DL1 ${ }^{\mathrm{u} / \mathrm{u}}$-Gruppe mit den Allelen 3DL1*053, *087, *109 und Spender 2 als Träger zweier neuer KIR3DL1-Allele, zeigten in toto die besten funktionellen Ergebnisse in den Experimenten gegen die verwendete B-lymphoblastoide L721.221Zellinien.

Die Ergebnisse der vorliegenden Arbeit zeigen, dass bei der Spenderauswahl für NK-Zellbasierten Immuntherapie neben der Genotypisierung die allelische KIR-Subtypisierung als wertvolles Werkzeug entschiedener berücksichtigt werden sollte. Dafür ist es jedoch notwendig weiter an KIR-Subtypisierung und -Gruppierung Strategien zu arbeiten, um Natürlichen Killerzellen Wege in die klinische Standardpraxis zu bahnen. 


\subsection{Englisch}

In Germany, the annual prevalence of leukemia is around 12.000 individuals. Leukemia is a serious oncological disease, in which mature bone marrow tissue mutates and is displaced by immature and dysfunctional progenitor cells (leukemic blasts). This leads to increasingly restricted blood formation. Acute forms of leukemia, if left untreated, can lead to death within a few weeks and therefore require immediate diagnostics and a swift therapy. Chances of recovery exist if the affected bone marrow is adequately replaced after the transplantation of healthy hematopoietic stem cells (HSCT). Unfortunately, rejection reactions of the donor material (Graft-versus-Host Disease, GvHD) remain quite common.

Natural killer cells represent the smallest lymphocyte population in human blood and form part of the innate immune system. They were first discovered in 1975 by Kiessling, Klein et al. ${ }^{17}$ Due to their ability to kill certain cancer cells in vitro, there has been increasing interest in researching their activating and inhibiting surface receptors. The killer cell immunoglobulin-like receptors (KIR) form a particularly diverse NK cell receptor family. Up to 17 highly polymorphic KIR genes are located on chromosome 19. The genetic manifestation and surface expression varies from individual to individual and is the prerequisite for the diversity of KIR-expressing NK cells. NK cells have the ability to categorize tissue into endogenous or foreign cells. Inhibitory killer immunoglobulin-like receptors (iKIR) use HLA class I proteins (MHC-I) on the surface of healthy cells to do so. These protect healthy cells from a cytotoxic NK cell attack. In order to develop the ability to differentiate, NK cells undergo a complex process of education. ${ }^{48}$ At its end there are licensed effector cells that can detect and kill cancer-transformed, cellular-stressed and virusinfected cells in the intact organism by means of targeted cytolysis. ${ }^{49}$

Donor selection is an important factor in the success of a stem cell transplant. Infused donor NK cells protect the graft by actively eliminating remaining leukemia cells. That desirable side effect is known as the Graft-versus-Leukemia (GvL) effect. Ruggeri et al. were able to show that transplant strategies based on KIR ligand mismatches in particular lead to fewer relapses, less GvHD and better overall survival in patients with acute myeloid leukemia (AML) after HSCT. For this reason and due to sufficient data the KIR-HLA mismatch is now taken into account in the selection of suitable NK cell donors and KIR genotyping, in addition to HLA typing, has become a standardized procedure in many institutes. In addition, there is growing evidence that individual allelic polymorphisms within the KIR genes of 
individual donors have a major influence on the functionality of their NK cells. ${ }^{204,205}$ The allelic subtyping of KIRs is a challenge due to ever-increasing numbers of newly discovered alleles. In January 2019, 66 alleles have already been described for KIR2DL1 and up to 150 alleles for KIR3DL1 are stored in the Immuno Polymorphism Database (IPD).

The present work presents a clinically suitable subtyping method to investigate allelic differences within the gene loci of the KIR receptors 2DL1 and 3DL1. For experimental purpose NK cells from 20 healthy individuals were functionally examined and genetically analysed for KIR. The main aim of the study was to identify particularly potent NK cell donors within all individuals and to characterize them on the basis of certain polymorphisms and/or expression of KIR receptors. When subtyping the KIR2DL1 genes 12 different, already known KIR2DL1 alleles were determined. The most common alleles within them were 2DL1 $* 001, * 00201, * 00302, * 00401$ and $* 00403.5$ of the 20 donors could be assigned to the functionally highly potent $\mathrm{R}^{245}$ allele group (AS arginine at position 245 ). ${ }^{203}$ Donor 13 showed a supposedly new null allele variant with negative KIR2DL1-SSP, donor 20 showed a new heterozygous variant, resulting in the combination of an arginine with alanine $\left(R / A^{245}\right)$. In the allelic subtyping of KIR3DL1, 25 different, already known KIR3DL1 alleles were determined from the 20 donors. Donor 2 showed numerous, predominantly homozygous deviations from the reference frequency, especially in exon 5, and was rated as a new allele variation. The most common KIR3DL1 alleles were 3DL1 *00101, *002 and *087. Flow cytometric measurements showed that the well-known null allele 3DL1 *0040101 in donor 14 did not lead to any surface expression of the receptor ${ }^{215}$, while donors 11 and 16 carrying the allele 3DL1 $* 00402$ presented a surface expression around 10\%. In order to functionally test the grouped donor NK cells they were experimentally stimulated with four different transgenic L721.221 cell lines that had different MHC characteristics (see section 3.2.1). The functional potency of the donated NK cells was measured using a CD107 degranulation assay. According to the current status of KIR3DL1 alleles only 53 of the 150 known alleles have been examined for allelic expression patterns. Conversely, this means that there is hardly any data for around 65\% of the other known KIR3DL1 alleles. Consequently, the majority of identified alleles were counted as unknown expression (KIR3DL1 ${ }^{\mathrm{u} / \mathrm{u}}$ ). Donors 4 and 19 of the high expression group (KIR3DL1 $\left.{ }^{\mathrm{h} / \mathrm{h}}\right)$, as well as donors 5 and 10 of the KIR3DL1 $1^{\mathrm{u} / \mathrm{u}}$ group carrying the alleles 3DL1*053,*087,*109 and donor 2 showing two new KIR3DL1 alleles, in toto showed the best functional results in the experiments against Blymphoblastoid L721.221 cell lines. 
The results show that allelic KIR subtyping of donors is a valuable tool in addition to genotyping. Therefore it should be given greater consideration in the selection of NK cell donors in the future. However, it is necessary to continue investigating in KIR subtyping and grouping strategies in order to further open ways for natural killer cells into standard clinical practice. 


\section{Anhang}

\subsection{Ergänzende Abbildungen und Tabellen}

Tabelle 24 Tabellarische Darstellung der Hauptantigene [eckige Klammer] der HLA-Klasse-I-Moleküle A, B und C mit ihren jeweiligen Unterantigenen und korrespondierendem Epitop (eigene Zusammenstellung; kein Anspruch auf Vollständigkeit).

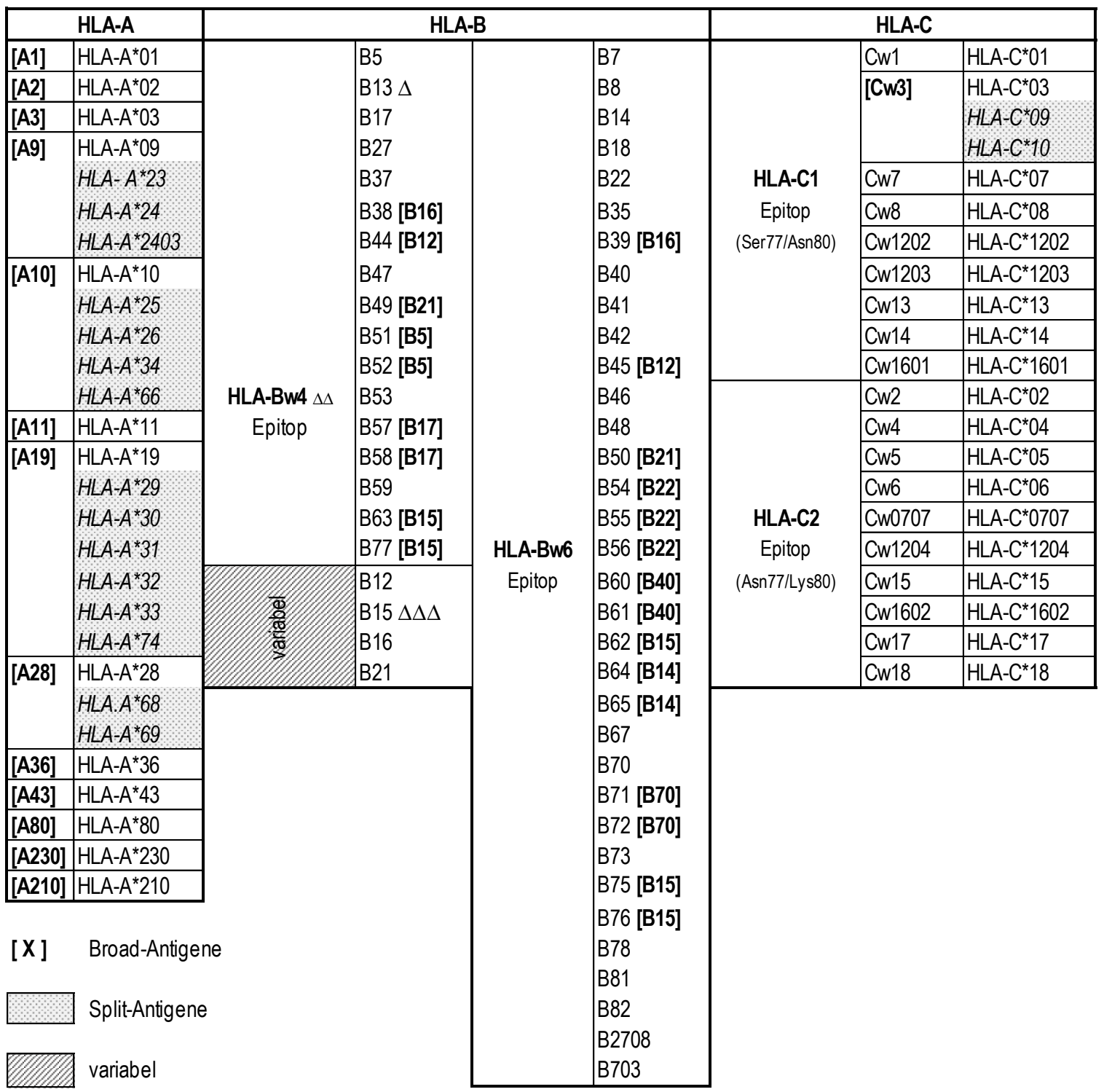

$\Delta$ nicht $\mathrm{B}^{*} 1301$ und ${ }^{*} 1302$

$\Delta \Delta$ ebenfalls: HLA-A9, -A23, -A24, -A2403, -A25 und -A32

$\Delta \Delta \Delta$ HLA-B1503 trägt ein Bw4-Epitop; HLA-B1502 dagegegen ein Bw6-Epitop. 


\begin{tabular}{|c|c|}
\hline Primersequenz $\mathrm{i} 7 \mathrm{~F}$ & AAATGAGGACCCAGAAGTGCCCTCCGAGCTCTTTTGTTGACTTCCGTCTCCTACAG \\
\hline \multicolumn{2}{|l|}{ EXON 8 (Position 1-53) } \\
\hline AA Codon & $27 \quad 33$ \\
\hline \multirow[t]{2}{*}{ 3DL1*0010101 } & AT GCT GCT GTA ATG GAC CAA GAG CCT GCA GGG AAC AGA ACA GCC AAC AGC GAG \\
\hline & $\begin{array}{l}\text { GTAGGTGCTCCTCGGCCCAGCCTCGTGGCTAGTGTTATTCCCAAACAGTCCTGGAAAA } \\
\text { CGTGAGCACCCTCCCTCACTCAGCATTTCCCTCCCTCACTCAGCATTTCCCTCTCTCCAG }\end{array}$ \\
\hline \multicolumn{2}{|l|}{ EXON 9 (Position 1-177) } \\
\hline AA Codon & 19 \\
\hline 3DL1*0010101 & GAC TCT GAT GAA CAA GAC CCT GAG GAG GTG ACA TAC GCA CAG TTG GAT CAC TGC GTT \\
\hline AA Codon & 100 \\
\hline 3DL1*0010101 & TTC ACA CAG AGA AAA ATC ACT CGC CCT TCT CAG AGG CCC AAG ACA CCC CCT ACA GAT \\
\hline Primersequenz E9R-s & [T CGC CCT TCT CAG AGG C] \\
\hline AA Codon & 118 \\
\hline 3DL1*0010101 & ACC ATC TTG TAC ACG GAA CTT CCA AAT GCT AAG CCC \\
\hline AA Codon & $\begin{array}{llll}151 & 157 & 166 & 175\end{array}$ \\
\hline 3DL1*0010101 & AGA TCC AAA GTT GTC TCC TGC CCA TGA \\
\hline Primersequenz E9R-n1 & $\begin{array}{l}\text { GCACCACAGTCAGGCCTTGAGGACGTCTTCTAGGGAGACAACAGCCCTGTCTCAAAACCGAG } \\
\text { TTGCCAGCTCCCATGTACCAGCAGCTGGAATCTGAAGGCGTGAGTCTTCATCTTAGGGCATCG } \\
\text { CTCCTCCTCACGCCACAAATCTGGTGCCTCTCTCTTGCTTACAAATGTCTAGGTCCCCACTGCC } \\
\text { TGCTGGAAAGAAAACACACTCCTTGCTTAGCCCACAGTTCTCCATTTCACTTGACCCCTGCCO } \\
\text { ACCTCTCCAACCTAACTGGCTTACTTCCTAGTCTACTTGAGGCTGCAATCACACTGAGGAACTC } \\
\text { ACAATTCCAAACATACAAGAGGCTCCCTCTTGACGTGGCACTTACCCACGTGCTGTTCCACCTT } \\
\text { CCCTCATGCTGTTTCACCTTTCTTCGGACTATTTCCAGCCTTCTGTCAGCAGGGAACTTATAA } \\
\text { AATITITGTGATTCAATGTAGCTGTCTCCTCTTCAAATAAACATGTCTGCCCTCAT }\end{array}$ \\
\hline
\end{tabular}

Abbildung 48 Dargestellt ist die Basensequenz des F-Primers i7F (orange; oben) und des R-Primers E9R-s (blau) angelehnt an Belle et al. zur KIR3DL1-Sequenzierung des Exons 8 und 9.202 Weiter unten ist die Basensequenz des in der vorliegenden Arbeit verwendeten neu entworfenen E9R-n1 Primers (orange; unten) zur vollständigen Sequenzierung von Exon 9 bis einschließlich Position 177 gezeigt. 
Tabelle 25 Zusammenstellung der Reaktionsansätze für die Amplifikations-PCR der KIR-Gene KIR2DL1- und KIR3DL1.

\begin{tabular}{|lc|}
\hline Reaktionsansatz für Amplifikat A (KIR2DL1) & Volumen in $\mu \mathrm{l}$ \\
\hline RNase-freies Wasser & 33 \\
Hifi PCR Buffer (10x) & 5 \\
DMSO (5\%) & 2,5 \\
Magnesiumsulfat (50mM) & 2 \\
DNA (0,5 - $1 \mu \mathrm{g})$ & 2 \\
antisense Primer & 2 \\
sense Primer & 2 \\
dNTP Mix (10mM) & 1 \\
Platinum High-Fidelity Taq DNA Polymerase & 0,5 \\
\cline { 2 - 2 } & $50 \mu \mathrm{l}$ gesamt \\
\hline
\end{tabular}

\begin{tabular}{|lc|}
\hline Reaktionsansatz für Amplifikat B1 + B2 (KIR2DL1) & Volumen in $\mu \mathrm{l}$ \\
\hline RNase-freies Wasser & 30 \\
Hifi PCR Buffer (5x) & 10 \\
DNA $(0,5-1 \mu \mathrm{g})$ & 2 \\
antisense Primer & 2,5 \\
sense Primer & 2,5 \\
DMSO (5\%) & 1,5 \\
dNTP Mix (10mM) & 1 \\
Phusion High-Fidelity DNAPolymerase & 0,5 \\
\hline & $50 \mu l$ gesamt \\
\hline
\end{tabular}

\begin{tabular}{|lc|}
\hline Reaktionsansatz für Amplifikate A, B, C1, C2 (KIR3DL1) & Volumen in $\mu \mathrm{l}$ \\
\hline Rnase-freies Wasser & 37,1 \\
Longrange PCR Buffer (10x) & 5 \\
dNTP Mix (10mM) & 2,5 \\
antisense Primer & 2 \\
sense Primer & 2 \\
DNA(0,5 - 1 $\mu \mathrm{g})$ & 1 \\
Longrange PCR-Enzyme-Mix & 0,4 \\
\hline
\end{tabular}


Tabelle 26 Auflistung der Taq-Polymerase spezifischen Thermocycler Parameter für die unterschiedlichen Amplifikate von KIR2DL1 (Amplifikate A, B1 und B2) und KIR3DL1 (Amplifikate A, B, C1 und C2).

\section{KIR2DL1}

\begin{tabular}{|c|c|c|c|c|}
\hline $\begin{array}{l}\text { Amplifikat A } \\
\text { (KIR2DL1) }\end{array}$ & Zeit & $\begin{array}{c}\text { Temperatur } \\
\left({ }^{\circ} \mathrm{C}\right) \\
\end{array}$ & $\begin{array}{l}\text { Wiederholung } \\
\text { en }\end{array}$ & $\begin{array}{c}\text { Programmname } \\
\text { (individuell) } \\
\end{array}$ \\
\hline Initiation & $2 \mathrm{~min}$ & 95 & \multirow{9}{*}{$-35 x$} & \multirow{9}{*}{ 2DL1APLA } \\
\hline Denaturierung & $20 \mathrm{~s}$ & 95 & & \\
\hline Annealing & $45 \mathrm{~s}$ & 64 & & \\
\hline Elongation & $5 \mathrm{~min}$ & 68 & & \\
\hline Denaturierung & $20 \mathrm{~s}$ & 95 & & \\
\hline Annealing & $45 \mathrm{~s}$ & 61 & & \\
\hline Elongation & $5 \mathrm{~min}$ & 68 & & \\
\hline Ende & $10 \mathrm{~min}$ & 68 & & \\
\hline Kühlung & $\infty$ & 4 & & \\
\hline $\begin{array}{l}\text { Amplifikate B1 + B2 } \\
\text { (KIR2DL1) }\end{array}$ & Zeit & $\begin{array}{c}\text { Temperatur } \\
\left({ }^{\circ} \mathrm{C}\right) \\
\end{array}$ & $\begin{array}{l}\text { Wiederholung } \\
\text { en }\end{array}$ & $\begin{array}{c}\text { Programmname } \\
\text { (individuell) }\end{array}$ \\
\hline Initiation & $30 \mathrm{~s}$ & 98 & \multirow{6}{*}{$-35 x$} & \multirow{6}{*}{$\begin{array}{l}\text { 2DL1B1PHU } \\
\text { 2DL1B2PHU }\end{array}$} \\
\hline Denaturierung & $10 \mathrm{~s}$ & 98 & & \\
\hline Annealing & $30 \mathrm{~s}$ & 62 & & \\
\hline Elongation & $\begin{array}{l}4 \mathrm{~min} * \\
15 \mathrm{~s} *\end{array}$ & 72 & & \\
\hline Ende & $10 \mathrm{~min}$ & 72 & & \\
\hline Kühlung & $\infty$ & 4 & & \\
\hline
\end{tabular}

* Für Amplifikat B1 wurde die Zeiteinstellung 4 min, für das kürzere Amplifikat B2 dagegen 15 sec gewählt.

\section{KIR3DL1}

\begin{tabular}{|c|c|c|c|c|}
\hline $\begin{array}{l}\text { Amplifikate } \\
\text { A,B,C1,C2 } \\
\text { (KIR3DL1) }\end{array}$ & Zeit & $\begin{array}{c}\text { Temperatur } \\
\left({ }^{\circ} \mathrm{C}\right) \\
\end{array}$ & $\begin{array}{l}\text { Wiederholung } \\
\text { en }\end{array}$ & $\begin{array}{c}\text { Programmname } \\
\text { (individuell) }\end{array}$ \\
\hline Initiation & $3 \mathrm{~min}$ & 93 & \multirow{6}{*}{$-35 x$} & \multirow{6}{*}{ 3DL1ALL } \\
\hline Denaturierung & $15 \mathrm{~s}$ & 93 & & \\
\hline Annealing & $45 \mathrm{~s}$ & 60 & & \\
\hline Elongation & $7 \mathrm{~min}$ & 68 & & \\
\hline Ende & $10 \mathrm{~min}$ & 68 & & \\
\hline Kühlung & $\infty$ & 4 & & \\
\hline
\end{tabular}


Tabelle 27 Auflistung der verwendete Primer für die Amplifikation der KIR-Gene KIR2DL1 und -3DL1 und der Sequenzierung ihrer Exone 1 bis 9. Die in der Tabelle mit ( $\left.{ }^{*}\right)$ bezeichneten Primer, wurde auch später für die zweite Sequenzier-PCR in 1:100 Verdünnung verwendet werden.

\begin{tabular}{|c|c|c|c|c|c|c|}
\hline \multirow{2}{*}{$\begin{array}{l}\text { Amplifikatbezeichnung } \\
\text { (KIR2DL1-Gen) }\end{array}$} & \multirow{2}{*}{ Größe } & \multirow{2}{*}{ Strang } & \multicolumn{4}{|c|}{ Verwendete Primer } \\
\hline & & & Bezeichnung & Länge (bp) & Verdünnung & Nukleotidsequenz \\
\hline \multirow{2}{*}{ A } & \multirow{2}{*}{$5,6 \mathrm{~kb}$} & sense & 2DL1-E1F-M13F & 19 & $1: 10$ & 5'- GGC AGC ACC ATG TCG CTC T $\quad-3^{\prime}$ \\
\hline & & antisense & 2DL1-E5R * & 20 & 1:10 & 5'- CAAGCAGTG GGT CAC TTG AC -3' \\
\hline \multirow{2}{*}{ B1 } & \multirow{2}{*}{$7,9 \mathrm{~kb}$} & sense & $2 \mathrm{DL} 1-\mathrm{i} 4 \mathrm{~F}^{*}$ & 20 & 1:10 & 5'- AAG ATC CTC CCT GAG GAAAC $\quad-3^{\prime}$ \\
\hline & & antisense & 2DL1-i7R * & 20 & 1:10 & 5'- AGG GAC CAT CCT GTT TGT GA -3' \\
\hline \multirow{2}{*}{ B2 } & \multirow{2}{*}{$\sim 0,5 \mathrm{~kb}$} & sense & $2 \mathrm{DL} 1-\mathrm{i} 7 \mathrm{~F}$ * & 20 & $1: 10$ & 5'- AAATGAGGACCC AGAAGT GC $\quad-3^{\prime}$ \\
\hline & & antisense & 2DL1- E9AR * & 20 & 1:10 & 5'- TGT TGT CTC CCT AGAAGACG -3' \\
\hline \multicolumn{2}{|l|}{ Exon 1} & antisense & 2DL1-i1R3 & 19 & 1:100 & 5'- GGC CCATCACTC CAT СТC T $-3^{\prime}$ \\
\hline \multirow{2}{*}{\multicolumn{2}{|c|}{ Exon 2}} & sense & 2DL1-i1F & 19 & 1:100 & 5'- CAAGAC TCACAG CCC AGT G $\quad-3^{\prime}$ \\
\hline & & antisense & 2DL1-i2R & 20 & 1:100 & 5'- GGAGGC AAG GTC AGAAAT GT -3 ' \\
\hline \multirow{2}{*}{\multicolumn{2}{|c|}{ Exon 4}} & sense & 2DL1-i2F & 21 & 1:100 & 5'- GAC ACC TTC TAAACT CAC AAC -3' \\
\hline & & antisense & 2DL1-i4R & 20 & $1: 100$ & 5'- AAT TCC TGG ATC ATT CAC TC -3 ' \\
\hline \multirow{3}{*}{\multicolumn{2}{|c|}{ Exon 5}} & sense & 2DL1-i4F & 20 & 1:100 & 5'- AAG ATC CTC CCT GAG GAAAC $\quad-3^{\prime}$ \\
\hline & & sense & 2DL1- E5FN & 20 & 1:100 & 5'- AGG CCC ATG AAC GTAGGC TC -3' \\
\hline & & antisense & 2DL1-i5R & 21 & $1: 100$ & 5'- AGG CTC TAG GAT CAT AGG ACF -3' \\
\hline \multirow{2}{*}{\multicolumn{2}{|c|}{ Exon 6}} & sense & 2DL1-i5F & 20 & 1:100 & 5'- GCC TTT CTT TAT GCC AAT GT -3' \\
\hline & & antisense & 2DL1-i6RN & 20 & 1:100 & 5'- TGT CAG AGC TGT GAG AT G CT -3' \\
\hline \multirow{2}{*}{\multicolumn{2}{|c|}{ Exon 7}} & sense & 2DL1-i6FN & 19 & $1: 100$ & 5'- ATC TGG GTG CTT GTC CTAA $\quad-3^{\prime}$ \\
\hline & & antisense & 2DL1-i7R & 20 & 1:100 & 5'- AGG GAC CAT CCT GTT TGT GA -3' \\
\hline \multirow{2}{*}{\multicolumn{2}{|c|}{ Exon $8-9$}} & sense & 2DL1-i7F & 20 & 1:100 & 5'- AAATGAGGACCC AGAAGT GC \\
\hline & & antisense & 2DL1-E9AR & 20 & $1: 100$ & 5'- TGT TGT CTC CCT AGAAGACG -3' \\
\hline
\end{tabular}

\begin{tabular}{|c|c|c|c|c|c|c|}
\hline \multirow{2}{*}{$\begin{array}{l}\text { Amplifikatbezeichnung } \\
\text { (KIR3DL1-Gen) }\end{array}$} & \multirow{2}{*}{ Größe } & \multirow{2}{*}{ Strang } & \multicolumn{4}{|c|}{ Verwendete Primer } \\
\hline & & & Bezeichnung & Länge (bp) & Verdünnung & Nukleotidsequenz \\
\hline \multirow{2}{*}{ A } & \multirow{2}{*}{$2,1 \mathrm{~kb}$} & sense & 3DL1/S1-5'UTR & 19 & 01:10 & 5'- TGT CT G CAC CGG CAG CAC C \\
\hline & & antisense & 3DL1- E4R-560 & 19 & 01:10 & 5'- TAG GTC CCT GCAAGG GCAA \\
\hline \multirow{2}{*}{ B } & \multirow{2}{*}{$2,3 \mathrm{~kb}$} & sense & $3 \mathrm{DL} 1-\mathrm{i} 3 \mathrm{~F}^{*}$ & 21 & 01:10 & 5'- GAT GCC TTC TAAACT CAC AAC -3 \\
\hline & & antisense & 3DL1-i5R * & 20 & 01:10 & 5'- TGC ATC TGT CCATGC TTT TC -3 \\
\hline \multirow{2}{*}{ C1 } & \multirow{2}{*}{$0,5 \mathrm{~kb}$} & sense & $3 D L 1-i 4 F-c^{*}$ & 20 & 01:10 & 5'- GGT CAT AGAGCAGGG GAG TG -3 \\
\hline & & antisense & 3DL1-i6R * & 20 & 01:10 & 5'- CCC TTT CAC TGT TGG AGT GT -3 \\
\hline \multirow{2}{*}{ C2 } & \multirow{2}{*}{$1,0 \mathrm{~kb}$} & sense & $3 \mathrm{DL} 1-\mathrm{i} 6 \mathrm{~F}$ * & 20 & 01:10 & 5'- AGG GGT CAAACATCT CAACT $\quad-3$ \\
\hline & & antisense & 3DL1- E9R * & 17 & 01:10 & 5'- GCC TCT GAG AAG GGC GA \\
\hline \multirow{2}{*}{\multicolumn{2}{|c|}{ Exon 1}} & antisense & 3DL1-i1R & 20 & $1: 100$ & 5'- CTC CAC TTC AGG CCC ATAAC -3 \\
\hline & & & & & $1: 100$ & \\
\hline \multirow{2}{*}{\multicolumn{2}{|c|}{ Exon 2}} & sense & 3DL1-i1F & 19 & 1:100 & 5'- CAAGAC GCACAG CCC AGT G -3 \\
\hline & & antisense & $3 D L 1-i 2 R$ & 21 & 1:100 & 5'- GGAAGG CAAGGT CAG AAATGT -3 \\
\hline \multicolumn{2}{|l|}{ Exon 3} & sense & $3 \mathrm{DL} 1-\mathrm{i} 2 \mathrm{~F}$ & 20 & 1:100 & 5'- GAG AAT CTT CTG GGC ACT GG -3 \\
\hline Exolio & & antisense & 3DL1-i3R & 20 & 1:100 & 5'- GAG GTG GGACAG TGAGAAGC -3 \\
\hline & sense & 3DL1-i3F & 21 & 1:100 & 5'- GAT GCC TTC TAAACT CAC AAC -3 \\
\hline \multicolumn{2}{|l|}{ Exon 4} & antisense & 3DL1-i4R & 20 & 1:100 & 5'- AAG TCC TGG ATC ATT CAC TC -3 \\
\hline \multirow{3}{*}{\multicolumn{2}{|c|}{ Exon 5}} & sense & 3DL1-E5F-s & 20 & 1:100 & 5'- ССT СTT СТC СTT CCAGGT CC -3 \\
\hline & & sense & 3DL1-i4F-c & 20 & 1:100 & 5- GGT CAT AGA GCAGGG GAG TG -3 \\
\hline & & antisense & $3 D L 1-i 5 R$ & 20 & 01:10 & 5'- TGC ATC TGT CCATGC TTT TC -3 \\
\hline \multirow{2}{*}{\multicolumn{2}{|c|}{ Exon 6}} & sense & $3 \mathrm{DL} 1-\mathrm{i} 5 \mathrm{~F}$ & 20 & 1:100 & 5'- GCC TTT CTT TAT GCC AAT GT -3 \\
\hline & & antisense & $3 D L 1-i 6 R$ & 20 & 1:100 & 5'- CCC TTT CAC TGT TGG AGT GT -3 \\
\hline \multirow{2}{*}{\multicolumn{2}{|c|}{ Exon 7}} & sense & $3 \mathrm{DL} 1-\mathrm{i} 6 \mathrm{~F}$ & 20 & 1:100 & 5'- AGG GGT CAAACATCT CAACT $\quad-3$ \\
\hline & & antisense & 3DL1-i7R & 19 & 1:100 & 5'- AGC TGT GTG CTC CCATCC T -3 \\
\hline \multirow{3}{*}{\multicolumn{2}{|c|}{ Exon $8-9$}} & sense & 3DL1-i7F & 20 & 1:100 & 5'- AAATGAGGACCC AGAAGT GC $\quad-3$ \\
\hline & & antisense & 3DL1-E9R-n1 & 20 & 1:100 & 5'- ACA GGG CTG TTG TCT CCC TA -3 \\
\hline & & antisense & 3DL1-E9R-s & 17 & $1: 100$ & 5'- GCC TCT GAG AAG GGC GA \\
\hline
\end{tabular}

Primer angelehnt an Belle et al. (2008) 
Tabelle 28 Übersetzung der DNA-Basentriplets in Aminosäuren (links); Legende zur Aminosäurennomenklatur (rechts).

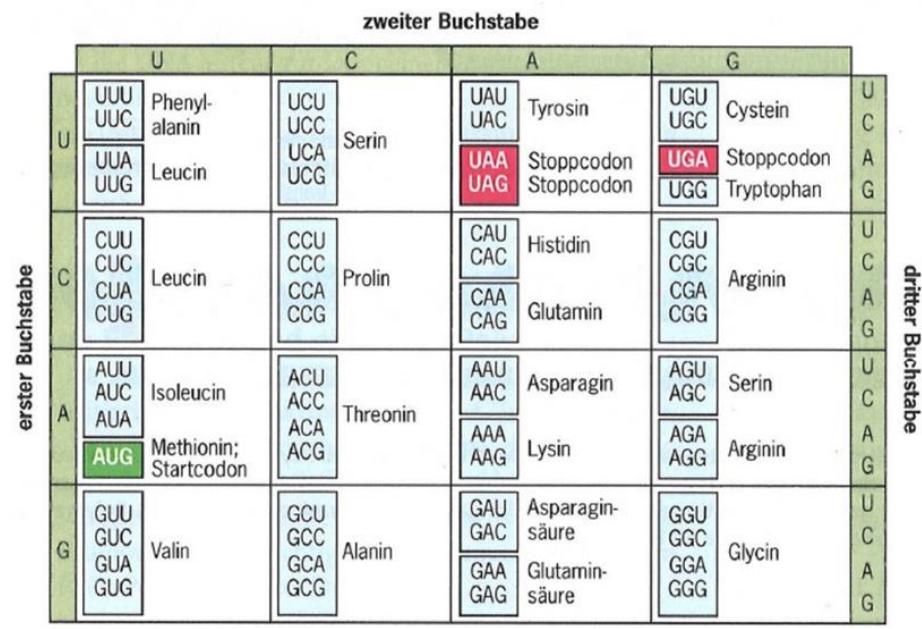

\begin{tabular}{|c|c|c|}
\hline $\begin{array}{c}\text { Einbuchstabiges } \\
\text { Symbol }\end{array}$ & $\begin{array}{c}\text { Aminosäuren- } \\
\text { bezeichnung }\end{array}$ & $\begin{array}{c}\text { Dreibuchstabige } \\
\text { Abkürzung }\end{array}$ \\
\hline A & Alanin & Ala \\
\hline$R$ & Arginin & Arg \\
\hline N & Asparagin & Asn \\
\hline$D$ & Asparaginsäure & Asp \\
\hline C & Cystein & Cys \\
\hline$Q$ & Glutamin & Gln \\
\hline E & Glutaminsāure & Glu \\
\hline$G$ & Glycin & Gly \\
\hline H & Histidin & His \\
\hline I & Isoleucin & lle \\
\hline L & Leucin & Leu \\
\hline K & Lysin & Lys \\
\hline M & Methionin & Met \\
\hline F & Phenyalanin & Phe \\
\hline P & Prolin & Pro \\
\hline S & Serin & Ser \\
\hline$T$ & Threonin & Thr \\
\hline W & Tryptophan & Trp \\
\hline Y & Tyrosin & Tyr \\
\hline V & Valin & Val \\
\hline
\end{tabular}


Tabelle 29 Überblick relevanter im EasySep ${ }^{\mathrm{TM}}$ Human NK Cell Enrichment Kit enthaltene CD-Antigene mit Zuordnung der spezifischen Zellexpression. [Angelehnt an das Lehrbuch "Pädiatrische Allergologie und Immunologie" (Hrsg. U. Wahn, R. Seger, V. Wahn, G. Holländer), Elsevier-Verlag, September 2005 und W. Luttmann et al., Der Experimentator: Immunologie, Experimentator, DOI 10.1007/978-3-642-41899-0, Springer-Verlag Berlin Heidelberg, 2014]

\begin{tabular}{|c|c|c|c|c|}
\hline CD-Antigen & $\begin{array}{l}\text { Alternative } \\
\text { Bezeichnung }\end{array}$ & Zelluläre Expression & $\begin{array}{l}\text { Molekulares } \\
\text { Gewicht } \\
\text { (kDa) }\end{array}$ & Funktion (*) \\
\hline CD3 & T3 & Thymozyten, T-Lymphozyten & $20-28$ & $\begin{array}{l}\text { Assoziiert mit dem T-Zell-Antigen- } \\
\text { Rezeptor (TZR) zur } \\
\text { Signaltransduktion }\end{array}$ \\
\hline CD4 & T4, L3T4 & $\begin{array}{l}\text { Thymozyten, T-Lymphozyten, } \\
\text { Monozyten, Makrophagen }\end{array}$ & 55 & 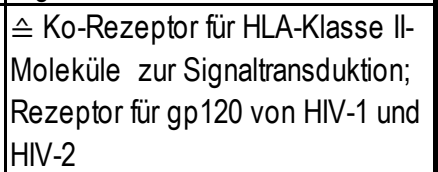 \\
\hline CD14 & LPS receptor & Myelomonozytische Zellen & $53-55$ & $\begin{array}{l}\text { Rezeptor für Lipopolysaccharide } \\
\text { und das Lipopolysaccharid- } \\
\text { Bindungsprotein (LBP) }\end{array}$ \\
\hline CD16a & FcyRIIIa & $\begin{array}{l}\text { plazentäre Trophoblasten; } \\
\text { NK-Zellen, Makrophagen und } \\
\text { T-Lymphozyten }\end{array}$ & \multirow[t]{2}{*}{$70-85$} & $\begin{array}{l}\text { ^FFc-Rezeptor für die vermittelte } \\
\text { Phagozytose und den antikörper- } \\
\text { abhängige-zellvermittelten } \\
\text { Zytotoxizität (ADCC)- Mechanismus }\end{array}$ \\
\hline CD16b & $F c \gamma R I I / \beta$ & $\begin{array}{l}\text { Endothelzellen; Neutrophile/ } \\
\text { Eosinophile Granulozyten }\end{array}$ & & 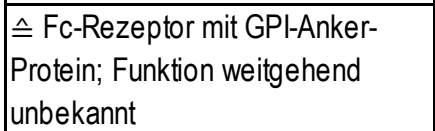 \\
\hline CD19 & B4 & B- Lymphozyten & 95 & $\begin{array}{l}\text { Ko-Rezeptor von B-Lymphozyten; } \\
\text { Komplexbildung mit CD21 (CR2) } \\
\text { und CD81 (TAPA-1) }\end{array}$ \\
\hline CD20 & $B 1$ & B- Lymphozyten & $33-37$ & $\begin{array}{l}\text { Mögliche Funktion in der } \\
\text { Differenzierung und Stimulation } \\
\text { der B-Zellaktivierung }\end{array}$ \\
\hline CD56 & NCAM, MSK39 & $\begin{array}{l}\text { Neurone, Glia- und Muskelzellen; } \\
\text { NK-Zellen, auch: } \gamma \delta \text {-T-Zellen, CD8 } \\
\text { T- Lymphozyten, Dendritische } \\
\text { Zellen }\end{array}$ & $120-180$ & $\begin{array}{l}\text { Zelladhäsion, synaptische } \\
\text { Plastizität, Immunzell-Aktivierung } \\
\text { und -Zytotoxizität }\end{array}$ \\
\hline CD66b & $\begin{array}{l}\text { CEACAM8, CGM6; } \\
\text { ehemals CD67 }\end{array}$ & Granulozyten & $95-100$ & $\begin{array}{l}\text { Zelladhäsion und -migration, } \\
\text { Pathogenbindung }\end{array}$ \\
\hline CD123 & IL-3Ra, IL3RA & $\begin{array}{l}\text { Stammzellen des } \\
\text { Knochenmarks, basophile } \\
\text { Granulozyten, } \\
\text { Monozyten, Megakaryozyten }\end{array}$ & 70 & $\begin{array}{l}\text { Â IL-3 Rezeptor a-Kette; } \\
\text { Proliferations- und } \\
\text { Differenzierungmarker } \\
\text { hämatopoetischer Zelllinien }\end{array}$ \\
\hline HLA-DR & $\begin{array}{l}\text { Human Leukocyte } \\
\text { Antigen - D Related }\end{array}$ & $\begin{array}{l}\text { CD4+ T-Helferzellen, Dendritische } \\
\text { Zellen, Makrophagen, B- } \\
\text { Lymphozyten }\end{array}$ & $\begin{array}{c}\text { a-Kette } \\
(34 \mathrm{kDa})+/- \\
\text { mehrere } \\
\beta-\text { Ketten } \\
(\sim 28 \mathrm{kDa})\end{array}$ & $\begin{array}{l}\text { Regulation und Modulation von } \\
\text { Immunzellfunktionen; Marker für } \\
\text { Immunaktivität }\end{array}$ \\
\hline
\end{tabular}

* CD-Antigene nicht vollständig aufgelistet 


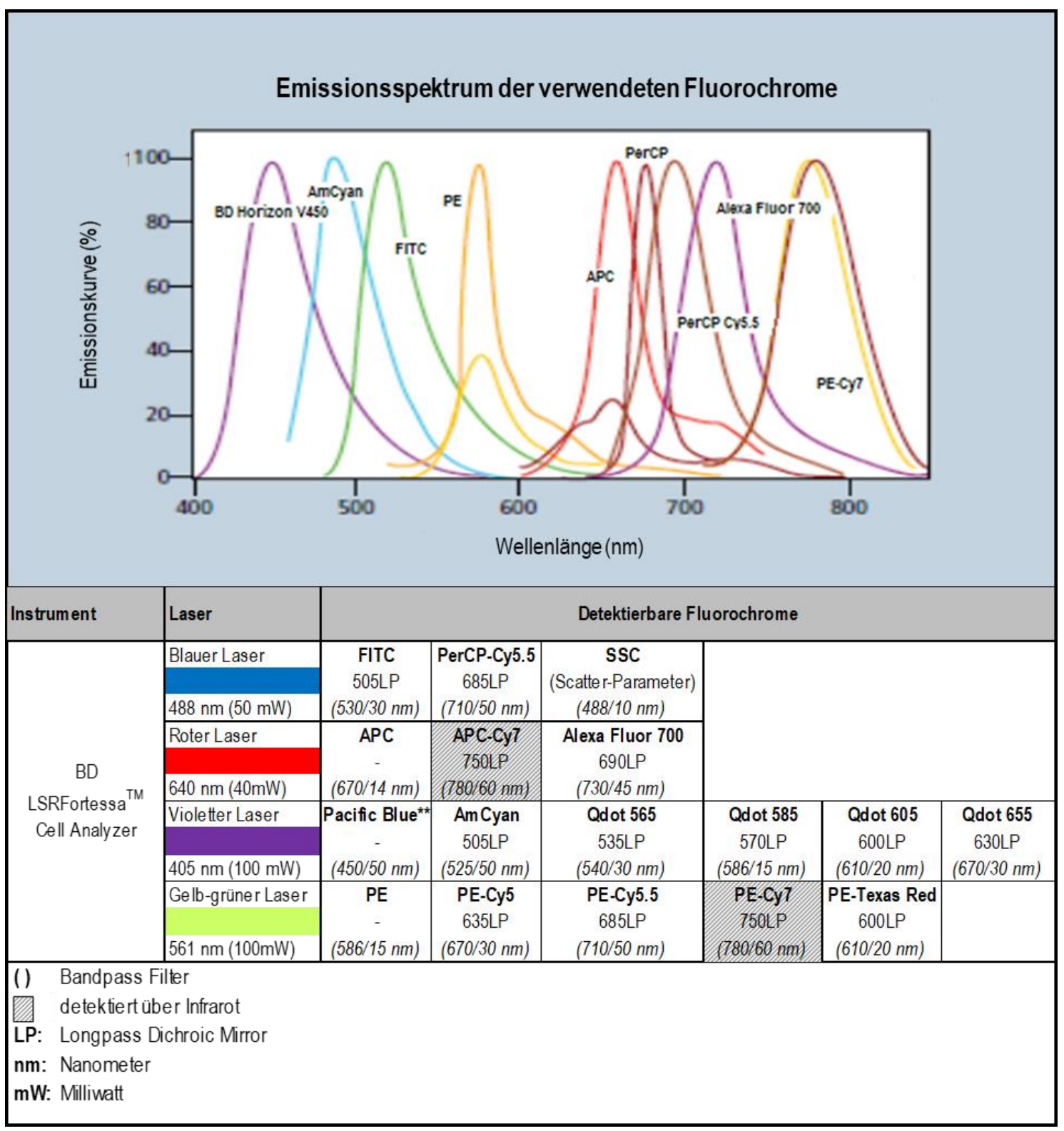

Abbildung 49 Emissionsspektrum der verwendeten Fluorochrome (oben) und Auflistung des Laser-Detektionsarms im BD LSRFortessa ${ }^{\mathrm{TM}}$ Cell Analyzer (unten). [Quelle: https://www.bdbiosciences.com/documents/bd_Isrfortessa_ brochure.pdf ] 
Tabelle 30 Darstellung der spenderspezifischen HLA-A, -B und -C Allele und dem daraus resultierendem MHC-I-Profil der 20 untersuchten NK-Zell-Spendern..

\begin{tabular}{|c|c|c|c|c|c|c|c|c|c|}
\hline \multirow{3}{*}{ Spender } & \multirow{3}{*}{ Haplotyp } & \multirow{3}{*}{$\begin{array}{l}\overline{\bar{z}} \\
\frac{\tilde{\alpha}}{x}\end{array}$} & \multirow{3}{*}{ 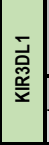 } & \multicolumn{4}{|c|}{ Donor KIR-Ligand = HLA-Typisierung } & \multirow{3}{*}{\multicolumn{2}{|c|}{$\begin{array}{l}\text { MHC-I } \\
\text { Profil }\end{array}$}} \\
\hline & & & & \multicolumn{2}{|c|}{ HLA-C } & HLA-A/B & \multirow{2}{*}{$\begin{array}{c}\text { HLA-B } \\
\text { Bw6 }\end{array}$} & & \\
\hline & & & & Gruppe C1 & Gruppe C2 & Bw4 & & & \\
\hline 5 & $A$ & & & HLA-C $01: 02,{ }^{*} 07: 01$ & - & HLA-B`27:05 & HLA-B*08:01 & \multirow{8}{*}{$(\mathrm{C} 1 / \mathrm{C} 1)$} & (Bw4/Bw6) \\
\hline 2 & B & & & HLA-C ${ }^{*} 01: 02,{ }^{*} 07: 02$ & - & - & \multirow{2}{*}{$\begin{array}{l}\text { HLA-B*07:02, *15:01 [B62] } \\
\text { HLA-B*62, *35 }\end{array}$} & & \multirow{7}{*}{ (Bw6/Bw6) } \\
\hline 6 & B & & & HLA-C*03:03, *03:04 & - & - & & & \\
\hline 7 & B & & & HLA-C*07 & - & - & HLA- $B^{*} 07,{ }^{*} 08$ & & \\
\hline 12 & B & & & HLA-C*01, *03 & - & - & HLA-B* $40,{ }^{*} 56$ & & \\
\hline 13 & B & & & HLA-C*07:02 & - & - & HLA-B*07:02 & & \\
\hline 15 & $A$ & & & HLA-C*07 & - & - & HLA- B*07 & & \\
\hline 19 & $\mathrm{~B}$ & & & HLA-C*03, ${ }^{*} 07$ & - & - & HLA-B*18:01, *40:01 & & \\
\hline 1 & $B$ & & & HLA-C*01:02 & HLA-C ${ }^{*} 16: 02$ & HLA-B*27, ${ }^{*} 51$ & - & & (Bw4/Bw4) \\
\hline 3 & A & & & HLA-C*03:01 & HLA-C $05: 01$ & HLA-B*44, *58 & - & & \\
\hline 4 & B & & & HLA-C*03:04 & HLA-C ${ }^{*} 16: 02$ & HLA-B*44 & HLA-B*40 & & \\
\hline 9 & $B$ & & & HLA-C*07:02 & HLA-C ${ }^{*} 15: 02$ & HLA-B*51 & HLA-B*07 & $(C 1 / C 2)$ & \\
\hline 10 & B & & & HLA-C*07:02 & HLA-C*04:01 & HLA-B*44:03 & HLA-B*07:02 & (C1/C2) & (Rw4/RwG) \\
\hline 14 & B & & & HLA-C ${ }^{*} 07: 02,{ }^{*} 07: 50$ & HLA-C ${ }^{*} 06: 02$ & HLA-B*57 & HLA-B*07 & & (BW4/BWb) \\
\hline 16 & B & & & HLA-C*07:02 & HLA-C $06: 02$ & HLA- $B^{*} 57: 01$ & HLA- $B^{*} 07: 02$ & & \\
\hline 18 & B & & & HLA-C*07:01 & HLA-C*05:01 & HLA-B*44 & HLA-B*08 & & \\
\hline 8 & $B$ & & & - & HLA-C*15:02, *16:02 & HLA-B ${ }^{*} 51$ & - & & (Rw4/Rw4) \\
\hline 20 & $B$ & & & - & HLA-C*05:01 & HLA-B*44:02 & - & (C)/C) & (BW4/BW4) \\
\hline 17 & B & & & - & HLA-C*04:01, *06:02 & HLA-B*57 & HLA-B*35 & (CZ/しL) & (Bw4/Bw6) \\
\hline 11 & B & & & - & HLA-C*02:02, $C^{*} 04: 01$ & - & HLA-B*35:03, *40:02 & & (Bw6/Bw6) \\
\hline
\end{tabular}

Tabelle 31 Abweichende polymorphe Positionen bei der Untersuchung des kaum bzw. nicht-exprimierten KIR3DL $1{ }^{*} 004-$ Allels.

\begin{tabular}{|c|c|c|c|c|c|}
\hline $\begin{array}{l}\text { Rezeptorbereich } \\
\text { AS-Position }\end{array}$ & $\begin{array}{c}\text { D0-Domäne } \\
44\end{array}$ & $\begin{array}{c}\text { D0-Domäne } \\
86\end{array}$ & $\begin{array}{c}\text { D2-Domäne } \\
218\end{array}$ & $\begin{array}{c}\text { ZYT-Region } \\
353\end{array}$ & $\begin{array}{c}\text { ZYT-Region } \\
365\end{array}$ \\
\hline Exon & & 3 & 5 & 8 & 9 \\
\hline Exon-Position & 123 & 250 & 62 & 17 & 3 \\
\hline *0010101 & $\begin{array}{c}{[\mathrm{AGA}]^{\text {Arginin }}} \\
\text { A }\end{array}$ & $\begin{array}{r}{[\mathrm{TCG}]^{\text {Serin }}} \\
\text { C }\end{array}$ & $\begin{array}{r}{[A G C]^{\text {Serin }}} \\
\text { C }\end{array}$ & $\begin{array}{c}{[\mathrm{GAC}]^{\text {Asparaginsäure }}} \\
\text { C }\end{array}$ & $\begin{array}{c}{[\mathrm{GAC}]^{\text {Asparaginsäure }}} \\
\text { C }\end{array}$ \\
\hline verändertes Triplet & {$[\text { GGA }]^{\text {Glycin }}$} & {$[\mathrm{TTG}]^{\text {Leucin }}$} & {$[A G T]^{\text {Serin }}$} & {$[\mathrm{GAT}]^{\text {Asparaginsäure }}$} & {$[\mathrm{GAT}]^{\text {Asparaginsäure }}$} \\
\hline${ }^{*} 0040101$ & $G$ & $T$ & - & - & - \\
\hline${ }^{\star} 0040102$ & $G$ & $T$ & - & - & - \\
\hline *0040103 & G & $\mathrm{T}$ & - & - & - \\
\hline${ }^{*} 00402$ & $G$ & $T$ & - & - & $T$ \\
\hline${ }^{*} 00403$ & $G$ & $T$ & $T$ & - & $T$ \\
\hline${ }^{*} 00404$ & $\bar{G}$ & $T$ & - & $T$ & - \\
\hline
\end{tabular}

Ergänzung: AS-Position 182 (Exon 4 - Position 252) zeigt für alle 3DL1*004-Allele [TCC] Serin.

\subsection{Auswertungs- und Ergebnistabellen der Subtypisierung von KIR2DL1 und KIR3DL1}

$\rightarrow$ Ab Seite 125 bis 133 
Tabelle 32 Tabellarische Zusammenstellung untersuchter funktioneller Polymorphismen des KIR3DL1-Gens mit jeweiliger Literaturangabe. Eigene Zusammenstellung relevanter (A) und wahrscheinlich unrelevanter (B) funktioneller KIR3DL1-Polymorphismen. [Tabelle angelehnt an Campbell, Purdy et al. (2011)53]

\begin{tabular}{|c|c|c|c|c|c|c|}
\hline $\begin{array}{l}\text { Zugeschriebener } \\
\text { Effekt }\end{array}$ & $\begin{array}{l}\text { Rezeptor- } \\
\text { bereich }\end{array}$ & $\begin{array}{l}\text { AS- } \\
\text { Position }\end{array}$ & $\left|\begin{array}{l}\text { AS-Sequenz } \\
\text { des reifen } \\
\text { KIR3DL1-Proteins }\end{array}\right|$ & \begin{tabular}{|l} 
untersuchtes \\
Allel
\end{tabular} & $\begin{array}{l}\text { Ergänzung der } \\
\text { polymorphen Allele }\end{array}$ & Literaturnachweis \\
\hline $\begin{array}{l}\text { senktkIR3DL1 } \\
\text { oberflähenexpression }\end{array}$ & Do-Domäne & V18L & SAVLPRG & $3 D L 1 * 053$ & Leucin-18 ebenfalls bei $30 L 11^{*} 073$ & Thomas etal. (2008) \\
\hline $\begin{array}{l}\text { verthindertkR32011 } \\
\text { Oberfähnenexpression } \\
\text { (veränderte Falutung) }\end{array}$ & Do-Domäne & S86L & TGWLAPS & 3DL1*004 & 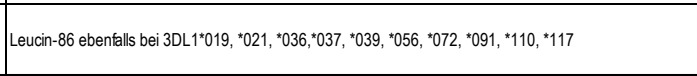 & Pando etal. (2003) \\
\hline \multirow{2}{*}{ 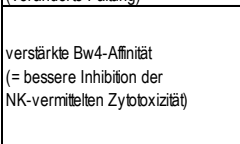 } & Do-Domäne & $\begin{array}{l}\text { AS } 49-52 \\
\begin{array}{l}\text { (v.a. F50A+ } \\
\text { H51A) }\end{array} \\
\end{array}$ & HIP IFHG RIF & \begin{tabular}{|l} 
geltend fir alle bis \\
2002 \\
dokumentierten \\
KIR3DL1-Alllele
\end{tabular} & & Khakoo etal. (2002), Norman etal. (2007) \\
\hline & $\frac{\text { D2-Domäne }}{\text { TM- Bereich }}$ & $\frac{\mathrm{R} 238}{1320}$ & \begin{tabular}{|l} 
SRERGAH \\
HLHILIG
\end{tabular} & $\frac{3 D L 1 * 002}{3 D L 11^{*} 002}$ & \begin{tabular}{|l|} 
Arginin-238 ebenfalls bei $3 D L 1^{*} 054$ \\
alle we-teren KIR3DL1-Allele 1 s.u...
\end{tabular} & \begin{tabular}{|l} 
Carr etal. (2005) \\
Carr etal. (2005)
\end{tabular} \\
\hline $\begin{array}{l}\text { stärkerer Inhibilion gegenüber HLA- } \\
B^{*} 1513\end{array}$ & D2-Domäne & W283L & PYELSDP & $3 D L 1 * 059$ & 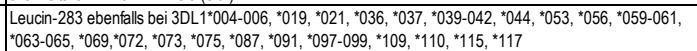 & Sharma etal (2009), Norman etal. (2007) \\
\hline $\begin{array}{l}\text { sërkerere Inhibition gegenüber HLA- } \\
A^{*} 3201\end{array}$ & D2-Domäne & W283 & PYEW SDP & $3 \mathrm{DL} 1{ }^{*} 015$ & alle weiteren KR33DL1-Allele (s.o.) & $\begin{array}{l}\text { Sharma etal (2009), } \\
\text { Norman etal. (2007) }\end{array}$ \\
\hline 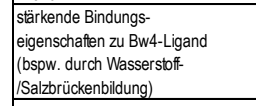 & D2-Domäne & $\begin{array}{l}s 228 \\
S 279 \\
E 282\end{array}$ & $\begin{array}{l}\text { SRSSYDM } \\
\text { FRHSPYE } \\
\text { SPYEWSD }\end{array}$ & keine Angabe & 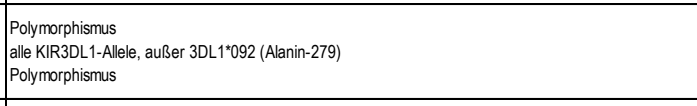 & $\begin{array}{l}\text { Boyington etal. (2001), Sharma etal (2009) } \\
\text { Boyington etal. (2001), Khakoo etal. (2002) } \\
\text { Boyington etal. (2001), Norman etal. (2007), Sharma etal. (2009) }\end{array}$ \\
\hline \multirow{3}{*}{ 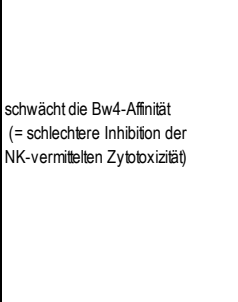 } & D1-Domäne & $\begin{array}{l}1139 K \\
\text { P182S }\end{array}$ & $\begin{array}{l}\text { KEGKSKD } \\
\text { THTSYQLL }\end{array}$ & keine Angabe & 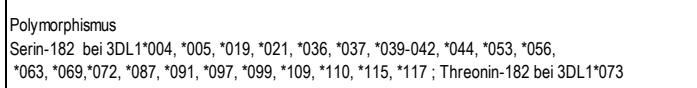 & $\begin{array}{l}\text { Boyington etal. (2001), Khakoo etal. (2002) } \\
\text { Sharma etal. (2009) }\end{array}$ \\
\hline & D2-Domäne & $\begin{array}{l}\text { Y200A } \\
\text { E201A } \\
\text { D230H } \\
\text { G238 } \\
\text { H278A } \\
\end{array}$ & $\begin{array}{l}\text { TGPAEKP } \\
\text { GPYAKPS } \\
\text { SSYHMYH } \\
\text { SREGGAH } \\
\text { SFRASPY }\end{array}$ & keine Angabe & 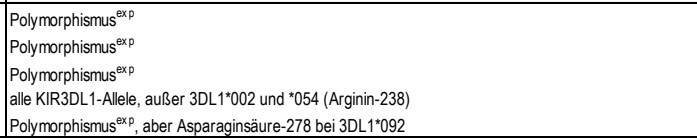 & $\begin{array}{l}\text { Boyington etal. (2001), Khakoo etal. (2002) } \\
\text { Boyington etal. (201), Khakoo etal. (2002), Sharma etal. (2009) } \\
\text { Boyington etal. (2001), Khakoo etal. (2002), Norman etal. (2007) } \\
\text { Carr etal. (2005) } \\
\text { Boyinglon etal. (2001), Khakoo etal. (2002), Norman etal. (2007) }\end{array}$ \\
\hline & TM- Bereich & $1320 \mathrm{~V}$ & HLH & 3DL1*007 & 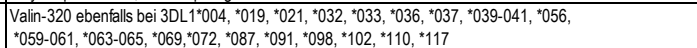 & Carr etal. (2005) \\
\hline \multirow[b]{2}{*}{$\begin{array}{l}\text { vertindert } \\
\text { HLA-A'2402 Bindung }\end{array}$} & D1-Domäne & Y300 & RCHCRHR & keine Angabe & Cystein-30 bei 30 DL 10019 & Sharma etal (2009) \\
\hline & D2-Domäne & $\begin{array}{l}\text { L166R } \\
\text { P1992 } \\
\text { R277C }\end{array}$ & $\begin{array}{l}\text { PMMLALA } \\
\text { VTGPYEK } \\
\text { GSFCHSP }\end{array}$ & keine Angabe & 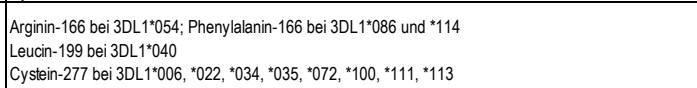 & $\begin{array}{l}\text { Boyington etal. (2001), Sharma etal (2009), Norman etal. (2007) } \\
\text { Boyingto etal. (2000)1) Sharma atal (20009), Norman etal. (2007) } \\
\text { Sharma etal (2009), Norman etal. (2007) }\end{array}$ \\
\hline
\end{tabular}

B. KIR3DL1-Polymorphismen ohne bisher erkenntichen funktionellen Effekt

\begin{tabular}{|c|c|c|c|c|c|c|}
\hline $\begin{array}{l}\text { Zugeschriebener } \\
\text { Effekt }\end{array}$ & \begin{tabular}{|l} 
Rezeptor- \\
bereich
\end{tabular} & \begin{tabular}{|l} 
AS- \\
Position
\end{tabular} & \begin{tabular}{|l|} 
AS-Sequenz \\
des refifen \\
KIR3DL1-Proteins
\end{tabular} & \begin{tabular}{|l} 
untersuchtes \\
Allel
\end{tabular} & $\begin{array}{l}\text { Ergänzung der } \\
\text { polymorphen Allele }\end{array}$ & Literaturnachweis \\
\hline unbekannt & Do-Domäne & R44G & KEDGIHI & 3DL1"002 & 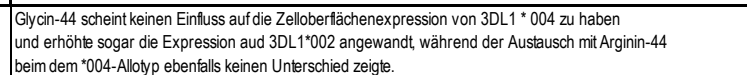 & Pando et al. (2003) \\
\hline unbekannt & CYT-Domäne & $E / Q 373$ & $\begin{array}{l}\text { QDPEEVT } \\
\text { QDPQEVT }\end{array}$ & $\begin{array}{l}3011^{* 002} \\
3 D 1+1 * 07\end{array}$ & Mutabonen in AS-Position 373 hatten bei den Allelen 3DL1"002 oder 3DL1*007 keinen funktionellen EFfekt & Carr etal. (2005) \\
\hline
\end{tabular}


Tabelle 33 Auswertungstabelle zur Bestimmung der KIR2DL1-Allele der untersuchten NK-Zell-Spender. [Stand Januar 2019, Quelle: https://www.ebi.ac.uk/ipd/kir]

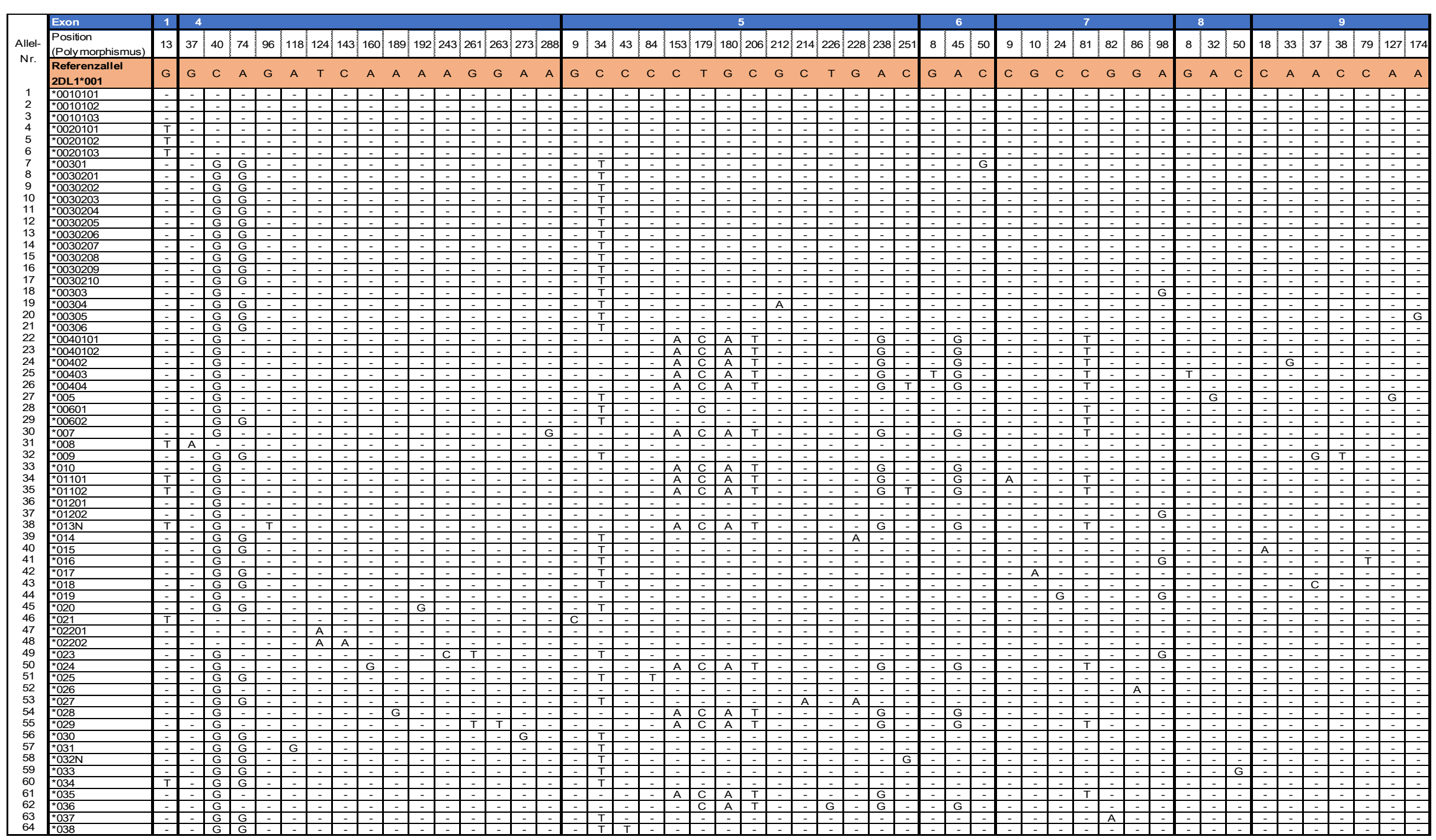


Tabelle 34 Ergebnistabelle der KIR2DL1-Subtypisierung der untersuchten NK-Zell-Spender 1 bis 20. Weiß hinterlegt sind die jeweiligen Nukleotidpositionen, deren Basen von der Referenzallelsequenz abweichen. Umrahmt wurden solche Basen(-kombinationen), die keinem der bisher beschriebenen Allele eindeutig zugeordnet werden konnten. [Stand Januar 2019, Quelle: https://www.ebi.ac.uk/ipd/kir]

\begin{tabular}{|c|c|c|c|c|c|c|c|c|c|c|c|c|c|c|c|c|c|c|c|c|c|c|c|c|c|c|c|}
\hline \multicolumn{3}{|c|}{ Exonposition } & 1 & \multicolumn{5}{|c|}{4} & \multicolumn{9}{|c|}{5} & \multicolumn{2}{|c|}{6} & \multicolumn{4}{|c|}{7} & \multicolumn{2}{|c|}{8} & \multicolumn{2}{|c|}{9} \\
\hline \multicolumn{3}{|c|}{ Nukleotidposition } & 13 & 40 & 74 & 124 & 243 & 261 & 34 & 84 & 153 & 179 & 180 & 206 & 212 & 214 & 238 & 45 & 50 & 9 & 10 & 81 & 98 & 8 & 32 & 37 & 127 \\
\hline \multicolumn{3}{|c|}{ Referenzallel 2DL1*0010101 } & \multirow{3}{*}{ G } & \multirow{2}{*}{ C } & \multirow{2}{*}{ A } & \multirow{2}{*}{$T$} & \multirow{2}{*}{ A } & \multirow{2}{*}{ G } & \multirow{2}{*}{ C } & \multirow{2}{*}{ C } & \multirow{2}{*}{ C } & \multirow{2}{*}{$\mathbf{T}$} & \multirow{2}{*}{ G } & \multirow{2}{*}{ C } & \multirow{2}{*}{ G } & \multirow{2}{*}{ C } & 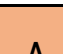 & 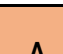 & $c$ & $c$ & $G$ & $c$ & $\Delta$ & $G$ & $\mathbf{A}$ & $\Delta$ & $\mathbf{A}$ \\
\hline Spender & Spenderal & & & & & & & & & & & & & & & & A & A & 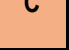 & $\checkmark$ & $G$ & 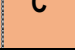 & A & $\checkmark$ & A & $A$ & $\mathrm{~A}$ \\
\hline 1 & $2 \mathrm{DL} 1 * 00403$ & $2 \mathrm{DL} 1{ }^{*} 005$ & & $G$ & & & & & $\mathrm{C} / \mathrm{T}$ & & $\mathrm{C} / \mathrm{A}$ & $\mathrm{T} / \mathrm{C}$ & $\mathrm{G} / \mathrm{A}$ & $\mathrm{C} / \mathrm{T}$ & & & $\mathrm{A} / \mathrm{G}$ & $A / G$ & & & & $\mathrm{C} / \mathrm{T}$ & & $\mathrm{G} / \mathrm{T}$ & $\mathrm{A} / \mathrm{G}$ & & $A / G$ \\
\hline 2 & $2 \mathrm{DL} 1 * 00401$ & $2 \mathrm{DL} 1{ }^{*} 00403$ & & G & & & & & & & A & C & $A$ & $T$ & & & $G$ & $G$ & & & & $T$ & & $\mathrm{G} / \mathrm{T}$ & & & \\
\hline 3 & $2 \mathrm{DL} 1{ }^{*} 001$ & $2 \mathrm{DL} 1{ }^{*} 00201$ & $\mathrm{G} / \mathrm{T}$ & & & & & & & & & & & & & & & & & & & & & $\mathrm{G} / \mathrm{T}$ & & & \\
\hline 4 & $2 \mathrm{DL} 1{ }^{*} 00201$ & & $T$ & & & & & & & & & & & & & & & & & & & & & $\mathrm{G} / \mathrm{T}$ & & & \\
\hline 5 & $2 \mathrm{DL} 1^{*} 00302^{\Delta}$ & $2 \mathrm{DL} 1^{*} 00602^{\Delta}$ & & G & $G$ & & & & $T$ & & & $\mathrm{~T} / \mathrm{C}$ & $\mathrm{G} / \mathrm{A}$ & & & & A/G & & & & & $C / T$ & & $\mathrm{G} / \mathrm{T}$ & & A/G & \\
\hline 6 & $2 \mathrm{DL} 1{ }^{*} 00403$ & $2 \mathrm{DL} 1{ }^{*} 00302$ & & $G$ & $\mathrm{~A} / \mathrm{G}$ & & & & $\mathrm{C} / \mathrm{T}$ & & $\mathrm{C} / \mathrm{A}$ & $T / C$ & $\mathrm{G} / \mathrm{A}$ & $\mathrm{C} / \mathrm{T}$ & & & $\mathrm{A} / \mathrm{G}$ & $A / G$ & & & & $\mathrm{C} / \mathrm{T}$ & & $\mathrm{G} / \mathrm{T}$ & & & \\
\hline 7 & $2 \mathrm{DL} 1{ }^{*} 00403$ & $2 \mathrm{DL} 1{ }^{*} 00401$ & & G & & & & & & & $A$ & $C$ & A & $T$ & & & $G$ & $G$ & & & & $T$ & & $\mathrm{G} / \mathrm{T}$ & & & \\
\hline 8 & $2 \mathrm{DL} 1{ }^{*} 00301$ & $2 \mathrm{DL} 1{ }^{*} 00302$ & & G & $G$ & & & & $T$ & & & & & & & & & & $\mathrm{C} / \mathrm{G}$ & & & & & & & & \\
\hline 9 & $2 \mathrm{DL} 1{ }^{*} 00601$ & 2DL1*001 & & $\mathrm{C} / \mathrm{G}$ & & & & & $\mathrm{C} / \mathrm{T}$ & & & $\mathrm{T} / \mathrm{C}$ & & & & & & & & & & $\mathrm{C} / \mathrm{T}$ & & $\mathrm{G} / \mathrm{T}$ & & & \\
\hline 10 & $2 \mathrm{DL} 1 * 01101$ & 2DL1*005 & $\mathrm{G} / \mathrm{T}$ & G & & & & & $\mathrm{C} / \mathrm{T}$ & & $\mathrm{C} / \mathrm{A}$ & $\mathrm{T} / \mathrm{C}$ & $\mathrm{G} / \mathrm{A}$ & $\mathrm{C} / \mathrm{T}$ & & & & $\mathrm{A} / \mathrm{G}$ & & $\mathrm{A} / \mathrm{C}$ & & $\mathrm{C} / \mathrm{T}$ & & & $\mathrm{A} / \mathrm{G}$ & & $\mathrm{A} / \mathrm{G}$ \\
\hline 11 & 2DL1*00403 & 2DL1*00401 & & G & & & & & & & A & $\mathrm{C}$ & A & $T$ & & & G & $G$ & & & & $T$ & & $\mathrm{G} / \mathrm{T}$ & & & \\
\hline 12 & $2 \mathrm{DL} 1 * 00403$ & $2 \mathrm{DL} 1{ }^{*} 00401$ & & $G$ & & & & & & & A & $C$ & $A$ & $T$ & & & & $G$ & & & & $T$ & & $\mathrm{G} / \mathrm{T}$ & & & \\
\hline 13 & $2 \mathrm{DL} 1 * 02201 \mathrm{~N}^{\text {neu }}$ & $2 \mathrm{DL} 1 * 023 \mathrm{~N}^{\text {neu }}$ & & C/G & & $T / A$ & $\mathrm{~A} / \mathrm{C}$ & $G / T$ & & $C / T$ & & A & & & $\mathrm{G} / \mathrm{A}$ & $\mathrm{C} / \mathrm{A}$ & & & & A & $\mathrm{G} / \mathrm{A}$ & & & & G & & \\
\hline 14 & 2DL1*01101 & 2DL1*00602 & $\mathrm{G} / \mathrm{T}$ & G & $A / G$ & & & & $\mathrm{C} / \mathrm{T}$ & & $\mathrm{C} / \mathrm{A}$ & $\mathrm{T} / \mathrm{C}$ & $\mathrm{G} / \mathrm{A}$ & $\mathrm{CIT}$ & & & $\mathrm{A} / \mathrm{G}$ & $A / G$ & & $\mathrm{C} / \mathrm{A}$ & & $T$ & & $\mathrm{G} / \mathrm{T}$ & & & \\
\hline 15 & $2 \mathrm{DL} 1{ }^{*} 00302$ & $2 \mathrm{DL} 1{ }^{*} 00201$ & $\mathrm{G} / \mathrm{T}$ & $\mathrm{C} / \mathrm{G}$ & $A / G$ & & & & $\mathrm{C} / \mathrm{T}$ & & & & & & & & & & & & & & & & & & \\
\hline 16 & $2 \mathrm{DL} 1 * 00601$ & $2 \mathrm{DL} 1{ }^{*} 001$ & & $\mathrm{C} / \mathrm{G}$ & & & & & $\mathrm{C} / \mathrm{T}$ & & & $T / C$ & & & & & & & & & & $C / T$ & & $\mathrm{G} / \mathrm{T}$ & & & \\
\hline 17 & $2 \mathrm{DL} 1 * 017$ & $2 \mathrm{DL} 1{ }^{*} 00403$ & & G & $\mathrm{A} / \mathrm{G}$ & & & & $\mathrm{C} / \mathrm{T}$ & & $\mathrm{C} / \mathrm{A}$ & $T / C$ & $\mathrm{G} / \mathrm{A}$ & $\mathrm{C} / \mathrm{T}$ & & & $\mathrm{A} / \mathrm{G}$ & $A / G$ & & & $\mathrm{G} / \mathrm{A}$ & $\mathrm{C} / \mathrm{T}$ & & $\mathrm{G} / \mathrm{T}$ & & & \\
\hline 18 & $2 \mathrm{DL} 1{ }^{*} 00401$ & $2 \mathrm{DL} 1{ }^{*} 00201$ & $\mathrm{G} / \mathrm{T}$ & $\mathrm{C} / \mathrm{G}$ & & & & & & & $\mathrm{C} / \mathrm{A}$ & $\mathrm{T} / \mathrm{C}$ & $\mathrm{G} / \mathrm{A}$ & $\mathrm{C} / \mathrm{T}$ & & & $\mathrm{A} / \mathrm{G}$ & $\mathrm{A} / \mathrm{G}$ & & & & $\mathrm{C} / \mathrm{T}$ & & & & & \\
\hline 19 & $2 \mathrm{DL} 1{ }^{*} 01201$ & 2DL1*001 & & $\mathrm{C} / \mathrm{G}$ & & & & & & & & & & & & & & & & & & & & & & & \\
\hline 20 & 2DL1*00302 & $2 \mathrm{DL} 1^{*} 01201^{\text {neu }}$ & & G & $\mathrm{A} / \mathrm{G}$ & & & & $\mathrm{C} / \mathrm{T}$ & & & & & & & & & & & & & $C / G$ & & $\mathrm{G} / \mathrm{T}$ & & & \\
\hline
\end{tabular}


Tabelle 35 Auswertungstabelle zur Bestimmung der KIR3DL1-Allele der untersuchten NK-Zell-Spender in sechs Teilen. [Stand Januar 2019, Quelle: https://www.ebi.ac.uk/ipd/kir]

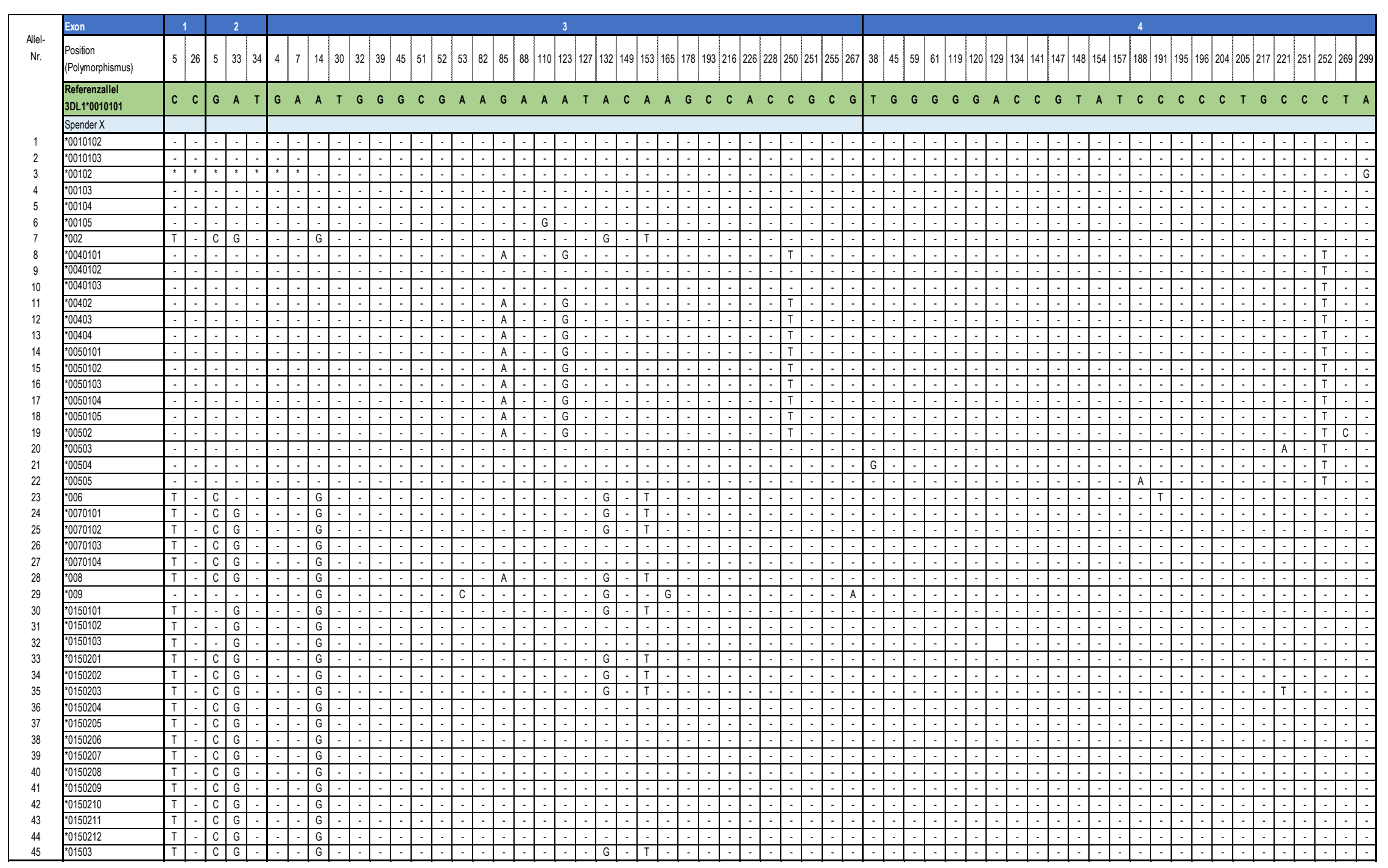




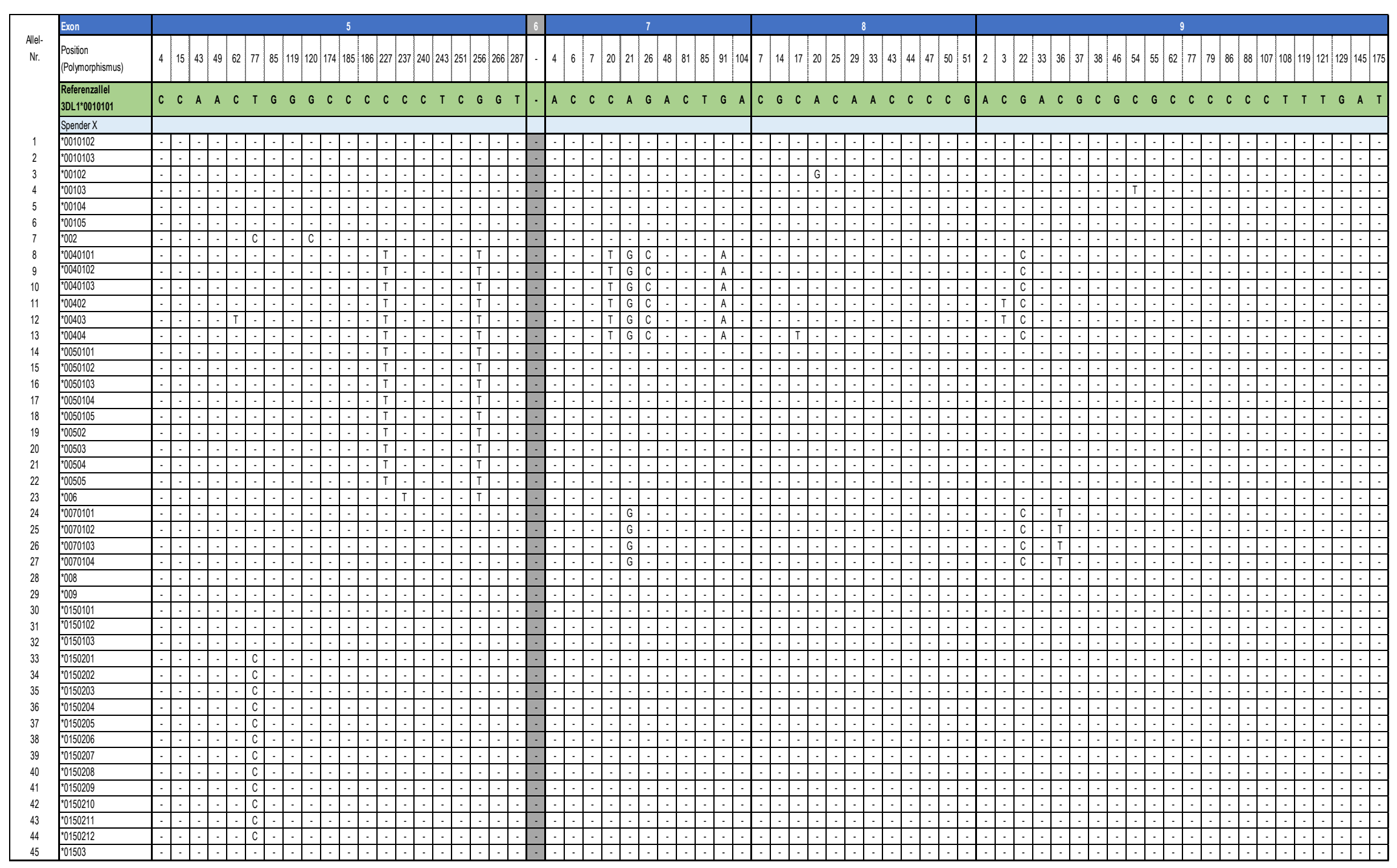




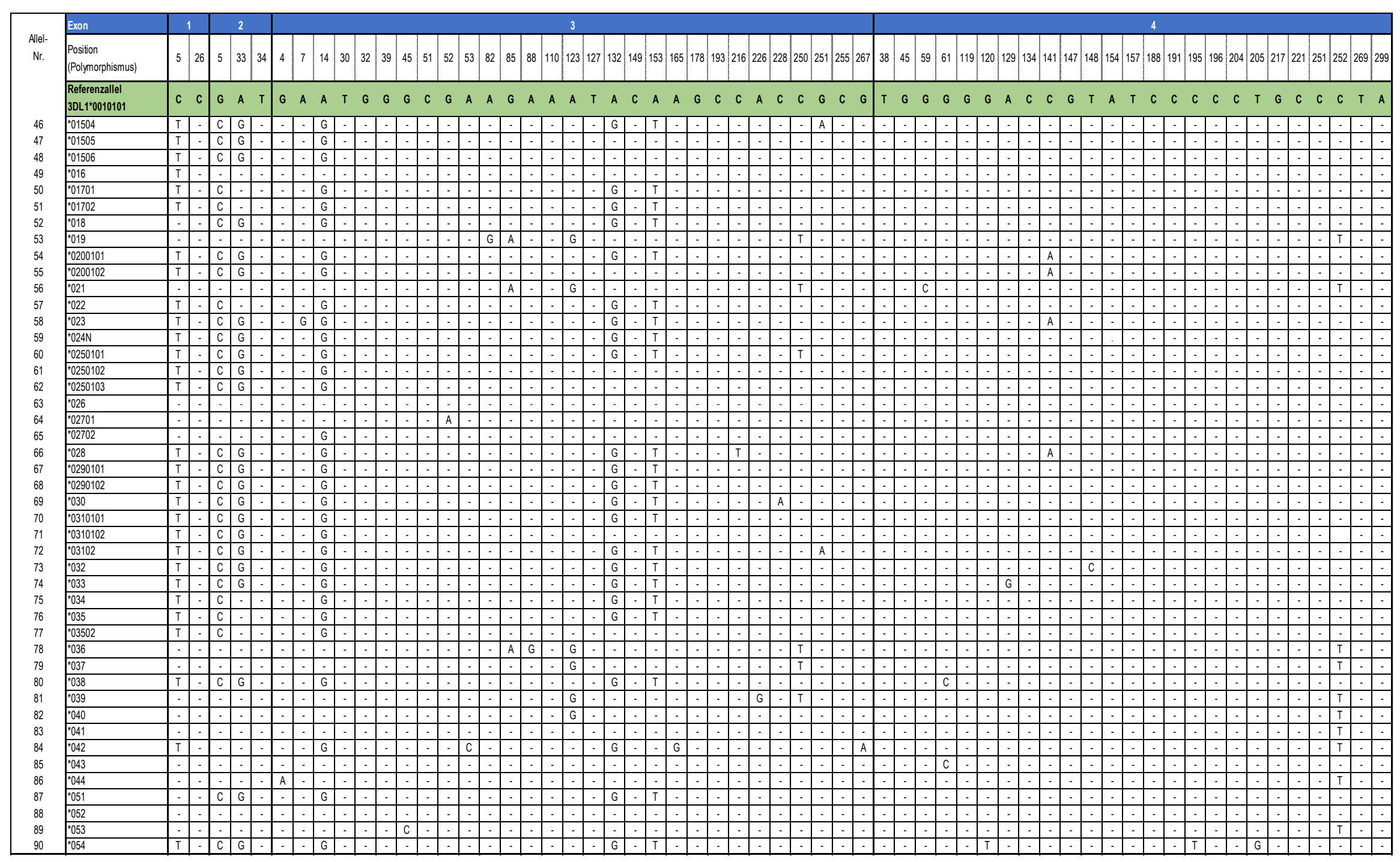




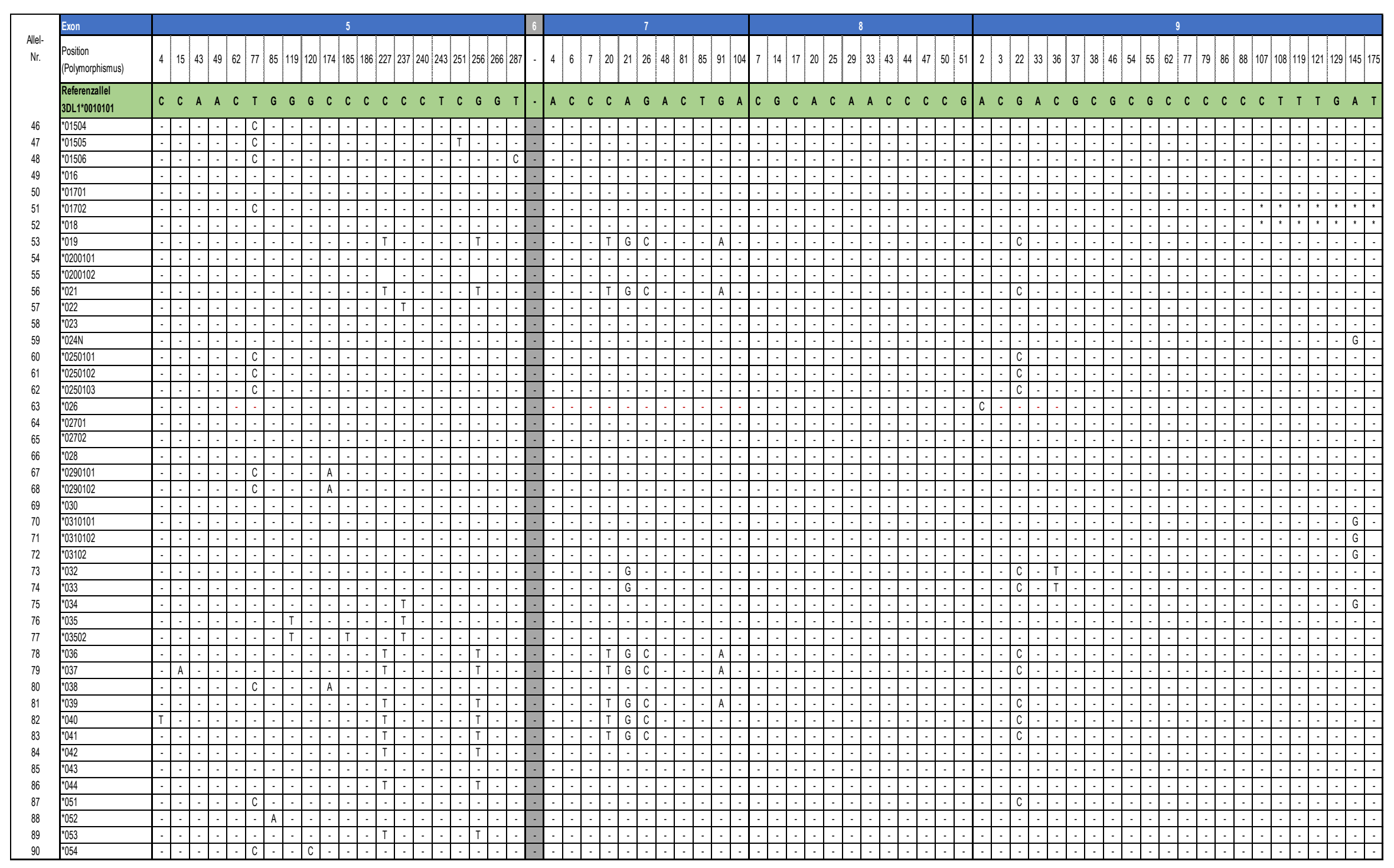




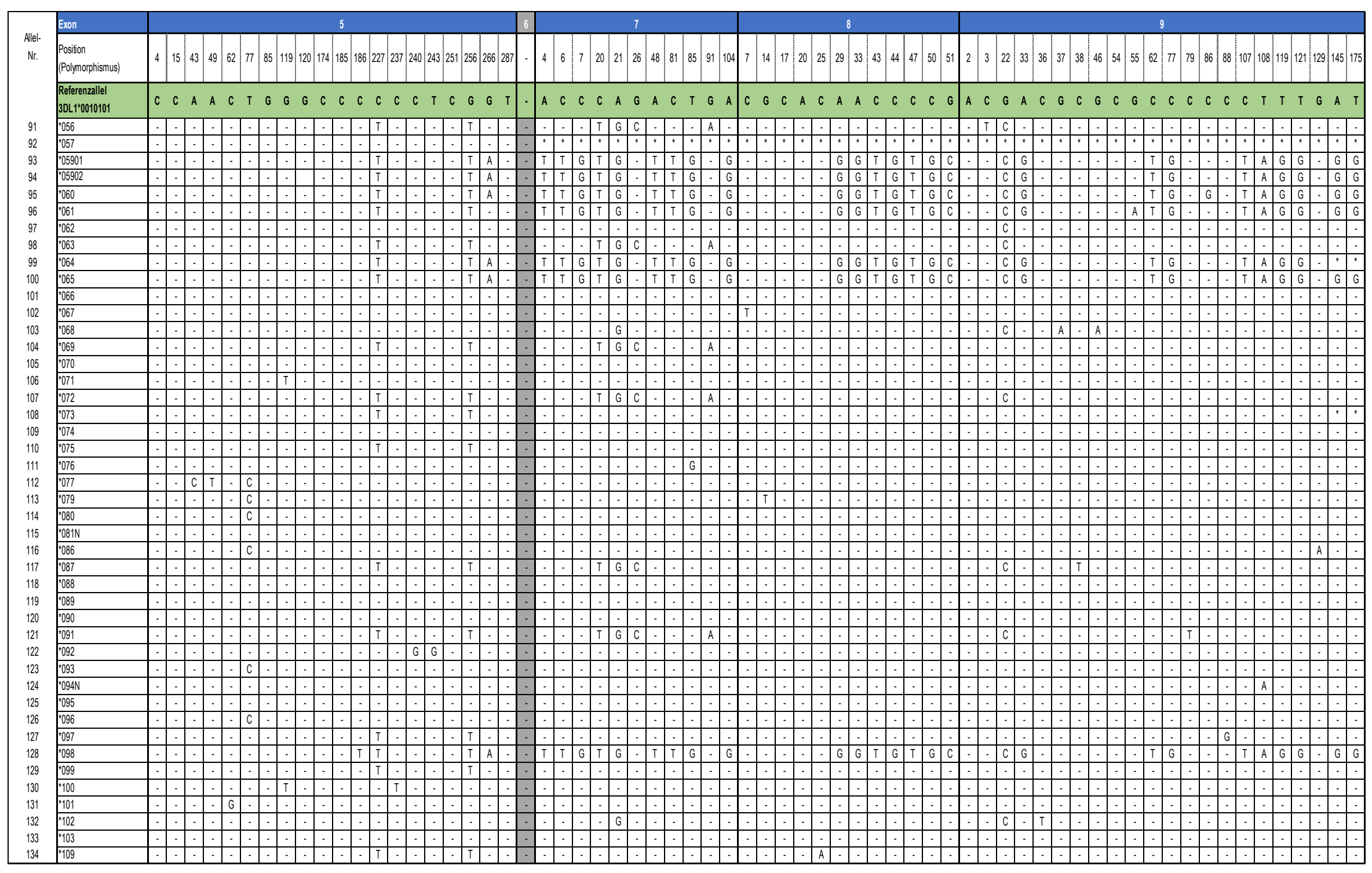

Teil 5/6 


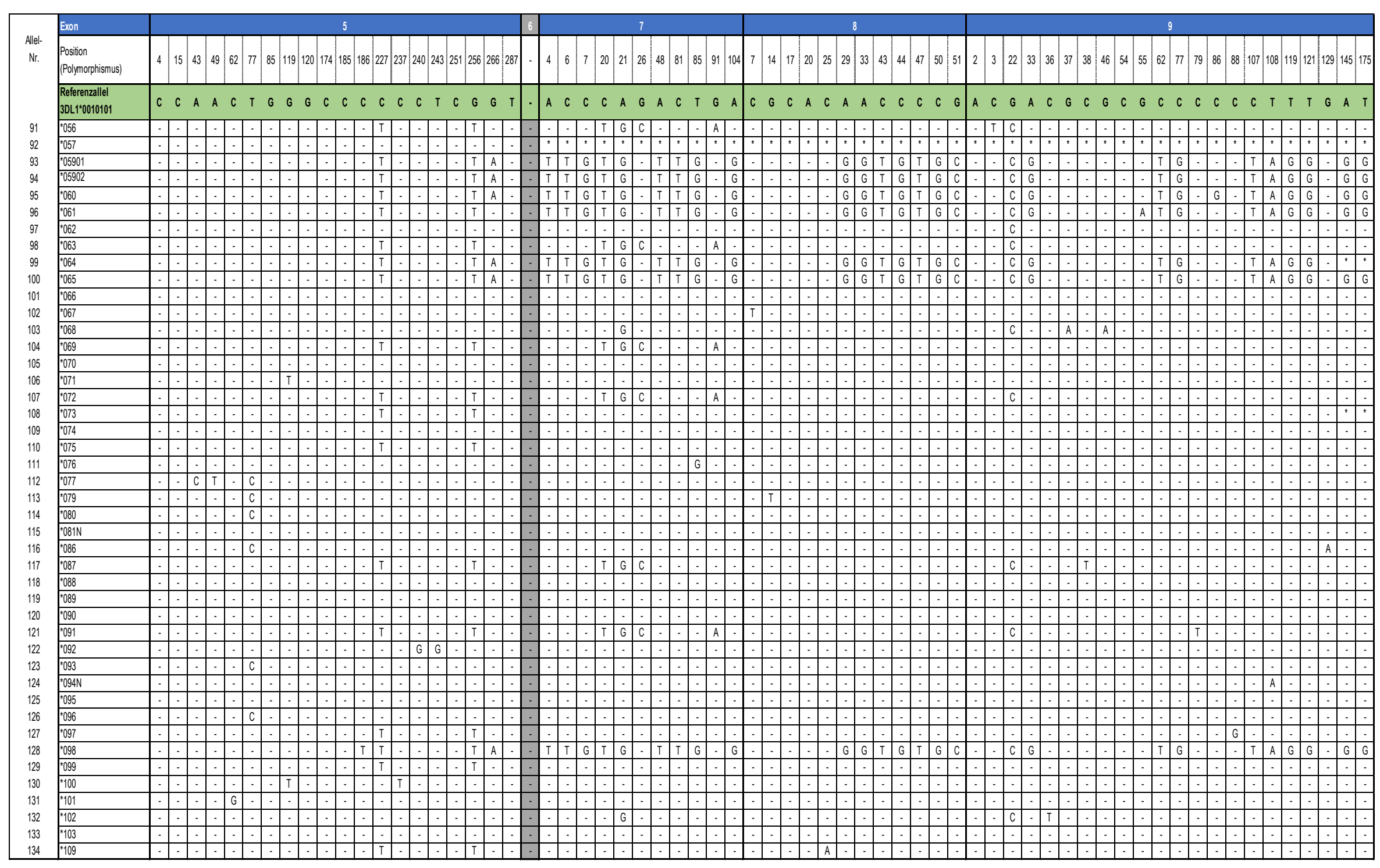


Tabelle 36 Ergebnistabelle der KIR3DL1-Subtypisierung der untersuchten NK-Zell-Spender 1 bis 20. Weiß hinterlegt sind die jeweiligen Nukleotidpositionen, deren Basen von der Referenzallelsequenz abweichen. Umrahmt wurden solche Basen(-kombinationen), die keinem der bisher beschriebenen Allele eindeutig zugeordnet werden konnten. [Stand Januar 2019, Quelle: https://www.ebi.ac. uk/ipd/kir]

\begin{tabular}{|c|c|c|c|c|c|c|c|c|c|c|c|c|c|c|c|c|c|c|c|c|c|c|c|c|c|c|c|c|c|c|c|}
\hline \multicolumn{4}{|c|}{ Exonposition } & \multicolumn{2}{|c|}{1} & \multicolumn{3}{|c|}{2} & \multicolumn{13}{|c|}{3} & \multicolumn{10}{|c|}{4} \\
\hline Nukleotic & osition & & & 5 & 26 & 5 & 33 & 34 & 14 & 53 & 82 & 85 & 123 & 132 & 153 & 165 & 216 & 226 & 250 & 251 & 267 & 38 & 45 & 59 & 61 & 120 & 129 & 195 & 196 & 205 & 252 \\
\hline \multicolumn{4}{|c|}{ Referenzallel 3DL1*00101 } & \multirow{2}{*}{$C$} & \multirow{2}{*}{$C$} & \multirow{2}{*}{ G } & \multirow{2}{*}{$A$} & \multirow{2}{*}{$T$} & \multirow{2}{*}{$A$} & \multirow{2}{*}{$A$} & \multirow{2}{*}{$A$} & \multirow{2}{*}{ G } & \multirow{2}{*}{$A$} & \multirow{2}{*}{$A$} & \multirow{2}{*}{$A$} & \multirow{2}{*}{$A$} & \multirow{2}{*}{$c$} & \multirow{2}{*}{$A$} & 0 & 0 & 0 & $T$ & 0 & 0 & 0 & 0 & 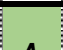 & 0 & 0 & $T$ & 0 \\
\hline Spender & & Spenderallele & & & & & & & & & & & & & & & & & $C$ & $G$ & $G$ & $T$ & $G$ & $G$ & $G$ & $G$ & $A$ & $c$ & $c$ & 1 & $c$ \\
\hline 1 & 3DL1*008 & 3DL1*069 ${ }^{\Delta}$ & & $C / T$ & $C / T$ & $G / C$ & $A / G$ & & $A / G$ & & & $A$ & $A / G$ & $A / G$ & $A / T$ & & & & $\mathrm{C} / \mathrm{T}$ & & & $T / G$ & $G / C$ & & $G / C$ & & $A / G$ & & C/G & & $C / T$ \\
\hline 2 & $3 D L 1 * X^{\text {neu }}$ & $3 D L 1 * X^{\text {neu }}$ & & $\mathrm{T}$ & $T$ & & & & & & & & G & & & & $T$ & $C$ & $T$ & $T$ & C & * & * & & $C$ & & & $C / T$ & & A & $\mathrm{C} / \mathrm{T}$ \\
\hline 3 & 3DL1*002 & $3 \mathrm{DL} 1{ }^{*} 087$ & & $\overline{C / T}$ & & $\mathrm{G} / \mathrm{C}$ & $A / G$ & & $\mathrm{~A} / \mathrm{G}$ & & & & & $A / G$ & $A / T$ & & & & & & & & & & & & & & & & $C / T$ \\
\hline 4 & 3DL1*00101 & 3DL1*002 & & $\mathrm{C} / \mathrm{T}$ & & $\mathrm{G} / \mathrm{C}$ & $A / G$ & & $\mathrm{~A} / \mathrm{G}$ & & & & & $A / G$ & $A / T$ & & & & & & & & & & & & & & & & \\
\hline 5 & 3DL1*087 & 3DL1*097 & & & & & & & & & & & & & & & & & & & & & & & & & & & & & $\mathrm{T}$ \\
\hline 6 & 3DL1*01501 & 3DL1*00701 & & $\mathrm{T}$ & & $C$ & G & & G & & & & & G & $\mathrm{T}$ & & & & & & & & & & & & & & & & \\
\hline 7 & 3DL1*00101 & 3DL1*054 & & $\mathrm{C} / \mathrm{T}$ & & $\mathrm{G} / \mathrm{C}$ & $A / G$ & & $\mathrm{~A} / \mathrm{G}$ & & & & & $A / G$ & $A / T$ & & & & & & & & & & & $G / T$ & & $\mathrm{C} / \mathrm{T}$ & & $T / G$ & \\
\hline 8 & 3DL1*00101 & 3DL1*076 & & $\mathrm{C} / \mathrm{T}$ & & $\mathrm{G} / \mathrm{C}$ & $\mathrm{A} / \mathrm{G}$ & & $\mathrm{A} / \mathrm{G}$ & & & & & $\mathrm{A} / \mathrm{G}$ & $\mathrm{A} / \mathrm{T}$ & & & & & & & & & & & & & & & & \\
\hline 9 & 3DL1*01702 & 3DL1*095 & & $\mathrm{C} / \mathrm{T}$ & & $\mathrm{G} / \mathrm{C}$ & & $\mathrm{T} / \mathrm{C}$ & $\mathrm{A} / \mathrm{G}$ & & & & & $A / G$ & $\mathrm{~A} / \mathrm{T}$ & & & & & & & & & & & & & & & & \\
\hline 10 & 3DL1*087 & 3DL1*109 & & & & & & & & & & & & & & & & & & & & & & & & & & & & & $\mathrm{T}$ \\
\hline 11 & 3DL1*002 & 3DL1*00402 & & $\mathrm{C} / \mathrm{T}$ & & $\mathrm{G} / \mathrm{C}$ & $\mathrm{A} / \mathrm{G}$ & & $\mathrm{A} / \mathrm{G}$ & & & $\mathrm{G} / \mathrm{A}$ & $A / G$ & $\mathrm{~A} / \mathrm{G}$ & $\mathrm{A} / \mathrm{T}$ & & & & $\mathrm{C} / \mathrm{T}$ & & & & & & & & & & & & \\
\hline 12 & 3DL1*068 & 3DL1*097 & & $\mathrm{C} / \mathrm{T}$ & & $\mathrm{G} / \mathrm{C}$ & $A / G$ & & $A / G$ & & & & & $A / G$ & $A / T$ & & & & & & & & & & & & & & & & $C / T$ \\
\hline 13 & 3DL1*00103 & $3 \mathrm{DL} 1^{*} 076$ & & $\mathrm{C} / \mathrm{T}$ & & $\mathrm{G} / \mathrm{C}$ & $\mathrm{A} / \mathrm{G}$ & & $\mathrm{A} / \mathrm{G}$ & & & & & $\mathrm{A} / \mathrm{G}$ & $\mathrm{A} / \mathrm{T}$ & & & & & & & & & & & & & & & & \\
\hline 14 & 3DL1*0040101 & $3 \mathrm{DL} 1^{*} 00501^{\Delta}$ & & * & * & & & & & & & A & $G$ & & & & & & $T$ & & & & & & & & & & & & $T$ \\
\hline 15 & 3DL1*00101 & 3DL1*099 & 3DL1*016 & * & * & & & & & & & & & & & & & & & & & & & & & & & & & & $\mathrm{C} / \mathrm{T}$ \\
\hline 16 & 3DL1*00402 & 3DL1*01501 & $3 \mathrm{DL} 1^{*} 0310102$ & * & * & * & $A / G$ & & $\mathrm{~A} / \mathrm{G}$ & & & $\mathrm{G} / \mathrm{A}$ & $A / G$ & & & & & & $\mathrm{C} / \mathrm{T}$ & & & & & & & & & & & & $C / T$ \\
\hline 17 & 3DL1*087 & 3DL1*021 & & & & & & & & & & $\mathrm{G} / \mathrm{A}$ & $A / G$ & & & & & & $\mathrm{C} / \mathrm{T}$ & & & & & $\mathrm{G} / \mathrm{C}$ & & & & & & & $\mathrm{T}$ \\
\hline 18 & 3DL1*019 & 3DL1*00501 & & & & & & & & & $\mathrm{A} / \mathrm{G}$ & A & G & & & & & & $\mathrm{T}$ & & & & & & & & & & & & $\mathrm{T}$ \\
\hline 19 & 3DL1*008 & 3DL1*00101 & & $\mathrm{C} / \mathrm{T}$ & & $\mathrm{G} / \mathrm{C}$ & $A / G$ & & $\mathrm{~A} / \mathrm{G}$ & & & $\mathrm{G} / \mathrm{A}$ & & $A / G$ & $A / T$ & & & & & & & & & & & & & & & & \\
\hline 20 & 3DL1*009 & 3DL1*054 & & $\mathrm{C} / \mathrm{T}$ & & $\mathrm{G} / \mathrm{C}$ & $A / G$ & & G & $\mathrm{A} / \mathrm{C}$ & & & & G & $\mathrm{A} / \mathrm{T}$ & A/G & & & & & $\mathrm{G} / \mathrm{A}$ & & & & & $G / T$ & & $\mathrm{C} / \mathrm{T}$ & & $T / G$ & \\
\hline
\end{tabular}




\subsection{Labormaterial}

\subsubsection{Verwendete Medien}

\begin{tabular}{|c|c|c|c|}
\hline \multicolumn{2}{|c|}{ Zielzellen Grundmedium } & \multicolumn{2}{|l|}{ Zielzell-Medium für L721.221-ØHLA } \\
\hline RMPI-Medium & $\begin{array}{r}500,0 \\
\mathrm{ml}\end{array}$ & Grundmedium ohne Zusätze & $100,0 \mathrm{ml}$ \\
\hline FCS (hitzeinaktiviert) & $50,0 \mathrm{ml}$ & \multicolumn{2}{|l|}{ Zielzell-Medium für L721.221-Bw4 } \\
\hline Penicillin/Streptamycin & $5,0 \mathrm{ml}$ & Grundmedium ohne Zusätze & $100,0 \mathrm{ml}$ \\
\hline GlutaMax & $5,0 \mathrm{ml}$ & \multicolumn{2}{|l|}{ Zielzell-Medium für L721.221-Cw1 (C1) } \\
\hline NEAA * & $5,0 \mathrm{ml}$ & Grundmedium & $100,0 \mathrm{ml}$ \\
\hline \multirow[t]{4}{*}{ Natriumpyruvat } & $5,0 \mathrm{ml}$ & Geneticin (G-418) & $1,0 \mathrm{mg} / \mathrm{ml}$ \\
\hline & & \multicolumn{2}{|l|}{ Zielzell-Medium für L721.221-Cw6 (C2) } \\
\hline & & Grundmedium & $100,0 \mathrm{ml}$ \\
\hline & & Hygromycin B & $0,5 \mathrm{mg} / \mathrm{ml}$ \\
\hline
\end{tabular}

* NEAA $=$ non-essential amino acids

\begin{tabular}{|lr|}
\hline NK-Zell-Medium & \\
\hline X-Vivo 10 Grundmedium & 200,0 \\
$5 \%$ Humanplasma & $\mathrm{ml}$ \\
Penicillin/Streptamycin & $20,0 \mathrm{ml}$ \\
Proleukin IL-2 & $2,0 \mathrm{ml}$ \\
\hline
\end{tabular}

\subsubsection{Verwendete Puffer}

\begin{tabular}{|lr|}
\hline NK-Zell-lsolierungspuffer \\
\hline PBS (ohne $\mathrm{Ca}^{2+} / \mathrm{Mg}^{2+}$ ) & $50,0 \mathrm{ml}$ \\
FCS (hitzeinaktiviert) & $1,0 \mathrm{ml}$ \\
EDTA & $0,1 \mathrm{ml}$ \\
\hline
\end{tabular}

\begin{tabular}{|lr|}
\hline TBE-Puffer & \\
\hline Reinst-Wasser & $1800,0 \mathrm{ml}$ \\
TBE $(10 \mathrm{x})$ & $200,0 \mathrm{ml}$ \\
\hline
\end{tabular}

\begin{tabular}{|lr|}
\hline FACS-Puffer \\
\hline PBS (ohne $\mathrm{Ca}^{2+} / \mathrm{Mg}^{2+}$ ) & $500,0 \mathrm{ml}$ \\
FCS (hitzeinaktiviert) & $25,0 \mathrm{ml}$ \\
Natriumazid & $5,0 \mathrm{ml}$ \\
EDTA & $2,0 \mathrm{ml}$ \\
\hline
\end{tabular}

\begin{tabular}{|lr|}
\hline \multicolumn{2}{|l|}{ Natriumacetat / EDTA-Ethanol-Puffer } \\
\hline NaOAc / EDTA-Lösung & $1,0 \mu \mathrm{l} /$ Probe \\
$96 \%$ Ethanol & $12,5 \mu \mathrm{l} /$ Probe \\
\hline
\end{tabular}




\subsubsection{Verwendete Lösungen}

\begin{tabular}{|c|c|c|c|}
\hline \multicolumn{2}{|l|}{ Exonuklease-Lösung } & \multicolumn{2}{|l|}{ DNA-Markerlösung } \\
\hline Exonuklease & $5,0 \mu \mathrm{l} /$ Probe & 6x DNA Loading Dye & $1,0 \mu \mathrm{l}$ \\
\hline \multirow[t]{2}{*}{ Alkaline Phosphatase } & $1,0 \mu \mathrm{l} /$ Probe & Reinst-Wasser & $4,0 \mu \mathrm{l}$ \\
\hline & & DNA ladder (Marker) & $1,0 \mu \mathrm{l}$ \\
\hline \multicolumn{2}{|l|}{ Ethidiumbromid-Lösung } & & \\
\hline Ethidiumbromid & $1 \%$ & \multicolumn{2}{|c|}{ 1\% Paraformaldehyd-Lösung (pH 7,4) } \\
\hline \multirow[t]{2}{*}{ TBE-Puffer } & $100,0 \mathrm{ml}$ & Paraformaldehyd & $4,0 \mathrm{~g}$ \\
\hline & & Natriumhydroxid & $1,0 \mathrm{ml}$ \\
\hline $1 \%$ Agarose-Gele & & PBS (10x) & $10,0 \mathrm{ml}$ \\
\hline Agarose & $1,0 \mathrm{~g}$ & Salzsäure & $4,0 \mathrm{ml}$ \\
\hline Tris-borate-EDTA-Puffer (TBE) & $100,0 \mathrm{ml}$ & Reinst-Wasser & $85 \mathrm{ml}$ \\
\hline
\end{tabular}

\subsubsection{Chemische Verbrauchsprodukte}

\begin{tabular}{|c|c|c|}
\hline Substanz & Konzentration & Hersteller \\
\hline Agarose & & Carl Roth GmbH \\
\hline Ethylendiamintetraessigsäure (EDTA) & & Wak-Chemie Medical GmbH \\
\hline Ethanol & & Carl Roth GmbH \\
\hline Ethidiumbromid & & Carl Roth $\mathrm{GmbH}$ \\
\hline Exonuklease & & Thermo Fisher Scientific Inc. \\
\hline FastAP ${ }^{\text {TM }}$ Alkalische Phosphatase & & Thermo Fisher Scientific Inc. \\
\hline FCS (hitzeinaktiviert) & & Biochrom GmbH \\
\hline Gene Ruler ${ }^{T M} 1 \mathrm{~kb}$ plus DNA ladder & & Thermo Fisher Scientific Inc. \\
\hline Geneticin (G-418) & $50 \mathrm{mg} / \mathrm{ml}$ & Invitrogen \\
\hline GlutaMax $^{\mathrm{TM}}$ & & Thermo Fisher Scientific Inc. \\
\hline Hygromycin B & $50 \mathrm{mg} / \mathrm{ml}$ & Thermo Fisher Scientific Inc. \\
\hline Interleukin-2 (Proleukin®) & & Novartis Pharma GmbH \\
\hline Lymphodex (Ficoll $\left.{ }^{\circledR}\right)$ & & Inno-Train GmbH \\
\hline Natriumazid & & Carl Roth GmbH \\
\hline Natriumacetat & & Carl Roth GmbH \\
\hline NEAA & & Thermo Fisher Scientific Inc. \\
\hline Paraformaldehyd & & Sigma-Aldrich \\
\hline $\begin{array}{l}\text { Gibco }{ }^{\mathrm{TM}} \text { Phosphate-Buffered Saline } \\
\text { (PBS) }\end{array}$ & $10 x$ & Thermo Fisher Scientific Inc. \\
\hline Gibco ${ }^{\text {TM }}$ Penicillin/Streptamycin & & Thermo Fisher Scientific Inc. \\
\hline Reinst-Wasser & & Thermo Fisher Scientific Inc. \\
\hline Gibco ${ }^{\text {TM }}$ RPMI-1640 Medium & & Thermo Fisher Scientific Inc. \\
\hline Salzsäure & & Carl Roth GmbH \\
\hline Gibco ${ }^{\mathrm{TM}}$ Tris-borate-EDTA (TBE) & & Thermo Fisher Scientific Inc. \\
\hline Gibco TM Trypanblau-Lösung & & Thermo Fisher Scientific Inc. \\
\hline$X^{X}$-Vivo ${ }^{\text {TM }} 10$ Medium & & Lonza Group AG \\
\hline
\end{tabular}




\subsubsection{Verwendete Kit-Systeme}

\begin{tabular}{|l|l|}
\hline Kit-System & Hersteller \\
\hline Olerup SSP® KIR Genotyping Kit & CareDx Inc. \\
EasySep ${ }^{\text {TM }}$ Human NK Cell Enrichment Kit (17955) & STEMCELL Technologies \\
QIAamp® DNA Mini Kit & Qiagen \\
BigDye $^{\text {TM }}$ Terminator v3.0 Ready Reaction Kit & Thermo Fisher Scientific Inc. \\
\hline
\end{tabular}

\subsubsection{Verwendete Antikörper}

Allophycocyanin-konjugierte Antikörper

\begin{tabular}{|l|l|l|}
\hline APC-Antkörper & Spezies & Hersteller \\
\hline Anti-CD56-APC & Maus- IgG1 & Beckmann Coulter \\
Anti-KIR2DL1-APC & Maus- IgG1 & R+D Systems \\
Anti-KIR3DL1-APC & Maus- IgG1 & Miltenyi Biotec GmbH \\
\hline
\end{tabular}

Fluoreceinisothiocyanat-konjugierte Antikörper

\begin{tabular}{|l|l|l|}
\hline FITC-Antikörper & Spezies & Hersteller \\
\hline Anti-107a-FITC & Maus- IgG1 & BD Biosciences \\
Anti-107b-FITC & Maus- IgG1 & BD Biosciences \\
Anti-HLA-ABC-FITC & Maus- IgG2a,k & BmT One Lambda Inc. \\
Anti-HLA-Bw4-FITC & Maus- IgG2a,k & eBioscience Inc. \\
\hline
\end{tabular}

Pacific blue-konjugierte Antikörper

\begin{tabular}{|l|l|l|}
\hline PB- Antikörper & Spezies & Hersteller \\
\hline Anti-CD3-PB & Maus- IgG1 & BD Biosciences \\
\hline
\end{tabular}

Phycoerythrin- konjugierte Antikörper

\begin{tabular}{|l|l|l|}
\hline PE-Antikörper & Spezies & Hersteller \\
\hline Anti-KIR2DL1-PE & Maus- IgG1 & Beckman Coulter \\
Anti-KIR2DL1/S1-PE & Maus- IgG1 & Miltenyi Biotec GmbH \\
Anti-KIR3DL1-PE & Maus- IgG1 & Beckman Coulter \\
Anti-KIR3DL1/S1-PE & Maus- IgG1 & Beckman Coulter \\
Anti-KIR2DL2/L3/S2-PE & Maus- IgG1 & Beckman Coulter \\
Isokontrolle-PE & Maus & \\
\hline
\end{tabular}


Phycoerythrincyanin-konjugierte Antikörper

\begin{tabular}{|l|l|l|}
\hline PeCy7-Antikörper & Spezies & Hersteller \\
\hline Anti-CD56-PeCy7 & Maus- IgG1 & Beckman Coulter \\
\hline
\end{tabular}

\subsubsection{Technische Geräte}

\begin{tabular}{|c|c|}
\hline Gerät & Hersteller \\
\hline 96-Kanal Sequenzer 3130 & Applied Biosystems \\
\hline BD LSRFortessa ${ }^{\mathrm{TM}}$ Analyzer & BD Biosciences \\
\hline Dispenser (Multipette $®$ plus) & Eppendorf AG \\
\hline Eismaschine SPR 80 & Eppendorf AG \\
\hline GelDoc ${ }^{\mathrm{TM}}$ EZ Imager & Bio-Rad Inc. \\
\hline Handzähler mit Fingerbügel & neoLab \\
\hline Horizon® 58 Horizontal Gel Electrophoresis Apparatus & Thermo Fisher Scientific Inc. \\
\hline Kühlbare Megafuge $® 1.0 \mathrm{R}$ & Heraeus \\
\hline Mikroskop Axiovert 25 & Carl Zeiss AG \\
\hline Nanodrop 2000 & Invitrogen \\
\hline Pipetus ${ }^{\circledR}$ (mit Induktiv-Ladestation) & Hirschmann Laborgeräte \\
\hline Reax TOP Reagenzglas-Schüttler & Heidolph \\
\hline S1000 TM Thermal Cycler & Bio-Rad Inc. \\
\hline Sterilbank Modell 1.2 & Holter LaminAir \\
\hline Taschenrechner WR-3000 & Citizen \\
\hline Forma ${ }^{\mathrm{TM}}$ Steri-Cycle ${ }^{\mathrm{TM}} \mathrm{CO}_{2}$ Incubator & Thermo Fisher Scientific Inc. \\
\hline Sprout ${ }^{\circledR}$ Tischzentrifuge & Biozym Scientific GmbH \\
\hline Wasserbad WNB7-45 & Memmert \\
\hline Wasserbad Beschwerungsringe für Gefäße & neoLab \\
\hline
\end{tabular}

\subsubsection{Verbrauchsmaterialien}

\begin{tabular}{|ll|}
\hline Material & Hersteller \\
\hline CELLSTAR® T25-Zellkulturflaschen $\left(25 \mathrm{~cm}^{2}\right)$ & Greiner Bio-One \\
CELLSTAR® T75-Zellkulturflaschen $\left(75 \mathrm{~cm}^{2}\right)$ & Greiner Bio-One \\
Neubauer-Zählkammer & Carl Roth $\mathrm{GmbH}$ \\
Glas-Pasteurpipette $(270 \mathrm{~mm})$ & Carl Roth $\mathrm{GmbH}$ \\
Kyro-Röhrchen mit Außengewinde & Greiner Bio-One \\
Falcon ${ }^{\text {TM}}$-Röhrchen $(15 \mathrm{ml})$ & BD Biosciences \\
Falcon ${ }^{\text {TM }-R o ̈ h r c h e n ~}(50 \mathrm{ml})$ & BD Biosciences \\
Ein-Kanal-Mikropipettensysteme $(0,5-10 \mu \mathrm{l})$ & Eppendorf AG \\
Ein-Kanal-Mikropipettensysteme $(2-20 \mu \mathrm{l})$ & Eppendorf AG \\
Ein-Kanal-Mikropipettensysteme $(20-200 \mu \mathrm{l})$ & Eppendorf AG
\end{tabular}


Ein-Kanal-Mikropipettensysteme (100-1000 $\mu$ l)

Eppendorf AG

Deckglas für Neubauer-Zählkammer

Carl Roth $\mathrm{GmbH}$

Mikrotiterplatten (6, $12,24,96$ Kavitäten)

Greiner Bio-One

Verschlussmatten für Mikrotiterplatten

Greiner Bio-One 


\section{Abbildungsverzeichnis}

Abbildung 1 Schematischer Überblick der Blutzellbildung (Hämatopoese). Die hämatopoetische Stammzelle (HSZ) bildet hierbei den Ursprung aller Blutzellen. NK-Zellen sind Abkömmlinge der lymphatischen Zellreihe und bilden die verhältnismäßig kleinste Lymphozytenpopulation in menschlichen Blut. [Abbildung modifiziert mit Genehmigung von Donald Metcalf $\left.(2007)^{3}\right]$ - 1 -

Abbildung 2 Mikroskopische Aufnahme einer lymphoiden Natürlichen Killerzelle (eigene Erhebung) -2 -

Abbildung 3 Darstellung des strukturellen Aufbaus verschiedener KIRs. Dargestellt sind KIRs mit 2 oder 3 namensgebenden extrazellulären Immunoglobin (Ig)-Domänen. Anhand der Länge ihrer intrazellulären Domäne (KIR-L („long“) oder KIR-S („,short“)) und ihrer Signalmotive (ITIM oder ITAM) werden KIRs funktionell in aktivierende und inhibierende Rezeptortypen eingeteilt. [Abbildung modifiziert mit Genehmigung von Kuroki, Furukawa et al. (2012) ${ }^{61}$..- 6 -

Abbildung 4 Genetische Karte des erweiterten $>1$ mb langen Leukozyten-Rezeptor-Komplexes (LCR) auf Chromosom 19q13. [Abbildung übersetzt mit Genehmigung von Trowsdale, Barten et al. (2001) $)^{68}$ und Blackwell Publishing Ltd.] $-8-$

Abbildung 5 Genanordnung und -inhalt der humanen KIR-Haplotypen („Hap“) A, B und A/B. Die Zugehörigkeiten der aktivierenden und inhibierenden KIR-Rezeptoren sind in Bezug zu ihren zentromerischen („Cen“) bzw. telomerischen („Tel“) Gensegmenten B innerhalb des KIRGenlocus dargestellt. (rot= Haplotyp-A Segmente; blau= Haplotyp-B Segmente) -9 -

Abbildung 6 Systematik zur numerischen Nomenklatur von KIR-Allelen, am Beispiel von KIR2DL1. [Quelle: IPD Datenbank; https://www.ebi.ac.uk/ipd/kir/alleles.html] -11 -

Abbildung 7 Organisiation des MHC-Genlocus auf Chromosom 6. Hier befindet sich die genetische Information aller humanen Leukozytenantigene (HLA), welche in ihrer Gesamtheit das sogenannte HLA-System bilden (links) [Abbildung im Original aus der Publikation Berlingerio, Bonchi et al. (2009) ${ }^{88}$ ]. Molekularer Aufbau eines HLA-Klasse-I-Moleküle (MHC-I) und -Klasse-II-Moleküls (MHC-II). Das angelagerte $\beta 2$-Mikroglobulin wird dabei über Chromosom 15 kodiert (rechts) [Abbildung mit Genehmigung; modifiziert nach Moffett-King, Entrican et al. (2002) ${ }^{89}$. $-13-$ 
Abbildung 8 Kristallstrukturanalyse der Interaktion von KIR2DL1 mit seinem spezifischen HLA-Liganden Cw4 (Gruppe HLA-C2). [Abbildung im Original aus Kuroki, Furukawa et al. $\left.(2012)^{61}\right]$ $-15-$

Abbildung 9 Schematische Darstellung der funktionellen Erkennungsmechanismen von NKZellen. Der „missing-self“" und ,induced-self“-Erkennungsmechanismus von reaktiven NKZellen dient der Abtötung von veränderten oder transformierten Zielzellen führt. Im Rahmen der Selbsttoleranz werden gesunde Zellen anhand ihrer HLA-Klasse-I-Moleküle als körpereigen eingestuft und vor Zerstörung geschützt. [Abbildung modifiziert im Original aus Raulet, Vance et al. (2006) $\left.)^{117}\right]$ $-17-$

Abbildung 10 Schematische Darstellung des KIR-Ligand-mismatch Modells bei alloreaktiven NK-Zellen mit unterschiedlichem KIR-Set. In gelb dargestellt sind die aktiven NK-Zellen, die bei hämatopoetischer Stammzelltransplantation (HSZT) aufgrund fehlender inhibitorischer Liganden auf Seiten des Empfängers zur Lyse aktiviert werden und dadurch den GvL-Effekt steigern. [Abbildung übersetzt im Original aus Andersson, Malmberg et al. (2010) ${ }^{182}$ ]......... - 25 -

Abbildung 11 Zeitversetzt zur Transplantation der hämatopoetischen Stammzellen werden dem Patienten zusätzlich alloreaktive Spende-NK-Zellen sowie Spender-T-Zellen verabreicht, die in der Lage sind virusinfizierte Zellen ( $\downarrow$ Infektionsrate), dendritische Zellen ( $\downarrow$ GvHD), sowie verbleibende Leukämiezellen ( $\uparrow$ GvL-Effekt) auf Empfängerseite direkt zu eliminieren. Aus den transplantierten Spender-HSZ entstehen nach etwa 6-8 Wochen die ersten „reifen“ NK-Zellen. [Abbildung übersetzt im Original aus Moretta et al. (2014) ${ }^{193}$ ]. $-26-$

Abbildung 12 Auswertung eines Agarosegels nach Amplifikation mittels KIR Sequenzspezifischer Primer (SSP)-Methode. Für die Genotypisierung wurde eine vollständige HaplotypLängen-Sequenzierung via KIR-SSP durchgeführt. Das mit Ethidiumbromid angefärbte Agarosegel zeigt das KIR-SSP Ergebnis für Spender 16. Die eingefügten gelben Rechtecke demonstrieren die spezifischen Banden von KIRs und bestätigen des genetischen Vorhandenseins des jeweiligen KIR-Rezeptors bei dem untersuchten Spender. $-33-$

Abbildung 13 Darstellung der strukturellen Organisation einzelner KIR-Gene. Die kodierenden Regionen eines Exons sind in blau dargestellt, darüber ihre Größe in Basenpaaren (Bp). Das Pseudoexon 3 und die Exon 2- Deletion in KIR3DP1 sind dahingegen rot gekennzeichnet. Die Klammern unten in der Abbildung zeigen welche Exone für welche Proteindomäne oder -region im KIR-Rezeptor kodieren. [Quelle: IPD Datenbank, https://www.ebi.ac.uk/ipd /kir/genes.html] $-34-$ 
Abbildung 14 Amplifikationsstrategie der ersten Sequenzier-PCR des KIR2DL1-Gens von Exon 1 bis 9 (A; oben) und des KIR3DL1-Gens von Exon 1 bis 9 (B; unten). Die roten Ziffern zeigen die Primerpaare, die für die erste Sequenzier-PCR verwendet wurden. Die drei Amplifikate für KIR2DL1 und die vier Amplifikate für KIR3DL1 wurden anschließend mit Hilfe der in blauen Ziffern angegebenen Primerpaare exonisch sequenziert ( $\rightarrow$ vgl. Abschnitt 4.3.4).

Abbildung 15 Darstellung eines Agarosegels nach abgeschlossener Gelelektrophorese der ersten Sequenzier-PCR. In die Geltaschen wurden die Amplifikat-Proben mit jeweils $1 \mu$ l Ladepuffer (rötlich) pipettiert und pro Reihe der Standardlängen-Marker (blau) mitgeführt. -39 -

Abbildung 16 Darstellung der Exone 1 bis 9 mit dem dazugehörigen Ig-Rezeptor-Bereich, unterteilt in Domänen, welche für alle zwei Domänen bzw. drei Domänen KIRs gleichermaßen zutrifft. Einzige Ausnahme stellt Exon 3 dar, dass nur in Form der D0-Domäne bei KIR3DL kodiert wird. 206 $-43-$

Abbildung 17 Phasenbildung einer Heparin-Vollblutprobe nach Ficoll-Überschichtung vor (links) und nach (rechts) Dichtezentrifugation. Die oberste, rötliche Phase nach der Trennungszentrifugation des Röhrchens enthält das Blutplasma des Spenders. Die darunter milchig aussehende Phase wird (aus dem Englischen) als „Buffy-Coat“ bezeichnet. Dieser besteht hauptsächlich aus peripheren mononukleären Blutzellen (PBMZ) und macht nur etwa ein Prozent der Blutprobe aus. Darunter befindet sich das transparente Ficoll und abschließend ein dunkelrotes Sediment aus Granulozyten und Erythrozyten. $-44-$

Abbildung 18 Versuchsröhrchen aus dem Magnetständer nach Abkippen der NK-ZellSuspension. $-45$

Abbildung 19 Schematische Darstellung einer Neubauer-Zählkammer (links) mit allen vier Eckquadraten (E) und dem Mittelquadrat (M). Zusätzliche vergrößerte Darstellung eines Eckquadrat-Abschnitts der Zählkammer (rechts) bestehend aus 16 Kleinquadraten (K).... - 46 -

Abbildung 20 HLA-Oberflächenfärbung der verwendeten L721.221- C2 Zellkultur. Exemplarisch gezeigt ist die HLA-Oberflächenfärung der Zelllinie L721.221-C2 über den zeitlichen Verlauf von 10 Tagen während der Kultivierung. Erst nach Hinzugabe von Hygromycin $\mathrm{B}^{\circledR} \mathrm{zu}$ dem Basis-Tumormedium kommt es zur Selektionierung, sodass sich lediglich HLA-C positive Zielzellen in der durchflusszytometrischen Messung bestimmen lassen. 
Abbildung 21 Darstellung des BD LSRFortessaTM Cell Analyzer mit seiner Flusszelle (blau umkreist). $-51-$

Abbildung 22 Schematische Darstellung des Degranulationsprozesses bei NK-Zellen nach Zielzellkontakt.. Die Vesikel-Exozytose führt zu einer vorrübergehenden Expression der Vesikelproteine CD107a (LAMP-1)- und -b (LAMP-2) auf der äußeren NK-Zellmembran. Freigesetztes Perforin bildet eine porenartige Struktur an der Membran der Zielzelle, durch die Granzyme durchtreten und den Zelltod (Apoptose) vermitteln. Rab27a unterstützt den Transport und das Andocken von beladenen Vesikeln an die NK-Zellmembran. Munc18-2 und Syntaxin 11 ermöglichen die Fusion und Freisetzung von Granulatanteilen nach Priming durch Munc13-4. [Abbildung übersetzt mit Genehmigung von Hines, Nichols et al. (2017)210] .... - 54 -

Abbildung 23 Darstellung der zeitlichen Abfolge bei der Durchführung des CD107Degranulationsassays mit der NK-Zell-Probe eines Spenders. Die Hinzugabe spezifisch HLAexprimierender Zellreihen der Linie L721.221 (Schritt (2) markiert den Startzeitpunkt des Assays. Insgesamt erfolgen bis zur Messung zwei Antikörper-Färbungen (Schritt (1) und (3), welche durch ein vierstündiges Inkubationsintervall voneinander getrennt sind. $-55-$

Abbildung 24 Darstellung der allgemeinen Gating-Strategie während der FACS-Messungen, am Beispiel von Spender 9. Der eingegrenzte Bereich (P1) innerhalb des Punktwolkendiagramms zeigt die vitale Immunzell-Fraktion nach NK-Zell-Isolation aus PBMZs ( $\rightarrow$ vgl. Abschnitt 4.5). Quadrant Q4 entspricht den davon CD3-/ CD56+ Lymphozyten, welche der Population der gesamte NK-Zellen entspricht. Mittels APC-Färbung lassen sich daraus in der Histogrammansicht die Total-KIR2DL1 positiven NK-Zellen (P2) eingrenzen, welche innerhalb der Isokontrolle (ohne Zielzellkontakt), wie erwartet, keine CD107a-FITC-Aktivität (P3) zeigten.

Abbildung 25 Aufreihung der Genabschnitte (Exon 1 - 9) des NK-Rezeptors KIR2DL1, inklusive Basenpaar(bp)-Länge und Anzahl bisher bekannter variabler Stellen (Polymorphismen) in Bezug zum Referenzallel KIR2DL1*0010101. Je länger der Genabschnitt ist, desto mehr variable Stellen sind bisher beschrieben. Exon 3, als Pseudogenabschnitt, wurde hierbei vernachlässigt (gestrichelte Markierung). [Stand Januar 2019, Quelle: https://www.ebi.ac.uk/ipd/kir ] $61-$

Abbildung 26 Dargestellt sind Beispiele für DNA-Sequenzen für den 245-Polymorphismus (links). Die Buchstaben entsprechen den vier DNA-Basen Adenin (A), Guanin (G), Cytosin (C) und Thymidin (T). Daneben sind die gruppierten Ergebnisse der Spender 1- 20 bezogen auf 
beide durch Bari et al. beschriebene KIR2DL1- Polymorphismen dargestellt (rechts). Der eckig umklammerte Spender 13 exprimiert kein KIR2DL1 auf seiner Zelloberfläche. $-63-$

Abbildung 27 Aufreihung der Genabschnitte (Exon 1 - 9) des NK-Rezeptors KIR3DL1, inklusive Basenpaar(bp)- Länge und Anzahl der untersuchten Polymorphismen (variable Stellen) in Relation zu dem Referenzallel KIR3DL1*0010101. [Stand Januar 2019, Quelle: https://www.ebi.ac.uk/ipd/kir ] $-65-$

Abbildung 28 Analyse der Nukleotidsequenz bei Spender 2 im Bereich des Exons 5 innerhalb des KIR3DL1-Gens. Bereits bekannte Polymorphismen sind in fett grün dargestellt, solche die bisher nicht beschrieben sind dagegen in fett rot in der Referenzsequenz 3DL1*0010101 gekennzeichnet. Die aus den Polymorphismen sich ergebenden Aminosäurenabweichnungen sind unter Verwendung des Einbuchstabencodes in fett schwarz hervorgehoben. Aminosäuren, die durch einen bisher unbekannten Polymorphismus zustande kommen, sind zusätzlich dunkler-grau hinterlegt. Zusätzlich sieht man im unteren Teil der Abbildung zwei ausgewählte Abschnitte der Nukleotidsequenz (gelber und orangener Kasten). Darin werden insgesamt drei von der Referenz abweichenden Aminosäuren an den Positionen 253, 258 und 286 dargestellt. Eine entsprechende Legende zu dem Einbuchstabencode bei der Aminosäurennomenklatur befindet sich im Anhang (Tabelle 28). $-67-$

Abbildung 29 Analyse der Zelloberflächenmerkmale (HLA) der kultivierten Zelllinien L721.221-ØHLA. L721.221-Bw4, L721.221-C1, und L721.221-C2 mittels Durchflusszytometrie nach Inkubation mit den Fluoreszenz- gekoppelten Antikörper Anti-HLA-A,B,C-FITC und Anti-HLA-Bw4-FITC zur stetigen Qualitätskontrolle. $-71-$

Abbildung 30 Exemplarische Darstellung unterschiedlich starker Expressionsmuster am Beispiel des Killerzell-Immunoglobulin-ähnlichen Rezeptors KIR2DL1 von vier NK-ZellSpendern mittels Durchflusszytometrie. Für die Anfärbung der NK-Zellen wurde ein antiKIR2DL1-APC Antikörper verwendet. -72 -

Abbildung 31 Auflistung (links) und graphische Darstellung (rechts) der prozentualen Anteile der KIR2DL1 und KIR3DL1-Oberflächenexpression nach Anfärbung der Spender NK-Zellen mit Anti-KIR2DL1- und Anti-KIR2DL1-APC-Antikörper und Messung im Durchflusszytometer. Spender 13 zeigt keinerlei KIR2DL1-Oberflächenexpression bei negativer KIR-SSP, Spender 14 fällt analog durch seine fehlende KIR3DL1-Oberflächenexpression auf. Spender 18 wurde graphisch nicht berücksichtigt, da der KIR3DL1-Oberflächenanteil nicht untersucht wurde. -72 - 
Abbildung 32 Gatingstrategie zur Unterscheidung zwischen Total-KIR ${ }^{+}$und Single-KIR ${ }^{+} \mathrm{NK}-$ Zellen. Die NK-Zelpopulationen wurden selektiv verwendet, um die Alloreaktivitätsmessungen auf definierte HLA-Liganden innerhalb einzelner Individuen experimentell vergleichen zu können. Die im Feld Q3 FACS-definierte Single-KIR2DL1+ Population (KIR-PE negativ/ KIR2DL1-APC positiv) eignen sich im Folgenden zur Untersuchung der anteiligen Wirkung einzelner Rezeptortypen auf die gesamte NK-Zell-Alloreaktivität $-73-$

Abbildung 33 Optische Darstellung der relativen Anteile der Single-KIR2DL1+ NKZellfraktion von der Total-KIR2DL1+ NK-Zellpopulation der untersuchten Spender. Der Spender 13 zeigt keine KIR2DL1-Expression und ist nicht mit dargestellt -74 -

Abbildung 34 Optische Darstellung der relativen Anteile der Single-KIR3DL1 ${ }^{+}$NKZellfraktion von der Total-KIR3DL1+ NK-Zellpopulation. Die Spender 14 und 18 sind nicht mit dargestellt. $-75-$

Abbildung 35 Aktivitätsspanne, definiert nach minimaler und maximaler CD107-Aktivität (in Prozent) gegen die vier verwendeten L721.221-Zielzelllinien, für Haplotyp-A (rot) und Haplotyp-Bx (blau). Die integrierte Tabelle zeigt die dafür verwendeten Einzelergebnisse der haplotypisierten NK-Zell-Spender. Die geringste Aktivitätsspanne zeigt Haplotyp-AA gegenüber den Zelllinien L721.221-ØHLA und -Bw4. -77 -

Abbildung 36 Säulendiagrammdarstellung des durchschnittlichen prozentualen aktiven NKZell-Anteils der Total-KIR2DL1+ (1.; oben) und Single-KIR2DL1+ (2.; unten) der Spender Haplotyp-AA Gruppe (rot, n=3) und der Haplotyp-Bx Gruppe (blau, n=17). Alle Prozent-werte wurden für die Darstellung auf- bzw. abgerundet. -77 -

Abbildung 37 Säulendiagrammdarstellung des durchschnittlichen prozentualen aktiven NKZell-Anteils der gesamten NK-Zellpopulation (A), Total-KIR3DL1+ (3.; oben) und SingleKIR3DL1+ (4.; unten) der Spender Haplotyp-AAGruppe (rot, $n=3$ ) und der Haplotyp-Bx Gruppe (blau, n=17). Alle Prozentwerte wurden für die Darstellung auf- bzw. abgerundet.- 78 -

Abbildung 38 Auswertung des CD107-Degranulationsassays der nach MHC-I gruppierten KIR2DL1+ Spender NK-Zellen. Die abgebildeten Punkte entsprechen den Aktivitäten der einzelnen Spender (links) gegen L721.221-ØHLA und (rechts) gegen L721.221-Cw6 (스 HLAC C2). Die schwarze Linie zeigt die durchschnittliche CD107-Aktivität der nach ihren HLA-C Typisierungsergebnissen gruppierten Spender. Die graue Linie repräsentiert die Durchschnittsaktivität der Spender mit C2+ MHC-I-Profil, d.h. C2/C2 oder C1/C2 MHC-ILigand. $-80-$ 
Abbildung 39 Auswertung des CD107-Degranulationsassays der nach MHC-I gruppierten KIR3DL1+ Spender NK-Zellen. Die abgebildeten Punkte entsprechen den Aktivitäten der einzelnen Spender (links) gegen L721.221-ØHLA und (rechts) gegen L721.221-Bw4. Die schwarze Linie zeigt die durchschnittliche CD107-Aktivität der nach ihren HLA-A/-B Typisierungsergebnissen gruppierten Spender. Die graue Linie repräsentiert die Durchschnittsaktivität der Spender mit Bw4+ MHC-I-Profil $-81-$

Abbildung 40 Überblick der gruppierten 20 Spender beim Vergleich der Aktivität der gruppierten Total-KIR2DL1+ NK-Zellen gegen L721.221 ohne HLA-Ligand (= erwartete stärkste Aktivierung) mit der Aktivität bei Interaktion mit dem rezeptorspezifischen HLA-C2 Liganden Cw6 (= erwartete stärkste Inhibition). $-82-$

Abbildung 41 Überblick der gruppierten 20 Spender beim Vergleich der Aktivität der gruppierten Total-KIR2DL1+ NK-Zellen gegen L721.221 ohne HLA-Ligand mit höchster NKZell-Aktivität verglichen mit der gemessenen CD107-Aktivität bei Interaktion mit den Liganden Cw3 (HLA-C1) und Cw6 (HLA-C2) Liganden $-83-$

Abbildung 42 Spender $2\left(\mathrm{C}^{245}\right)$ fiel in allen Vergleichsabbildungen gleichermaßen durch eine auffällig hohe Aktivität gegenüber L721.221-Bw4 und -Cw6 Zielzellen auf. Auch Spender 7 $\left(\mathrm{C}^{245}\right)$, sowie Spender 6 aus der R/C ${ }^{245}$-Gruppe zeigten dem HLA-C2 Liganden Cw6 gegenüber ein signifikant vermindertes inhibitorisches Potenzial. $-83-$

Abbildung 43 Übersicht über die CD107-Aktivitätsmessungen der NK-Zellpopulationen TotalKIR2DL1+ und der Single-KIR2DL1+ innerhalb der R ${ }^{245}$-Spendergruppe ( $\left.\mathrm{n}=5\right)$. Es zeigen sich nahezu identische Ergebnisse (in \%) bei der Aktivitätsmessung gegenüber den vier L721.221Zelllinien. $-84-$

Abbildung 44 Exemplarische Darstellung von Rezeptorhistogrammen mit unterschiedlich starker Expressionsmuster der Spendergruppen high/high (KIR3DL1h/h), high/low (KIR3DL1h/l), low/unknown (KIR3DL11/u) und low/null (KIR3DL1/n) mittels Durchflusszytometrie. Für die Anfärbung der NK-Zellen wurde ein anti-KIR3DL1-APC Antikörper verwendet. $-85-$

Abbildung 45 Exemplarische Darstellung von Rezeptorhistogrammen mit unterschiedlich starker Expressionsmuster der Spendergruppen high/high (KIR3DL1h/h), high/low (KIR3DL1h/I), low/unknown (KIR3DL11/u) und low/null (KIR3DL11/n) mittels Durchflusszytometrie. Für die Anfärbung der NK-Zellen wurde ein anti-KIR3DL1-APC Antikörper verwendet $-86-$ 
Abbildung 46 Überblick der gruppierten KIR3DL1+ Spender beim Vergleich der Aktivität gegen L721.221 ohne HLA-Ligand (= erwartete stärkste Aktivität) mit der Aktivität bei Interaktion mit dem rezeptorspezifischen Liganden HLA-B mit Bw4 Epitop (= erwartete stärkste Inhibition). Die gestrichelte Linie stellt den Durchschnitt der Aktivitätswerte für die Spender der jeweiligen Expressionsgruppe dar $-87$

Abbildung 47 Das Säulendiagramm zeigt die alloreaktive CD107-Aktivität (\%) der gruppierten KIR3DL1+ NK-Zell-Spender gegenüber L721.221-ØHLA mit der zugehörigen prozentualen Oberflächenexpression des KIR3DL1-Rezeptors. Eine hohe KIR3DL1-Rezeptordichte in der KIR-Oberflächenfärbung steht in keinem direkten Verhältnis zur resultierenden Reaktivität der NK-Zellen. - 97 -

Abbildung 48 Dargestellt ist die Basensequenz des F-Primers i7F (orange; oben) und des RPrimers E9R-s (blau) angelehnt an Belle et al. zur KIR3DL1-Sequenzierung des Exons 8 und 9.202 Weiter unten ist die Basensequenz des in der vorliegenden Arbeit verwendeten neu entworfenen E9R-n1 Primers (orange; unten) zur vollständigen Sequenzierung von Exon 9 bis einschließlich Position 177 gezeigt. 114

Abbildung 49 Emissionsspektrum der verwendeten Fluorochrome (oben) und Auflistung des Laser-Detektionsarms im BD LSRFortessa ${ }^{\mathrm{TM}}$ Cell Analyzer (unten). [Quelle: https://www.bdbiosciences.com/documents/bd_lsrfortessa_brochure.pdf] -120 - 


\section{Tabellenverzeichnis}

Tabelle 1 Aktuelle Übersicht der Anzahl aller bisher bekannter Allele pro KillerzellImmunoglobulin-ähnlichem-Rezeptortypen (KIR.) [Quelle: IPD Datenbank unter https://www.ebi.ac.uk/ipd/kir/alleles.html; Stand Januar 2019] $-10-$

Tabelle 2 Differenzialtabelle zur Unterscheidung der HLA-Epitope Bw4, Bw6, C1 und C2 anhand der Aminosäurenreste an den Positionen 77 - 83 innerhalb der $\alpha_{1}$-Helix von HLA-A, $\mathrm{B}$ und $-\mathrm{C}$ $-13-$

Tabelle 3 NK-Zell-Rezeptoren und ihre spezifischen Liganden im Überblick. Vertreter der KIRRezeptorfamilie auf NK-Zellen können lediglich an die $\alpha$-Ketten von HLA-A, -B oder -C binden. Einzelne KIRs favorisieren bei der Interaktion in der Regel ein bestimmtes HLA-KlasseI-Molekül. [Erweiterte Tabelle in Anlehnung an Locatelli, Pende et al. (2013) ${ }^{107}$ ] $-15-$

Tabelle 4 Ursprung und HLA-Oberflächenmerkmale der verwendeten L721.221-Zelllinien..... $29-$

Tabelle 5 Auflistung der für die Generierung der Amplifikate von KIR2DL1 und KIR3DL1 verwendeten Primer und deren spezifische Größe (Kilobasen(Kb)-Länge). Mit* versehen sind alle Primer, die in veränderter 1:100 Verdünnung, in der späteren Sequenzier-PCR Anwendung erneut verwendet wurden $-38-$

Tabelle 6 Thermocycler-Parameter für die zweite Sequenzier-PCR zur Generierung spezifischer Exon-Amplifikate der KIR2DL1- und KIR3DL1-Gene. $-40-$

Tabelle 7 Protokoll-Parameter bei der Sequenzierung von KIR2DL1 und KIR3DL1 mittels Genetic Analyzer 3130xl (Applied Biosystems $\left.{ }^{\circledR}\right)$. $-42-$

Tabelle 8 Alphabetische Auflistung der verwendeten Fluorochrome für die Antikörperfärbungen und durchfusszytometrischen Messungen. [Quelle: Herstellerangaben von Beckmann Coulter Miltenyi Biotec, BD Pharmingen und R+D Systems] -50 -

Tabelle 9 Auflistung der verwendeten Fluorochrom-konjugierten Antikörper für die Oberflächenfärbung der L721.221-Zelllinien und Erläuterungen zu den erwarteten HLAOberflächenmerkmalen. $-52-$

Tabelle 10 Auflistung der verwendeten Fluorochrom-konjugierten Antikörper zur Analyse der KIR-Expression auf der Zelloberfläche der primären Spender NK-Zellen. Angaben für 100.000 


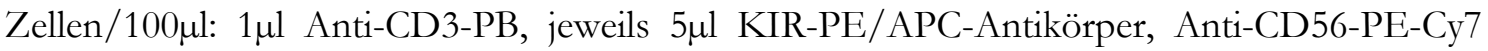
oder Anti-Maus-IgG1-PE. $-53-$

Tabelle 11 Auflistung der verwendeten Fluorochrom-konjugierten Antikörper zur Durchführung des CD107-Degranulationsassays. $-55-$

Tabelle 12 Übersicht der Ergebnisse des KIR-Profils (KIRom) von Spender 1 bis 20. Bei Spender 10 zeigen sich beispielsweise, bis auf einiger Allele des aktivierenden Rezeptors KIR2DS4, alle weiteren KIRs genetisch ausgeprägt. Die in der vorliegenden Arbeit untersuchten KIR-Gene sind farbig hinterlegt. [Abkürzungen: männlich (m) und weiblich (w)] $-58-$

Tabelle 13 Anhand des Genumfangs aktivierender KIRs (aKIRs) wurde der Haplotyp der Spender $1-20$ bestimmt $(\rightarrow$ vgl. Abschnitt 1.3.2). Haplotyp-AA Spender besitzen ausschließlich Gene, die dem Haplotypen A zugeordnet werden. Haplotyp-Bx Träger dagegen mindestens ein nicht zu Haplotyp-AA passendes KIR-Gen. $-59-$

Tabelle 14 Ergebnisse der selektiven HLA-Typisierung (Genloci für HLA-A, -B und -C) der 20 untersuchten Spender, welche Liganden von KIR2DL1 und KIR3DL1 darstellen. -60 -

Tabelle 15 Auflistung der gefundenen KIR2DL1-Allele, sowie deren Allelfrequenz innerhalb der Studiengruppe. (Detailierte Ansicht mit den Abweichungen zu dem Referenzallel KIR2DL1*0010101 in Tabelle 34 des Anhangs).

Tabelle 16 Darstellung der allelischen Kongruenzbeziehung der Polymorphismen an den ASPositionen 245 und 216 des KIR2DL1-Gens. Die Überlappungen hinsichtlich der Polymorphismen $\mathrm{C}^{245}$ (Cystein) und $\mathrm{E}^{216}$ (Glutaminsäure) sind durch die rote Markierung sichtbar gemacht. Allele, welche einen singulären Polymorphismus zeigen, bilden die Minderheit und sind in der Tabelle orange gekennzeichnet. $-64-$

Tabelle 17 Auflistung der gefundenen KIR3DL1-Allele, sowie deren Allelfrequenz innerhalb der Studiengruppe. (Detailierte Ansicht mit den Abweichungen zu dem Referenzallel KIR3DL1*0010101 in Tabelle 36 des Anhangs) $-66-$

Tabelle 18 Überblick der in der Literatur 2001 - 2015 beschriebenen allelische Expressionsstärken des inhibitorischen KIR3DL1-Rezeptors.205,215-218 Bei allen in den Tabellen nicht aufgeführten Allelen handelt es sich um unknown-Allele (,3DL1-u“), welche in der bisherigen Literatur keine Erwähnung finden. Sie entsprechen 65\% der KIR3DL1-Allele.. - 68 - 
Tabelle 19 Gruppierungsübersicht der 20 Spender anhand der 5 Untersuchungsgruppen high/high (KIR3DL1h/h), high/low (KIR3DL1h/I), high/unknown (KIR3DL1h/u), high/null (KIR3DL1 1 /n $)$ mit unterschiedlicher Rezeptor-Expressionsstärke. $69-$

Tabelle 20 Abweichende Spender beim Aktivitätsvergleich gegenüber verschiedenen Zielzelllinien. Wichtige Messwerte zum Verständnis der Abbildungen 40 und 41 wurden in fett hervorgehoben $-82-$

Tabelle 21 Messergebnisse des CD107-Assays der Total-KIR3DL1+ NK-Zellen nach Stimulation mit den Zellinien L721.221-ØHLA und -Bw4. $-88-$

Tabelle 22 Tabellarische Übersicht relevanter KIR3DL1-Polymorphismen aus den Arbeiten von Pando et al. (2003)216 und Carr et al. (2005) 221 $-94-$

Tabelle 23 Überblick der KIR-SSP Genotypisierungsergebnisse der 20 NK-Zell-Spender hinsichtlich ihres inhibierenden und aktivierenden KIR3D-Rezeptors. Spender 14 zeigte trotz positiver KIR-SSP bei bekanntem 3DL1*0040101 Nullallel entsprechend keine Oberflächenexpression des KIR3DL1-Rezeptors (gestrichelt). $-104-$

Tabelle 24 Tabellarische Darstellung der Hauptantigene [eckige Klammer] der HLA-Klasse-IMoleküle A, B und C mit ihren jeweiligen Unterantigenen und korrespondierendem Epitop (eigene Zusammenstellung; kein Anspruch auf Vollständigkeit). $-113-$

Tabelle 25 Zusammenstellung der Reaktionsansätze für die Amplifikations-PCR der KIR-Gene KIR2DL1- und KIR3DL1 $-115-$

Tabelle 26 Auflistung der Taq-Polymerase spezifischen Thermocycler Parameter für die unterschiedlichen Amplifikate von KIR2DL1 (Amplifikate A, B1 und B2) und KIR3DL1 (Amplifikate A, B, C1 und C2). $-116$

Tabelle 27 Auflistung der verwendete Primer für die Amplifikation der KIR-Gene KIR2DL1 und -3DL1 und der Sequenzierung ihrer Exone 1 bis 9. Die in der Tabelle mit $\left(^{*}\right)$ bezeichneten Primer, wurde auch später für die zweite Sequenzier-PCR in 1:100 Verdünnung verwendet werden. -117 -

Tabelle 28 Übersetzung der DNA-Basentriplets in Aminosäuren (links); Legende zur Aminosäurennomenklatur (rechts) -118 -

Tabelle 29 Überblick relevanter im EasySep ${ }^{\mathrm{TM}}$ Human NK Cell Enrichment Kit enthaltene CDAntigene mit Zuordnung der spezifischen Zellexpression. [Angelehnt an das Lehrbuch 
"Pädiatrische Allergologie und Immunologie" (Hrsg. U. Wahn, R. Seger, V. Wahn, G. Holländer), Elsevier-Verlag, September 2005 und W. Luttmann et al., Der Experimentator: Immunologie, Experimentator, DOI 10.1007/978-3-642-41899-0, Springer-Verlag Berlin Heidelberg, 2014] - 119 -

Tabelle 30 Darstellung der spenderspezifischen HLA-A, -B und -C Allele und dem daraus resultierendem MHC-I-Profil der 20 untersuchten NK-Zell-Spendern. - 121 -

Tabelle 31 Abweichende polymorphe Positionen bei der Untersuchung des kaum bzw. nichtexprimierten KIR3DL1*004-Allels. - 121 -

Tabelle 32 Tabellarische Zusammenstellung untersuchter funktioneller Polymorphismen des KIR3DL1-Gens mit jeweiliger Literaturangabe. Eigene Zusammenstellung relevanter (A) und wahrscheinlich unrelevanter (B) funktioneller KIR3DL1-Polymorphismen. [Tabelle angelehnt an Campbell, Purdy et al. (2011) ${ }^{53}$ ] - 122 -

Tabelle 33 Auswertungstabelle zur Bestimmung der KIR2DL1-Allele der untersuchten NKZell-Spender. [Stand Januar 2019, Quelle: https://www.ebi.ac.uk/ipd/kir] - 123 -

Tabelle 34 Ergebnistabelle der KIR2DL1-Subtypisierung der untersuchten NK-Zell-Spender 1 bis 20. Weiß hinterlegt sind die jeweiligen Nukleotidpositionen, deren Basen von der Referenzallelsequenz abweichen. Umrahmt wurden solche Basen(-kombinationen), die keinem der bisher beschriebenen Allele eindeutig zugeordnet werden konnten. [Stand Januar 2019, Quelle: https://www.ebi.ac.uk/ipd/kir]. - 124 -

Tabelle 35 Auswertungstabelle zur Bestimmung der KIR3DL1-Allele der untersuchten NKZell-Spender in sechs Teilen.[Stand Januar 2019, Quelle: https://www.ebi.ac.uk/ipd/kir] - 125 -

Tabelle 36 Ergebnistabelle der KIR3DL1-Subtypisierung der untersuchten NK-Zell-Spender 1 bis 20. Weiß hinterlegt sind die jeweiligen Nukleotidpositionen, deren Basen von der Referenzallelsequenz abweichen. Umrahmt wurden solche Basen(-kombinationen), die keinem der bisher beschriebenen Allele eindeutig zugeordnet werden konnten. [Stand Januar 2019, Quelle: https://www.ebi.ac. uk/ipd/kir].. 131 - 


\section{Literaturverzeichnis}

1. Lanier LL, Phillips JH. Evidence for three types of human cytotoxic lymphocyte. Immunology Today. 1986;7(5):132-134. doi:10.1016/0167-5699(86)90076-9.

2. Kondo M, Weissman IL, Akashi K. Identification of clonogenic common lymphoid progenitors in mouse bone marrow. Cell. 1997;91(5):661-672. doi:10.1016/s00928674(00)80453-5

3. Metcalf D. Concise review: hematopoietic stem cells and tissue stem cells: current concepts and unanswered questions. Stem Cells. 2007;25(10):2390-2395. doi:10.1634/stemcells.2007-0544.

4. Clément M V, Haddad P, Soulie A, Guillet J, Sasportes M. Involvement of granzyme B and perforin gene expression in the lytic potential of human natural killer cells. Research in Immunology. 1990;141(5):477-489. doi:10.1016/0923-2494(90)90017-S.

5. Gregoire C, Chasson L, Luci C, et al. The trafficking of natural killer cells. Immunol Rev. 2007;220:169-182. doi:10.1111/j.1600-065X.2007.00563.x.

6. Carrega P, Ferlazzo G. Natural killer cell distribution and trafficking in human tissues. Front Immunol. 2012;3. doi:10.3389/fimmu.2012.00347.

7. Zhang Y, Wallace DL, Lara CM de, et al. In vivo kinetics of human natural killer cells: the effects of ageing and acute and chronic viral infection. Immunology. 2007;121(2):258-265. doi:10.1111/j.1365-2567.2007.02573.x.

8. Miller JS, Alley KA, McGlave P. Differentiation of natural killer (NK) cells from human primitive marrow progenitors in a stroma-based long-term culture system: identification of a CD34+7+ NK progenitor. Blood. 1994;83(9):2594-2601.

9. Galy A, Travis M, Cen D, Chen B. Human T, B, natural killer, and dendritic cells arise from a common bone marrow progenitor cell subset. Immunity. 1995;3(4):459-473.

10. Huntington ND, Vosshenrich CAJ, Di Santo JP. Developmental pathways that generate natural-killer-cell diversity in mice and humans. Nat Rev Immunol. 2007;7(9):703-714. doi:10.1038/nri2154.

11. Caligiuri M A., Michael A. Human natural killer cells. Blood. 2008;112(3):461-469. doi:10.1182/blood-2007-09-077438. 
12. Kumar V, Ben-Ezra J, Bennett M, Sonnenfeld G. Natural Killer Cells in Mice Treated with 89Strontium: Normal Target-Binding Cell Numbers but Inability to Kill Even after Interferon Administration. The Journal of Immunology. 1979;123(4):1832-1838. PMID: 383842

13. Colucci F, Caligiuri MA, Di Santo JP. What does it take to make a natural killer? Nat Rev Immunol. 2003;3(5):413-425. doi:10.1038/nri1088.

14. Yokoyama WM, Kim S, French AR. The dynamic life of natural killer cells. Annu Rev Immunol. 2004;22:405-429. doi:10.1146/annurev.immunol.22.012703.104711.

15. Di Santo JP, Vosshenrich CAJ. Bone marrow versus thymic pathways of natural killer cell development. Immunol Rev. 2006;214:35-46. doi:10.1111/j.1600-065X.2006.00461.x.

16. Sun JC, Beilke JN, Lanier LL. Adaptive immune features of natural killer cells. Nature. 2009;457(7229):557-561. doi:10.1038/nature07665.

17. Kiessling R, Klein E, Wigzell H. "Natural" killer cells in the mouse. I. Cytotoxic cells with specificity for mouse Moloney leukemia cells. Specificity and distribution according to genotype. Eur J Immunol. 1975;5(2):112-117. doi:10.1002/eji.1830050208.

18. Nitta T., Yagita H., Sato K., Okumura K. Involvement of CD56 (NKH-1/Leu-19 antigen) as an adhesion molecule in natural killer-target cell interaction. J Exp Med. 1989;170(5):1757-1761. doi:10.1084/jem.170.5.1757

19. Cooper MA, Fehniger TA, Caligiuri MA. The biology of human natural killer-cell subsets. Trends Immunol. 2001;22(11):633-640. doi:10.1016/s1471-4906(01)02060-9

20. Mavilio D, Lombardo G, Benjamin J, et al. Characterization of CD56-/CD16+ natural killer (NK) cells: a highly dysfunctional NK subset expanded in HIV-infected viremic individuals. Proc Natl Acad Sci U S A. 2005;102(8):2886-2891. doi:10.1073/pnas.0409872102.

21. Reeves RK, Gillis J, Wong FE, Yu Y, Connole M, Johnson RP. CD16- natural killer cells: enrichment in mucosal and secondary lymphoid tissues and altered function during chronic SIV infection. Blood. 2010;115(22):4439-4446. doi:10.1182/blood-2010-01-265595.

22. Wilk E, Kalippke K, Buyny S, Schmidt RE, Jacobs R. New aspects of NK cell subset identification and inference of NK cells' regulatory capacity by assessing functional and genomic profiles. Immunobiology. 2008;213(3-4):271-283. doi:10.1016/j.imbio.2007.10.012. 
23. Moretta A, Tambussi G, Bottino C, et al. A novel surface antigen expressed by a subset of human CD3- CD16 + natural killer cells. Role in cell activation and regulation of cytolytic function. Journal of Experimental Medicine. 1990;171(3):695-714. doi:10.1084/jem.171.3.695.

24. Jacobs R, Hintzen G, Kemper A, et al. CD56bright cells differ in their KIR repertoire and cytotoxic features from CD56dim NK cells. Eur J Immunol. 2001;31(10):3121-3127. doi:10.1002/1521-4141(2001010)31:10<3121:AID-IMMU3121gt;3.0.CO;2-4.

25. Charles A Janeway, JR, Travers P, Walport M, Shlomchik MJ. Appendix II. Table with CD Antigens. Garland Science. 2001.

26. Hibbs ML, Selvaraj P, Carpen O, et al. Mechanisms for regulating expression of membrane isoforms of Fc gamma RIII (CD16). Science. 1989;246(4937):1608-1611. doi:10.1126/science.2531918.

27. Li X-Y, Wu L, Li S-W, et al. Effect of CD16a, the surface receptor of Kupffer cells, on the growth of hepatocellular carcinoma cells. International Journal of Molecular Medicine. 2016;37(6):1465-1474. doi:10.3892/ijmm.2016.2561.

28. Poli A, Michel T, Thérésine M, Andrès E, Hentges F, Zimmer J. CD56bright natural killer (NK) cells: an important NK cell subset. Immunology. 2009;126(4):458-465. doi:10.1111/j.1365-2567.2008.03027.x.

29. Fehniger TA, Cooper MA, Nuovo GJ, et al. CD56bright natural killer cells are present in human lymph nodes and are activated by T cell-derived IL-2: a potential new link between adaptive and innate immunity. Blood. 2003;101(8):3052-3057. doi:10.1182/blood-2002-09-2876.

30. Caligiuri MA, Zmuidzinas A, Manley TJ, Levine H, Smith KA, Ritz J. Functional consequences of interleukin 2 receptor expression on resting human lymphocytes. Identification of a novel natural killer cell subset with high affinity receptors. J Exp Med. 1990;171(5):15091526. doi: $10.1084 /$ jem.171.5.1509

31. Nagler A, Lanier LL, Phillips JH. Constitutive expression of high affinity interleukin 2 receptors on human CD16-natural killer cells in vivo. Journal of Experimental Medicine. 1990;171(5):1527-1533. doi:10.1084/jem.171.5.1527.

32. Robertson MJ, Soiffer RJ, Wolf SF, et al. Response of human natural killer (NK) cells to NK cell stimulatory factor (NKSF): cytolytic activity and proliferation of NK cells are 
differentially regulated by NKSF. Journal of Experimental Medicine. 1992;175(3):779-788. doi:10.1084/jem.175.3.779.

33. Shibuya A. Development and functions of natural killer cells. Int J Hematol. 2003;78(1):1-6. doi: 10.1007/BF02983233

34. Lanier LL. Up on the tightrope: natural killer cell activation and inhibition. Nat Immunol. 2008;9(5):495-502. doi:10.1038/ni1581.

35. Gerosa F, Baldani-Guerra B, Nisii C, Marchesini V, Carra G, Trinchieri G. Reciprocal activating interaction between natural killer cells and dendritic cells. J Exp Med. 2002;195(3):327333. doi: $10.1084 /$ jem. 20010938

36. Martin-Fontecha A, Thomsen LL, Brett S, et al. Induced recruitment of NK cells to lymph nodes provides IFN-gamma for $\mathrm{T}(\mathrm{H}) 1$ priming. Nat Immunol. 2004;5(12):1260-1265. doi:10.1038/ni1138.

37. Iversen A-C, Norris PS, Ware CF, Benedict CA. Human NK Cells Inhibit Cytomegalovirus Replication through a Noncytolytic Mechanism Involving LymphotoxinDependent Induction of IFN- $\beta$. The Journal of Immunology. 2005;175(11):7568-7574. doi:10.4049/jimmunol.175.11.7568.

38. Morandi B, Bougras G, Muller WA, Ferlazzo G, Munz C. NK cells of human secondary lymphoid tissues enhance $\mathrm{T}$ cell polarization via IFN-gamma secretion. Eur J Immunol. 2006;36(9):2394-2400. doi:10.1002/eji.200636290.

39. Gurer C, Strowig T, Brilot F, et al. Targeting the nuclear antigen 1 of Epstein-Barr virus to the human endocytic receptor DEC-205 stimulates protective T-cell responses. Blood. 2008;112(4):1231-1239. doi:10.1182/blood-2008-03-148072.

40. Smyth MJ, Kelly JM, Sutton VR, et al. Unlocking the secrets of cytotoxic granule proteins. J Leukoc Biol. 2001;70(1):18-29. doi: 10.1189/jlb.70.1.18

41. Trapani JA, Smyth MJ. Functional significance of the perforin/granzyme cell death pathway. Nat Rev Immunol. 2002;2(10):735-747. doi:10.1038/nri911.

42. Enari M, Talanian RV, Wrong WW, Nagata S. Sequential activation of ICE-like and CPP32-like proteases during Fas-mediated apoptosis. Nature. 1996;380(6576):723. doi:10.1038/380723a0. 
43. Enari M, Sakahira H, Yokoyama H, Okawa K, Iwamatsu A, Nagata S. A caspaseactivated DNase that degrades DNA during apoptosis, and its inhibitor ICAD. Nature. 1998;391(6662):43-50. doi:10.1038/34112.

44. Herberman Ronald B. Natural Killer Cells and Cells Mediating Antibody-Dependent Cytotoxicity against Tumors. In: Bach FH, Good RA, eds. Clinical Immunobiology. Vol. 4. Elsevier; 1980:73-88. doi:10.1016/B978-0-12-070004-2.50010-4

45. Cooper MA, Colonna M, Yokoyama WM. Hidden talents of natural killers: NK cells in innate and adaptive immunity. EMBO Rep. 2009;10(10):1103-1110. doi:10.1038/embor.2009.203.

46. Oldham RK, Herberman Ronald B. Evaluation of Cell-Mediated Cytotoxic Reactivity Against Tumor Associated Antigens with 125I-Iododeoxyuridine Labeled Target Cells. The Journal of Immunology. 1973;111(6):1862-1871. PMID:4750872

47. Herberman Ronald B., Nunn ME, Holden HT, Lavrin DH. Natural cytotoxic reactivity of mouse lymphoid cells against syngeneic and allogeneic tumors. II. Characterization of effector cells. International Journal of Cancer. 1975;16(2):230-239. doi:10.1002/ijc.2910160205.

48. Kim S, Poursine-Laurent J, Truscott SM, et al. Licensing of natural killer cells by host major histocompatibility complex class I molecules. Nature. 2005;436(7051):709. doi:10.1038/nature03847.

49. Anfossi N, André P, Guia S, et al. Human NK Cell Education by Inhibitory Receptors for MHC Class I. Immunity. 2006;25(2):331-342. doi:10.1016/j.immuni.2006.06.013.

50. Fernandez NC, Treiner E, Vance RE, Jamieson AM, Lemieux S, Raulet DH. A subset of natural killer cells achieves self-tolerance without expressing inhibitory receptors specific for self-MHC molecules. Blood. 2005;105(11):4416-4423. doi:10.1182/blood-2004-08-3156.

51. Cassatella MA, Anegon I, Cuturi MC, Griskey P, Trinchieri G, Perussia B. Fc gamma $\mathrm{R}(\mathrm{CD} 16)$ interaction with ligand induces $\mathrm{Ca} 2+$ mobilization and phosphoinositide turnover in human natural killer cells. Role of $\mathrm{Ca} 2+$ in Fc gamma $\mathrm{R}(\mathrm{CD} 16)$-induced transcription and expression of lymphokine genes. J Exp Med. 1989;169(2):549-567. doi:10.1084/jem.169.2.549

52. Lanier LL, Corliss BC, Wu J, Leong C, Phillips JH. Immunoreceptor DAP12 bearing a tyrosine-based activation motif is involved in activating NK cells. Nature. 1998;391(6668):703. doi:10.1038/35642. 
53. Campbell KS, Purdy AK. Structure/function of human killer cell immunoglobulin-like receptors: lessons from polymorphisms, evolution, crystal structures and mutations. Immunology. 2011;132(3):315-325. doi:10.1111/j.1365-2567.2010.03398.x.

54. Phillips JH, Gumperz JE, Parham P, Lanier LL. Superantigen-dependent, cell-mediated cytotoxicity inhibited by MHC class I receptors on T lymphocytes. Science. 1995;268(5209):403405. doi:10.1126/science. 7716542.

55. Mingari MC, Schiavetti F, Ponte M, et al. Human CD8+ T lymphocyte subsets that express HLA class I-specific inhibitory receptors represent oligoclonally or monoclonally expanded cell populations. PNAS. 1996;93(22):12433-12438. doi:10.1073/pnas.93.22.12433.

56. Uhrberg M, Valiante NM, Shum BP, et al. Human diversity in killer cell inhibitory receptor genes. Immunity. 1997;7(6):753-763. doi:10.1016/s1074-7613(00)80394-5

57. Valiante NM, Uhrberg M, Shilling HG, et al. Functionally and structurally distinct NK cell receptor repertoires in the peripheral blood of two human donors. Immunity. 1997;7(6):739751. doi:10.1016/s1074-7613(00)80393-3

58. Raulet DH, Vance RE, McMahon CW. Regulation of the natural killer cell receptor repertoire. Annu Rev Immunol. 2001;19:291-330. doi:10.1146/annurev.immunol.19.1.291.

59. Lanier LL. NK cell recognition. Annu Rev Immunol. 2005;23:225-274. doi:10.1146/annurev.immunol.23.021704.115526.

60. O'Connor GM, Hart OM, Gardiner CM. Putting the natural killer cell in its place. Immunology. 2006;117(1):1-10. doi:10.1111/j.1365-2567.2005.02256.x.

61. Kuroki K, Furukawa A, Maenaka K. Molecular recognition of paired receptors in the immune system. Front Microbiol. 2012;3:429. doi:10.3389/fmicb.2012.00429.

62. Colonna M, Samaridis J. Cloning of immunoglobulin-superfamily members associated with HLA-C and HLA-B recognition by human natural killer cells. Science. 1995;268(5209):405408. doi:10.1126/science. 7716543 .

63. Yusa S-i, Catina TL, Campbell KS. SHP-1- and Phosphotyrosine-Independent Inhibitory Signaling by a Killer Cell Ig-Like Receptor Cytoplasmic Domain in Human NK Cells. The Journal of Immunology. 2002;168(10):5047-5057. doi:10.4049/jimmunol.168.10.5047. 
64. Kikuchi-Maki A, Yusa S-i, Catina TL, Campbell KS. KIR2DL4 Is an IL-2-Regulated NK Cell Receptor That Exhibits Limited Expression in Humans but Triggers Strong IFN- $\gamma$ Production. The Journal of Immunology. 2003;171(7):3415-3425. doi:10.4049/jimmunol.171.7.3415.

65. Olcese L, Cambiaggi A, Semenzato G, Bottino C, Moretta A, Vivier E. Human killer cell activatory receptors for MHC class I molecules are included in a multimeric complex expressed by natural killer cells. The Journal of Immunology. 1997;158(11):5083-5086. PMID:9164921

66. Lanier LL, Corliss BC, Wu J, Leong C, Phillips JH. Immunoreceptor DAP12 bearing a tyrosine-based activation motif is involved in activating NK cells. Nature. 1998;391(6668):703707. doi:10.1038/35642.

67. Bléry M., Olcese L., Vivier E. Early signaling via inhibitory and activating NK receptors. Human Immunology. 2000;61(1):51-64. doi:10.1016/S0198-8859(99)00157-3.

68. Trowsdale J, Barten R, Haude A, Stewart CA, Beck S, Wilson MJ. The genomic context of natural killer receptor extended gene families. Immunol Rev. 2001;181:20-38. doi:10.1034/j.1600-065x.2001.1810102.x

69. Trowsdale J. Genetic and functional relationships between MHC and NK receptor genes. Immunity. 2001;15(3):363-374. doi:10.1016/S1074-7613(01)00197-2

70. Vilches C, Parham P. KIR: diverse, rapidly evolving receptors of innate and adaptive immunity. Annu Rev Immunol. 2002;20:217-251. doi:10.1146/annurev.immunol.20.092501.134942.

71. Mighell AJ, Smith NR, Robinson PA, Markham AF. Vertebrate pseudogenes. FEBS Lett. 2000;468(2-3):109-114. doi:10.1016/S0014-5793(00)01199-6

72. Korneev SA, Park JH, O'Shea M. Neuronal expression of neural nitric oxide synthase (nNOS) protein is suppressed by an antisense RNA transcribed from an NOS pseudogene. J Neurosci. 1999;19(18):7711-7720. doi:10.1523/JNeurosci.19-18-07711

73. Balakirev ES, Ayala FJ. Pseudogenes: are they "junk" or functional DNA? Annu Rev Genet. 2003;37:123-151. doi:10.1146/annurev.genet.37.040103.103949.

74. Mattick JS, Makunin IV. Non-coding RNA. Hum Mol Genet. 2006;15(suppl_1):R17R29. doi:10.1093/hmg/ddl046. 
75. Guttman M, Amit I, Garber M, et al. Chromatin signature reveals over a thousand highly conserved large non-coding RNAs in mammals. Nature. 2009;458(7235):223-227. doi:10.1038/nature07672.

76. Caley DP, Pink RC, Trujillano D, Carter DRF. Long Noncoding RNAs, Chromatin, and Development. The Scientific World Journal. 2010;10:90-102. doi:10.1100/tsw.2010.7.

77. Pink RC, Wicks K, Caley DP, Punch EK, Jacobs L, Francisco Carter DR. Pseudogenes: Pseudo-functional or key regulators in health and disease? RNA. 2011;17(5):792-798. doi:10.1261/rna.2658311.

78. Ghosal S, Das S, Chakrabarti J. Long Noncoding RNAs: New Players in the Molecular Mechanism for Maintenance and Differentiation of Pluripotent Stem Cells. Stem Cells Dev. 2013;22(16):2240-2253. doi:10.1089/scd.2013.0014.

79. Hirotsune S, Yoshida $\mathrm{N}$, Chen $\mathrm{A}$, et al. An expressed pseudogene regulates the messenger-RNA stability of its homologous coding gene. Nature. 2003;423(6935):91. doi:10.1038/nature01535.

80. Pyo C-W, Guethlein LA, Vu Q, et al. Different Patterns of Evolution in the Centromeric and Telomeric Regions of Group A and B Haplotypes of the Human Killer Cell Ig-Like Receptor Locus. PLOS ONE. 2010;5(12):e15115. doi:10.1371/journal.pone.0015115.

81. Hsu KC, Chida S, Geraghty DE, Dupont B. The killer cell immunoglobulin-like receptor (KIR) genomic region: gene-order, haplotypes and allelic polymorphism. Immunol Rev. 2002;190(1):40-52. doi:10.1034/j.1600-065X.2002.19004.x.

82. Re V de, Caggiari L, Zorzi M de, et al. Genetic Diversity of the KIR/HLA System and Susceptibility to Hepatitis C Virus-Related Diseases. PLoS One. 2015;10(2). doi:10.1371/journal.pone.0117420.

83. Martin AM, Freitas EM, Witt CS, Christiansen FT. The genomic organization and evolution of the natural killer immunoglobulin-like receptor (KIR) gene cluster. Immunogenetics. 2000;51(4):268-280. doi:10.1007/s002510050620.

84. Horton R, Coggill P, Miretti MM, et al. The LRC haplotype project: a resource for killer immunoglobulin-like receptor-linked association studies. Tissue Antigens. 2006;68(5):450-452. doi:10.1111/j.1399-0039.2006.00697.x. 
85. Parham P. Immunogenetics of killer cell immunoglobulin-like receptors. Molecular Immunology. 2005;42(4):459-462. doi:10.1016/j.molimm.2004.07.027.

86. Carrington M, Cullen M. Justified chauvinism: advances in defining meiotic recombination through sperm typing. Trends in Genetics. 2004;20(4):196-205. doi:10.1016/j.tig.2004.02.006.

87. Deutsche Knochenmarkspenderdatei. KIR-Profil für Stammzellspender: Typisierung zusätzlicher Marker ist von großer Bedeutung bei der Spenderauswahl. https://mediacenter.dkms.de/news/kir-profil/.

88. Berlingerio M, Bonchi F, Curcio M, Giannotti F, Turini F. Mining Clinical, Immunological, and Genetic Data of Solid Organ Transplantation. In: Kacprzyk J, Sidhu AS, Dillon TS, eds. Biomedical data and applications. Vol. 224. Berlin, Heidelberg: Springer-Verlag; 2009:211-236. Studies in Computational Intelligence; 224. doi:10.1007/978-3-642-02193-0_9

89. Moffett-King A, Entrican G, Ellis S, Hutchinson J, Bainbridge D. Natural killer cells and reproduction. Trends Immunol. 2002;23(7):332-333. doi:10.1016/S1471-4906(02)02261-5.

90. Khakoo SI, Thio CL, Martin MP, et al. HLA and NK Cell Inhibitory Receptor Genes in Resolving Hepatitis C Virus Infection. Science. 2004;305(5685):872-874. doi:10.1126/science.1097670.

91. Gumperz JE, Barber LD, Valiante NM, et al. Conserved and variable residues within the Bw4 motif of HLA-B make separable contributions to recognition by the NKB1 killer cellinhibitory receptor. The Journal of Immunology. 1997;158(11):5237-5241. PMID:9164941

92. Cella M, Longo A, Ferrara GB, Strominger JL, Colonna M. NK3-specific natural killer cells are selectively inhibited by Bw4-positive HLA alleles with isoleucine 80. Journal of Experimental Medicine. 1994;180(4):1235-1242. doi:10.1084/jem.180.4.1235.

93. Litwin V, Gumperz J, Parham P, Phillips JH, Lanier LL. NKB1: a natural killer cell receptor involved in the recognition of polymorphic HLA-B molecules. Journal of Experimental Medicine. 1994;180(2):537-543. doi:10.1084/jem.180.2.537.

94. Gumperz JE, Litwin V, Phillips JH, Lanier LL, Parham P. The Bw4 public epitope of HLA-B molecules confers reactivity with natural killer cell clones that express NKB1, a putative HLA receptor. Journal of Experimental Medicine. 1995;181(3):1133-1144. doi:10.1084/jem.181.3.1133 
95. Single RM, Martin MP, Gao X, et al. Global diversity and evidence for coevolution of KIR and HLA. Nat Genet. 2007;39(9):1114-1119. doi:10.1038/ng2077.

96. Sanjanwala B, Draghi M, Norman PJ, Guethlein LA, Parham P. Polymorphic Sites Away from the Bw4 Epitope That Affect Interaction of Bw4+ HLA-B with KIR3DL1. The Journal of Immunology. 2008;181(9):6293-6300. doi:10.4049/jimmunol.181.9.6293.

97. Colonna M, Borsellino G, Falco M, Ferrara GB, Strominger JL. HLA-C is the inhibitory ligand that determines dominant resistance to lysis by NK1- and NK2-specific natural killer cells. PNAS. 1993;90(24):12000-12004. doi:10.1073/pnas.90.24.12000.

98. Winter CC, Gumperz JE, Parham P, Long EO, Wagtmann N. Direct Binding and Functional Transfer of NK Cell Inhibitory Receptors Reveal Novel Patterns of HLA-C Allotype Recognition. The Journal of Immunology. 1998;161(2):571-577. PMID:9670929

99. Moesta AK, Norman PJ, Yawata M, Yawata N, Gleimer M, Parham P. Synergistic Polymorphism at Two Positions Distal to the Ligand-Binding Site Makes KIR2DL2 a Stronger Receptor for HLA-C Than KIR2DL3. The Journal of Immunology. 2008;180(6):3969-3979. doi:10.4049/jimmunol.180.6.3969.

100. Almeida CR, Ashkenazi A, Shahaf G, Kaplan D, Davis DM, Mehr R. Human NK Cells Differ More in Their KIR2DL1-Dependent Thresholds for HLA-Cw6-Mediated Inhibition than in Their Maximal Killing Capacity. PLOS ONE. 2011;6(9):e24927. doi:10.1371/journal.pone.0024927.

101. Hilton HG, Vago L, Aguilar AMO, et al. Mutation at Positively Selected Positions in the Binding Site for HLA-C Shows That KIR2DL1 Is a More Refined but Less Adaptable NK Cell Receptor Than KIR2DL3. The Journal of Immunology. 2012:1100431. doi:10.4049/jimmunol.1100431.

102. David G, Djaoud Z, Willem C, et al. Large Spectrum of HLA-C Recognition by Killer Ig-like Receptor (KIR)2DL2 and KIR2DL3 and Restricted C1 Specificity of KIR2DS2: Dominant Impact of KIR2DL2/KIR2DS2 on KIR2D NK Cell Repertoire Formation. The Journal of Immunology. 2013:1301580. doi:10.4049/jimmunol.1301580.

103. Isitman G, Tremblay-McLean A, Lisovsky I, et al. NK Cells Expressing the Inhibitory Killer Immunoglobulin-Like Receptors (iKIR) KIR2DL1, KIR2DL3 and KIR3DL1 Are Less 
Likely to Be CD16+ than Their iKIR Negative Counterparts. PLOS ONE. 2016;11(10):e0164517. doi:10.1371/journal.pone.0164517.

104. Wan AM, Ennis P, Parham P, Holmes N. The primary structure of HLA-A32 suggests a region involved in formation of the $\mathrm{Bw} 4 / \mathrm{Bw} 6$ epitopes. The Journal of Immunology.1986;137(11):3671-3674. PMID:2431040

105. Pittari G, Liu X-R, Selvakumar A, et al. NK Cell Tolerance of Self-Specific Activating Receptor KIR2DS1 in Individuals with Cognate HLA-C2 Ligand. The Journal of Immunology. 2013:1202120. doi:10.4049/jimmunol.1202120.

106. Karre K, Ljunggren HG, Piontek G, Kiessling R. Selective rejection of H-2-deficient lymphoma variants suggests alternative immune defence strategy. Nature. 1986;319(6055):675678. doi:10.1038/319675a0.

107. Locatelli F, Pende D, Mingari MC, et al. Cellular and molecular basis of haploidentical hematopoietic stem cell transplantation in the successful treatment of high-risk leukemias: role of alloreactive NK cells. Front Immunol. 2013;4:15. doi:10.3389/fimmu.2013.00015.

108. Yokoyama WM, Kim S. Licensing of natural killer cells by self-major histocompatibility complex class I. Immunol Rev. 2006;214(1):143-154. doi:10.1111/j.1600-065X.2006.00458.x.

109. Kim S, Sunwoo JB, Yang L, et al. HLA alleles determine differences in human natural killer cell responsiveness and potency. PNAS. 2008;105(8):3053-3058. doi:10.1073/pnas.0712229105.

110. Moretta L, Moretta A. Killer immunoglobulin-like receptors. Curr Opin Immunol. 2004;16(5):626-633. doi:10.1016/j.coi.2004.07.010.

111. Vivier E, Nunès JA, Vély F. Natural Killer Cell Signaling Pathways. Science. 2004;306(5701):1517-1519. doi:10.1126/science.1103478.

112. Ferlazzo G, Pack M, Thomas D, et al. Distinct roles of IL-12 and IL-15 in human natural killer cell activation by dendritic cells from secondary lymphoid organs. PNAS. 2004;101(47):16606-16611. doi:10.1073/pnas.0407522101.

113. Kärre K, Ljunggren HG, Piontek G, Kiessling R. Selective rejection of H-2-deficient lymphoma variants suggests alternative immune defence strategy. Nature. 1986;319(6055):675. doi:10.1038/319675a0. 
114. Storkus WJ, Alexander J, Payne JA, Dawson JR, Cresswell P. Reversal of natural killing susceptibility in target cells expressing transfected class I HLA genes. PNAS. 1989;86(7):23612364. doi:10.1073/pnas.86.7.2361.

115. Ljunggren H-G, Kärre K. In search of the 'missing self': MHC molecules and NK cell recognition. Immunology Today. 1990;11:237-244. doi:10.1016/0167-5699(90)90097-S.

116. Kärre K. NK Cells, MHC Class I Molecules and the Missing Self. Scandinavian Journal of Immunology. 2002;55(3):221-228. doi:10.1046/j.1365-3083.2002.01053.x.

117. Raulet DH, Vance RE. Self-tolerance of natural killer cells. Nat Rev Immunol. 2006;6(7):520-531. doi:10.1038/nri1863.

118. Höglund P, Sundbäck J, Olsson-Alheim MY, et al. Host MHC class I gene control of NK-cell specificity in the mouse. Immunol Rev. 1997;155(1):11-28. doi:10.1111/j.1600065X.1997.tb00936.x.

119. Yokoyama WM, Plougastel BFM. Immune functions encoded by the natural killer gene complex. Nature Reviews Immunology. 2003;3(4):304. doi:10.1038/nri1055.

120. Brodin P, Lakshmikanth T, Johansson S, Kärre K, Höglund P. The strength of inhibitory input during education quantitatively tunes the functional responsiveness of individual natural killer cells. Blood. 2009;113(11):2434-2441. doi:10.1182/blood-2008-05-156836.

121. Joncker NT, Fernandez NC, Treiner E, Vivier E, Raulet DH. NK Cell Responsiveness Is Tuned Commensurate with the Number of Inhibitory Receptors for Self-MHC Class I: The Rheostat Model. The Journal of Immunology. 2009;182(8):4572-4580. doi:10.4049/jimmunol.0803900.

122. Braud VM, Allan DS, O'Callaghan CA, et al. HLA-E binds to natural killer cell receptors CD94/NKG2A, B and C. Nature. 1998;391(6669):795-799. doi:10.1038/35869.

123. Moretta A, Bottino C, Vitale M, et al. Receptors for HLA class-I molecules in human natural killer cells. Annu Rev Immunol. 1996;14:619-648. doi:10.1146/annurev.immunol.14.1.619.

124. Freud AG, Yokohama A, Becknell B, et al. Evidence for discrete stages of human natural killer cell differentiation in vivo. Journal of Experimental Medicine. 2006;203(4):1033-1043. doi:10.1084/jem.20052507. 
125. Cooley S, Xiao F, Pitt M, et al. A subpopulation of human peripheral blood NK cells that lacks inhibitory receptors for self-MHC is developmentally immature. Blood. 2007;110(2):578-586. doi:10.1182/blood-2006-07-036228.

126. Ferlazzo G, Thomas D, Lin S-L, et al. The Abundant NK Cells in Human Secondary Lymphoid Tissues Require Activation to Express Killer Cell Ig-Like Receptors and Become Cytolytic. The Journal of Immunology. 2004;172(3):1455-1462. doi:10.4049/jimmunol.172.3.1455.

127. Moretta L, Bottino C, Pende D, Castriconi R, Mingari MC, Moretta A. Surface NK receptors and their ligands on tumor cells. Semin Immunol. 2006;18(3):151-158. doi:10.1016/j.smim.2006.03.002.

128. Drevs J. Selbsttoleranz von NK-Zellen. Dissertation, 2010.

129. Diefenbach A, Raulet DH. Strategies for target cell recognition by natural killer cells. Immunol Rev. 2001;181(1):170-184. doi:10.1034/j.1600-065X.2001.1810114.x.

130. Bauer S, Groh V, Wu J, et al. Activation of NK cells and T cells by NKG2D, a receptor for stress-inducible MICA. Science. 1999;285(5428):727-729. doi:10.1126/science.285.5428.727

131. Andre P, Castriconi R, Espeli M, et al. Comparative analysis of human NK cell activation induced by NKG2D and natural cytotoxicity receptors. Eur J Immunol. 2004;34(4):961-971. doi:10.1002/eji.200324705.

132. Jamieson AM, Diefenbach A, McMahon CW, Xiong N, Carlyle JR, Raulet DH. The Role of the NKG2D Immunoreceptor in Immune Cell Activation and Natural Killing. Immunity. 2002;17(1):19-29. doi:10.1016/S1074-7613(02)00333-3.

133. Long EO, Rajagopalan S. Stress Signals Activate Natural Killer Cells. Journal of Experimental Medicine. 2002;196(11):1399-1402. doi:10.1084/jem.20021747.

134. Spear P, Wu M-R, Sentman M-L, Sentman CL. NKG2D ligands as therapeutic targets. Cancer Immun. 2013;13(2):8. PMID:23833565

135. Raulet DH. Roles of the NKG2D immunoreceptor and its ligands. Nat Rev Immunol. 2003;3(10):781-790. doi:10.1038/nri1199. 
136. Guerra N, Pestal K, Juarez T, et al. A selective role of NKG2D in inflammatory and autoimmune diseases. Clinical Immunology. 2013;149(3, Part B):432-439. doi:10.1016/j.clim.2013.09.003.

137. Ogasawara K, Benjamin J, Takaki R, Phillips JH, Lanier LL. Function of NKG2D in natural killer cell-mediated rejection of mouse bone marrow grafts. Nat Immunol. 2005;6(9):938. doi:10.1038/ni1236.

138. Jung H, Hsiung B, Pestal K, Procyk E, Raulet DH. RAE-1 ligands for the NKG2D receptor are regulated by E2F transcription factors, which control cell cycle entry. Journal of Experimental Medicine. 2012;209(13):2409-2422. doi:10.1084/jem.20120565.

139. Raulet DH, Gasser S, Gowen BG, Deng W, Jung H. Regulation of ligands for the NKG2D activating receptor. Annu Rev Immunol. 2013;31:413-441. doi:10.1146/annurevimmunol-032712-095951.

140. Groh V, Wu J, Yee C, Spies T. Tumour-derived soluble MIC ligands impair expression of NKG2D and T-cell activation. Nature. 2002;419(6908):734. doi:10.1038/nature01112.

141. Ehrlich LIR, Ogasawara K, Hamerman JA, et al. Engagement of NKG2D by Cognate Ligand or Antibody Alone Is Insufficient to Mediate Costimulation of Human and Mouse CD8+ T Cells. The Journal of Immunology. 2005;174(4):1922-1931. doi:10.4049/jimmunol.174.4.1922.

142. Bryceson YT, March ME, Ljunggren H-G, Long EO. Synergy among receptors on resting NK cells for the activation of natural cytotoxicity and cytokine secretion. Blood. 2006;107(1):159-166. doi:10.1182/blood-2005-04-1351.

143. Kompetenznetz Leukämien. Häufigkeit von Leukämien in Deutschland. https://www.kompetenznetz-leukaemie.de/content/aerzte/epidemiologie/

144. Copelan EA. Hematopoietic stem-cell transplantation. $\mathrm{N}$ Engl J Med. 2006;354(17):1813-1826. doi:10.1056/NEJMra052638.

145. Mickelson EM, Petersdorf E, Anasetti C, Martin P, Woolfrey A, Hansen JA. HLA matching in hematopoietic cell transplantation. Human Immunology. 2000;61(2):92-100. doi:10.1016/S0198-8859(99)00151-2.

146. Flomenberg N, Baxter-Lowe LA, Confer D, et al. Impact of HLA class I and class II high-resolution matching on outcomes of unrelated donor bone marrow transplantation: HLA- 
C mismatching is associated with a strong adverse effect on transplantation outcome. Blood. 2004;104(7):1923-1930. doi:10.1182/blood-2004-03-0803.

147. Petersdorf EW, Anasetti C, Martin PJ, et al. Limits of HLA mismatching in unrelated hematopoietic cell transplantation. Blood. 2004;104(9):2976-2980. doi:10.1182/blood-2004-041674.

148. Lee SJ, Klein J, Haagenson M, et al. High-resolution donor-recipient HLA matching contributes to the success of unrelated donor marrow transplantation. Blood. 2007;110(13):45764583. doi:10.1182/blood-2007-06-097386.

149. Petersdorf EW, Hansen JA, Martin PJ, et al. Major-histocompatibility-complex class I alleles and antigens in hematopoietic-cell transplantation. N Engl J Med. 2001;345(25):17941800. doi:10.1056/NEJMoa011826.

150. Deutschen Arbeitsgemeinschaft für Knochenmark- und Blutstammzelltransplantation. Leitlinien zur allogenen Stammzelltransplantation: Konditionierung. 2016. https://www.dag-kbt.de/files/downloads/Leitlinien_Kap-03_Allgemeine\%20Anforderungen.pdf

151. Kanakry CG, Fuchs EJ, Luznik L. Modern approaches to HLA-haploidentical blood or marrow transplantation. Nature Reviews Clinical Oncology. 2016;13(1):10. doi:10.1038/nrclinonc.2015.128.

152. Kolb HJ, Mittermuller J, Clemm C, et al. Donor leukocyte transfusions for treatment of recurrent chronic myelogenous leukemia in marrow transplant patients. Blood. 1990;76(12):2462-2465. Blood (1990) 76 (12): 2462-2465. doi:10.1182/blood.V76.12.2462.2462

153. Kolb HJ, Schattenberg A, Goldman JM, et al. Graft-versus-leukemia effect of donor lymphocyte transfusions in marrow grafted patients. European Group for Blood and Marrow Transplantation Working Party Chronic Leukemia. Blood. 1995;86(5):2041-2050. PMID:7655033

154. Kolb H-J, Schmid C, Barrett AJ, Schendel DJ. Graft-versus-leukemia reactions in allogeneic chimeras. Blood. 2004;103(3):767-776. doi:10.1182/blood-2003-02-0342.

155. Antin JH. Graft-versus-leukemia: no longer an epiphenomenon. Blood. 1993;82:2273. PMID:8400279 
156. Drobyski WR, Keever CA, Roth MS, et al. Salvage immunotherapy using donor leukocyte infusions as treatment for relapsed chronic myelogenous leukemia after allogeneic bone marrow transplantation: efficacy and toxicity of a defined T-cell dose. Blood. 1993;82(8):2310-2318. PMID:8400284

157. Van Rhee F, Lin F, Cullis JO, et al. Relapse of chronic myeloid leukemia after allogeneic bone marrow transplant: the case for giving donor leukocyte transfusions before the onset of hematologic relapse. Blood. 1994;83(11):3377-3383. PMID:8193375

158. Mackinnon S, Papadopoulos EB, Carabasi MH, et al. Adoptive immunotherapy evaluating escalating doses of donor leukocytes for relapse of chronic myeloid leukemia after bone marrow transplantation: separation of graft-versus-leukemia responses from graft-versushost disease. Blood. 1995;86(4):1261-1268. PMID:7632930

159. Lima Md, Anagnostopoulos A, Munsell M, et al. Nonablative versus reduced-intensity conditioning regimens in the treatment of acute myeloid leukemia and high-risk myelodysplastic syndrome: dose is relevant for long-term disease control after allogeneic hematopoietic stem cell transplantation. Blood. 2004;104(3):865-872. doi:10.1182/blood-2003-11-3750.

160. Weiden PL, Flournoy N, Thomas ED, et al. Antileukemic effect of graft-versus-host disease in human recipients of allogeneic-marrow grafts. N Engl J Med. 1979;300(19):1068-1073. doi:10.1056/NEJM197905103001902.

161. Ruggeri L, Capanni M, Mancusi A, Martelli MF, Velardi A. The impact of donor natural killer cell alloreactivity on allogeneic hematopoietic transplantation. Transpl Immunol. 2005;14(3-4):203-206. doi:10.1016/j.trim.2005.03.008.

162. Bachar-Lustig E, Rachamim N, Li H-W, Lan F, Reisner Y. Megadose of T cell-depleted bone marrow overcomes MHC barriers in sublethally irradiated mice. Nature Medicine. 1995;1(12):1268. doi:10.1038/nm1295-1268.

163. Reisner Y, Martelli MF. Bone marrow transplantation across HLA barriers by increasing the number of transplanted cells. Immunology Today. 1995;16(9):437-440. doi:10.1016/01675699(95)80021-2.

164. Aversa F, Tabilio A, Terenzi A, et al. Successful engraftment of T-cell-depleted haploidentical "three-loci" incompatible transplants in leukemia patients by addition of recombinant human granulocyte colony-stimulating factor-mobilized peripheral blood progenitor cells to bone marrow inoculum. Blood. 1994;84(11):3948-3955. PMID:7524753 
165. Aversa F, Terenzi A, Felicini R, et al. Mismatched T cell-depleted hematopoietic stem cell transplantation for children with high-risk acute leukemia. Bone Marrow Transplant. 1998;22 Suppl 5:S29-32. PMID:9989886

166. Aversa F, Tabilio A, Velardi A, et al. Treatment of high-risk acute leukemia with T-celldepleted stem cells from related donors with one fully mismatched HLA haplotype. N Engl J Med. 1998;339(17):1186-1193. doi:10.1056/NEJM199810223391702.

167. Imai K, Matsuyama S, Miyake S, Suga K, Nakachi K. Natural cytotoxic activity of peripheral-blood lymphocytes and cancer incidence: an 11-year follow-up study of a general population. The Lancet. 2000;356(9244):1795-1799. doi:10.1016/S0140-6736(00)03231-1.

168. Coca S, Perez-Piqueras J, Martinez D, et al. The prognostic significance of intratumoral natural killer cells in patients with colorectal carcinoma. Cancer. 1997;79(12):2320-2328. doi:10.1002/(SICI)1097-0142(19970615)79:12<2320:AID-CNCR5>3.0.CO;2-P.

169. Ishigami S, Natsugoe S, Tokuda K, et al. Prognostic value of intratumoral natural killer cells in gastric carcinoma. Cancer. 2000;88(3):577-583. doi:10.1002/(SICI)10970142(20000201)88:3<577:AID-CNCR13>3.0.CO;2-V.

170. Villegas FR, Coca S, Villarrubia VG, et al. Prognostic significance of tumor infiltrating natural killer cells subset CD57 in patients with squamous cell lung cancer. Lung Cancer. 2002;35(1):23-28. doi:10.1016/S0169-5002(01)00292-6.

171. Hsia J-Y, Chen J-T, Chen C-Y, et al. Prognostic significance of intratumoral natural killer cells in primary resected esophageal squamous cell carcinoma. Chang Gung Med J. 2005;28(5):335-340. PMID:16086548

172. Balsamo M, Vermi W, Parodi M, et al. Melanoma cells become resistant to NK-cellmediated killing when exposed to NK-cell numbers compatible with NK-cell infiltration in the tumor. Eur J Immunol. 2012;42(7):1833-1842. doi:10.1002/eji.201142179.

173. Sun $Y$, Yao Z, Zhao Z, et al. Natural killer cells inhibit metastasis of ovarian carcinoma cells and show therapeutic effects in a murine model of ovarian cancer. Experimental and Therapeutic Medicine. 2018;16(2):1071-1078. doi:10.3892/etm.2018.6342.

174. Castriconi R, Daga A, Dondero A, et al. NK Cells Recognize and Kill Human Glioblastoma Cells with Stem Cell-Like Properties. The Journal of Immunology. 2009;182(6):3530-3539. doi:10.4049/jimmunol.0802845. 
175. Haspels HN, Rahman MA, Joseph JV, Gras Navarro A, Chekenya M. Glioblastoma Stem-Like Cells Are More Susceptible Than Differentiated Cells to Natural Killer Cell Lysis Mediated Through Killer Immunoglobulin-Like Receptors-Human Leukocyte Antigen Ligand Mismatch and Activation Receptor-Ligand Interactions. Front Immunol. 2018;9:1345. doi:10.3389/fimmu.2018.01345.

176. Kondo E, Koda K, Takiguchi N, et al. Preoperative Natural Killer Cell Activity as a Prognostic Factor for Distant Metastasis following Surgery for Colon Cancer. DSU. 2003;20(5):445-451. doi:10.1159/000072714.

177. Cerwenka A, Lanier LL. Natural killer cells, viruses and cancer. Nature Reviews Immunology. 2001;1(1):41. doi:10.1038/35095564.

178. Ljunggren H-G, Malmberg K-J. Prospects for the use of NK cells in immunotherapy of human cancer. Nature Reviews Immunology. 2007;7(5):329. doi:10.1038/nri2073.

179. Terme M, Ullrich E, Delahaye NF, Chaput N, Zitvogel L. Natural killer cell-directed therapies: moving from unexpected results to successful strategies. Nat Immunol. 2008;9(5):486. doi:10.1038/ni1580.

180. Vivier E, Tomasello E, Baratin M, Walzer T, Ugolini S. Functions of natural killer cells. Nat Immunol. 2008;9(5):503. doi:10.1038/ni1582.

181. Farag SS, Fehniger TA, Ruggeri L, Velardi A, Caligiuri MA. Natural killer cell receptors: new biology and insights into the graft-versus-leukemia effect. Blood. 2002;100(6):1935-1947. doi:10.1182/blood-2002-02-0350.

182. Andersson S, Malmberg J-A, Malmberg K-J. Tolerant and diverse natural killer cell repertoires in the absence of selection. Exp Cell Res. 2010;316(8):1309-1315. doi:10.1016/j.yexcr.2010.02.030.

183. Ruggeri L, Capanni M, Casucci M, et al. Role of Natural Killer Cell Alloreactivity in HLA-Mismatched Hematopoietic Stem Cell Transplantation. Blood. 1999;94(1):333-339. doi:10.1182/blood.V94.1.333.413a31_333_339

184. Ruggeri L, Capanni M, Urbani E, et al. Effectiveness of Donor Natural Killer Cell Alloreactivity in Mismatched Hematopoietic Transplants. Science. 2002;295(5562):2097-2100. doi:10.1126/science.1068440. 
185. Clausen J, Wolf D, Petzer AL, et al. Impact of natural killer cell dose and donor killercell immunoglobulin-like receptor (KIR) genotype on outcome following human leucocyte antigen-identical haematopoietic stem cell transplantation. Clinical \& Experimental Immunology. 2007;148(3):520-528. doi:10.1111/j.1365-2249.2007.03360.x.

186. Ruggeri L, Mancusi A, Capanni M, et al. Donor natural killer cell allorecognition of missing self in haploidentical hematopoietic transplantation for acute myeloid leukemia: challenging its predictive value. Blood. 2007;110(1):433-440. doi:10.1182/blood-2006-07038687.

187. Caligiuri MA, Velardi A, Scheinberg DA, Borrello IM. Immunotherapeutic Approaches for Hematologic Malignancies. Hematology. 2004;2004(1):337-353. doi:10.1182/asheducation2004.1.337.

188. Uharek L, Glass B, Gaska T, et al. Natural killer cells as effector cells of graft-versusleukemia activity in a murine transplantation model. Bone Marrow Transplant. 1993;12 Suppl 3:S57-60. PMID:8124260

189. Zeis M, Uharek L, Glass B, et al. Allogeneic NK cells as potent antileukemic effector cells after allogeneic bone marrow transplantation in mice. Transplantation. 1995;59(12):17341736. doi:10.1097/00007890-199506270-00016

190. Zeis M, Uharek L, Glass B, et al. Allogeneic MHC-mismatched activated natural killer cells administered after bone marrow transplantation provide a strong graft-versus-leukaemia effect in mice. British Journal of Haematology. 1997;96(4):757-761. doi:10.1046/j.13652141.1997.d01-2101.x.

191. Shlomchik WD, Couzens MS, Tang CB, et al. Prevention of Graft Versus Host Disease by Inactivation of Host Antigen-Presenting Cells. Science. 1999;285(5426):412-415. doi:10.1126/science.285.5426.412.

192. Ferlazzo G, Tsang ML, Moretta L, Melioli G, Steinman RM, Münz C. Human Dendritic Cells Activate Resting Natural Killer (NK) Cells and Are Recognized via the NKp30 Receptor by Activated NK Cells. Journal of Experimental Medicine. 2002;195(3):343-351. doi:10.1084/jem.20011149.

193. Moretta L, Montaldo E, Vacca P, et al. Human Natural Killer Cells: Origin, Receptors, Function, and Clinical Applications. IAA. 2014;164(4):253-264. doi:10.1159/000365632. 
194. Feuchtinger T. Zelluläre und Antikörper-basierte Immuntherapien der Leukämie. Drug Research. 2018;(68):1-30. doi:10.1055/a-0733-0805

195. Siegmund-Schultze N. CAR-T-Zellen erreichen die klinische Praxis. Deutsches Ärzteblatt. 2019; Jg. 116, Heft 49:B1888-B1891. https://www.aerzteblatt.de/archiv/211164/Neue-Strategien-in-der-Onkologie-CAR-T-Zellenerreichen-die-klinische-Praxis

196. Wang W, Jiang J, Wu C. CAR-NK for tumor immunotherapy: Clinical transformation and future prospects. Cancer Lett. 2020;472:175-180. doi:10.1016/j.canlet.2019.11.033.

197. Ni J, Miller M, Stojanovic A, Garbi N, Cerwenka A. Sustained effector function of IL12/15/18-preactivated NK cells against established tumors. Journal of Experimental Medicine. 2012;209(13):2351-2365. doi:10.1084/jem.20120944.

198. Canter RJ, Grossenbacher SK, Foltz JA, et al. Radiotherapy enhances natural killer cell cytotoxicity and localization in pre-clinical canine sarcomas and first-in-dog clinical trial. Journal for ImmunoTherapy of Cancer. 2017;5(1):98. doi:10.1186/s40425-017-0305-7.

199. Kavathas P, Bach FH, DeMars R. Gamma ray-induced loss of expression of HLA and glyoxalase I alleles in lymphoblastoid cells. Proc Natl Acad Sci U S A. 1980;77(7):4251-4255. doi:10.1073/pnas.77.7.4251

200. Shimizu Y, DeMars R. Production of human cells expressing individual transferred HLA-A,-B,-C genes using an HLA-A,-B,-C null human cell line. The Journal of Immunology. 1989;142(9):3320-3328. PMID:2785140

201. Hou LH, Steiner NK, Chen M, Belle I, Ng J, Hurley CK. KIR2DL1 allelic diversity: four new alleles characterized in a bone marrow transplant population and three families. Tissue Antigens. 2007;69(3):250-254. doi:10.1111/j.1399-0039.2006.00793.x.

202. Belle I, Hou L, Chen M, Steiner NK, Ng J, Hurley CK. Investigation of killer cell immunoglobulin-like receptor gene diversity in KIR3DL1 and KIR3DS1 in a transplant population. Tissue Antigens. 2008;71(5):434-439. doi:10.1111/j.1399-0039.2008.01017.x.

203. Bari R, Bell T, Leung W-H, et al. Significant functional heterogeneity among KIR2DL1 alleles and a pivotal role of arginine245. Blood. 2009;114(25):5182-5190. doi:10.1182/blood2009-07-231977. 
204. Bari R, Thapa R, Bao J, Li Y, Zheng J, Leung W. KIR2DL2/2DL3-E35 alleles are functionally stronger than -Q35 alleles. Sci Rep. 2016;6. doi:10.1038/srep23689.

205. Gagne K, Willem C, Legrand N, et al. Both the nature of KIR3DL1 alleles and the KIR3DL1/S1 allele combination affect the KIR3DL1 NK-cell repertoire in the French population. Eur J Immunol. 2013;43(4):1085-1098. doi:10.1002/eji.201243007.

206. Bashirova AA, Martin MP, McVicar DW, Carrington M. The killer immunoglobulin-like receptor gene cluster: tuning the genome for defense. Annu Rev Genomics Hum Genet. 2006;7:277-300. doi:10.1146/annurev.genom.7.080505.115726.

207. Carlsson SR, Fukuda M. Structure of human lysosomal membrane glycoprotein 1. Assignment of disulfide bonds and visualization of its domain arrangement. J Biol Chem. 1989;264(34):20526-20531. PMID:2584229

208. Cuervo AM, Dice JF. A receptor for the selective uptake and degradation of proteins by lysosomes. Science. 1996;273(5274):501-503. doi:10.1126/science.273.5274.501

209. Pols MS, Klumperman J. Trafficking and function of the tetraspanin CD63. Exp Cell Res. 2009;315(9):1584-1592. doi:10.1016/j.yexcr.2008.09.020.

210. Hines MR, Nichols KE. Go with the flow: perforin and CD107a in HLH. Blood. 2017;129(22):2954-2955. doi:10.1182/blood-2017-04-773192.

211. Alter G, Malenfant JM, Altfeld M. CD107a as a functional marker for the identification of natural killer cell activity. J Immunol Methods. 2004;294(1-2):15-22. doi:10.1016/j.jim.2004.08.008.

212. Thomas LM, Peterson ME, Long EO. Cutting edge: NK cell licensing modulates adhesion to target cells. J Immunol. 2013;191(8):3981-3985. doi:10.4049/jimmunol.1301159.

213. Cooper MA. Teach Your NK Cells Well. Immunity. 2016;45(2):229-231. doi:10.1016/j.immuni.2016.07.020.

214. Bari R, Rujkijyanont P, Sullivan E, et al. Effect of Donor KIR2DL1 Allelic Polymorphism on the Outcome of Pediatric Allogeneic Hematopoietic Stem-Cell Transplantation. J Clin Oncol. 2013;31(30):3782-3790. doi:10.1200/JCO.2012.47.4007. 
215. Gardiner CM, Guethlein LA, Shilling HG, et al. Different NK Cell Surface Phenotypes Defined by the DX9 Antibody Are Due to KIR3DL1 Gene Polymorphism. The Journal of Immunology. 2001;166(5):2992-3001. doi:10.4049/jimmunol.166.5.2992.

216. Pando MJ, Gardiner CM, Gleimer M, McQueen KL, Parham P. The Protein Made from a Common Allele of KIR3DL1 (3DL1*004) Is Poorly Expressed at Cell Surfaces due to Substitution at Positions 86 in Ig Domain 0 and 182 in Ig Domain 1. The Journal of Immunology. 2003;171(12):6640-6649. doi:10.4049/jimmunol.171.12.6640.

217. Trundley A, Frebel H, Des Jones, Chang C, Trowsdale J. Allelic expression patterns of KIR3DS1 and 3DL1 using the Z27 and DX9 antibodies. Eur J Immunol. 2007;37(3):780-787. doi:10.1002/eji.200636773.

218. Parham P, Norman PJ, Abi-Rached L, Guethlein LA. Variable NK Cell Receptors Exemplified by Human KIR3DL1/S1. The Journal of Immunology. 2011;187(1):11-19. doi:10.4049/jimmunol.0902332.

219. Pegram HJ, Ritchie DS, Smyth MJ, et al. Alloreactive natural killer cells in hematopoietic stem cell transplantation. Leuk Res. 2011;35(1):14-21. doi:10.1016/j.leukres.2010.07.030.

220. Cooley S, Trachtenberg E, Bergemann TL, et al. Donors with group B KIR haplotypes improve relapse-free survival after unrelated hematopoietic cell transplantation for acute myelogenous leukemia. Blood. 2009;113(3):726-732. doi:10.1182/blood-2008-07-171926.

221. Carr WH, Pando MJ, Parham P. KIR3DL1 Polymorphisms That Affect NK Cell Inhibition by HLA-Bw4 Ligand. The Journal of Immunology. 2005;175(8):5222-5229. doi:10.4049/jimmunol.175.8.5222.

222. Parham P, Moffett A. How did variable NK-cell receptors and MHC class I ligands influence immunity, reproduction and human evolution? Nat Rev Immunol. 2013;13(2):133-144. doi:10.1038/nri3370.

223. Martin MP, Gao X, Lee J-H, et al. Epistatic interaction between KIR3DS1 and HLA-B delays the progression to AIDS. Nat Genet. 2002;31(4):429-434. doi:10.1038/ng934.

224. Körner C, Altfeld M. Role of KIR3DS1 in human diseases. Front Immunol. 2012;3:326. doi:10.3389/fimmu.2012.00326. 
225. Mele D, Pasi A, Cacciatore $\mathrm{R}$, et al. Decreased interferon- $\gamma$ production by NK cells from KIR haplotype B carriers in hepatitis C virus infection. Liver Int. 2019;39(7):1237-1245. doi:10.1111/liv.14172.

226. Hiby SE, Regan L, Lo W, Farrell L, Carrington M, Moffett A. Association of maternal killer-cell immunoglobulin-like receptors and parental HLA-C genotypes with recurrent miscarriage. Hum Reprod. 2008;23(4):972-976. doi:10.1093/humrep/den011.

227. Xiong S, Sharkey AM, Kennedy PR, et al. Maternal uterine NK cell-activating receptor KIR2DS1 enhances placentation. J Clin Invest. 2013;123(10):4264-4272. doi:10.1172/JCI68991.

228. Boudreau JE, Giglio F, Gooley TA, et al. KIR3DL1/HLA-B Subtypes Govern Acute Myelogenous Leukemia Relapse After Hematopoietic Cell Transplantation. J Clin Oncol. 2017;35(20):2268-2278. doi:10.1200/JCO.2016.70.7059.

229. Maniangou B, Retière C, Gagne K. Next-generation sequencing technology a new tool for killer cell immunoglobulin-like receptor allele typing in hematopoietic stem cell transplantation. Transfusion Clinique et Biologique. 2018;25(1):87-89. doi:10.1016/j.tracli.2017.07.005.

230. Taner SB, Pando MJ, Roberts A, et al. Interactions of NK Cell Receptor KIR3DL1*004 with Chaperones and Conformation-Specific Antibody Reveal a Functional Folded State As Well As Predominant Intracellular Retention. The Journal of Immunology. 2011;186(1):62-72. doi:10.4049/jimmunol.0903657.

231. Mulrooney TJ, Zhang AC, Goldgur Y, Boudreau JE, Hsu KC. KIR3DS1-Specific D0 Domain Polymorphisms Disrupt KIR3DL1 Surface Expression and HLA Binding. The Journal of Immunology. 2015;195(3):1242-1250. doi:10.4049/jimmunol.1500243.

232. Karlhofer FM, Ribaudo RK, Yokoyama WM. MHC class I alloantigen specificity of Ly49+ IL-2-activated natural killer cells. Nature. 1992;358(6381):66-70. doi:10.1038/358066a0.

233. Carrington M, Wang S, Martin MP, et al. Hierarchy of resistance to cervical neoplasia mediated by combinations of killer immunoglobulin-like receptor and human leukocyte antigen loci. J Exp Med. 2005;201(7):1069-1075. doi:10.1084/jem.20042158.

234. López-Vázquez A, Miña-Blanco A, Martínez-Borra J, et al. Interaction between KIR3DL1 and HLA-B*57 supertype alleles influences the progression of HIV-1 infection in a 
Zambian population. Human Immunology. 2005;66(3):285-289. doi:10.1016/j.humimm.2005.01.001.

235. Martin MP, Qi Y, Gao X, et al. Innate partnership of HLA-B and KIR3DL1 subtypes against HIV-1. Nat Genet. 2007;39(6):733-740. doi:10.1038/ng2035.

236. He Y, Tian Z. NK cell education via nonclassical MHC and non-MHC ligands. Cell Mol Immunol. 2017;14(4):321-330. doi:10.1038/cmi.2016.26.

237. Barber DF, Faure M, Long EO. LFA-1 contributes an early signal for NK cell cytotoxicity. J Immunol. 2004;173(6):3653-3659. doi:10.4049/jimmunol.173.6.3653.

238. Mace EM, Zhang J, Siminovitch KA, Takei F. Elucidation of the integrin LFA-1mediated signaling pathway of actin polarization in natural killer cells. Blood. 2010;116(8):12721279. doi:10.1182/blood-2009-12-261487.

239. Hou S, Ge K, Zheng X, Wei H, Sun R, Tian Z. CD226 protein is involved in immune synapse formation and triggers Natural Killer (NK) cell activation via its first extracellular domain. J Biol Chem. 2014;289(10):6969-6977. doi:10.1074/jbc.M113.498253.

240. Boudreau JE, Liu X-R, Zhao Z, et al. Cell-Extrinsic MHC Class I Molecule Engagement Augments Human NK Cell Education Programmed by Cell-Intrinsic MHC Class I. Immunity. 2016;45(2):280-291. doi:10.1016/j.immuni.2016.07.005.

241. Elliott JM, Wahle JA, Yokoyama WM. MHC class I-deficient natural killer cells acquire a licensed phenotype after transfer into an MHC class I-sufficient environment. J Exp Med. 2010;207(10):2073-2079. doi:10.1084/jem.20100986.

242. Joncker NT, Shifrin N, Delebecque F, Raulet DH. Mature natural killer cells reset their responsiveness when exposed to an altered MHC environment. J Exp Med. 2010;207(10):20652072. doi:10.1084/jem.20100570.

243. Kadri N, Wagner AK, Ganesan S, et al. Dynamic Regulation of NK Cell Responsiveness. Curr Top Microbiol Immunol. 2016;395:95-114. doi:10.1007/82_2015_485.

244. Luu TT, Ganesan S, Wagner AK, et al. Independent control of natural killer cell responsiveness and homeostasis at steady-state by $\mathrm{CD} 11 \mathrm{c}+$ dendritic cells. Sci Rep. 2016;6:37996. doi:10.1038/srep37996. 
245. Yawata M, Yawata N, Draghi M, Little A-M, Partheniou F, Parham P. Roles for HLA and KIR polymorphisms in natural killer cell repertoire selection and modulation of effector function. Journal of Experimental Medicine. 2006;203(3):633-645. doi:10.1084/jem.20051884.

246. O'Connor GM, Guinan KJ, Cunningham RT, Middleton D, Parham P, Gardiner CM. Functional polymorphism of the KIR3DL1/S1 receptor on human NK cells. J Immunol. 2007;178(1):235-241. doi:10.4049/jimmunol.178.1.235.

247. Lutz CT. Human leukocyte antigen $\mathrm{Bw} 4$ and $\mathrm{Bw} 6$ epitopes recognized by antibodies and natural killer cells. Curr Opin Organ Transplant. 2014;19(4):436-441. doi:10.1097/MOT.0000000000000103.

248. Thananchai H, Gillespie G, Martin MP, et al. Cutting Edge: Allele-specific and peptidedependent interactions between KIR3DL1 and HLA-A and HLA-B. J Immunol. 2007;178(1):3337. doi:10.4049/jimmunol.178.1.33.

249. Khakoo SI, Geller R, Shin S, Jenkins JA, Parham P. The D0 Domain of KIR3D Acts as a Major Histocompatibility Complex Class I Binding Enhancer. Journal of Experimental Medicine. 2002;196(7):911-921. doi:10.1084/jem.20020304.

250. Vivian JP, Duncan RC, Berry R, et al. Killer cell immunoglobulin-like receptor 3DL1mediated recognition of human leukocyte antigen B. Nature. 2011;479(7373):401. doi:10.1038/nature10517.

251. Boyington JC, Sun PD. A structural perspective on MHC class I recognition by killer cell immunoglobulin-like receptors. Molecular Immunology. 2002;38(14):1007-1021. doi:10.1016/s0161-5890(02)00030-5.

252. Fadda L, O'Connor GM, Kumar S, et al. Common HIV-1 Peptide Variants Mediate Differential Binding of KIR3DL1 to HLA-Bw4 Molecules. J Virol. 2011;85(12):5970-5974. doi:10.1128/JVI.00412-11.

253. Schleinitz N, Vély F, Harlé J-R, Vivier E. Natural killer cells in human autoimmune diseases. Immunology. 2010;131(4):451-458. doi:10.1111/j.1365-2567.2010.03360.x.

254. Poggi A, Zocchi MR. NK cell autoreactivity and autoimmune diseases. Front Immunol. 2014;5:27. doi:10.3389/ fimmu.2014.00027.

255. Erten G, Aktas E, Deniz G. Natural killer cells in allergic inflammation. Chem Immunol Allergy. 2008;94:48-57. doi:10.1159/000154856 
256. Nikzad R, Angelo LS, Aviles-Padilla K, et al. Human natural killer cells mediate adaptive immunity to viral antigens. Sci Immunol. 2019;4(35). doi:10.1126/sciimmunol.aat8116.

257. Lightner A, Schust DJ, Chen Y-BA, Barrier BF. The fetal allograft revisited: does the study of an ancient invertebrate species shed light on the role of natural killer cells at the maternal-fetal interface? Clin Dev Immunol. 2008;2008:631920. doi:10.1155/2008/631920.

258. Sargent IL, Borzychowski AM, Redman CWG. NK cells and pre-eclampsia. J Reprod Immunol. 2007;76(1-2):40-44. doi:10.1016/j.jri.2007.03.009.

259. Kopcow HD, Karumanchi SA. Angiogenic Factors and Natural Killer (NK) Cells in the Pathogenesis of Preeclampsia. J Reprod Immunol. 2007;76(1-2):23-29. doi:10.1016/j.jri.2007.03.018.

260. Osuga Y, Koga K, Hirota Y, Hirata T, Yoshino O, Taketani Y. Lymphocytes in endometriosis. Am J Reprod Immunol. 2011;65(1):1-10. doi:10.1111/j.1600-0897.2010.00887.x.

261. Natural killer cells for cancer immunotherapy: a new CAR is catching up. EBioMedicine. Published by Elsevier B.V. [Editorial Overview]. 2019;39:1-2. doi:10.1016/j.ebiom.2019.01.018 


\section{Eigene Veröffentlichungen}

Vorliegende Ergebnisse der Arbeit wurden in folgendem Publikationsorgan veröffentlicht:

Y. El-Nahry, P. S. A. Becker, P. Bader, C. Seidl, Functional Analysis of Allelic Typed Donor Natural Killer Cell Receptors KIR2DL1 and KIR3DL1 for Improved Outcome in Stem Cell Transplantation, HLA Immune Response Genetics, Volume 89, Issue 6, p.384-481, Abstracts for the 31st European Immunogenetics and Histocompatibility Conference (EFI) 25th Annual Meeting of the German Society for Immunogenetics (DGI) Mannheim/Heidelberg, Germany, 2017. Teilnahme und Postervorstellung am 01.05.2017.

Y. El-Nahry, P. S.A. Becker, C. Seidl, Better Alloreactive Prediction in Immunotherapy through Allelic-Type Based Functional Analysis of 20 KIR3DL1+ Donors with Different Surface Expression Phenotypes, , HLA Immune Response Genetics Volume 93, Issue 5, p.256-401, Abstracts for the 33rd European Immunogenetics and Histocompatibility Conference (EFI), Lisbon, Portugal, 2019. Teilnahme und wissenschaftlichem Vortrag am 10.05.2019. 


\section{Lebenslauf}

\section{Persönliche Daten}

Name

Geburtstag/-ort

Handynummer

E-Mail

\section{Ausbildung}

Seit 02/2019

21.08.2018

08.05.2018

13.10.2016

Seit 2016

14.03.2013

$2010-2016$

27.06.2009

$2001-2009$
Yasmin El-Nahry
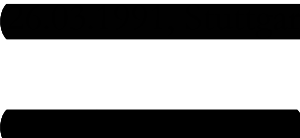

Assistenzärztin für Geburtsmedizin, Charité- Universitätsmedizin Berlin (Campus Virchow)

Approbation

Dritter Abschnitt der Ärztlichen Prüfung (Note: sehr gut)

Zweiter Abschnitt der Ärztlichen Prüfung (Note: $g u t$ )

Medizinische Doktorandin in der Abteilung für Transplantationsimmunologie und Immungenetik unter der Leitung von Prof. Dr. Christian Seidl; Labor des Instituts für Transfusionsmedizin und Immunhämatologie, DRKBlutspendedienst Frankfurt am Mai 24.03.2017: Promotionsvereinbarung

Erster Abschnitt der Ärztlichen Prüfung (Note: $g u t)$

Studium der Humanmedizin (Vorklinik und Klinik), Johann Wolfgang Goethe-Universität Frankfurt am Main

Abitur (Note: 1,7)

Schulzeit am Werner-von-Siemens-Gymnasium, Berlin 


\section{Studentische Nebentätigkeiten}

$2013-2015$

$2011-2012$
Tutorin im Fach Chirurgie, Universitätsklinikum Frankfurt am Main

Kardiologische Assistentin im Krankenhaus Havelhöhe, Berlin

\section{Soziales Engagement}

\section{Praktika und Famulaturen}

$2017-2018$

$05 / 2016$

$09 / 2014$

$09 / 2013$

$05 / 2013$

$11 / 2009$

$09 / 2009$

$07 / 2009$
Praktisches Jahr

1. Tertial, Innere Medizin: Klinikum Frankfurt Höchst

2. Tertial, Chirurgie: Chapel Allerton Hospital, Leeds (Großbritannien) und Ernst-von-Bergmann Klinikum, Potsdam

3. Tertial, Gynäkologie und Geburtsmedizin: Charité Berlin

Famulatur, Hals-Nasen-Ohren-Heilkunde, Uniklinikum Frankfurt am Main

Famulatur, Praxis für Allgemeinmedizin, Oberhausen

Famulatur, Gynäkologie \& Geburtshilfe, Universitätsmedizin Mainz

Famulatur, Neurologie, Vivantes Auguste-Viktoria-Klinikum Berlin

Pflegepraktikum, Augenheilkunde, Cairo University Hospital (Ägypten)

Pflegepraktikum, Chirurgie, Krankenhaus Waldfriede Berlin

Pflegepraktikum, Geriatrie, Evangelisches Krankenhaus Hubertus Berlin 


\section{Kurse und Kongresse}

$05 / 2019$

$11 / 2018$

$10 / 2018$

$06 / 2018$

$03 / 2018$

$05 / 2017$

$2013 / 2014$
Teilnahme am EFI/DGI-Kongress "The 33rd European Immunogenetics and Histocompatibility Conference", Lissabon (Portugal)

10.05.2019: Wissenschaftlicher Vortrag (Promotionsthema)

Teilnahme am Kurs „Psychosomatische Grundversorgung“, Sylt

Neumitglied der Gesellschaft für Geburtsmedizin und Gynäkologie Berlin (GGGB)

Teilnahme am GIB „1.Geburtsmedizinischer Intensivkurs Berlin“

Teilnahme an der Fortbildung „Ultraschall in der PränatalmedizinKasuistiken“, Klinik für Geburtsmedizin, Berlin

Teilnahme am EFI/DGI-Kongress "The 31st European Immunogenetics and Histocompatibility Conference", Mannheim/Heidelberg

01.06.2017: Wissenschaftliche Postervorstellung (Promotionsthema)

Zweifache Teilnahme am ISCOMS „International Student Congress Of (bio)Medical Sciences", Groningen (Niederlande) - Ernennung zur deutschen Botschafterin des Kongresses (2014) 